\author{
Universidade de São Paulo \\ Instituto de Astronomia, Geofísica e Ciências Atmosféricas
}

Departamento de Astronomia

Jhon Yana Galarza

\title{
Análise da composição química das gêmeas solares HIP 100963, HD 45184 e a descoberta da gêmea solar Inti 1
}

São Paulo 

Jhon Yana Galarza

\section{Análise da composição química das gêmeas solares HIP 100963, HD 45184 e a descoberta da gêmea solar Inti 1}

Dissertação apresentada ao Departamento de Astronomia do Instituto de Astronomia, Geofísica e Ciências Atmosféricas da Universidade de São Paulo como requisito parcial para a obtenção do título de Mestre em Ciências.

Versão Corrigida. O original encontrase disponível na Unidade

Área de Concentração: Astronomia

Orientador: Prof. Dr. Jorge Meléndez

São Paulo 

Dedico este trabalho à minha professora, orientadora e amiga María Luisa Aguilar Hurtado, quem foi a primeira astrônoma do Peru. 



\section{Agradecimentos}

À minha querida família: Aurelio Yana, Ines Galarza e Luis Yana Galarza, pelo seu apoio, assistência e carinho ao longo dos anos sem os quais a realização desta dissertação teria sido impossível.

À minha noiva Cecilia Toledo, pela companhia de todos os dias, pelo apoio nos momentos mais difíceis e também pelos bons momentos que ajudaram ao sucesso deste trabalho.

Ao meu orientador Dr. Jorge Meléndez, pela orientação, paciência, prestatividade e as inúmeras oportunidades que me deu, permitindo a minha formação científica.

Aos meus colegas do grupo SAMPA: Leonardo dos Santos, Marília Carlos, Henrique Reggiani, Lorenzo Spina e Marcelo Tucci, pelas importantes discussões astrofísicas que contribuíram ao desenvolvimento desta dissertação.

Ao meu colega de sala Rafael Campos, pela ajuda nas correções deste trabalho. Também aos meus colegas do IAG por propiciarem um ambiente instigante à pesquisa.

Aos professores cuja ajuda foi indispensável para enriquecer meus conhecimentos. Agradeço em especial à Dra. Silvia Rossi pela prestatividade.

À CNPq pela concessão da bolsa de mestrado.

Esta tese/dissertação foi escrita em IATEX com a classe IAGTESE, para teses e dissertações do IAG. 

"O universo não foi feito à medida do ser humano, mas tampouco lhe é adverso: é-lhe indiferente."

Carl Sagan

"Ser jovem e não ser revolucionário é uma contradição genética." Ernesto Guevara de la Serna, o "Che Guevara" 



\section{Resumo}

O objetivo deste trabalho é realizar uma análise diferencial detalhada linha a linha para verificar se 2MASS J23263267-0239363 (nomeada de Inti 1) é uma gêmea solar. Também investigar a origem do padrão de abundâncias de HIP 100963, a correlação de lítio e idade, os elementos voláteis e refratários, e os elementos pesados através dos processos $-s$ e $-r$.

Os espectros das estrelas Inti 1, HD 45184, HIP 100963 e o Sol (empregando luz refletida nos asteroides Vesta e Iris) foram obtidos usando o espectrógrafo HIRES do telescópio Keck I, atingindo uma alta resolução e razão de sinal-ruido. Medi manualmente as lar-

guras equivalentes (EWs) das linhas do ferro para determinar os parâmetros atmosféricos através do equilíbrio espectroscópico diferencial. A temperatura efetiva e a gravidade superficial também foram obtidas empregando calibrações fotométricas e usando o método trigonométrico. Determinei a composição química dos elementos voláteis, refratários e de captura de nêutrons. Desenvolvi o código terra para reproduzir os padrões de abundâncias observados em HD 45184 e Inti 1. As idades foram obtidas usando isócronas (usando $\mathrm{q}^{2}$ ), a relação [Y/Mg], e atividade estelar (apenas para HIP 100963).

Conclui que a estrela Inti 1 é uma gêmea solar fraca e tem um padrão de abundâncias similar ao do Sol. HD 45184 mostra um padrão similar às gêmeas solares próximas, isto é, ricas em elementos refratários em relação aos voláteis. Confirmou-se que HIP 100963 é uma gêmea solar e demonstrei que seu padrão de abundâncias é solar depois de corrigir por GCE; isto poderia significar que HIP 100963 e Inti 1 poderiam ter formado planetas rochosos. HIP 100963 mostra enriquecimento de elementos dos processos $-s$ e $-r$, sugerindo que os elementos de captura de nêutrons são ricos em estrelas jovens. Da mesma forma que com outras gêmeas solares, HIP 100963 apresenta uma depleção de lítio que é causada pela evolução estelar, e sua abundância de lítio segue a correlação lítio e idade. 



\section{Abstract}

The aim of this work is to perform a detailed line-by-line differential analysis to verify whether 2MASS J23263267-0239363 (designated as Inti 1) is indeed a solar twin. I also investigate the origin of the abundance pattern of HIP 100963, the Li-age correlation, the volatile and refractory elements, and the heavy elements from the $s$ - and $r$-processes.

The spectra of the stars Inti 1, HD 45184, HIP 100963 and the Sun (using reflected light from the asteroids Vesta and Iris) were obtained employing the HIRES spectrograph on the Keck I telescope, reaching a high-resolution and high signal-to-noise ratio. I measured by hand the equivalent widths (EWs) of iron lines to determine the stellar parameters through the differential spectroscopic equilibrium. The effective temperature and surface gravity were also obtained by using photometric calibrations and through the trigonometric technique. I determined the composition of volatile, refractory, and neutron-capture elements. I developed the code terra to reproduce the abundance patterns observed in HD 45184 and Inti 1. The age and mass were obtained using isochrones (using $\mathrm{q}^{2}$ ), the [Y/Mg] ratio, and stellar activity (only for HIP 100963).

I conclude that the star Inti 1 is a faint solar twin and has an abundance pattern similar to the Sun. HD 45184 shows an pattern similar to nearby solar twins, meaning enhanced in refractory relative to volatile elements. I confirmed that HIP 100963 is a solar twin and demonstrate that its abundance pattern is about solar after corrections for GCE; this could mean that HIP 10063 and Inti 1 may have formed rocky planets. HIP 100963 present enrichment in $s$ - and $r$-process elements, suggesting that neutron capture elements are enhanced in young stars. Like in other solar twins, HIP 100963 shows a depletion in lithium that is caused by stellar evolution, and its lithium abundance follows the Li-age correlation. 



\section{Lista de Figuras}

1.1 Amostra das 88 gêmeas solares de Ramírez et al. (2014) em função da temperatura efetiva. A linha pontilhada representa à temperatura solar. . . . .

1.2 Diferenças $\Delta[\mathrm{X} / \mathrm{Fe}]$ (Sol - <gêmeas solares $>$ ) entre a composição química do Sol e gêmeas solares vs. número atômico (painel esquerdo) e temperatura de condensação (painel direito) (Meléndez et al., 2009) . . . . . . . . . . . . .

1.3 Painel esquerdo: a média do padrão de abundâncias de 22 gêmeas solares em função da temperatura de condensação. Painel direito: a inclinação da média do padrão de abundâncias dos elementos refratários e a média das abundâncias dos elementos voláteis em função dos parâmetros atmosféricos. Créditos das imagens: Ramírez et al. (2009). . . . . . . . . . . . . . . .

1.4 A média do padrão de abundâncias químicas das amostras estudadas por Ramírez et al. (2010). Notar que nesta figura são mostrados apenas os trabalhos onde os parâmetros estelares foram determinados usando os espectros (equilíbrio espectroscópico). . . . . . . . . . . . . . . . .

1.5 Diferenças em abundâncias químicas no Sol, observadas em latitudes altas e no equador solar. Fonte: Kiselman et al. (2011) . . . . . . . . . . . . . .

1.6 Diferenças entre as abundâncias do Sol obtidas com o asteroide Juno e Ceres (painel esquerdo), como também de Ceres e Vesta (painel direito). Créditos das imagem: Meléndez et al. (2012) e Bedell et al. (2014). . . . . . . . . . .

1.7 Razão de abundâncias entre a média das gêmeas solares em relação ao Sol (linha vermelha) e as abundâncias do Sistema Solar poluídas por estrelas AGB, supernovas e hipernovas. Créditos da imagem: Meléndez et al. (2012). 37 
1.8 Diferença entre as abundâncias químicas de 16 Cyg A e 16 Cyg B. A linha pontilhada é a média dos elementos voláteis e a linha sólida é o padrão dos elementos refratários. A linha vermelha tracejada e pontilhada é a média do padrão de abundâncias das gêmeas solares. Fonte: Tucci Maia et al. (2014).

1.9 Imagem da estrela jovem TW Hydrae e seu disco protoplanetário realizado pelo ALMA. Os espaços vazios indicam que existe formação planetária no sistema. Fonte: ESO e Andrews et al. (2016). . . . . . . . . . . . . . . 40

1.10 Distribuição de temperaturas na nebulosa solar. Fonte: Freedman e Kauf$\operatorname{mann}(2005) \ldots \ldots \ldots \ldots \ldots$

1.11 As abundâncias elementais da fotosfera solar (Asplund et al., 2009) vs. a composição química dos condritos CI (Lodders et al., 2009) . . . . . . . . .

1.12 Abundância dos primeiros 41 elementos químicos presentes na fotosfera solar

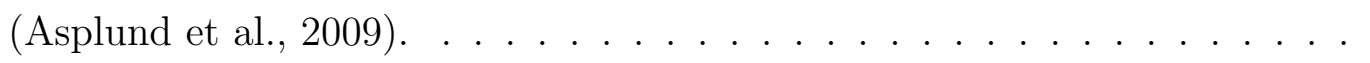

1.13 Composição da fotosfera solar adicionando 4 massas terrestres de material tipo terra (painel superior), de tipo condrítico CM (painel do meio) e uma mistura de material terrestre e condrítico (painel inferior). A linha representa o ajuste das 11 gêmeas solares analisadas por Meléndez et al. (2009).

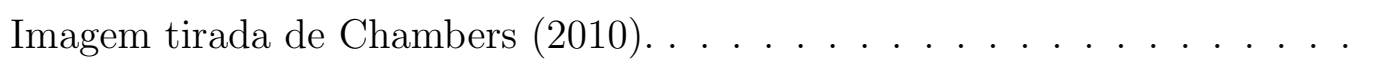

2.1 Abundâncias diferenciais da gêmea solar HIP 100963 estimadas usando os modelos de atmosfera de Castelli e Kurucz (2004) e de Gustafsson et al. (2008), em função do número atômico $($ Z) . . . . . . . . . . . . . . . 51

2.2 Esquema ilustrativo da definição de largura equivalente. Imagem tirada e modificada de Rutten $(2003)$. . . . . . . . . . . . . . . . . .

2.3 Ilustração gráfica de uma curva de crescimento mostrando seus três regimes (linha fraca, saturada e forte). Imagem tirada de Gray (2005) . . . . . . . . 54

2.4 A razão da constante $C_{6}$ de Barklem et al. (2000) e Unsold (1955) em função do potencial de excitação. . . . . . . . . . . . . . . . . . . .

2.5 Ajuste do perfil da linha Mn I em $12976 \AA$, sem levar em conta a estrutura hiperfina (painel esquerdo) e considerando a estrutura hiperfina (painel direito). O eixo vertical em ambos painéis indica o fluxo. Imagens tiradas de Meléndez (2001) . . . . . . . . . . . . . . . . 5 57 
2.6 Curva de crescimento mostrando o efeito de microturbulência (0, 2 e 5 $\mathrm{kms}^{-1}$ ) para linhas espectrais saturadas. Fonte: Gray $(2005)$. . . . . . . . 58

2.7 Dependência com a gravidade superficial para a curva de crescimento de linhas de Fe II. Imagem tirada de Gray $(2005)$. . . . . . . . . . . . . . .

2.8 Abundância diferencial do ferro em função do potencial de excitação (painéis superiores), largura equivalente reduzida (painéis do meio) e comprimento de onda (painéis inferiores). As cruzes azuis representam o Fe I e os círculos verdes o Fe II. As linhas sólidas azuis dos painéis superiores e do meio correspondem aos ajustes de Fe I, enquanto as linhas sólidas pretas nos painéis inferiores representam o valor médio de abundância de ferro $[\mathrm{Fe} / \mathrm{H}]$. As imagens correspondem às abundâncias do ferro obtidas dos espectros de XO-2N e XO-2S (Ramírez et al., 2015) . . . . . . . . . 60

2.9 O painel superior mostra as abundâncias diferenciais do asteróide Iris e Vesta. A linha pontilhada vermelha representa o valor da abundância de $[\mathrm{Fe} / \mathrm{H}]$. O painel inferior mostra a diferença entre as abundâncias estimadas nesta dissertação e as de Bedell et al. (2014) (T-B). Esta diferença é de apenas $0.002(\sigma=0.003)$ dex. . . . . . . . . . . . . . .

2.10 Ilustração da estimativa dos parâmetros atmosféricos da gêmea solar HIP 100963. O equilíbrio espectroscópico é atingido quando a $T_{\text {eff }}=5818 \mathrm{~K}$, $\log g=4.49 \operatorname{dex},[\mathrm{Fe} / \mathrm{H}]=-0.003$ dex e $v_{t}=1.03 \mathrm{kms}^{-1}$. A linha vermelha central representa a solução final. Os efeitos de variar $\Delta T_{\text {eff }}= \pm 30$ $\mathrm{K}, \Delta \log g= \pm 0.10$ dex e $\Delta v_{t}= \pm 0.1 \mathrm{kms}^{-1}$ são mostrados nos painéis superiores, do meio e inferiores, respectivamente. . . . . . . . . . .

2.11 Síntese espectral do lítio em torno de 6707.8 A. O espectro de ID 102684698 é representado pelos círculos pretos cheios, enquanto o melhor ajuste do perfil teórico pela linha sólida azul. Os diferentes valores de lítio $(0.50,0.85$ e 1.2) são mostrados com os perfis de linha de cor verde, vermelho e azul, respectivamente. Fonte: do Nascimento et al. (2013). . . . . . . . . . . . .

3.1 A separação entre a Inti 1 e a estrela BPS CS 22949-0037 é de apenas 49.16". A imagem foi tirada do Aladin Sky Atlas (http://aladin.ustrasbg.fr). . . . 
3.2 Comparação dos espectros de HD 45184, Inti 1 e o Sol na faixa entre 5321 e 5336 Å. O painel (a) ilustra o espectro de HD 45184 (círculos azuis abertos) e o Sol (linha vermelha sólida). O painel (b) mostra o espectro do Sol (linha vermelha sólida) e a candidata a gêmea solar Inti 1 (círculos azuis abertos); ambos têm uma notável semelhança. A diferente composição química é revelada através de medições cuidadosas linha a linha. Os resíduos entre o Sol e HD 45184 (S-H), e o Sol e Inti 1 (S-I) são exibidos nos painéis (c) e (d), respectivamente. . . . . . . . . . . . . . . . .

3.3 Mapa de avermelhamento de Inti 1. Fonte: IRSA. . . . . . . . . . . . . . 72

3.4 Os espectros sem normalizar de Inti 1 e o Sol (painéis superiores), normalizados (painéis do meio) e a razão dos espectros normalizados (painel inferior). 74

3.5 Exemplo de quatro linhas espectrais e as escolhas dos seus pseudos-contínuos, respectivamente. Fonte: Bedell et al. (2014) . . . . . . . . . . . . . . 77

3.6 Efeitos no ajuste da $[\mathrm{Fe} / \mathrm{H}]$ vs $\chi$ com variações em temperatura de +20 $\mathrm{K}$ (painel superior) e $-20 \mathrm{~K}$ (painel inferior). O painel do meio mostra o equilíbrio de excitação quando a $T_{\text {eff }}=5837 \mathrm{~K}$. Os círculos azuis representam o Fe I e os triângulos verdes representam o Fe II, enquanto a linha sólida vermelha é o ajuste. . . . . . . . . . . . . . . . . . . .

3.7 Variação da velocidade de microturbulência e seus efeitos sobre o ajuste ao variar $+0.1 \mathrm{kms}^{-1}$ (painel superior) e $-0.1 \mathrm{kms}^{-1}$ (painel inferior). O painel do meio mostra o equilíbrio de ionização quando $v_{t}=1.04 \mathrm{kms}^{-1}$. Os círculos, triângulos e linha sólida representam o mesmo que a Figura 3.6. .

3.8 Abundância diferencial da Inti 1 em função do comprimento de onda. Os círculos, triângulos e linha sólida representam o mesmo que a Figura 3.6 e

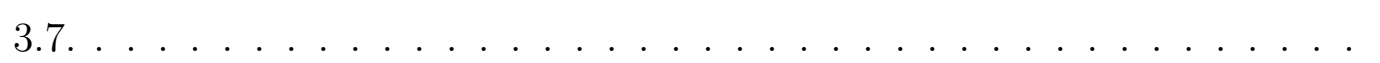

3.9 Abundância diferencial do ferro para a estrela HD 45184 em função do potencial de excitação (painel superior), largura equivalente reduzida (painel do meio) e comprimento de onda (painel inferior). As cruzes azuis e os círculos verdes representam o Fe I e Fe II, a linha sólida azul o ajuste (painel superior e central) e a linha preta o valor médio da abundância de ferro

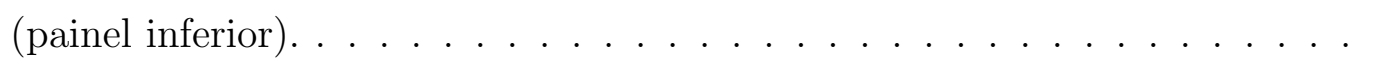


3.10 Painéis superiores: relação empírica do cor- $T_{\text {eff }}$. Diamantes cheios representam estrelas com $-0.5<[\mathrm{Fe} / \mathrm{H}] \leq 0.5$, triângulos voltados para acima a estrelas com $-1.5<[\mathrm{Fe} / \mathrm{H}] \leq-0.5$, triângulos voltados para abaixo a estrelas com $-2.5<[\mathrm{Fe} / \mathrm{H}] \leq-1.5$ e círculos abertos a estrelas com $[\mathrm{Fe} / \mathrm{H}] \leq-2.5$. Os quadrados abertos representam às estrelas muito pobres em metais HE02330343 e HE1327-2326. Painéis inferiores: os resíduos dos ajustes como uma função da metalicidade. Fonte: Casagrande et al. (2010) . . . . . . . . . .

3.11 Painel superior: Comparação entre as abundâncias $[\mathrm{X} / \mathrm{H}]$ estimadas nesta dissertação e as determinadas por Nissen (2015). Painel inferior: De modo igual que para o painel superior, no entanto para a razão $[\mathrm{X} / \mathrm{Fe}]$. . . . . . .

3.12 Estimativas da idade, massa, luminosidade, magnitude absoluta e raio para as gêmeas solares HD 45184 e Inti 1. As linhas pontilhadas representam os resultados mais prováveis.

3.13 Distribuição de probabilidade da idade de HD 45184 (painel superior) e Inti 1 (painel inferior). As linhas pontilhadas representam a idade mais provável. As diferentes regiões representam \pm 1 sigma e \pm 2 sigma de incerteza. . . .

3.14 Abundâncias normalizadas dos condritos CI carbonáceos (CM, CO e CV) e condritos ordinários (OC) em relação a sua temperatura de condensação. Note que os elementos estão divididos em refratários (> $1500 \mathrm{~K})$, moderadamente voláteis (entre 700 e $1350 \mathrm{~K}$ ) e altamente voláteis $(<700 \mathrm{~K})$. Fonte: Alexander et al. (2001). . . . . . . . . . . . . . . . . . .

3.15 Variação da massa estelar em relação a sua massa convectiva e metalicidade usando os modelos de evolução estelar de Siess et al. (2000). . . . . . . . .

3.16 Composição da fotosfera solar adicionando $4 \mathrm{M}_{\oplus}$ de uma mistura de material rochoso (terrestre mais meteorítica) à zona convectiva do Sol. As abundâncias de Chambers (2010) e as estimadas nesta dissertação são representadas por estrelas vermelhas e círculos azuis, respectivamente. . . . .

3.17 Comparação entre as abundâncias determinadas nesta dissertação e as de Nissen (2015), em função da temperatura de condensação (Lodders, 2003). 
3.18 Painel superior: Padrão de abundância de HD 45184 (círculos vermelhos) em relação à temperatura de condensação. O padrão químico de HD 45184 (triângulos azuis) foi determinado adicionando $3.5 \mathrm{M}_{\oplus}$ de material rochoso à zona convectiva do Sol. Painel inferior: A razão de abundâncias diferenciais de Inti 1 (círculos vermelhos) relativa ao Sol em função da temperatura de condensação. A média do padrão de abundância das 11 gêmeas solares estudadas por Meléndez et al. (2009) é representada pela linha pontilhada. O padrão de abundâncias de Inti 1 (triângulos azuis) foi determinado adicionando $1.5 \mathrm{M}_{\oplus}$ de material rochoso à zona convectiva do Sol. Os elementos de captura de nêutrons são representados por quadrados em ambos painéis.

3.19 Comparação entre os 4 tipos de carbonáceos (CI, CV, CO e CM) em função da temperatura de condensação, para o padrão de abundâncias de Meléndez et al. (2009), representada pela linha. A massa meteorítica adoptada é $2 \mathrm{M}_{\oplus}$, e a massa de composição terrestre é $2 \mathrm{M}_{\oplus} \ldots \ldots$. . . . . . . . . . . . 98

4.1 Espectro HIRES de HIP 100963 (círculos azuis) e o Sol (linha sólida vermelha) na faixa entre 5400 e 5410 Å. Os resíduos entre o Sol e HIP 100963 $(\mathrm{S}-\mathrm{H})$ são exibidos no painel inferior. . . . . . . . . . . . . . . . . . 103

4.2 Abundância diferencial de HIP 100963 em relação ao Sol em função do potencial de excitação (painel superior) e largura equivalente reduzida (painel inferior). Em ambas figuras os círculos azuis representam o Fe I, os quadrados verdes o Fe II e a linha sólida vermelha o ajuste. . . . . . . . . . . . . 104

4.3 Representação das bandas $R, H, K$ e $V$ em um espectro obtido pelo observatório Keck. Note nas bandas $H$ e $K$ a alta atividade cromosférica. Imagem tirada de Wright et al. (2004) . . . . . . . . . . . . . . . . . . . 107

4.4 Espectro de HIP 100963 na faixa entre 3928 e $3945 \AA$ mostrando emissão cromosférica no centro da linha. . . . . . . . . . . . . . . . . 108 
4.5 Valores médios de $\log R_{H K}^{\prime}$ em função da idade de aglomerados. Os triângulos cheios e abertos representam a média dos valores $\log R_{H K}^{\prime}$ nos aglomerados (Tabela 7 em Mamajek e Hillenbrand (2008)). O círculo cheio é o Sol e o quadrado aberto representa à média de anãs de tipo solar tomadas da amostra de Valenti e Fischer (2005). Imagem tirada de Mamajek e Hillenbrand

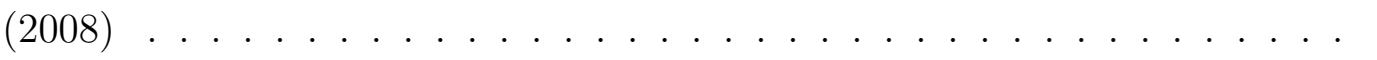

4.6 Ambos painéis mostram as correções de abundância para o O I 777 em modelos de NLTE. O painel superior representa as correções para uma estrela que deixa a sequência principal (turn-off star) com $T_{\text {eff }}=6500 \mathrm{~K}$ e $\log g=4.0$ dex, enquanto para o painel inferior são para uma estrela anã com $T_{\text {eff }}=5500 \mathrm{~K}$ e $\log g=4.0$ dex. Fonte: Amarsi et al. (2015). . . . . 110

4.7 Comparação entre o padrão de abundâncias estimadas nesta dissertação e o padrão determinado por Ramírez et al. (2009) em função da temperatura de condensação, $\mathrm{T}_{\text {cond }}($ Lodders, 2003) . . . . . . . . . . . . . . 111

4.8 Painel superior: Abundâncias diferenciais observadas em relação ao Sol e em função da temperatura de condensação. Painel inferior: Padrão de abundâncias depois de corrigir por GCE à idade solar. Ajustes lineares aos dados (excluindo os elementos de captura de nêutrons) são representados graficamente em cada painel com uma linha sólida verde. Os elementos de captura de nêutrons são representados por quadrados de cor cinza em ambos painéis. Sigma representa a dispersão sobre o ajuste linear. . . . . . 114

4.9 Comparação da razão de $[\mathrm{X} / \mathrm{H}]_{\mathrm{T}_{\text {cond }}}$ (círculos vermelhos cheios) com as abundâncias preditas a partir da poluição de estrelas AGB (hexágonos abertos)

4.10 Abundâncias residuais $[\mathrm{X} / \mathrm{H}]_{\mathrm{r} \text {-process }}$ devido à contribuição do processo- $r$. Abundâncias preditas usando o padrão de abundâncias do processo- $r$ no Sistema Solar por Bisterzo et al. (2014) e Simmerer et al. (2004), são também representadas graficamente com linhas sólidas e pontilhadas, respectivamente.117

4.11 Síntese espectral da linha de Fe I (6727.050 A), que foi usada para estimar o $v \sin i$. Para ajustar o perfil necessitou-se de uma largura gaussiana (FWHM) de $0.086 \AA, v \sin i=1.5 \mathrm{kms}^{-1}$, fator de escurecimento de limbo de 0.6 e $v_{\text {macro }}=3.43 \mathrm{kms}^{-1} \ldots \ldots \ldots \ldots \ldots \ldots$ 
4.12 Síntese espectral de lítio em 6708 A. Círculos abertos e fechados representam o espectro de HIP 100963 e o Sol, respectivamente, enquanto o espectro sintético é representado pela linha sólida vermelha. . . . . . . . . . . . . 120

$4.13 \mathrm{Li}$ vs. idade para HIP 100963 (quadrado vermelho) baseado em análise NLTE e idade isocronal. A abundância de Li para outras estrelas analisadas pelo nosso grupo em anteriores trabalhos (Ramírez et al., 2011; Meléndez et al., 2012; Monroe et al., 2013; Meléndez et al., 2014) é mostrado com círculos azuis. Os erros das abundâncias de lítio são menores do que o tamanho do círculo. Os modelos de depleção de Li são também mostrados com diferentes linhas. . . . . . . . . . . . . . . . . . . 121

C.1 Parâmetros de entrada para a ferramenta synth. Fonte: Carlos (2015).170

C.2 Espectro do Sol na faixa de 6707.3-6708.2 ̊ mostrando os diferentes elementos químicos que influem na determinação da abundância do lítio (6707.75 A) . Fonte: Carlos et al. (2016). . . . . . . . . . . . . . . . . . . 171

C.3 Parâmetros de entrada para a ferramenta abfind. Imagem tirada de Carlos (2015) . . . . . . . . . . . . . . . . . . . . . . . . . . . . . . 


\section{Lista de Tabelas}

3.1 Comparação das cores de Inti 1 e o Sol. . . . . . . . . . . . . . . . . 772

3.2 Comparação dos parâmetros estelares da gêmea solar HD 45184 . . . . . . 81

3.3 Temperatura efetiva fotométrica de Inti 1 e HD 45184. . . . . . . . . . . . 83

3.4 Abundâncias químicas de HD 45184 e Inti 1, e seus erros. . . . . . . . . . . 85

3.5 Parâmetros fundamentais de Inti 1 . . . . . . . . . . . . . . . . . . . 93

4.1 Comparação dos parâmetros atmosféricos da gêmea solar HIP 100963 .. 105

4.2 Temperatura efetiva fotométrica de HIP 100963. . . . . . . . . . . 105

4.3 Parâmetros fundamentais . . . . . . . . . . . . . . . . . . . 107

4.4 Abundâncias químicas de HIP 100963, e seus erros. . . . . . . . . . . . . . 112

4.5 Abundância dos elementos de captura de nêutrons e sua decomposição em HIP $100963 \ldots \ldots \ldots \ldots \ldots \ldots \ldots$

A.1 As abundancias da fotosfera, meteoritos e a temperatura de condensação são de Asplund et al. (2009), Lodders (2010) e Lodders (2003) . . . . . . . . . 145

A.2 Lista de linhas atómicas adotadas . . . . . . . . . . . . . . . . . 146

A.3 Correção hiperfina das linnhas para as quais foi aplicada. . . . . . . . . . . 151 



\section{Sumário}

1. Introdução . . . . . . . . . . . . . . . . . . . 27

1.1 Histórico . . . . . . . . . . . . . . . . . . . . . . . . . . [ 27

1.2 Gêmeas solares . . . . . . . . . . . . . . . . . . . . [29]

1.2.1 Aplicações das gêmeas solares . . . . . . . . . . . . . . . 31

1.2.2 Importância no estudo de Planetas . . . . . . . . . . . . . . . . 32

1.3 Formação de planetas rochosos . . . . . . . . . . . . . . . . . . . . 39

1.3.1 Hipótese nebular . . . . . . . . . . . . . . . . . 39

1.3.2 Temperatura de condensação . . . . . . . . . . . . 41

1.3.3 Abundâncias químicas do Sistema Solar . . . . . . . . . . 42

1.4 Organização da Dissertação . . . . . . . . . . . . . . . . 45

2. Atmosferas estelares e cálculo de abundâncias químicas . . . . . . . . . . . . 47

2.1 Atmosfera Estelar . . . . . . . . . . . . . . . . . . . . 47

2.2 Equilíbrio Termodinâmico local (LTE) . . . . . . . . . . . . . . 49

2.3 Modelos de Atmosfera . . . . . . . . . . . . . . . . . . . . . . 50

2.4 Formação das linhas de absorção . . . . . . . . . . . . . . . . . . . . . 50

2.5 Abundâncias químicas . . . . . . . . . . . . . . 52 52

2.6 Larguras Equivalentes $(\mathrm{EWs}) \ldots \ldots \ldots \ldots \ldots$

2.7 Alargamento de linhas . . . . . . . . . . . . . . . . . . 54

2.8 Lista de linhas . . . . . . . . . . . . . . . . . . . . . . . . . . . 55

2.9 Correção hiperfina . . . . . . . . . . . . . . . . . 5 56

2.10 Abundâncias diferenciais . . . . . . . . . . . . . . . . . 56

2.11 Estimativa dos parâmetros atmosféricos . . . . . . . . . . . . . 58 
2.12 Estimativa $\operatorname{dos} \operatorname{erros} \ldots \ldots \ldots \ldots \ldots \ldots$

2.12.1 Erros nos parâmetros atmosféricos . . . . . . . . . . . . 59

2.12.2 Estimativa dos erros nas abundâncias . . . . . . . . . . . . 61

2.13 Verificação dos erros usando asteroides . . . . . . . . . . . . . . 61

$2.14 \mathrm{O}$ código qoyllur-quipu $\left(\mathrm{q}^{2}\right) \ldots \ldots \ldots \ldots \ldots \ldots$

2.15 Síntese Espectral de Lítio . . . . . . . . . . . . . . . . 65

3. A descoberta fortuita da gêmea solar fraca Inti $1 \ldots \ldots$. . . . . . . 67

3.1 Dados espectroscópicos . . . . . . . . . . . . . . . . . . . 68

$3.2 \quad$ As cores de Inti $1 \ldots \ldots$

3.3 Normalização do Contínuo . . . . . . . . . . . . . . . . . . . 773

3.4 Correção de velocidade radial . . . . . . . . . . . . . . 75

3.5 Medição de larguras equivalentes . . . . . . . . . . . . . . . 76

3.6 Determinação dos parâmetros estelares . . . . . . . . . . . . . . . 78

3.7 Análise de abundâncias . . . . . . . . . . . . . . . . . . . . . 84

3.8 Idade e Massa . . . . . . . . . . . . . . . . . . . . . . . . . 86

3.9 Metodologia para a determinação da massa rochosa faltante . . . . . . . 90

3.9 .1 Massa convectiva . . . . . . . . . . . . . . . . . . . . 92

3.9 .2 Massa rochosa faltante . . . . . . . . . . . . . . . 93

3.10 Padrão de abundâncias e resultados . . . . . . . . . . . . . . . 95

3.11 Conclusões . . . . . . . . . . . . . . . . . . . . . . . . . . . . 98

4. Análise de alta precisão da gêmea solar HIP 100963 . . . . . . . . . . . . . 101

4.1 Estudos prévios de HIP 100963 . . . . . . . . . . . . . . . . . 101

4.2 Observação e redução de dados . . . . . . . . . . . . . . . . . . . 102

4.3 Análise de abundâncias . . . . . . . . . . . . . . . . . . . . . . . . 103

4.3 .1 Parâmetros estelares . . . . . . . . . . . . . . . . . . . 103

4.3 .2 Idade e massa . . . . . . . . . . . . . . . . . . . . 106

4.3 .3 Padrão de abundâncias . . . . . . . . . . . . . . . . . . . . . 110

4.4 Discussão . . . . . . . . . . . . . . . . . . . . . . . . . . 1113

4.4 .1 Os elementos leves $(\mathrm{Z} \leq 30) \ldots \ldots \ldots \ldots \ldots$

4.4.2 Elementos de captura de nêutrons $(\mathrm{Z}>30) \quad \ldots \ldots \ldots \ldots$

4.4 .3 Abundância de Lítio . . . . . . . . . . . . . . . . . . . . . . 118 
4.4.4 Conclusões . . . . . . . . . . . . . . . . . . . . . . . 121

5. Conclusões e perspectivas . . . . . . . . . . . . . . . . . . 123

Referências . . . . . . . . . . . . . . . . . 127

Apêndice 143

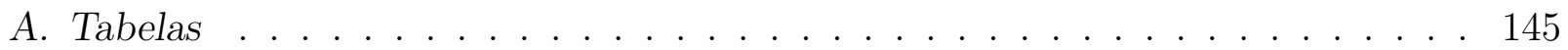

A.1 Abundâncias químcas do Sol . . . . . . . . . . . . . . . . . . . 145

A.2 Lista de linhas . . . . . . . . . . . . . . . . . . . . . 146

A.3 Correção hiperfina . . . . . . . . . . . . . . . . . . . . . . . . . . . . 151

B. Código terra . . . . . . . . . . . . . . . . . . . 161

B.0.1 Código para estimar a massa convectiva . . . . . . . . . . . 161

B.0.2 Código para estimar a massa rochosa faltante . . . . . . . . . 163

C. Determinação de abundâncias químicas usando MOOG . . . . . . . . . . . . 169

C.0.1 Síntese do lítio . . . . . . . . . . . . . . . 169

C.0.2 Abundâncias químicas a partir da curva de crescimento . . . . . . . 172

D. Artigos . . . . . . . . . . . . . . . . . . . 173 

Capítulo 1

\section{Introdução}

\subsection{Histórico}

O Universo conhecido é composto de $69 \%$ de energia escura, 26\% de matéria escura e só $5 \%$ de matéria bariônica (planetas, estrelas, etc.), de acordo com os resultados de Planck Collaboration et al. (2015). Neste cenário, o Sol é apenas uma estrela entre bilhões no Universo, porém é importante pois o Sistema Solar é o único sistema conhecido onde sabemos que há um planeta que abriga vida. A Terra é o único dos 8 planetas do Sistema Solar que reúne todas as condições necessárias para a existência de vida complexa: a distância ideal ao Sol, uma atmosfera com oxigênio e dióxido de carbono, água no estado líquido e uma idade avançada o suficiente para a diversificação da vida (culminando na espécie humana).

Desde a antiguidade, os homens observaram fenômenos astronômicos tais como o anoitecer, eclipses, etc., e acreditaram que esses fenômenos eram devidos a algum deus. O Sol foi o deus mais comum e importante para muitos povos. Essa crença prevaleceu por milênios; por exemplo, na cultura egípcia o Sol era chamado Amon-Ra, enquanto para os gregos Phoebus. Os homens antigos da América do Sul também cultuavam o Sol. Por exemplo, para o Império Inca o Sol era um deus chamado Int:1. Muitas destas civilizações usaram seus conhecimentos de astronomia para a construção de cidades, calendários astronômicos, como também no plantio e colheita de alimentos.

Com o passar dos anos, a humanidade começou a explicar os fenômenos da natureza de uma forma diferente. Uma interpretação distinta sobre o Sol iniciou-se na Grécia nos anos

\footnotetext{
${ }^{1}$ Inti era o deus mais importante do Império Inca, considerado como o progenitor de todos os seus imperadores.
} 
430 a.C., quando o filósofo Anaxágoras referiu-se ao Sol como uma pedra quente. Isso foi muito importante porque o Sol tornou-se um objeto de estudo, perdendo assim sua origem divina. Posteriormente, Ptolomeu sugeriu que o Sol fosse um planeta orbitando a Terra; no século XVI Nicolau Copérnico propôs que o Sol encontrava-se localizado no centro do Sistema Solar e no mesmo século Giordano Bruno concluiu que o Sol era apenas uma entre muitas outras estrelas no Universo. Logo, Kepler, com ajuda das observações de Tycho Brahe, confirmou que os planetas orbitam o Sol e determinou as três leis do movimento planetário.

Por volta do ano 1600, os primeiros telescópios surgiram na Holanda e cerca de dez anos depois Galileu Galilei construiu o seu próprio telescópio, observando os planetas e seus satélites, os anéis de Saturno e também as manchas solares.

A era da espectroscopia começou com Isaac Newton, quando demonstrou que a luz solar pode ser decomposta em várias cores, formando um espectro como no arco-íris. Em 1802, William Heyde Wollaston observou pela primeira vez as linhas escuras do espectro e as interpretou erroneamente como o limite das cores. Alguns anos mais tarde, Joseph van Fraunhofer começou a investigar este fenômeno usando um espectroscópio de sua própria invenção e descobriu 574 linhas escuras no espectro solar (linhas de Fraunhofer). Fraunhofer também observou as linhas dos espectros de outras estrelas tais como: Sirius, Castor, Pollux, Capella, Betelgeuse e Procyon. Ele percebeu que algumas linhas são de origem terrestre. No ano 1833, William Herschel sugeriu que as linhas poderiam ser de origem terrestre ou da atmosfera das estrelas, posteriormente Sir Brewster confirmou que algumas linhas são de origem terrestre. Por volta de 1860, Kirchoff e Bunsen descobriram que cada elemento químico está associado a um conjunto de linhas espectrais; eles deduziram que as linhas de Fraunhofer ocorrem por causa da absorção de cores específicas nas camadas exteriores do Sol. A espectroscopia em um eclipse solar eventualmente levou à descoberta do elemento hélio no Sol, antes de ser identificado na Terra. Através de prismas e redes de difração, os astrônomos conseguiram desenvolver um novo campo de pesquisa: a espectroscopia estelar.

Uma das maiores questões da ciência é se existem outros planetas que talvez possam abrigar vida. Embora se suspeitasse por muito tempo da existência de planetas fora de nosso Sistema Solar (exoplanetas), foi apenas em 1995 que os astrônomos Mayor e Queloz anunciaram a descoberta de um exoplaneta ao redor de 51 Peg, uma estrela do tipo solar 
(Mayor e Queloz, 1995) Notoriamente, este exoplaneta e muitos outros descobertos posteriormente, têm uma massa comparável à de Júpiter e estão localizados a distâncias muito próximas de suas estrelas hospedeiras, o que é diferente de nosso Sistema Solar, pois nessa região temos apenas planetas de tipo rochoso como a Terra. Este viés observacional deve-se ao fato de que é mais fácil detectar planetas mais massivos em órbitas mais internas, já que eles exercem maior influência sobre as suas estrelas.

Embora já conheçamos mais de 3477 exoplanetas segundo a Exoplanet Encyclopedia ${ }^{3}$, a maioria deles provavelmente não tem condições propícias para a vida como em nossa Terra, que além de ser um planeta rochoso orbita dentro da zona habitável do Sistema Solar, isto é, na região onde é possível ter água líquida na superfície. Os avanços em instrumentação provavelmente vão permitir algum dia detectar uma outra Terra orbitando uma estrela de tipo solar na zona habitável, mas por enquanto não podemos detectar este tipo de planeta. Portanto, não sabemos ainda se o nosso sistema planetário é único ou se existem muitas outras Terras habitáveis lá fora.

\subsection{Gêmeas solares}

Estrelas gêmeas solares são estrelas similares ao Sol (Cayrel de Strobel, 1996) em distintas propriedades tais como: massa, composição química, idade, temperatura efetiva, luminosidade, gravidade superficial, campo magnético, atividade cromosférica, rotação equatorial, etc., dentro dos erros observacionais. Por conseguinte, os espectros dessas estrelas deveriam ser, por definição, indistinguíveis do Sol.

Surgiram questões interessantes sobre se esses objetos têm uma grande chance de conter sistemas planetários similares ao nosso, e se talvez têm possibilidade de abrigar vida baseada em carbono e água ou de encontrar algum tipo de vida inteligente. Todas estas questões com fundo filosófico incitaram os pesquisadores a uma procura intensa de tais estrelas. Não obstante, nos primeiros 25 anos de pesquisa não foi encontrada nenhuma gêmea solar (Cayrel de Strobel, 1996).

Porto de Mello e da Silva (1997) descobriram a primeira gêmea solar (18 Sco) e mostraram que todos seus parâmetros atmosféricos são similares aos do Sol. Dez anos depois,

\footnotetext{
${ }^{2}$ A descoberta do primeiro exoplaneta foi anunciada por Lawton e Wright (1989), e os dois seguintes exoplanetas foram descobertos por Wolszczan (1992), em torno de estrelas de nêutrons.

3 http://exoplanet.eu/
} 


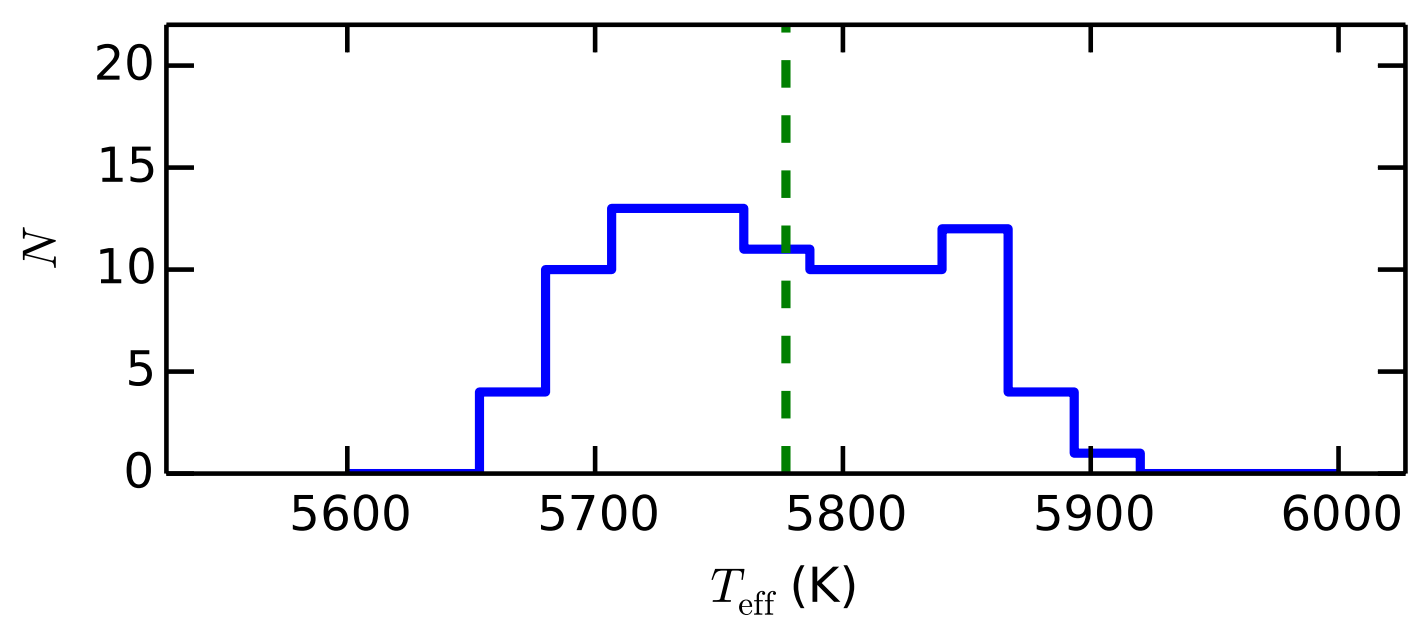

Figura 1.1: Amostra das 88 gêmeas solares de Ramírez et al. (2014) em função da temperatura efetiva. A linha pontilhada representa à temperatura solar.

outras três gêmeas solares foram descobertas: HIP 78399, HD 98618 e HIP 100963 King et al., 2005; Meléndez et al., 2006a; Takeda et al., 2007). Não obstante, essas quatro estrelas descobertas não são gêmeas solares perfeitas porque são mais abundantes em lítio do que o Sol (abundância de 3 a 6 vezes maior). Logo, Meléndez e Ramírez (2007) descobriram a estrela HIP 56948, a melhor gêmea solar descoberta até hoje, com os parâmetros estelares e as abundâncias idênticas aos do Sol, incluído o lítio, que é apenas um pouco acima do valor solar (Meléndez et al., 2012). Depois, Ramírez et al. (2009) sugeriram uma nova definição para esses objetos: uma estrela é uma gêmea solar se seus parâmetros atmosféricos estão dentro da seguinte faixa dos parâmetros solares: $\Delta T_{e f f}=100 \mathrm{~K}, \Delta \log g=0.1$ dex e $\Delta[\mathrm{Fe} / \mathrm{H}]=0.1$ dex.

Tendo em conta essa definição, nos últimos anos as gêmeas solares têm aumentado em número para aproximadamente uma centena (Pasquini et al., 2008; Petit et al., 2008; Meléndez et al., 2009; Ramírez et al., 2009; Takeda e Tajitsu, 2009; Baumann et al., 2010; Önehag et al., 2011; Datson et al., 2012, 2014; do Nascimento et al., 2013; Meléndez et al. 2014; Porto de Mello et al., 2014, Ramírez et al., 2014; Yana Galarza et al., 2016; Mahdi et al., 2016). Como exemplo, na Figura 1.1 são mostradas as gêmeas solares da amostra estudada por Ramírez et al. (2014). 


\subsubsection{Aplicações das gêmeas solares}

O Sol é a estrela mais conhecida e por conseguinte a mais estudada. Praticamente todas as estrelas são comparadas com o Sol; por exemplo, se calculamos a massa, raio, luminosidade, metalicidade, etc., de uma determinada estrela, todos estes parâmetros normalmente estão em relação aos do Sol. Para comparar qualquer estrela com o Sol, o ideal seria observar ambas estrelas com o mesmo telescópio, para assim eliminar erros sistemáticos e de calibrações. Não obstante, nem todos os telescópios estão desenvolvidos para observar o Sol, por conseguinte a utilização de gêmeas solares na comparação com outras estrelas é de muita importância.

As gêmeas solares também são úteis para testes e aplicações astronômicas, tais como: estabelecer o ponto zero das calibrações fundamentais de temperatura e metalicidade fotométrica (Holmberg et al., 2006; Casagrande et al., 2010; Meléndez et al., 2010; Datson et al., 2014), são fontes de estudo para subtrair a luz solar refletida em asteroides e assim estudar sua mineralogia (p. ex. Lazzaro et al., 2004, Jasmim et al., 2013), como testes de interiores estelares e modelos de evolução estelar (p. ex. do Nascimento et al., 2009; Tucci Maia et al., 2015; Carlos et al., 2016), para pesquisar a evolução química do disco galáctico (p. ex. Nissen, 2015; Spina et al., 2016), estudar a evolução rotacional do Sol do Nascimento et al., 2013, 2014) e medir distâncias usando seus espectros (Jofré et al., 2015).

Outra aplicação importante das gêmeas solares é o estudo da acreção de elementos refratários por causa da formação de planetas. Usando uma nova técnica no estudo de abundâncias químicas diferenciais a altíssima precisão (0.01 dex), Meléndez et al. (2009) encontraram que a diferença de abundâncias entre o Sol e as gêmeas solares não é zero, e portanto demostraram que o Sol tem anomalias químicas (ver o painel esquerdo da Figura 1.2. Essas anomalias têm uma correlação muito forte com a temperatura de condensação (Lodders, 2003) dos elementos químicos (ver o painel direito da Figura 1.2). Meléndez et al. (2009) descobriram que o Sol tem uma deficiência nos elementos refratários $\left(T_{C} \geq 900 \mathrm{~K}\right)$ com relação aos elementos voláteis $\left(T_{C} \leq 900 \mathrm{~K}\right)$, sugerindo que as anomalias químicas do Sol estão relacionadas à formação de planetas em nosso Sistema Solar.

Ramírez et al. (2009) estudaram as abundâncias de 64 estrelas com parâmetros fundamentais similares aos do Sol (22 gêmeas solares), e confirmaram a forte relação entre as 

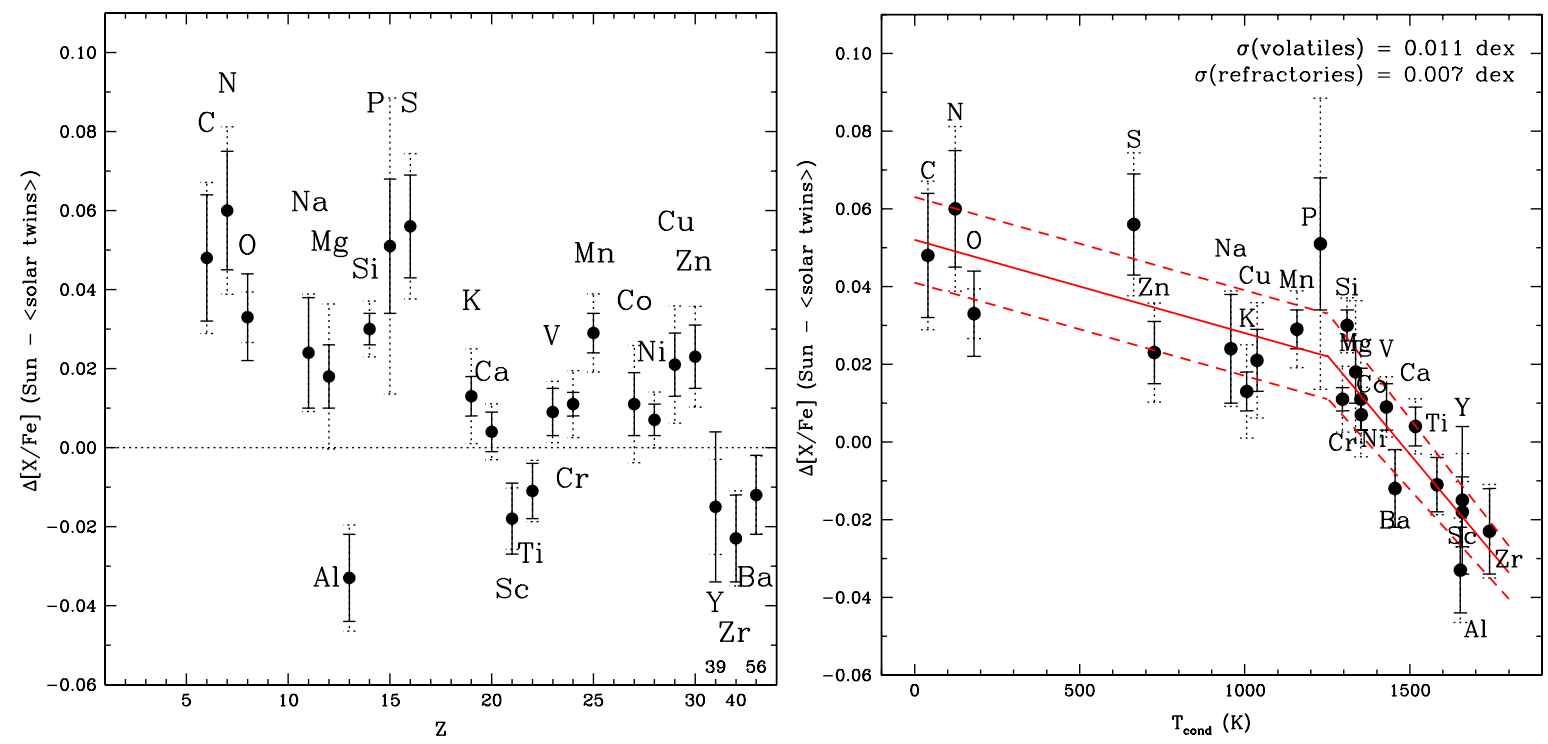

Figura 1.2: Diferenças $\Delta[\mathrm{X} / \mathrm{Fe}]$ (Sol - <gêmeas solares $>$ ) entre a composição química do Sol e gêmeas solares vs. número atômico (painel esquerdo) e temperatura de condensação (painel direito) (Meléndez et al. 2009).

abundâncias químicas e a temperatura de condensação. No painel à esquerda da Figura 1.3 é mostrada a média do padrão químico de 22 gêmeas solares; fica claro que os elementos refratários $\left(T_{C}>900 K\right)$ são mais abundantes do que os voláteis $\left(T_{C}<900 K\right)$. Encontraram também que as gêmeas e análogas solares com metalicidade inferior que a do Sol $([\mathrm{Fe} / \mathrm{H}]<0)$ apresentam excesso de elementos refratários em relação aos do Sol (ver painel direito da Figura 1.3. . Não obstante, para gêmeas e análogas solares com metalicidade maior que a do Sol $([\mathrm{Fe} / \mathrm{H}]>0)$, a situação é oposta. Isso pode refletir efeitos de evolução química da Galáxia.

\subsubsection{Importância no estudo de Planetas}

A descoberta de Meléndez et al. (2009) vem gerando muita controvérsia até hoje. Autores como Gonzalez et al. (2010); González Hernández et al. (2010); Schuler et al. (2011); Adibekyan et al. (2014); Maldonado et al. (2015a) e Nissen (2015) pesquisaram esta relação usando estrelas com e sem planetas, e todos confirmaram o padrão de abundâncias encontrado por Meléndez et al. (2009) e Ramírez et al. (2009). Não obstante, a maioria destes autores coloca dúvidas na relação, pois notam que não existe muita diferença entre estrelas com e sem planetas.

Devido à controvérsia gerada, de forma independente, Ramírez et al. (2010) analisaram 

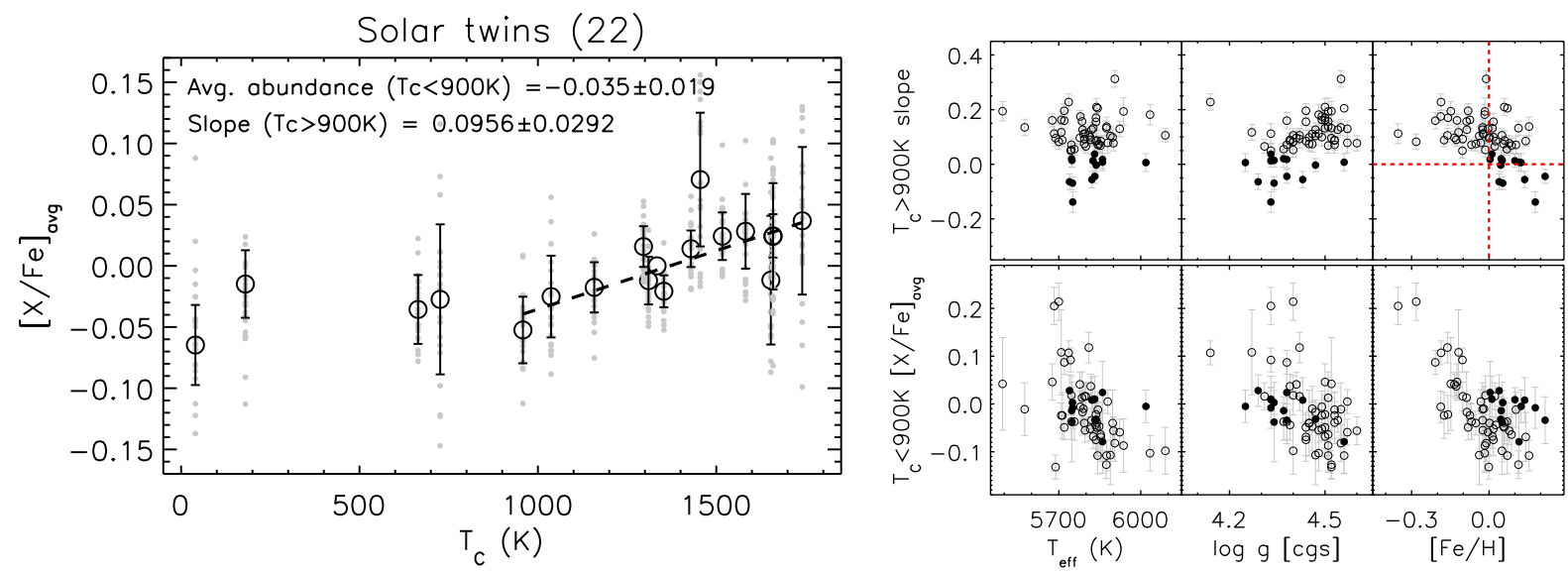

Figura 1.3: Painel esquerdo: a média do padrão de abundâncias de 22 gêmeas solares em função da temperatura de condensação. Painel direito: a inclinação da média do padrão de abundâncias dos elementos refratários e a média das abundâncias dos elementos voláteis em função dos parâmetros atmosféricos. Créditos das imagens: Ramírez et al. (2009).

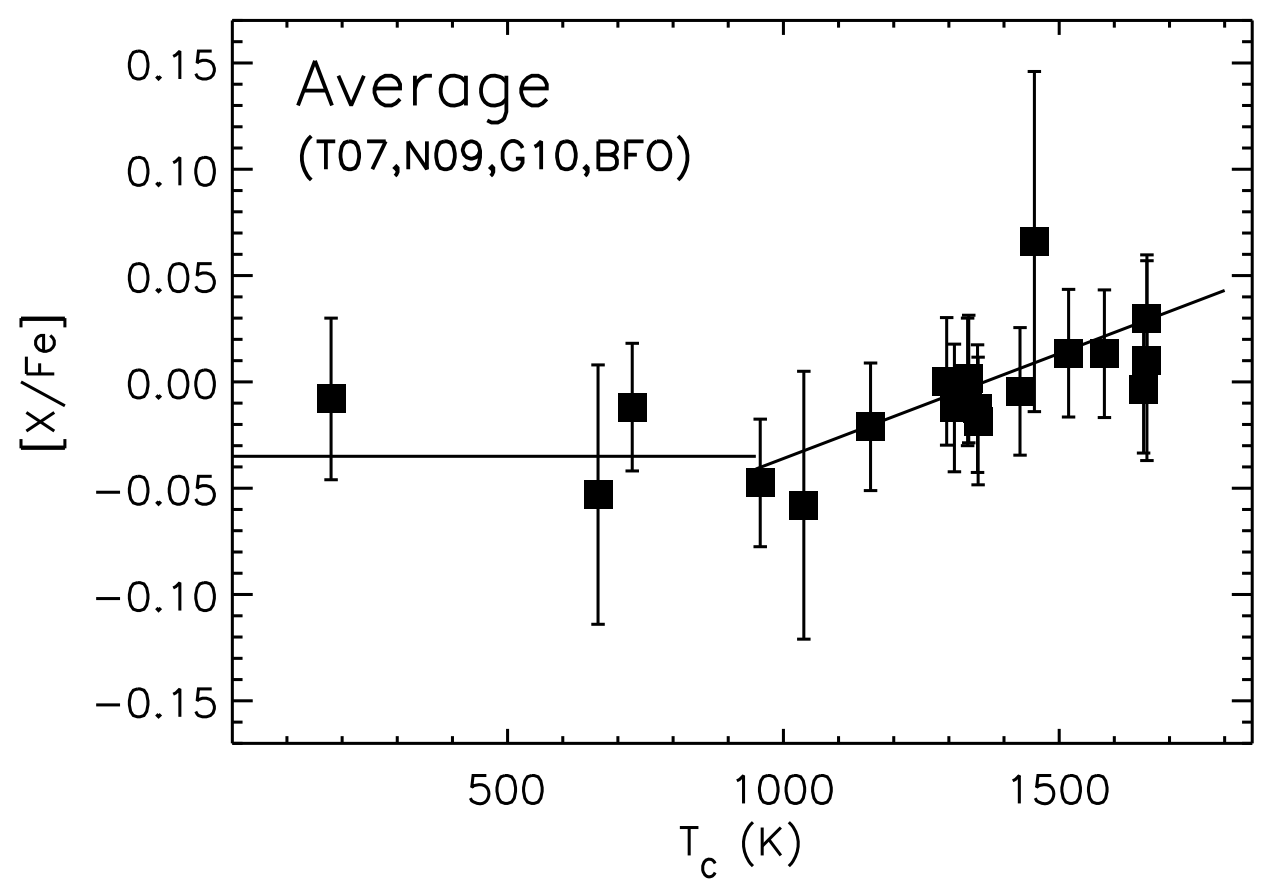

Figura 1.4: A média do padrão de abundâncias químicas das amostras estudadas por Ramírez et al. (2010). Notar que nesta figura são mostrados apenas os trabalhos onde os parâmetros estelares foram determinados usando os espectros (equilíbrio espectroscópico). 


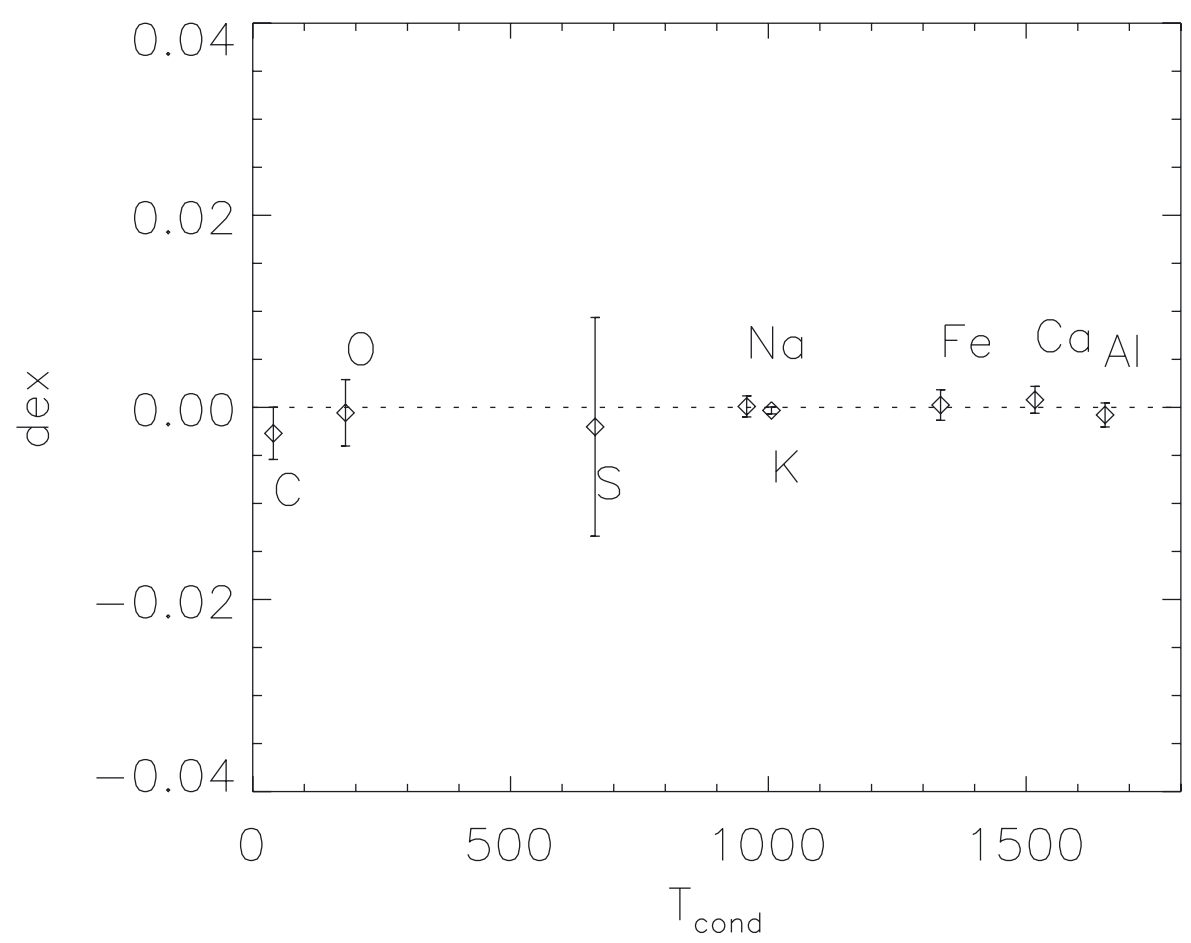

Figura 1.5: Diferenças em abundâncias químicas no Sol, observadas em latitudes altas e no equador solar. Fonte: Kiselman et al. (2011).

as amostras de Reddy et al. (2003); Allende Prieto et al. (2004); Takeda (2007); Neves et al. (2009) e González Hernández et al. (2010) e obtiveram os mesmos resultados que foram encontrados por Meléndez et al. (2009) (ver Figura 1.4).

Pensou-se também na possibilidade de que essas peculiaridades poderiam ter sido geradas por um efeito de idade ou talvez devido à evolução química da Galáxia, mas estes efeitos foram descartados em Meléndez et al. (2009) para o padrão médio das gêmeas solares. Outro efeito a considerar foi o ângulo de inclinação com que foram observadas as gêmeas solares, que poderia gerar pequenas diferenças nas abundâncias. Para verificar isso, Kiselman et al. (2011) observaram o Sol em diferentes latitudes e demostraram que as abundâncias do Sol são independentes da latitude, sem nenhuma variação dentro de 0.005 dex (ver Figura 1.5).

Estudou-se também a possibilidade de se a escolha do asteroide $\rfloor^{4}$ introduz alguma anomalia química no padrão de abundâncias. O primeiro teste foi realizado por Meléndez et al. (2012), onde eles analisaram o espectro da gêmea solar 18 Sco e compararam com o

\footnotetext{
${ }^{4} \mathrm{O}$ espectro do Sol é observado pela luz refletida nos asteroides. Os asteroides que são tipicamente usados com tal finalidade são: Vesta, Ceres, Juno e Iris.
} 
espectro solar obtido através dos asteroides Juno $(R=110000)$ e Ceres $(R=100000)$, e encontraram uma diferença em abundância de apenas 0.002 dex $(\sigma=0.005)$. Posteriormente, Bedell et al. (2014) observaram o espectro do Sol usando os asteroides Ceres e Vesta que foram obtidos com o ESPaDOnS no CFHT ( $\sim$ 80000), e encontraram uma diferença em abundância de só 0.001 dex $(\sigma=0.006)$ (Figura 1.6). Eles também observaram o asteroide Iris com o MIKE $(\mathrm{R}=65000)$ e compararam com o asteroide Vesta observado com o mesmo espectrógrafo, obtendo uma diferença de 0.006 dex $(\sigma=0.008)$. Portanto, pode-se concluir que a escolha do asteroide não tem efeito significativo no padrão de abundâncias observadas. Na seção 2.13 discutirei com mais detalhe os cálculos mencionados acima.

Determinações isotópicas nos meteoritos de tipo condrito mostraram a presença de radionuclídeos de vida curta $5^{5}$ nos estágios iniciais do Sistema Solar. Estes elementos são produzidos em estrelas do ramo assintótico das gigantes (AGB), como também em supernovas, e provavelmente foram espalhados na nebulosa solar. Por conseguinte, o padrão químico observado no Sol em relação às gêmeas solares poderia ser explicado por estes tipos de contribuições. No entanto, Meléndez et al. (2012) mostraram que a poluição por estrelas AGB, supernovas de tipo Ia, II, e hipernovas não explicam as peculiaridades observadas no Sol (Ver Figura 1.7).

Planetas gigantes e sua assinatura química: O sistema binário 16 Cyg é composto por duas gêmeas solares: 16 Cyg A e 16 Cyg B. Esta última possui um planeta gigante (Cochran et al., 1997). Por conseguinte, o sistema binário 16 Cyg é excelente para estudar se o padrão de abundância química de 16 Cyg B foi afetado ou não pela presença do seu planeta. Levando em conta que ambas estrelas foram formadas da mesma nebulosa, uma comparação entre suas abundâncias revelaria novas evidências sobre a assinatura planetária proposta por Meléndez et al. (2009). Considerando isso, Ramírez et al. (2011) estudaram este sistema com resolução espectral R $=60000$ e encontraram que existe uma diferença significativa de abundâncias entre ambas estrelas (16 Cyg A - 16 Cyg B) de 0.041 dex. Esta diferença reforça a ideia de que a presença de planetas afeta a composição química das estrelas. Não obstante, Schuler et al.

\footnotetext{
${ }^{5}$ Os radionuclídeos de vida curta têm uma vida média de $\approx 100 \mathrm{Myr}$, e o conhecimento do seu origem é fundamental para extrair informação sobre os diferentes tipos de abundâncias iniciais presentes nos objetos primitivos do Sistema Solar.
} 

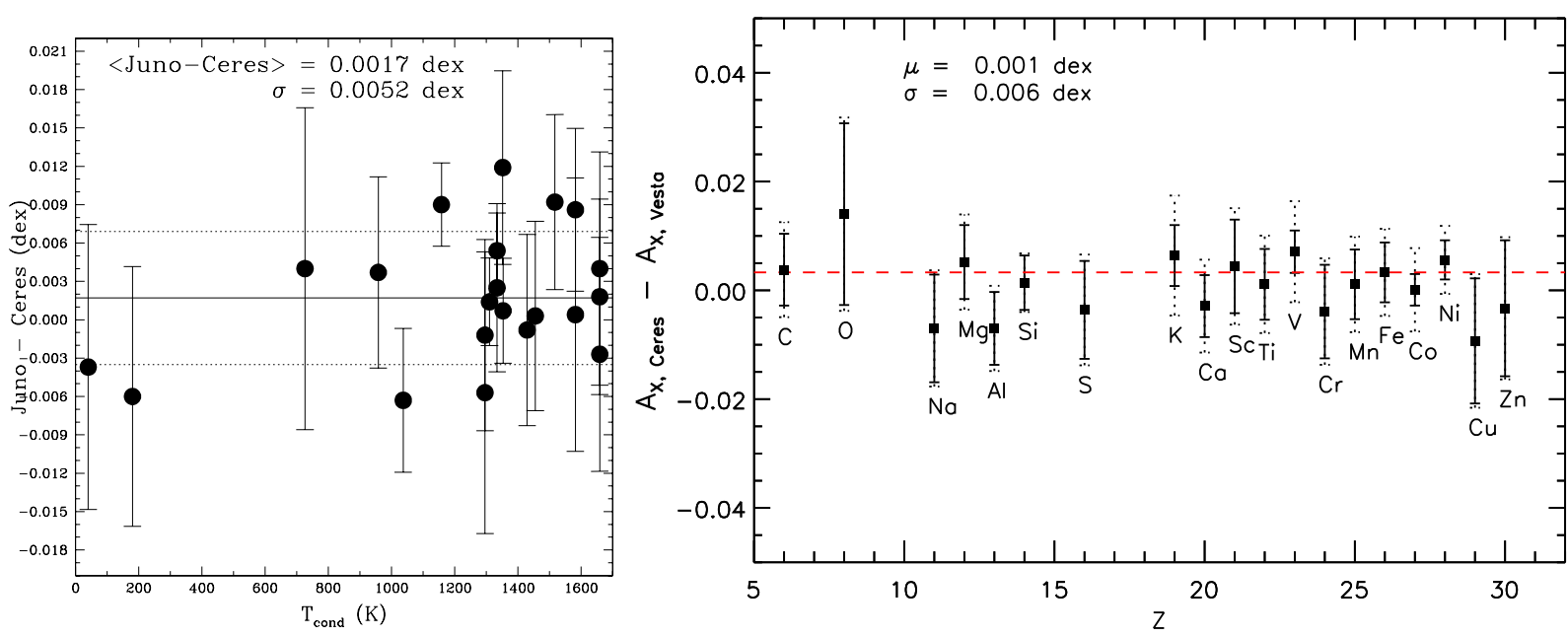

Figura 1.6: Diferenças entre as abundâncias do Sol obtidas com o asteroide Juno e Ceres (painel esquerdo), como também de Ceres e Vesta (painel direito). Créditos das imagem: Meléndez et al. (2012) e Bedell et al. (2014).

(2011) usando espectros com $\mathrm{R}=45000$ não encontraram uma diferença relevante entre a composição química da estrela com e sem planeta gigante. Posteriormente, Tucci Maia et al. (2014) analisaram o mesmo sistema mas com maior resolução (R $=81000)$, determinando uma diferença (Cyg A - Cyg B) de 0.03 dex nos elementos voláteis e 0.06 dex nos elementos refratários. Eles argumentaram que a primeira diferença poderia significar que esse planeta gigante é composto de metais que foram tomados do disco protoplanetário para formá-lo. A segunda diferença e talvez a mais importante, poderia ser devido ao núcleo rochoso do planeta. A diferença química entre as componentes do sistema 16 Cyg é mostrada na Figura 1.8 .

Planetas em gêmeas solares: Um grande projeto (ESO Large Programme) de procura de planetas em gêmeas solares é liderado pelo professor Jorge Meléndez. Este projeto ganhou 88 noites de observação com o espectrógrafo HARPS, no telescópio de 3.6 m do Observatório La Silla do ESO. Os parâmetros atmosféricos, atividade estelar, massas e idades da amostra podem ser encontrados em Ramírez et al. (2014). Um segundo resultado do projeto foi a recente descoberta de um gêmeo de Júpiter em torno de uma gêmea do Sol (HIP 11915) (Bedell et al., 2015). Considerando o que as teorias de formação de planetas no Sistema Solar indicam, a presença do gigante gasoso Júpiter foi fundamental para a formação de planetas terrestres, como também para a estabilidade da Terra. Portanto, a descoberta de nosso grupo (Bedell et al. 


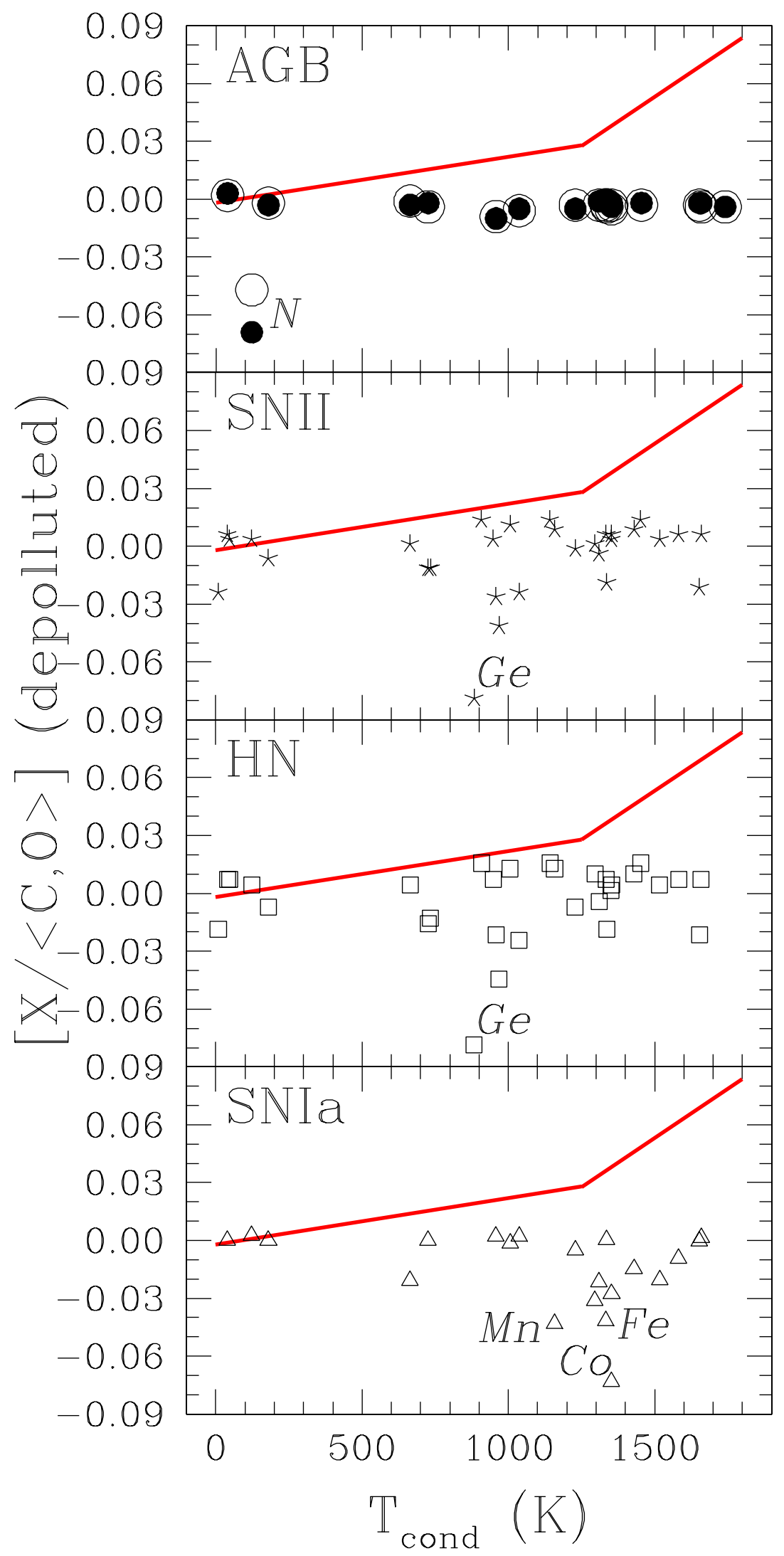

Figura 1.7: Razão de abundâncias entre a média das gêmeas solares em relação ao Sol (linha vermelha) e as abundâncias do Sistema Solar poluídas por estrelas AGB, supernovas e hipernovas. Créditos da imagem: Meléndez et al. (2012). 


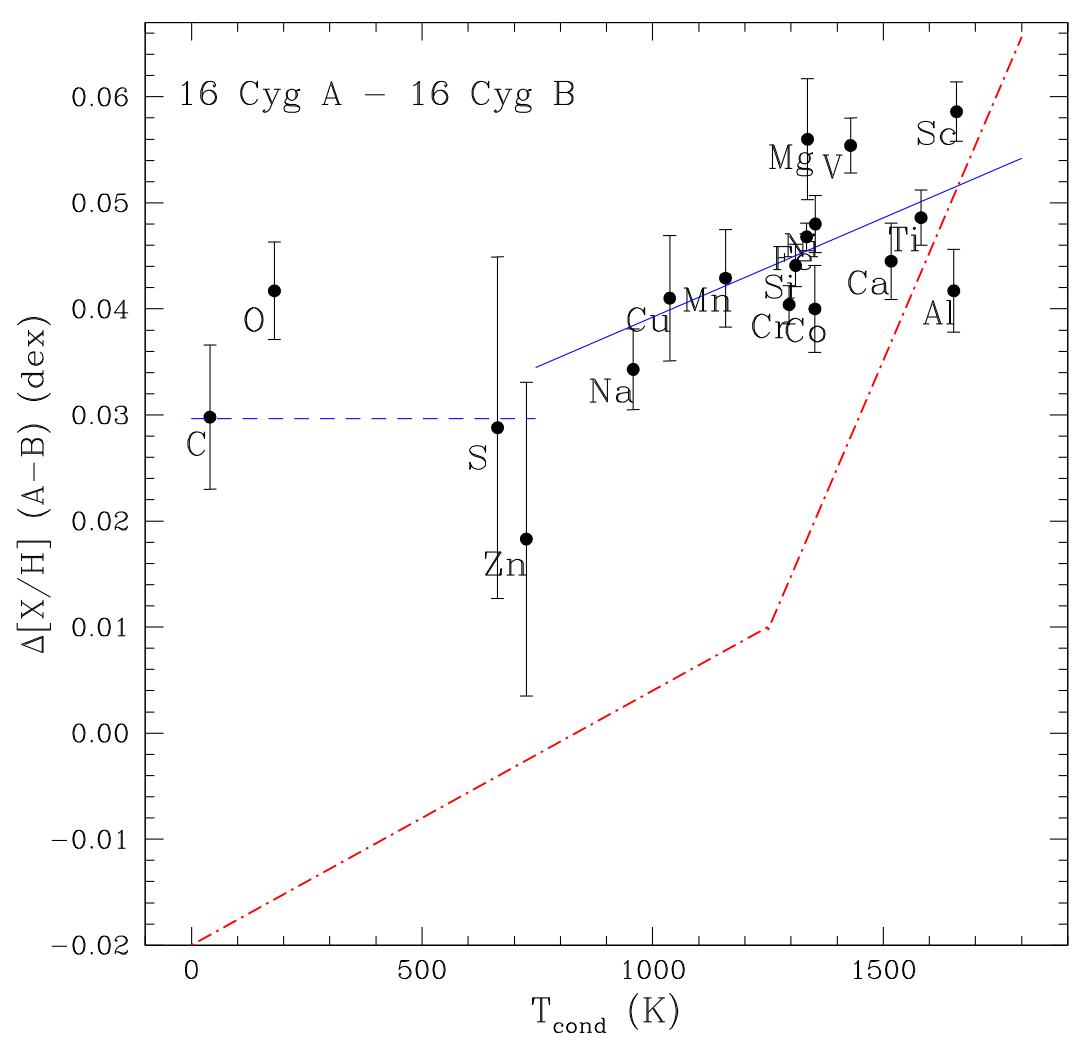

Figura 1.8: Diferença entre as abundâncias químicas de 16 Cyg A e 16 Cyg B. A linha pontilhada é a média dos elementos voláteis e a linha sólida é o padrão dos elementos refratários. A linha vermelha tracejada e pontilhada é a média do padrão de abundâncias das gêmeas solares. Fonte: Tucci Maia et al. (2014).

2015) é importante na procura de um sistema planetário que seja semelhante ao nosso. No entanto, eles não descobriram apenas um planeta com massa quase idêntica à do Júpiter, mas também revelaram que o planeta encontra-se quase exatamente na mesma posição que Júpiter ocupa no nosso Sistema Solar e que a composição química, idade e massa da gêmea solar são aproximadamente as mesmas do Sol. Este sistema descoberto é um candidato em potencial para abrigar um sistema planetário semelhante ao nosso, e talvez, a existência de um planeta terrestre que poderia conter algum tipo de vida. 


\subsection{Formação de planetas rochosos}

\subsubsection{Hipótese nebular}

As observações da Via Láctea e de outras galáxias indicam que a maioria das estrelas foram formadas em aglomerados. Estes por sua vez, nasceram em nuvens moleculares, ou seja, em grandes volumes de gás frio que são compostos de hidrogênio molecular, hélio e moléculas orgânicas complexas (Ehrenfreund e Charnley, 2000; Yeghikyan, 2011). As nuvens moleculares são os objetos mais massivos do disco galáctico, com massas entre $10^{3}$ e $10^{7} \mathrm{M}_{\odot}$ (Murray, 2011). Estas são perturbadas por explosões de supernovas (Williams, 2010) e posteriormente colapsam por efeitos gravitacionais (Reipurth et al., 2007).

As nuvens moleculares são objetos estruturados com uma hierarquia descrita como clumps e cores (Williams et al., 2000). Os clumps têm massas entre 10 e $10^{3} \mathrm{M}_{\odot}$ e poderiam conter aglomerados de grupos jovens de estrelas, enquanto os cores são pequenas estruturas que formam estrelas individuais com massa de aproximadamente $1 \mathrm{M}_{\odot}$ di Francesco et al. 2007).

Em $\sim 10^{4}$ anos, simulações acompanhadas de observações mostram um grande e denso envelope da protoestrela de aproximadamente entre 1000 e 10000 AU de raio, com um fluxo bipolar no centro. Em $10^{5}$ anos, o envelope é menos denso devido ao fato de que a maior parte colapsou no disco. Observações revelam a presença de um disco denso de raio entre 500 e $1000 \mathrm{AU}$, onde o núcleo da estrela continua aumentando. Nesta etapa são reveladas as estruturas do envelope exterior, o disco de acreção interno e a matéria ejetada em forma perpendicular ao disco (Hayashi, 1966; Shu et al., 1987; Feigelson e Montmerle, 1999: Andre et al., 2000, Montmerle et al., 2006). Em $10^{6}$ anos, o envelope é finalmente esgotado, deixando uma estrela luminosa, um disco circunstelar massivo e um jato bipolar. Como resultado da pressão do gás, força de gravidade, campos magnéticos e a rotação, gerou-se o disco protoplanetário com movimento de rotação e formando uma protoestrela densa no centro (Greaves, 2005). Nesta fase, autores sugerem que o Sol tenha sido uma estrela T Tauri (Bertout, 1989; Caffe et al., 1987). Depois, em $\sim 10^{7}$ anos, o disco da estrela e seu jato desaparecem. O equilíbrio hidrostático é atingido e a pressão do núcleo da estrela é o suficiente para fundir o hidrogênio no seu núcleo. Recentemente, Andrews et al. (2016) descobriram a evidência observacional de formação planetária numa órbita semelhante à da Terra ao redor da estrela TW Hydrae (ver Figura 1.9); esta descoberta 


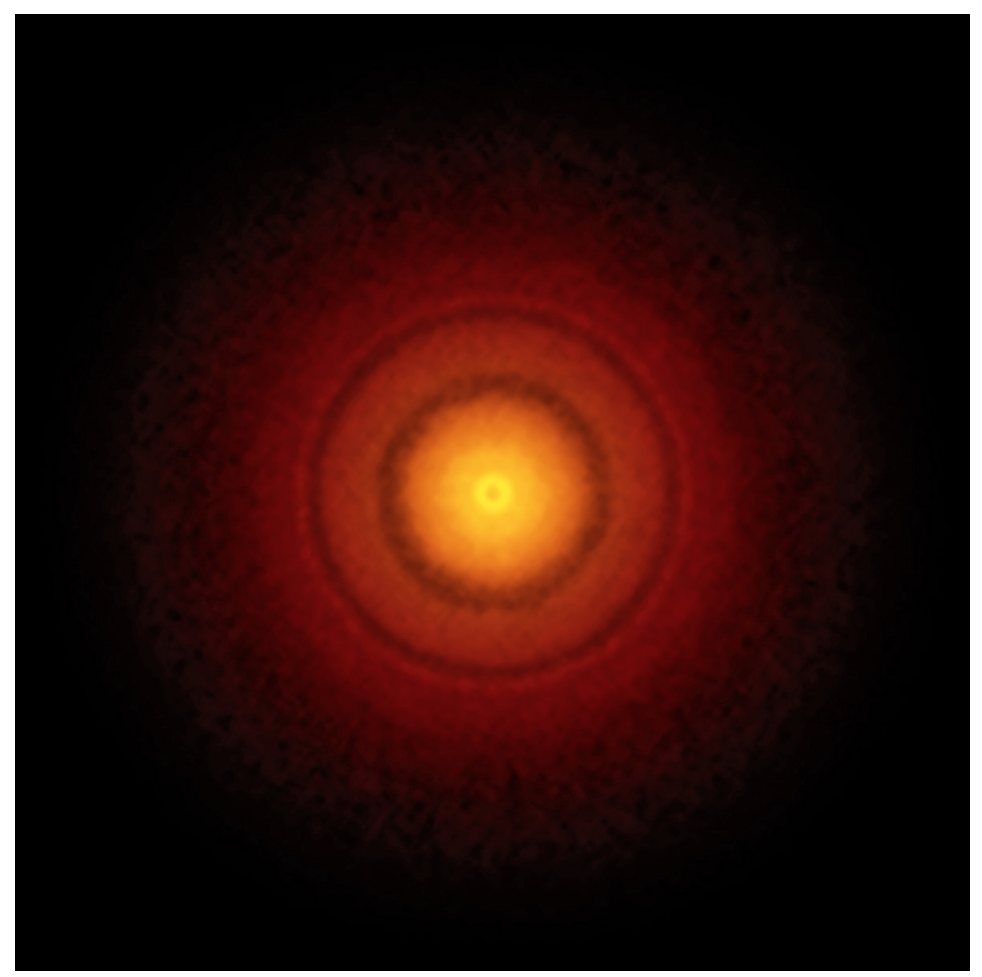

Figura 1.9: Imagem da estrela jovem TW Hydrae e seu disco protoplanetário realizado pelo ALMA. Os espaços vazios indicam que existe formação planetária no sistema. Fonte: ESO e Andrews et al. (2016).

reforça a teoria de formação planetária explicada anteriormente.

Em $10^{6}$ anos, os graõs de poeira interestelar submicrônicos crescem para tamanhos de cm através de colisões mútuas resultando em ligações químicas e eletrostáticas (Weidenschilling, 1977; Hayashi et al., 1985). Depois, os pebble $\underbrace{6}$ crescem em planetesimais por colisões e, logo, passam por instabilidade gravitacional (Weidenschilling e Cuzzi, 1993). A gravidade dos planetesimais, com quilômetros em tamanho ou maiores, torna-se forte o suficiente para manter os fragmentos da colisão, resultando em protoplanetas através de colisões mútuas por interação gravitacional (Wetherill e Stewart, 1989). Em $10^{7}$ anos, o sistema de protoplanetas evolui como um sistema de N corpos através da interação gravitacional e ocasionalmente grandes impactos entre eles podem ocorrer. Os protoplanetas que atingem a massa crítica (entre $10-15 \mathrm{M}_{\oplus}$ ) para capturar o gás do disco protoplanetário, tornam-se gigantes gasosos (Pollack et al., 1996), caso contrário, tornam-se planetas terrestres (Chambers e Wetherill, 1998).

\footnotetext{
${ }^{6}$ Refere-se a pebble accretion, onde o acréscimo de objetos vão desde os cm até metros de diâmetro.
} 


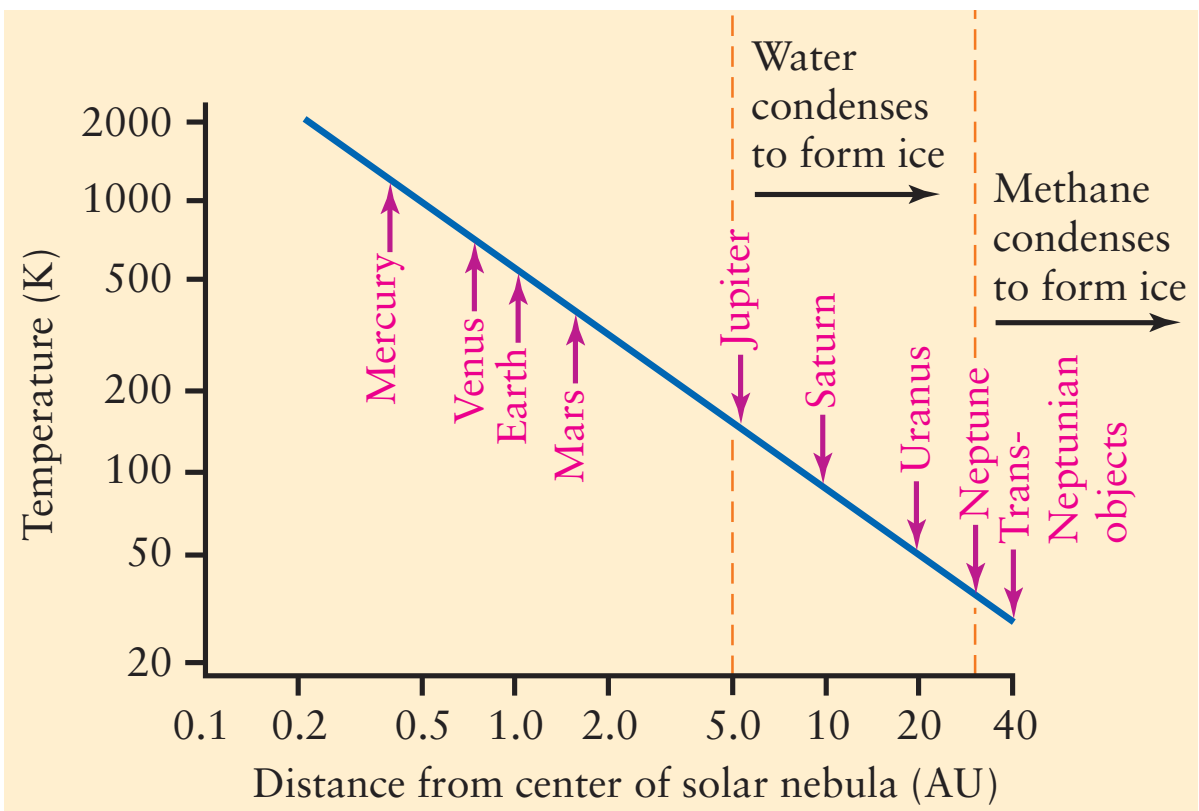

Figura 1.10: Distribuição de temperaturas na nebulosa solar. Fonte: Freedman e Kaufmann (2005).

\subsubsection{Temperatura de condensação}

Conhecer as condições iniciais de temperatura, pressão, densidade e composição química da nebulosa solar ajudaria na compreensão de como os planetas, asteroides e cometas foram formados. A distribuição de densidade diminui do centro ao longo da nebulosa solar, assim como também a pressão e a temperatura. Nesta distribuição, certos elementos ou substâncias encontram-se em estado sólido, dependendo da temperatura de condensação $\left(\mathrm{T}_{\text {cond }}\right)$. Lodders $(2003)$ determinou a $\mathrm{T}_{\text {cond }}$ de todos os elementos para a nebulosa solar; essas temperaturas são mostradas na Tabela A.1.

Considerando o explicado acima, pode-se deduzir que na zona interna da nebulosa solar os materiais com altas temperaturas $\left(\mathrm{T}_{\text {cond }} \geq 900 \mathrm{~K}\right)$ como o ferro, o magnésio, entre outros (os materiais refratários), sobreviveram no seu estado sólido, no entanto substâncias como a água, metano e a amônia foram vaporizadas pelas altas temperaturas, ou seja, nas regiões internas se formaram planetas rochosos. Entretanto, na zona exterior do disco, encontrase os materiais com baixas temperaturas $\left(\mathrm{T}_{\text {Cond }} \leq 900 \mathrm{~K}\right)$ (os materiais voláteis), esses materiais junto como os refratários formaram os planetas gigantes gasosos. É importante mencionar que os elementos mais abundantes como o hidrogênio e o hélio têm temperaturas de condensação próxima do zero absoluto, por isso estes elementos sempre estiveram em estado gasoso durante as etapas iniciais do Sistema Solar. Na Figura 1.10 é mostrada a 


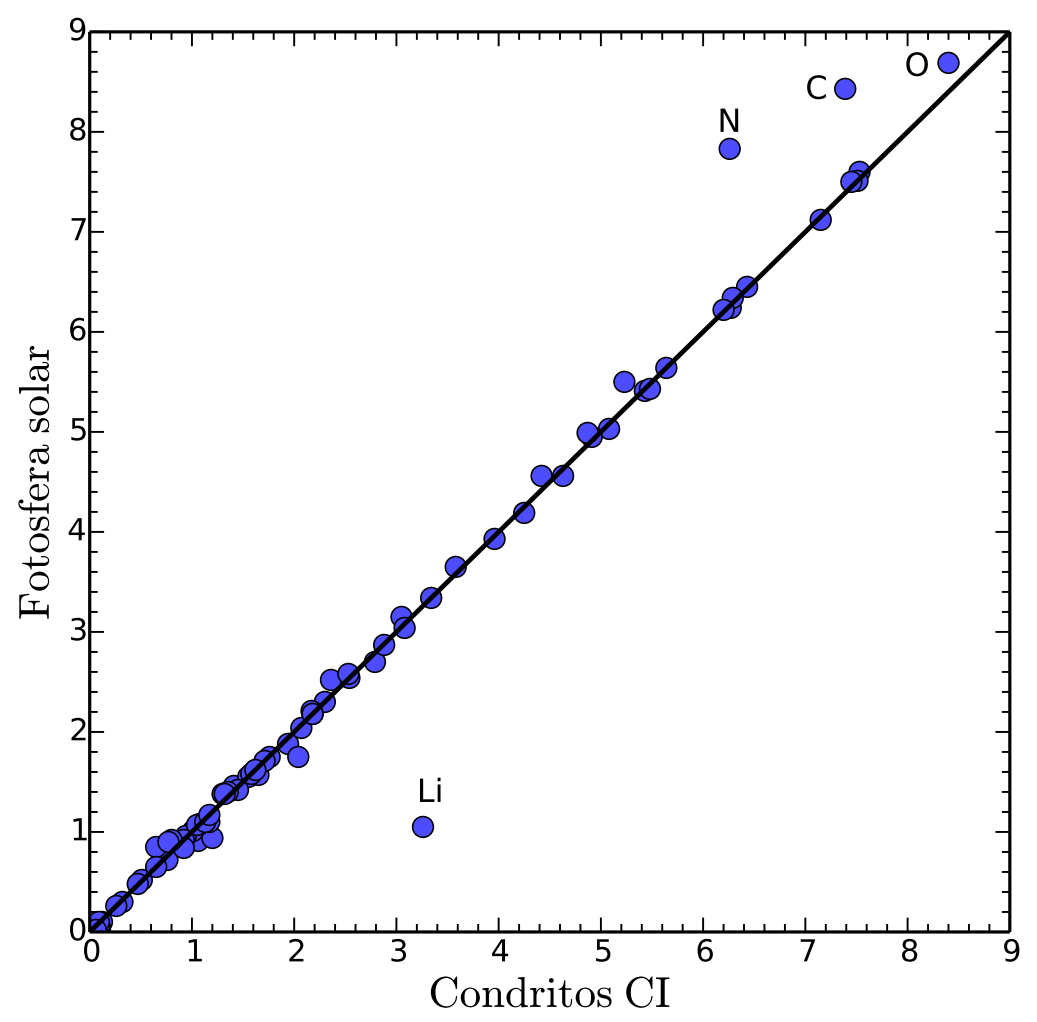

Figura 1.11: As abundâncias elementais da fotosfera solar Asplund et al. 2009 vs. a composição química dos condritos CI (Lodders et al., 2009).

variação da temperatura em relação à distância do centro da nebulosa solar; a partir de uma distância de 5 UA a temperatura é suficientemente baixa para que a água se condense em gelo, e a partir dos 30 UA o metano também se condensa para formar gelo. Isso explicaria porque no Sistema Solar existem planetas rochosos e gasosos.

\subsubsection{Abundâncias químicas do Sistema Solar}

O estudo da composição química solar é muito importante para compreender o processo de formação de planetas e a distribuição dos elementos químicos no Sistema Solar. As abundâncias químicas do Sistema Solar são determinadas de duas formas: usando meteoritos e por espectroscopia da fotosfera do Sol. Os meteoritos mais antigos e comuns são os carbonáceos CI7] cuja composição química é parecida à do Sol (ver Figura 1.11), porque contêm a matéria primordial da nuvem de gás que originou o Sistema Solar com todos os planetas e o Sol. Assim, os meteoritos condritos são importantes porque permitem analisar

\footnotetext{
${ }^{7}$ Sua designação I deriva do meteorito Ivuna encontrado em 1938 na Tanzânia.
} 


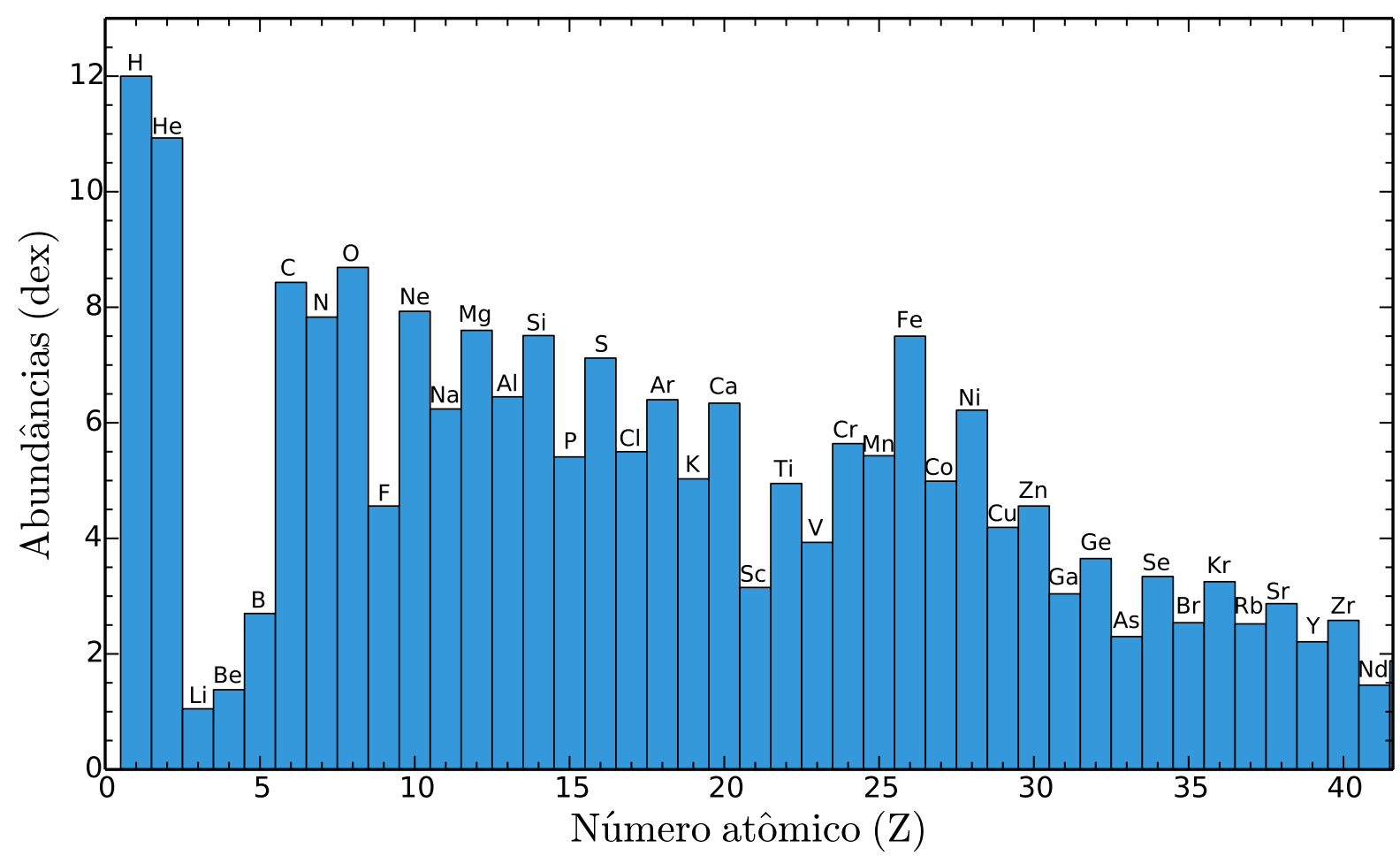

Figura 1.12: Abundância dos primeiros 41 elementos químicos presentes na fotosfera solar Asplund et al. 2009 ).

estruturas primitivas presentes há 4.5 bilhões de anos.

Lodders (2003) determinou as abundâncias químicas de 4 meteoritos carbonáceos CI. Posteriormente, Lodders et al. (2009) calcularam com maior precisão a composição química destes meteoritos usando uma nova tecnologia ICP-MS (Inductively Coupled Plasma Mass Spectrometry). No mesmo ano, Asplund et al. (2009) determinaram as abundâncias solares mais precisas até hoje conhecidas, onde usaram um modelo de atmosfera 3D, e o cálculo de abundâncias foi realizado em equilíbrio termodinâmico local (LTE) e para alguns elementos foram consideradas correções de não-equilíbrio termodinâmico local (NLTE), conseguindo assim determinar com muita acurácia as abundâncias a partir das linhas dos elementos presentes na fotosfera solar. Os resultados de Lodders (2003) e Asplund et al. (2009) são listados na Tabela A.1. As abundâncias de Asplund et al. (2009) também são mostradas na Figura 1.12 É importante notar que na Figura 1.11 a abundância do lítio solar é menor do que o lítio condrítico, porquanto o lítio solar foi destruído por reações nucleares no Sol (p. ex. Carlos et al. 2016). 


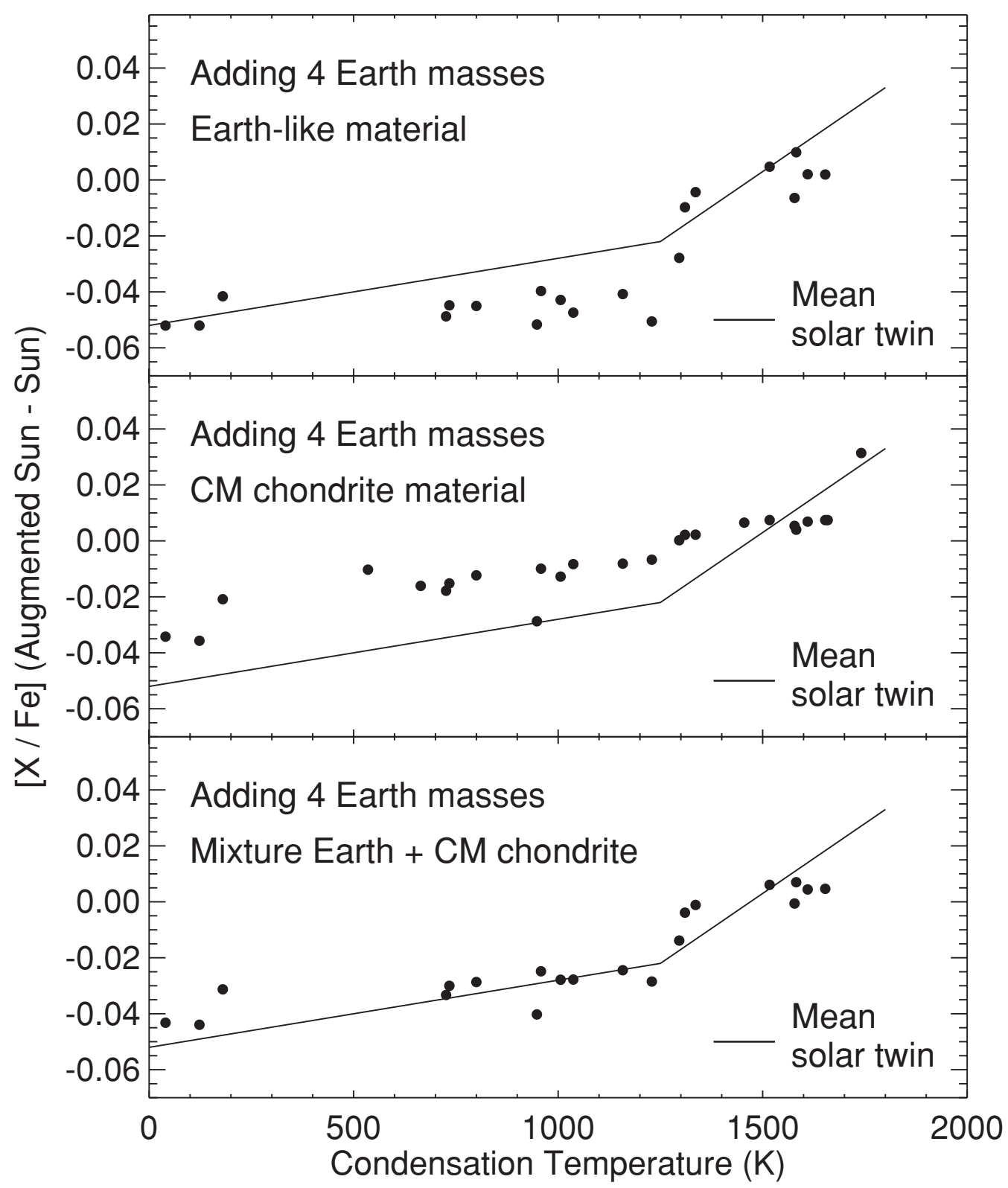

Figura 1.13: Composição da fotosfera solar adicionando 4 massas terrestres de material tipo terra (painel superior), de tipo condrítico CM (painel do meio) e uma mistura de material terrestre e condrítico (painel inferior). A linha representa o ajuste das 11 gêmeas solares analisadas por Meléndez et al. (2009). Imagem tirada de Chambers $(2010)$. 
Chambers (2010) mostrou que a massa dos elementos refratários na zona convectiva do Sol é suficiente para formar os planetas rochosos. Ele fez um estudo detalhado para 20 elementos, usando o padrão de abundâncias da Terra e de meteoritos (Waenke e Dreibus, 1988; Wasson e Kallemeyn, 1988) e mostrou um excelente acordo com o padrão de abundâncias observadas no Sol em relação à média de 11 gêmeas solares (Meléndez et al., 2009). Foi necessário introduzir uma mistura de $4 \mathrm{M}_{\oplus}$ de material rochoso na zona convectiva do Sol para reproduzir esse padrão de abundâncias, como mostrado na Figura 1.13 .

\subsection{Organização da Dissertação}

Esta dissertação está dividida em cinco capítulos e quatro apêndices. No capítulo 2 descreverei a metodologia utilizada na determinação dos parâmetros atmosféricos e das abundâncias elementais usando larguras equivalentes. Apresentarei também detalhadamente todos os procedimentos, princípios teóricos e dados das linhas adotadas, assim como mostrarei a precisão atingida na minha análise de espectros solares obtidos com diferentes asteroides. No capítulo 3 reportarei a descoberta da gêmea solar Inti 1 e compararei seus parâmetros atmosféricos e abundâncias químicas com a gêmea solar brilhante HD 45184, com o fim de verificar a precisão atingida, como também determinarei a massa e idade destas estrelas. Neste capítulo será apresentado o código terra, que desenvolvi para estimar o material rochoso na zona convectiva de estrelas de tipo solar. No capítulo 4 determinarei os parâmetros atmosféricos de HIP 100963 e explicarei a origem de suas abundâncias químicas e os efeitos de evolução química da Galáxia. Também descreverei a técnica para a obtenção da abundância de lítio e discutirei a sua relação com a idade estelar. Os resultados desta dissertação são resumidos no capítulo 5, onde apresentarei também as conclusões e perspectivas deste trabalho. No apêndice A mostrarei as tabelas com as composições químicas, lista de linhas e correções hiperfinas, no apêndice B.0.1 é apresentado o código terra e no apêndice C é explicado o uso do código MOOG para as estimativas de abundâncias. E finalmente no apêndice $\mathrm{D}$ são apresentados os dois artigos originais publicados no Astronomy \& Astrophysics como resultado desta dissertação. 
Capítulo 2

\section{Atmosferas estelares e cálculo de abundâncias químicas}

Neste capítulo revisarei alguns conceitos básicos de atmosferas estelares. Descreverei a metodologia aplicada no cálculo da composição química de estrelas, e como exemplo a técnica será aplicada a diferentes observações do Sol, mostrando que é possível atingir uma precisão de 0.01 dex. Para tal fim, seguirei especialmente os livros de Gray (2005) e Rutten (2003) e as teses de doutorado de Barbuy (1982) e Meléndez (2001).

\subsection{Atmosfera Estelar}

Uma estrela como o Sol é composta de um núcleo, uma zona radiativa, zona de convecção e a sua atmosfera. Os fótons são criados no núcleo e emergem do interior da estrela até a atmosfera. A fotosfera é a região onde os fótons são absorvidos ou espalhados pelos elétrons, átomos e moléculas. É de fundamental interesse o transporte radiativo devido a que este descreve a formação de linhas na fotosfera.

Assumindo que a fotosfera é um gás monoatômico perfeito, não-degenerado e nãorelativístico, a pressão total $\left(\mathrm{P}_{\mathrm{T}}\right)$, ou seja, a pressão do gás $\left(\mathrm{P}_{\mathrm{g}}\right)$ e dos elétrons $\left(\mathrm{P}_{\mathrm{e}}\right)$ está relacionada diretamente com a sua temperatura $(\mathrm{T})$ através da seguinte equação:

$$
\begin{aligned}
\mathrm{P}_{\mathrm{T}} & =\mathrm{P}_{\mathrm{g}}+\mathrm{P}_{\mathrm{e}} \\
& =\left(\mathrm{N}_{\mathrm{g}}+\mathrm{N}_{\mathrm{e}}\right) \mathrm{kT},
\end{aligned}
$$

sendo $\mathrm{N}_{\mathrm{g}}, \mathrm{N}_{\mathrm{e}}$ e k o número de partículas por unidade de volume, número de elétrons por unidade de volume e a constante de Boltzmann.

A interação dos fótons com os elementos químicos presentes na fotosfera da estrela geram as linhas de absorção no espectro eletromagnético. A forma e intensidade destas linhas são fundamentais para a determinação das abundâncias químicas. Não obstante, 
para obter uma interpretação objetiva destas linhas precisa-se de um modelo que descreva as condições físicas da fotosfera. Os modelos de atmosfera dependem dos parâmetros atmosféricos básicos, isto é, da temperatura efetiva $\left(T_{\text {eff }}\right)$, gravidade superficial $(\log g)$, velocidade de microturbulência $\left(v_{t}\right)$ e metalicidade $[\mathrm{Fe} / \mathrm{H}]$.

A $T_{\text {eff }}$ de uma estrela é definida como a temperatura de um corpo negro com o mesmo fluxo total $(F)$ na superfície da estrela:

$$
F=\sigma T_{e f f}^{4}
$$

Se a estrela se encontra a uma distância $d$, o fluxo integrado medido na Terra é:

$$
F(r)=\sigma T_{e f f}^{4}\left(\frac{R}{d}\right)^{2},
$$

sendo $R$ o raio da estrela e $R / d$ o semi-diâmetro angular. Na pratica, a equação 2.3 não costuma ser usada para estimar a $T_{\text {eff }}$, pois as medidas do diâmetro angular de estrelas são bastante imprecisas e limitadas a estrelas anãs muito próximas ou estrelas gigantes brilhantes. Devido a isso tem se desenvolvido calibrações fotométricas que relacionam cores e $T_{\text {eff }}$. Nesta dissertação a $T_{\text {eff }}$ é determinada de forma espectroscópica (ver seção 2.11) e validaremos os resultados estimando a $T_{\text {eff }}$ segundo calibrações fotométricas desenvolvidas por Casagrande et al. (2010), como detalhado na seção 3.6 .

A gravidade superficial é dada pela equação entre a constante gravitacional $(G)$, massa $(M)$ e raio $(R)$ da estrela:

$$
g=\frac{G M}{R^{2}}
$$

A formação das linhas na fotosfera é afetada pela gravidade superficial através da pressão do gás $\left(\mathrm{P}_{g}=g^{2 / 3}\right)$ e a densidade eletrônica. Uma diminuição da pressão implica um decréscimo da densidade e portanto também do número de colisões entre partículas. Por conseguinte, as linhas de estrelas gigantes são mais estreitas do que nas estrelas anãs.

A partir da equação 2.4 e a relação $R^{2} \propto L T_{e f f}^{-4}$, é possível determinar a gravidade superficial:

$$
\log \left(\frac{g}{g_{\odot}}\right)=\log \left(\frac{M}{M_{\odot}}\right)+4 \log \left(\frac{T_{\text {eff }}}{T_{\text {eff }, \odot}}\right)+\log \left(\frac{L_{\odot}}{L}\right) .
$$

Usando a definição de magnitude bolométrica o último termo da equação 2.5 pode ser escrito:

$$
\log \left(\frac{L_{\odot}}{L}\right)=0.4\left(M_{b o l}-M_{b o l, \odot}\right)
$$


Substituindo a equação 2.6 na equação 2.5, obtém-se:

$$
\log \left(\frac{g}{g_{\odot}}\right)=\log \left(\frac{M}{M_{\odot}}\right)+4 \log \left(\frac{T_{e f f}}{T_{e f f, \odot}}\right)+0.4\left(M_{b o l}-M_{b o l, \odot}\right) .
$$

A magnitude bolométrica absoluta é dada por (p. ex. Nissen et al., 1997):

$$
M_{b o l}=V+B C+5 \log \pi+5
$$

onde $V$ é a magnitude visual da estrela, $B C$ é a correção bolométrica e $\pi$ é a paralaxe em unidades de arco-segundo. Adotando $M_{b o l, \odot}=4.736$ (Bessell et al., 1998), a equação 2.7 pode ser escrita:

$$
\log \left(\frac{g}{g_{\odot}}\right)=\log \left(\frac{M}{M_{\odot}}\right)+4 \log \left(\frac{T_{\text {eff }}}{T_{\text {eff }, \odot}}\right)+0.4 V+0.4 B C+2 \log \pi+0.1056 .
$$

Para estrelas anãs com metalicidade solar e $4200 \mathrm{~K}<T_{\text {eff }}<7000 \mathrm{~K}$ pode-se adotar a $B C$ de Meléndez et al. (2006b):

$$
B C=-1.6240+4.5066 \theta-3.12936 \theta^{2},
$$

onde $\theta=5040 / T_{\text {eff }}$. Estimarei a gravidade superficial usando o método espectroscópico (que será explanado na seção 2.11) e validarei o resultado usando a gravidade trigonométrica.

\subsection{Equilíbrio Termodinâmico local (LTE)}

Para quantificar o ganho ou perda de um campo de radiação é necessário conhecer a sua ocupação atômica, os estados moleculares e de ionização. Em LTE, a taxa de população de um nível de excitação ' $i$ ' $\left(n_{i j}\right)$ com número total de átomos $\left(n_{j}\right)$ no estado de ionização ' $j$ ', é dada pela equação de Boltzmann:

$$
\frac{n_{i j}}{n_{j}}=\frac{g_{i}}{U_{j}(T)} 10^{-\theta \chi_{e x c}}
$$

onde $g_{i}$ é o peso estatístico do estado $i, U_{j}(T)$ é a função de partição, $\chi_{\text {exc }}$ é a energia de excitação do nível inferior e $\theta=5040 / T$. A equação de ionização de Saha é dada por:

$$
\frac{n_{j+1}}{n_{j}} P_{e}=\frac{\left(2 \pi m_{e}\right)^{3 / 2}(k T)^{5 / 2}}{h^{3}} \frac{2 U_{j+1}(T)}{U_{j}(T)} \exp \left(-\frac{I_{j, j+1}}{k T}\right),
$$

onde $n_{j+1} / n_{j}$ é a razão de estados de ionização, $P_{e}$ é a pressão eletrônica, $h$ é a constante de Planck, $m_{e}$ é a massa do elétron e $I_{j, j+1}$ é o potencial de ionização. Em LTE todos os níveis de população atômico, iônico e molecular são determinados pela estatística de Saha-Boltzmann, que é definida pela temperatura local. Também, assume-se a igualdade da função fonte com a função de Planck $\left(S_{\nu}=B_{\nu}\right)$. 


\subsection{Modelos de Atmosfera}

Os modelos de atmosfera desempenham um papel essencial na determinação dos parâmetros atmosféricos e das abundâncias químicas estelares. São usados para modelar as linhas presentes na fotosfera estelar, seja empregando a técnica de larguras equivalentes ou de síntese espectral (ver apêndice C).

Um modelo de atmosfera é um modelo físico das camadas mais externas de uma estrela que descreve como variam os parâmetros termodinâmicos em relação à profundidade óptica. Modelar atmosferas estelares é bastante complexo devido a que é preciso considerar o equilíbrio termodinâmico local, equilíbrio hidrostático, simetria esférica e aproximação plano-paralela, além das opacidades necessárias. É importante notar que nos modelos de atmosfera são negligenciados os campos magnéticos, manchas, proeminências e granulações.

Os modelos de fotosfera mais usados e que adotarei nesta dissertação são os modelos de Castelli e Kurucz (2004) e de Gustafsson et al. (2008), conhecidos também como modelos de Kurucz e Marcs, respectivamente.

Para a estrela HIP 100963 determinei suas abundâncias usando ambos modelos e não encontrei diferenças significativas. A diferença media de abundancias entre ambos modelos (Modelo de Kurucz - Modelo de Marcs) é de apenas $0.003(\sigma=0.002)$ dex; como mostrado na Figura 2.1.

\subsection{Formação das linhas de absorção}

É sabido que o fluxo na superfície da estrela $\left(\tau_{\nu=0}\right)$ é dado por Gray, 2005):

$$
F_{\nu}\left(\tau_{\nu}=0\right)=2 \pi \int_{0}^{\infty} S_{\nu}\left(t_{\nu}\right) E_{2}\left(t_{\nu}\right) d t_{\nu}
$$

onde $E_{2}\left(t_{\nu}\right)$ é uma integral exponencia! ${ }^{1}$. Assumindo LTE nas camadas da atmosfera, a função fonte é substituída pela emissão de corpo negro $\left(S_{\nu}\left(t_{\nu}\right)=B_{\nu}(T)\right)$, portanto a equação 2.13 é dada por:

$$
F_{\lambda}\left(\tau_{\nu}=0\right)=2 \pi \int_{0}^{\infty} B_{\nu}(T) E_{2}\left(\tau_{\nu}\right) d \tau_{\nu}
$$

\footnotetext{
${ }^{1}$ A integral exponencial é definida em Gray (2005) como: $E_{n}(x) \equiv \int_{1}^{\infty} \exp (-x \omega) / \omega^{n} d \omega$
} 


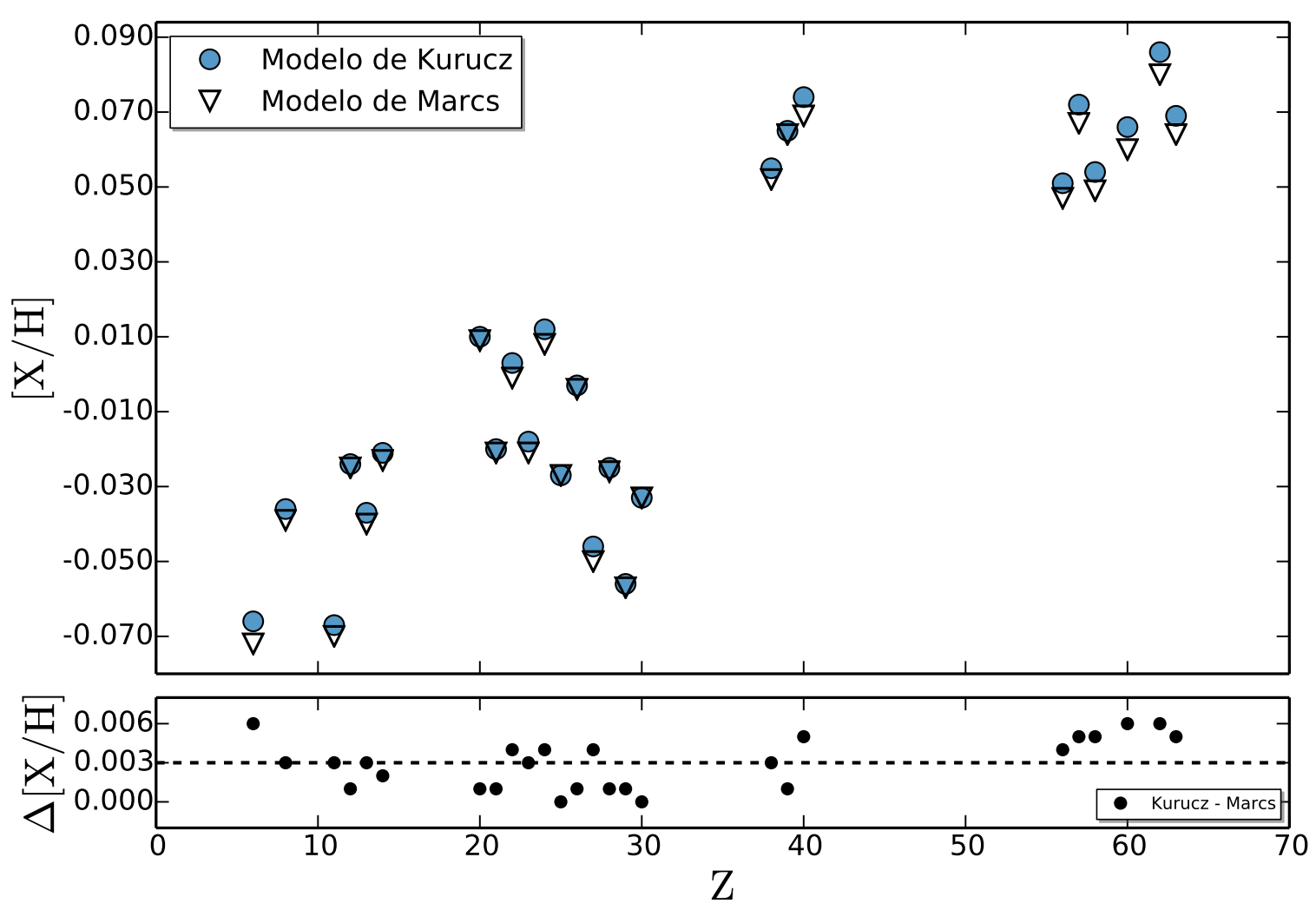

Figura 2.1: Abundâncias diferenciais da gêmea solar HIP 100963 estimadas usando os modelos de atmosfera de Castelli e Kurucz (2004) e de Gustafsson et al. (2008), em função do número atômico (Z).

A equação 2.14 também pode ser escrita como:

$$
F_{\lambda}\left(\tau_{\lambda}=0\right)=2 \pi \int_{0}^{\infty} B_{\lambda}(T) E_{2}\left(\tau_{\lambda}\right)\left(\kappa_{\text {lin }, \lambda}+\kappa_{\text {cont }, \lambda}\right)\left(\frac{\tau_{0}}{\kappa_{\text {cont }, 0}}\right) \frac{d \log \tau_{0}}{\log e},
$$

onde $\kappa_{l i n, \lambda}$ e $\kappa_{c o n t, \lambda}$ são os coeficientes de absorção da linha e do contínuo, $\tau_{0}$ é definida como uma profundidade óptica de referência (geralmente $5000 \AA$ ). Para calcular $\tau_{\lambda}$ usa-se a seguinte equação:

$$
\tau_{\lambda}\left(\tau_{0}\right)=\int_{-\infty}^{\log \tau_{0}}\left(\frac{\kappa_{\text {lin }, \lambda}+\kappa_{\text {cont }, \lambda}}{\kappa_{\text {cont }, 0}}\right) t_{0} \frac{\log t_{0}}{\log e},
$$

sendo $t_{0}$ uma variável auxiliar que descreve a profundidade óptica. O coeficiente de absorção da linha $\left(\kappa_{l i n, \lambda}\right)$ pode ser obtido para uma linha atômica por (Barbuy, 1982 ; Meléndez, 2001):

$$
\kappa_{l i n, \lambda}=\frac{\pi e^{2}}{m_{e} c^{2}} \lambda^{2} g f \alpha P \frac{H(u, a)}{\Delta \lambda_{D} \sqrt{\pi}}(1-\exp (-h c / \lambda k T)),
$$

onde $e$ é a carga do elétron, $m_{e}$ é a massa do elétron, $\lambda$ é o comprimento de onda central da linha, $g$ é o peso estatístico do nível inferior de transição, $f$ é a força de oscilador, $\alpha$ é a abundância do elemento, $P$ é a população do estado inferior dividido pelo peso estatístico, $H(u, a)$ é a função de Hjertings, $\Delta \lambda_{D}$ é o alargamento doppler e $h$ é a constante de Planck. 


\subsection{Abundâncias químicas}

As abundâncias químicas são definidas como:

$$
A_{\mathrm{X}}=\log \left(\frac{n_{\mathrm{X}}}{n_{H}}\right)+12
$$

onde $n_{\mathrm{X}}$ expressa a densidade numérica (número de átomos por unidade de volume) do elemento $\mathrm{X}$ e $n_{H}$ o número de átomos de hidrogênio por unidade de volume. A razão de abundâncias do elemento X em relação ao Sol é dada por:

$$
\begin{aligned}
{[\mathrm{X} / \mathrm{H}] } & \equiv A_{\mathrm{X}, \star}-A_{\mathrm{X}, \odot} \\
& \equiv \log \left(\frac{n_{\mathrm{X}}}{n_{H}}\right)_{\star}-\log \left(\frac{n_{\mathrm{X}}}{n_{H}}\right)_{\odot},
\end{aligned}
$$

sendo ‘ $\star$ ' e ‘ $\odot$ ’ símbolos que representam a estrela em estudo e o Sol, respectivamente. Em astronomia, costuma-se escrever as abundâncias dos elementos em relação à abundância de ferro $[\mathrm{X} / \mathrm{Fe}]$. A partir da equação 2.19 obtém-se:

$$
\begin{aligned}
{[\mathrm{X} / \mathrm{Fe}] } & \equiv \log \left(\frac{n_{\mathrm{X}}}{n_{F e}}\right)_{\star}-\log \left(\frac{n_{\mathrm{X}}}{n_{F e}}\right)_{\odot} \\
& \equiv \log \left(\frac{n_{\mathrm{X}} / n_{H}}{n_{F e} / n_{H}}\right)_{\star}-\log \left(\frac{n_{\mathrm{X}} / n_{H}}{n_{F e} / n_{H}}\right)_{\odot} \\
& \equiv\left[\log \left(\frac{n_{\mathrm{X}}}{n_{H}}\right)_{\star}-\log \left(\frac{n_{\mathrm{X}}}{n_{H}}\right)_{\odot}\right]-\left[\log \left(\frac{n_{F e}}{n_{H}}\right)_{\star}-\log \left(\frac{n_{F e}}{n_{H}}\right)_{\odot}\right] \\
& \equiv[\mathrm{X} / \mathrm{H}]-[\mathrm{Fe} / \mathrm{H}] .
\end{aligned}
$$

A abundância de um elemento X $\left(A_{\mathrm{X}}\right)$ é calculada efetuando a média das abundâncias determinadas a partir de várias linhas do mesmo elemento presentes no espectro estelar, enquanto as abundâncias solares $\left(A_{\odot}\right)$ podem ser estimadas através do espectro solar. Nesta dissertação adotarei as abundâncias solares de Asplund et al. (2009) (ver Tabela A.1 e Figura 1.12).

\subsection{Larguras Equivalentes (EWs)}

A composição química estelar é determinada de duas formas: usando o método de larguras equivalentes ou empregando o método de síntese espectral (ver subseção 2.15). Por ora, descreverei o método de larguras equivalentes, que consiste em medir as larguras equivalentes dos elementos químicos para depois compará-las com curvas de crescimento. 


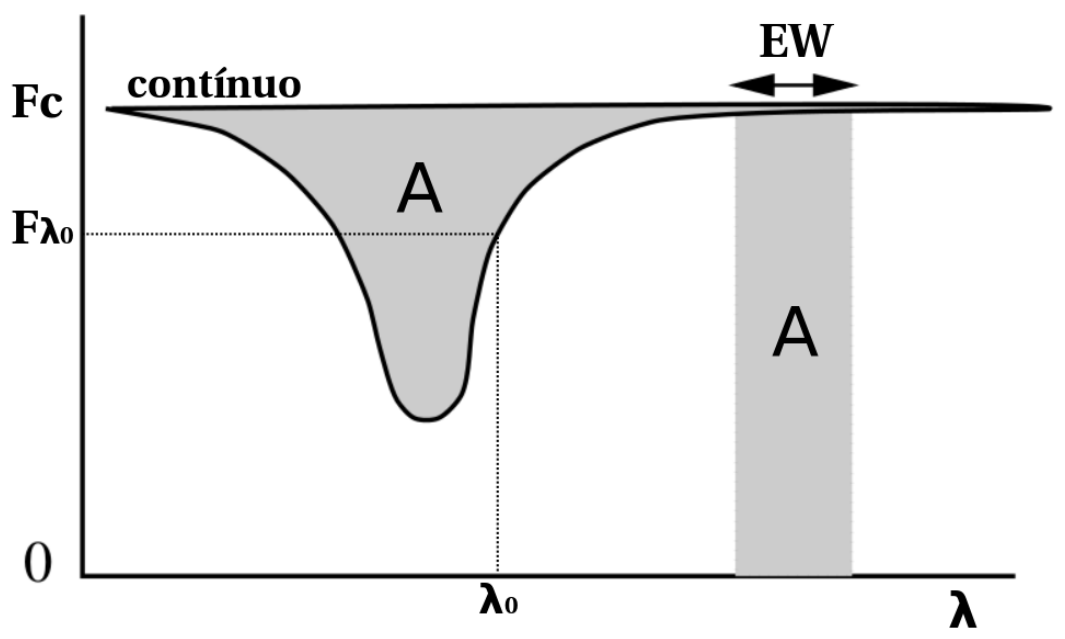

Figura 2.2: Esquema ilustrativo da definição de largura equivalente. Imagem tirada e modificada de Rutten (2003).

A largura equivalente $(E W)$ de uma linha espectral é dada pela seguinte equação:

$$
E W=\int_{0}^{\infty}\left(1-\frac{F_{\lambda}}{F_{c}}\right) d \lambda
$$

onde $F_{c}$ e $F_{\lambda}$ são, respectivamente, o fluxo no contínuo e na linha. A interpretação de largura equivalente é que o perfil de linha é substituído por um retângulo de 'largura equivalente' que tem a mesma quantidade de energia quanto o perfil de linha (ver Figura 2.2 .

Como a maioria das linhas usadas nesta dissertação é fraca, pode-se usar a seguinte relação para a largura equivalente reduzida $(E W / \lambda)$ (Gray, 2005):

$$
\log (E W / \lambda)=B+A_{\mathrm{X}}+\log (g f)+\log \lambda-\theta \chi_{\text {exc }}-\log \kappa_{\text {cont }, \lambda},
$$

onde $g f$ é o produto do peso estatístico $(g)$ pela força de oscilador $(f), \lambda$ é o comprimento de onda e $B$ é uma constante para uma determinada estrela e um determinado íon, e $\theta=5040 / T$. É importante notar que Meléndez (2014) define $B=\log C-12$ e $A_{\mathrm{X}}=\left(n_{\mathrm{X}} / n_{H}\right)+12$. O importante da relação 2.22 é que uma variação em $A_{\mathrm{X}}$ pode ser equivalente a variações em $g f, \lambda, \chi_{\text {exc }}$ e $\kappa_{\text {cont }, \lambda}$. Consequentemente pode-se gerar uma curva de crescimento apenas mudando a abundância $A_{\mathrm{X}}$. Na Figura 2.3 é mostrada a evolução da largura equivalente reduzida em relação à abundância na curva de crescimento. 


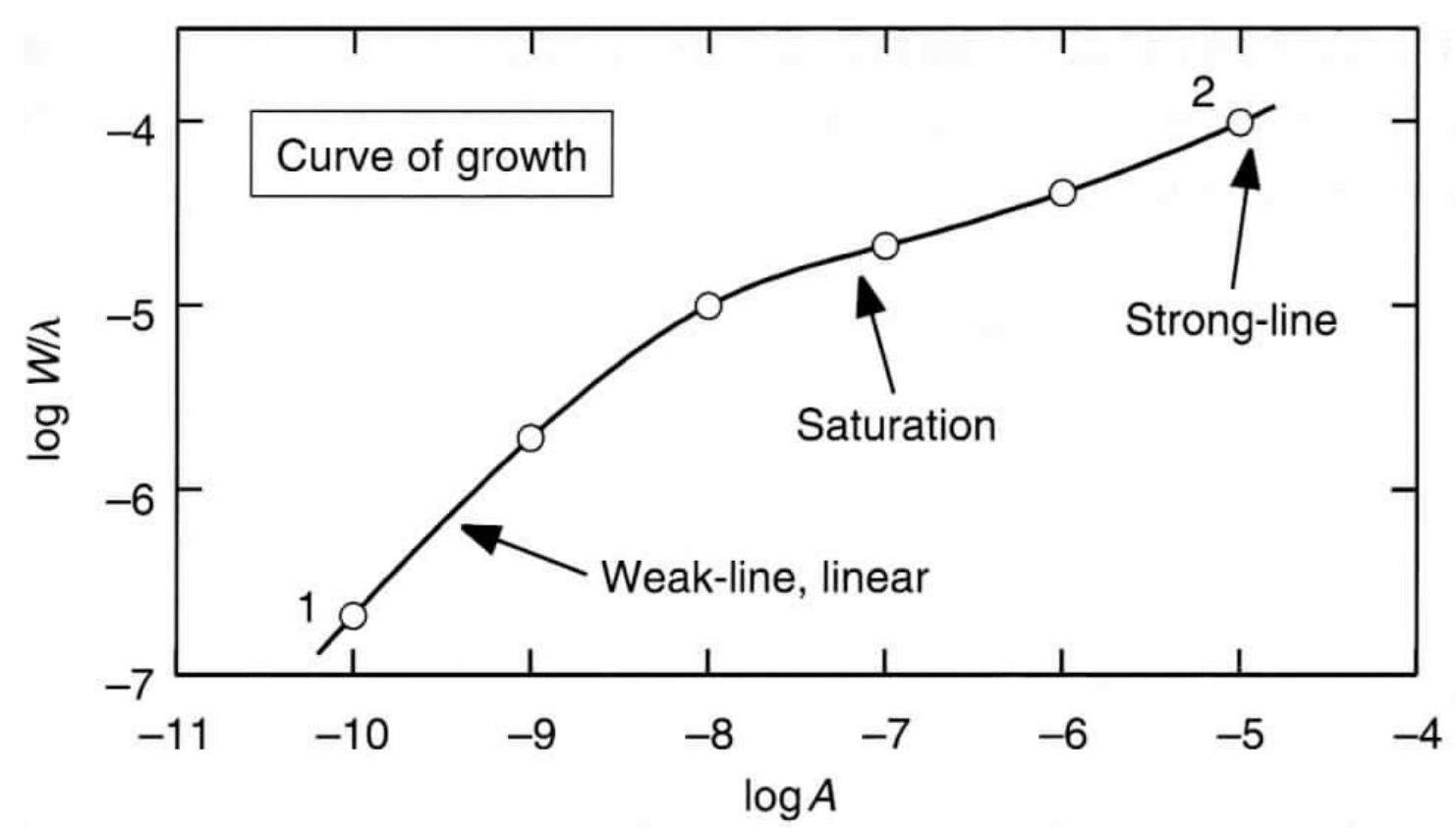

Figura 2.3: Ilustração gráfica de uma curva de crescimento mostrando seus três regimes (linha fraca, saturada e forte). Imagem tirada de Gray (2005).

\subsection{Alargamento de linhas}

Para usar as EWs como indicadores de composição química considera-se os mecanismos de alargamento de linhas, que podem ser causados por vários processos físicos. Os principais mecanismos são: alargamento natural, doppler térmico e colisional. Considerase de importância o alargamento colisional devido a colisões com o hidrogênio, pois esse elemento é o mais abundante.

A constante de alargamento colisional (Gray, 2005) é:

$$
\gamma_{6} \approx 17 v^{3 / 5} C_{6}^{2 / 5} N
$$

onde $C_{6}$ é a constante de interação, $N$ é o número de perturbadores por unidade de volume e $v$ é a velocidade. Geralmente, para estimar o valor de $C_{6}$ usa-se a forma mais simples que é dada por Unsold (1955):

$$
C_{6}=0.3 \times 10^{-30}\left[\frac{1}{\left(I-\chi-\chi_{\lambda}\right)^{2}}-\frac{1}{(I-\chi)^{2}}\right],
$$

sendo $I$ o potencial de ionização, $\chi$ o potencial de excitação do nível inferior da transição e $\chi_{\lambda}=1.2398 \times 10^{-4} \lambda^{-1}$ é a energia do fóton da linha. Valores mais acurados de $C_{6}$ foram estimados por Barklem et al. (2000) a partir de cálculos detalhados. Estes valores estão contidos na pasta de dados de MOOG. Usando a equação 2.24 estimei os valores de $C_{6}$ de 


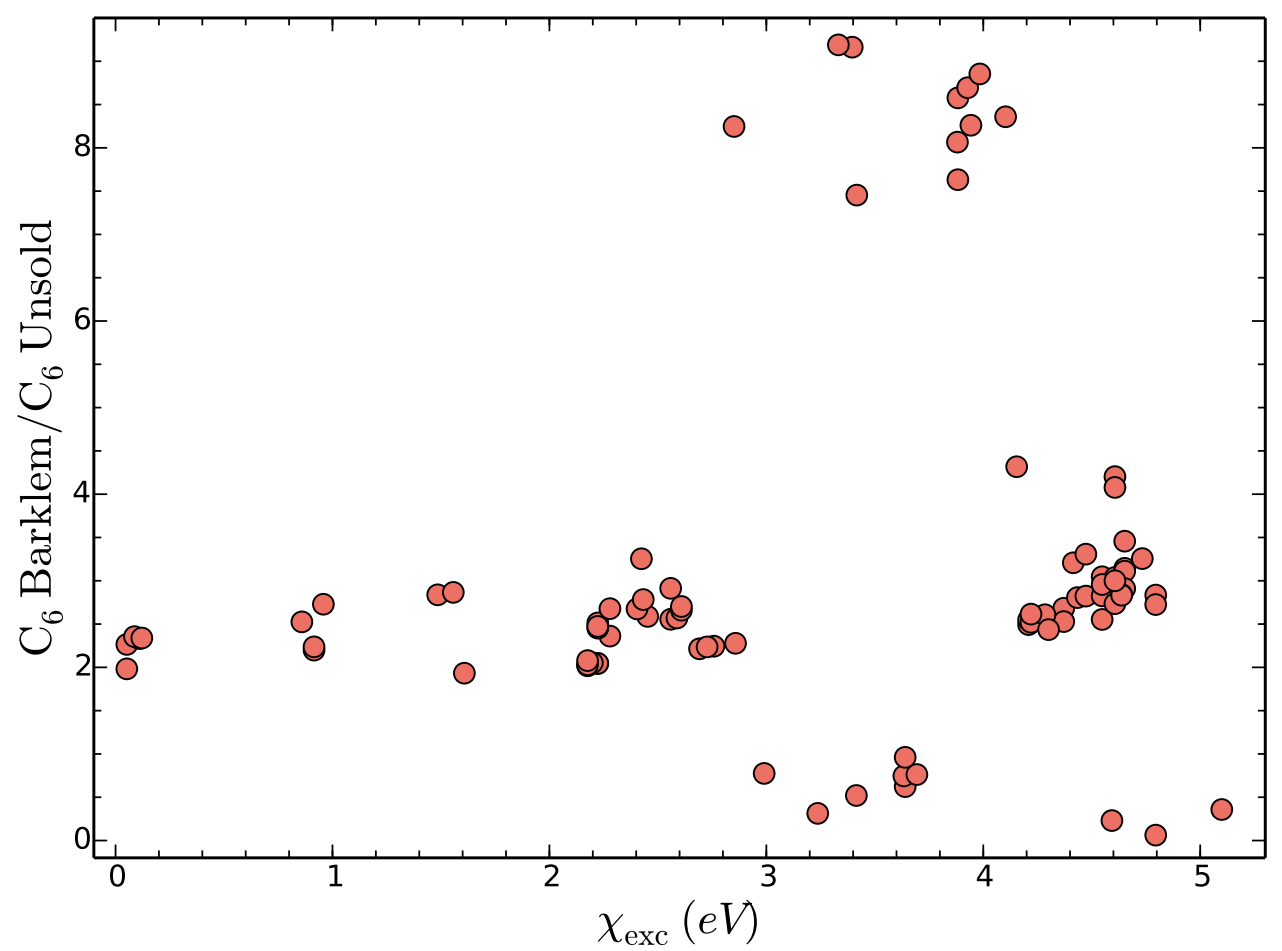

Figura 2.4: A razão da constante $C_{6}$ de Barklem et al. (2000) e Unsold (1955) em função do potencial de excitação.

Unsold (1955) e estes foram comparados com os resultados de Barklem et al. (2000), e que são mostrados na Figura 2.4. É importante notar que o valor de Unsold (1955) é apenas um limite inferior. Tipicamente esse valor é multiplicado por um fator de 2. Existem várias opções para a constante de interação no MOOG, é possível obter os valores de $C_{6}$ a partir da fórmula de Unsold (1955) usando o parâmetro damping $=0$, enquanto para damping $=1$ o MOOG adota os valores de $C_{6}$ estimados por Barklem et al. (2000).

\subsection{Lista de linhas}

A lista de linhas atômicas é formada de 99 linhas de Fe I, 18 de Fe II e 253 linhas de outras especies, tais como: C, O, Na, Mg, Al, Si, S, K, Ca, Sc, Ti, V, Cr, Mn, Co, Ni, Cu, Zn, Rb, Sr, Y, Zr, Mo, Ru, Rh, Pd, Ag, Ba, La, Ce, Pr, Nd, Sm, Eu, Gd, Dy, Yb, C2, $\mathrm{CH}, \mathrm{NH}$ e $\mathrm{OH}$. Esta lista é constantemente atualizada. A última versão foi publicada em Meléndez et al. (2014). As linhas escolhidas foram de preferencia linhas não saturadas e com mínima contaminação (blending). Os valores de $\log g f$ foram tomados de valores de laboratório quando estes estavam disponíveis, e complementados com valores teóricos ou valores solares. O $C_{6}$ é baseado nos cálculos de Barklem et al. (2000) ou o valor de Unsold 


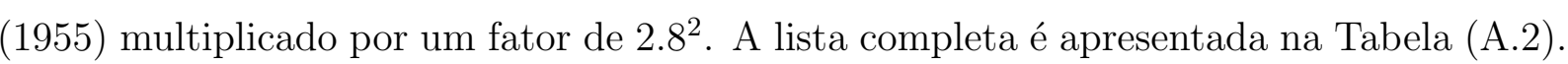

\subsection{Correção hiperfina}

Quando as linhas do espectro de átomos com número atômico ímpar são observadas com altíssima resolução no laboratório, pode-se ver que estão compostas por várias linhas cujas separações são menores a $0.01 \mathrm{~nm}$. Isso indica que as componentes dos níveis de energia dos átomos são divididas em muitas outras, as quais são causadas pela interação entre o momento angular do núcleo $(\vec{I})$ e dos elétrons $(\vec{J})$, gerando assim o momento angular total $\vec{F}(=\vec{J}+\vec{I})$.

Estimar abundâncias químicas sem levar em conta a estrutura hiperfina pode causar erros grandes, devido a que superestimaríamos o valor da abundância do elemento que está envolvido na transição. Por exemplo, desprezando a estrutura hiperfina para o Mn I, Booth et al. (1984) encontraram variações de até 0.64 dex. Meléndez (2001) realizou o ajuste para o perfil de Mn I em $12976 \AA$ A levando em conta a estrutura hiperfina cujo resultado é mostrado na Figura 2.5. No painel à esquerda desta figura o espectro sintético (linha contínua) de Mn I não ajusta o perfil observado (círculos) porque não são consideradas as componentes hiperfinas. Já no painel direito o perfil é satisfatoriamente ajustado levando em conta as 15 componentes hiperfinas do Mn I (barras) dessa transição.

Os elementos que apresentam estrutura hiperfina são: $\mathrm{Ba}{ }^{3}, \mathrm{Co}, \mathrm{Cu}, \mathrm{Eu}, \mathrm{La}, \mathrm{Mn}, \mathrm{V}$ e Y. A lista de linhas destes elementos são as usadas por Meléndez et al. (2014) e mostradas na Tabela A.3.

\subsection{Abundâncias diferenciais}

A análise espectroscópica diferencial consiste em determinar os parâmetros atmosféricos e as abundâncias em relação a um objeto padrão com parâmetros atmosféricos bem conhecidos; de preferência o objeto de interesse e o padrão devem ter parâmetros similares.

O propósito da técnica diferencial é diminuir os problemas que existem nas incertezas

\footnotetext{
${ }^{2}$ Valor aproximado de correção estimado pelo professor Jorge Meléndez usando linhas de diferentes elementos químicos.

${ }^{3}$ É importante notar que para Ba não é levada em conta a estrutura hiperfina mas sim as diferentes componentes isotópicas.
} 

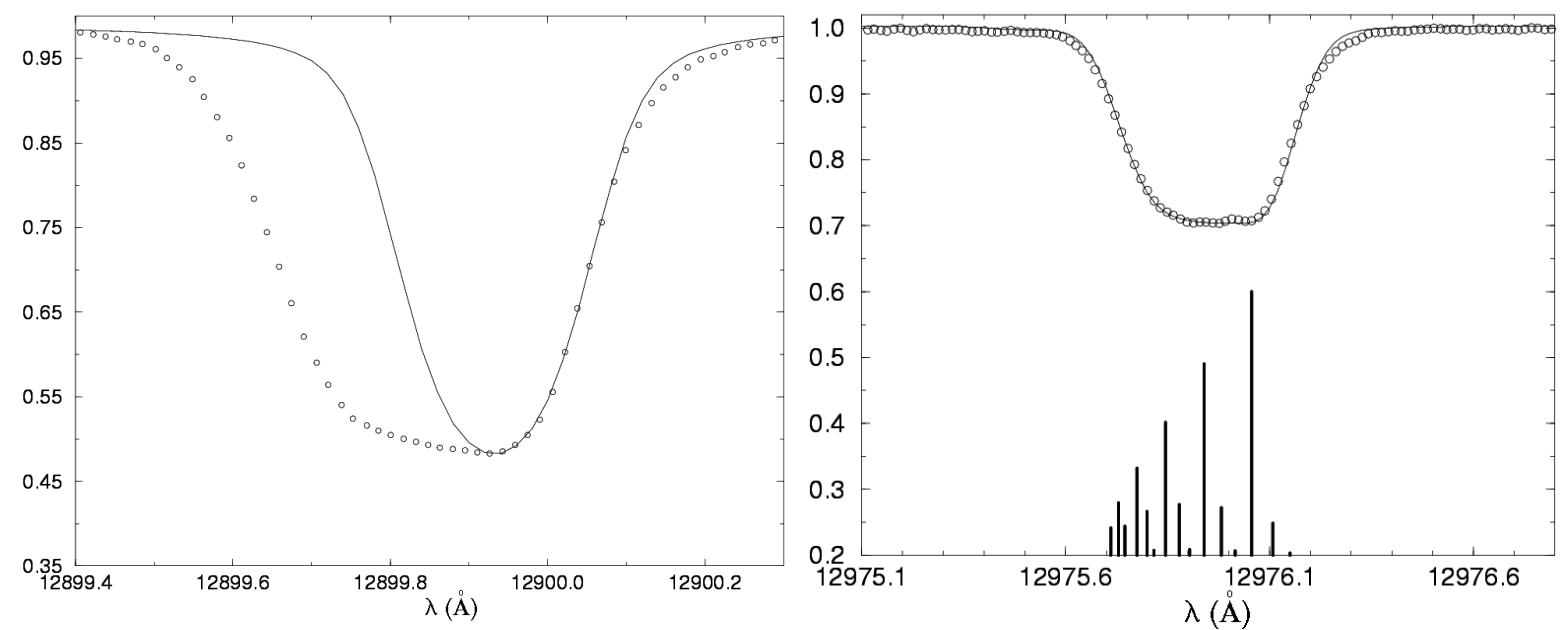

Figura 2.5: Ajuste do perfil da linha Mn I em $12976 \AA$ A, sem levar em conta a estrutura hiperfina (painel esquerdo) e considerando a estrutura hiperfina (painel direito). O eixo vertical em ambos painéis indica o fluxo. Imagens tiradas de Meléndez (2001).

associadas à determinação de abundâncias químicas, tais como os problemas nos modelos de atmosfera e especificamente nas incertezas dos valores $g f$. Para gêmeas solares que têm como estrela de referência o Sol, estas incertezas são canceladas atingindo erros da ordem de 0.01 dex (p. ex. Meléndez et al., 2009; Ramírez et al., 2009, 2011; Meléndez et al., 2012; Monroe et al., 2013; Tucci Maia et al., 2014; Ramírez et al., 2014; Bedell et al., 2014; Meléndez et al., 2014; Ramírez et al., 2014; Nissen, 2015; Spina et al., 2016; Ramírez et al., 2015; Yana Galarza et al., 2016, e outros). Porém, para abundâncias absolutas o erro é pelo menos 0.05 dex (Asplund et al., 2009). Para uma análise diferencial as principais fontes de erro a considerar são os erros devido às incertezas das medidas de EWs e erros sistemáticos devido às incertezas dos parâmetros atmosféricos (seção 2.12).

É possível estudar a abundância diferencial para uma linha fraca em duas estrelas; a partir da equação 2.22 obtém-se usando como padrão o Sol:

$$
\log \left(E W_{\mathrm{X}, \mathrm{i}}^{\star} / E W_{\mathrm{X}, \mathrm{i}}^{\odot}\right)=A_{\mathrm{X}, \mathrm{i}}^{\star}-A_{\mathrm{X}, \mathrm{i}}^{\odot}-\left(\theta^{\star}-\theta^{\odot}\right) \chi_{\text {exc }}-\log \left(\kappa_{\text {cont }, i}^{\star} / \kappa_{\text {cont }, i}^{\odot}\right) .
$$

No caso em que o alvo é uma gêmea solar, o último termo da equação 2.25 é pequeno pois os coeficientes de absorção para a estrela e para o Sol são similares. Por conseguinte, a abundância diferencial para a linha $i$ do elemento $\mathrm{X}\left(\delta A_{\mathrm{X}, \mathrm{i}}=A_{\mathrm{X}, \mathrm{i}}-A_{\mathrm{X}, \mathrm{i}}^{\odot}\right)$ é dada por:

$$
\delta A_{\mathrm{X}, \mathrm{i}} \sim \log \left(\frac{E W_{\mathrm{X}, \mathrm{i}}^{\star}}{E W_{\mathrm{X}, \mathrm{i}}^{\odot}}\right)+\left(\theta^{\star}-\theta^{\odot}\right) \chi_{e x c} .
$$




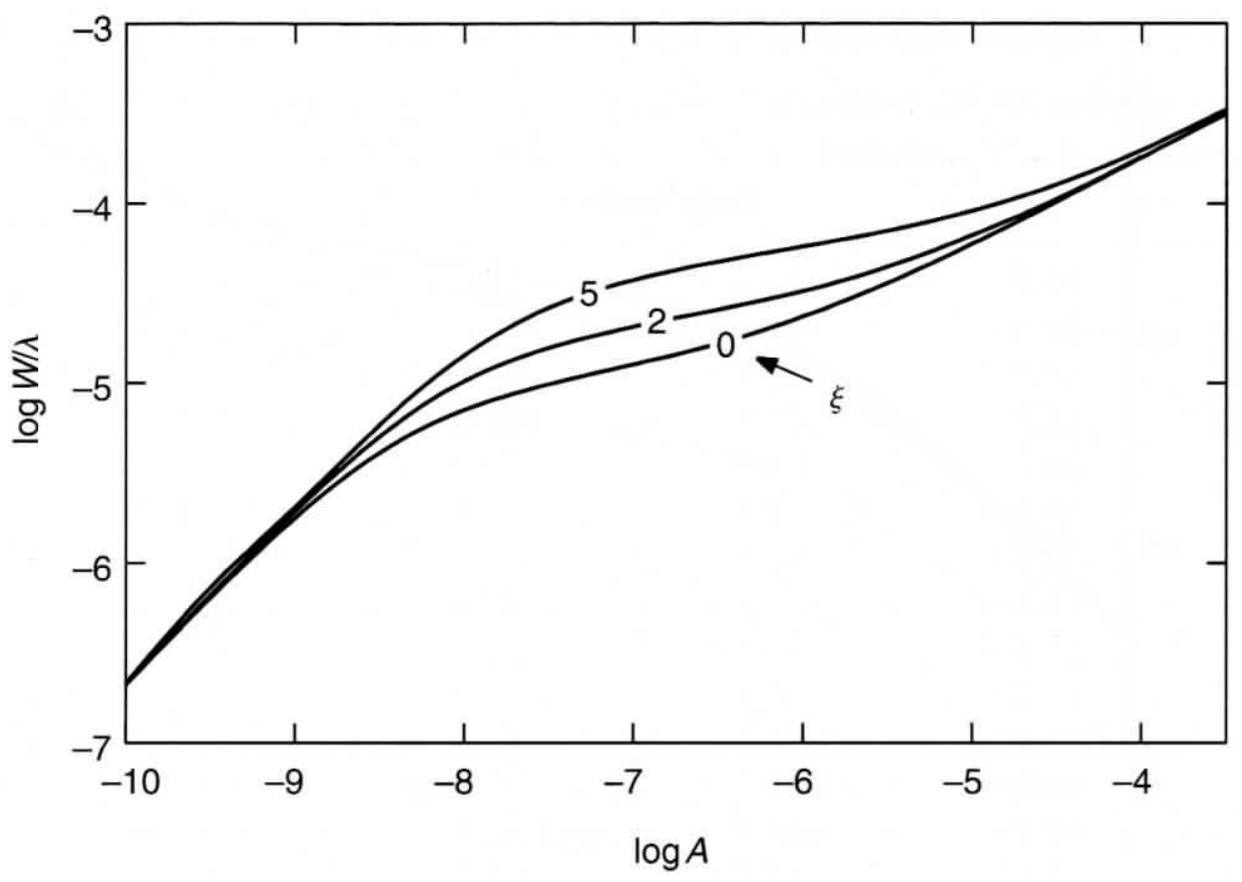

Figura 2.6: Curva de crescimento mostrando o efeito de microturbulência $\left(0,2\right.$ e $\left.5 \mathrm{kms}^{-1}\right)$ para linhas espectrais saturadas. Fonte: Gray (2005).

Portanto, é possível determinar abundâncias diferenciais linha a linha com altíssima precisão apenas com boas medidas de larguras equivalentes e conhecendo a temperatura de ambas estrelas, como também o potencial de excitação da linha em questão.

\subsection{Estimativa dos parâmetros atmosféricos}

Com a finalidade de determinar os parâmetros atmosféricos $\left(T_{e f f}, \log g, v_{t} e[\mathrm{Fe} / \mathrm{H}]\right)$, usa-se as $E W s$ das linhas do Fe I e do Fe II, e um modelo de atmosfera (ver seção 2.3).

Para determinar a temperatura efetiva $\left(T_{e f f}\right)$, o equilíbrio de excitação diferencial deve ser satisfeito através da equação 2.26, usando linhas de Fe I (ver painéis superiores da Figura 2.8), isto é:

$$
\frac{d\left(\delta A_{F e, i}\right)}{d \chi_{e x c}}=0 .
$$

A velocidade de microturbulência $\left(v_{t}\right)$ é evocada para explicar o alargamento das linhas espectrais saturadas (ver Figura 2.6), adicional ao alargamento Doppler térmico. O valor de $v_{t}$ é obtido impondo a não dependência com o logaritmo da largura equivalente reduzida $(\mathrm{EW} / \lambda)$ (ver painéis do meio da Figura 2.8), ou seja:

$$
\frac{d \delta A_{F e I, i}}{d \log (E W / \lambda)}=0
$$




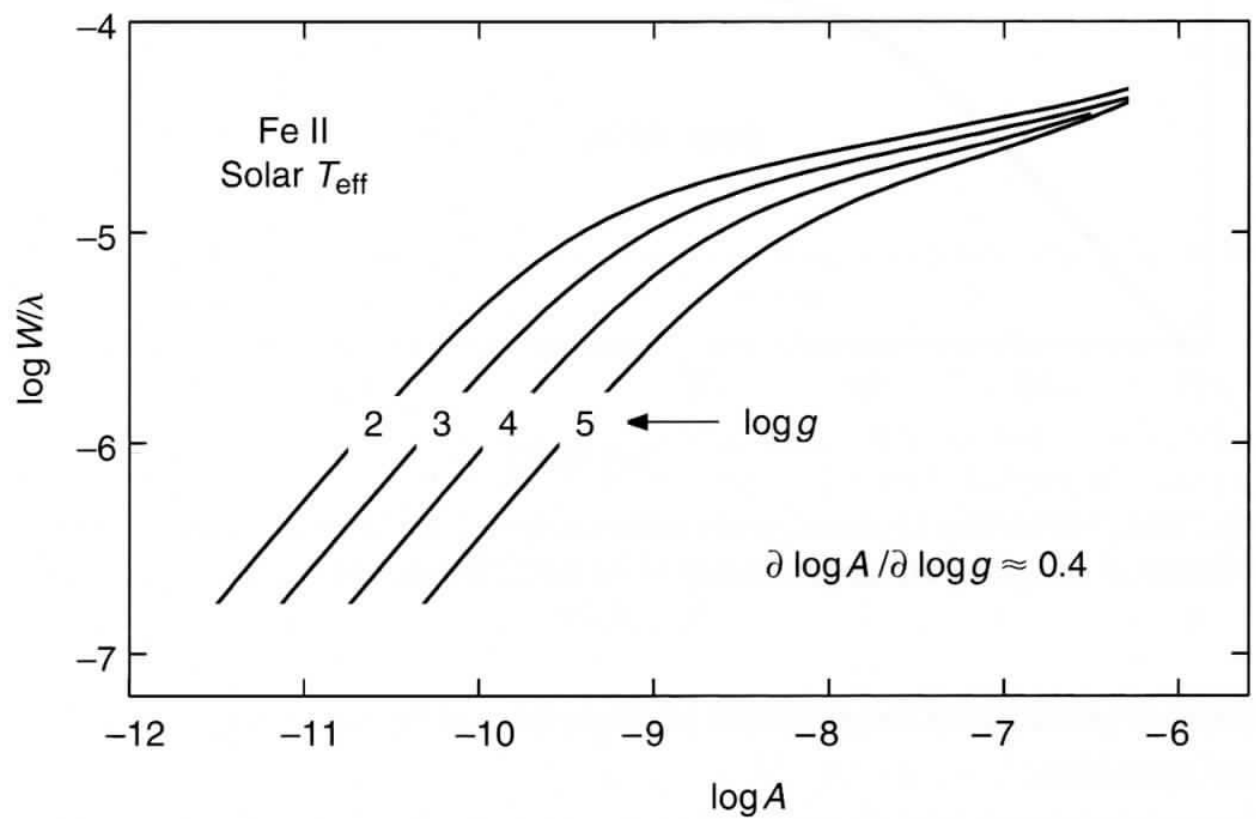

Figura 2.7: Dependência com a gravidade superficial para a curva de crescimento de linhas de Fe II. Imagem tirada de Gray (2005).

A Figura 2.7 mostra os efeitos do $\log g$ sobre as linhas fracas. O equilíbrio de ionização diferencial é atingido quando as abundâncias obtidas a partir de Fe II e Fe I coincidem (ver painéis inferiores da Figura 2.8):

$$
<\delta A_{F e I I, i}>-<\delta A_{F e I, i}>=0
$$

\subsection{Estimativa dos erros}

Nesta seção explicarei a técnica para o cálculo do erro das abundâncias químicas.

\subsubsection{Erros nos parâmetros atmosféricos}

O erro da temperatura efetiva está relacionado com o erro na inclinação da reta no diagrama de abundâncias de Fe I vs. o potencial de excitação $\left(\chi_{e x c}\right)$. Este erro é obtido variando-se a temperatura efetiva (mantendo fixos os demais parâmetros) até que o módulo da inclinação tenha um valor igual ao erro da inclinação.

Para determinar o erro da metalicidade, considerou-se o erro obtido na determinação de $[\mathrm{Fe} / \mathrm{H}]$ através das larguras equivalentes. O erro da gravidade superficial é obtido mudando o valor de $\log g$ até que a diferença entre as médias das abundâncias de Fe I e Fe II seja igual à soma quadrática do erro padrão de ambas abundâncias de ferro. 
$\mathrm{XO}-2 \mathrm{~N}: 5307,4.3,0.409,0.93$ [iris]
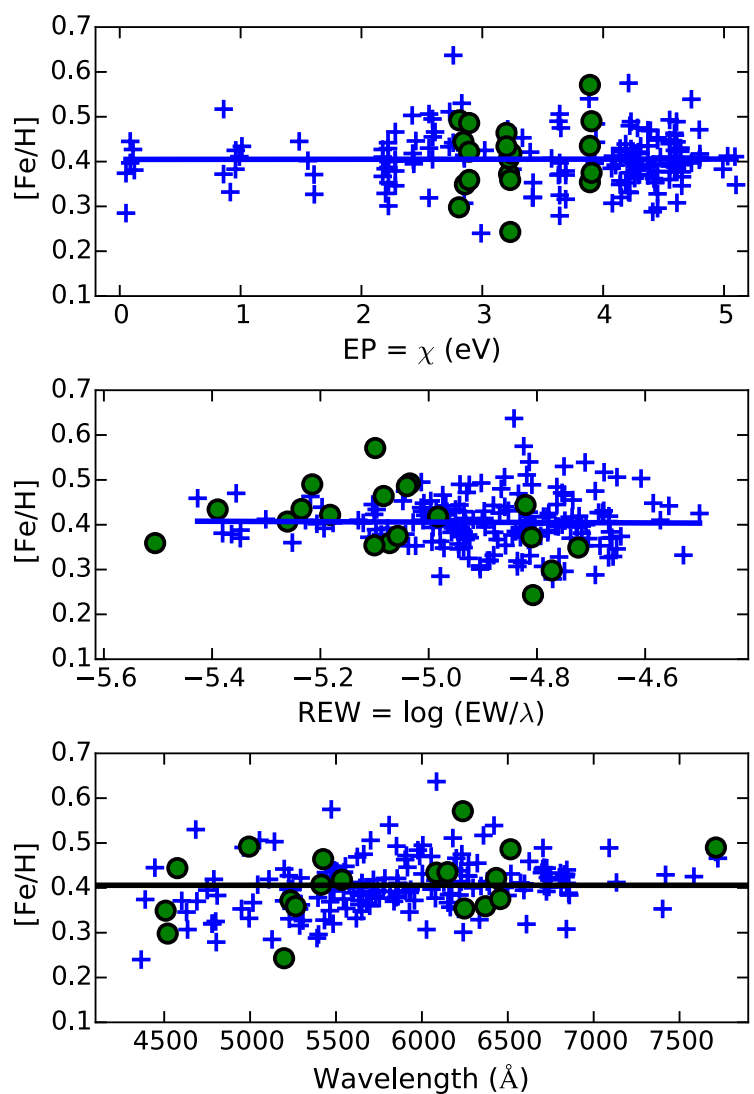

XO-2S : 5374, 4.33, 0.351, 0.94 [iris]
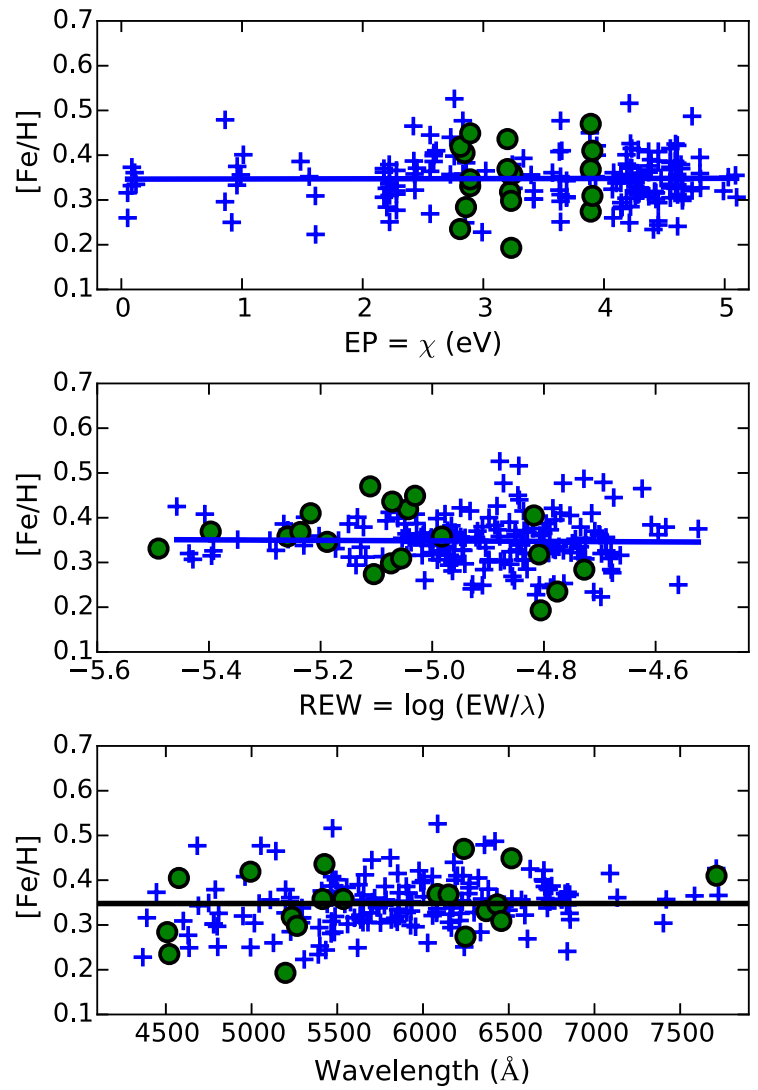

Figura 2.8: Abundância diferencial do ferro em função do potencial de excitação (painéis superiores), largura equivalente reduzida (painéis do meio) e comprimento de onda (painéis inferiores). As cruzes azuis representam o Fe I e os círculos verdes o Fe II. As linhas sólidas azuis dos painéis superiores e do meio correspondem aos ajustes de Fe I, enquanto as linhas sólidas pretas nos painéis inferiores representam o valor médio de abundância de ferro $[\mathrm{Fe} / \mathrm{H}]$. As imagens correspondem às abundâncias do ferro obtidas dos espectros de XO-2N e XO-2S (Ramírez et al. 2015).

O erro da velocidade de microturbulência é obtido de forma similar ao erro da temperatura efetiva, ou seja, variando-se os valores de microturbulência até que o módulo da inclinação coincida com o erro da inclinação do ajuste linear do diagrama $[\mathrm{Fe} / \mathrm{H}]$ vs. $\log (E W / \lambda)$.

Para fins práticos, considera-se que o equilíbrio de excitação, ionização e a não dependência com o $\log (\mathrm{EW} / \lambda)$ são satisfeitas quando:

- A inclinação no diagrama $[\mathrm{Fe} / \mathrm{H}]$ vs. $\chi$ é zero dentro de $1 / 3$ do erro do coeficiente angular devido à dispersão nas abundâncias.

- A diferença de $\Delta \mathrm{FeI}-\Delta \mathrm{FeII}$ é zero dentro de $1 / 3 \sqrt{(\sigma / \sqrt{n})_{\mathrm{FeI}}^{2}+(\sigma / \sqrt{n})_{\mathrm{FeII}}^{2}}$, onde $(\sigma / \sqrt{n})$ é o erro padrão e $n$ o número de linhas. 
- A inclinação no diagrama $[\mathrm{Fe} / \mathrm{H}]$ vs. $\log (E W / \lambda)$ é zero dentro de $1 / 3$ do erro do coeficiente angular.

Os erros atingidos nos parâmetros atmosféricos de gêmeas solares são da ordem de 5-10 K em $T_{\text {eff }}$ e 0.01-0.02 em $\log g$ e $v_{t}$ (p. ex. Bedell et al., 2014; Ramírez et al., 2014; Meléndez et al., 2012).

\subsubsection{Estimativa dos erros nas abundâncias}

Para estimar o erro das abundâncias químicas considera-se dois tipos de contribuições: o erro observado $\left(\sigma_{o b s}=\sigma / \sqrt{n}\right)$ e o erro devido às incertezas dos parâmetros atmosféricos. A primeira é estimada calculando o desvio padrão da abundância média de um conjunto de linhas do mesmo elemento. A segunda é determinada avaliando o erro nas abundâncias diferenciais que é introduzido por cada parâmetro.

Portanto, o erro final das abundâncias químicas $\left(\sigma_{\text {abun }}\right)$ é dado por:

$$
\sigma_{\text {abun }}=\sqrt{\sigma_{\text {obs }}^{2}+\sigma_{T_{e f f}}^{2}+\sigma_{\log g}^{2}+\sigma_{v_{t}}^{2}}
$$

sendo $\sigma_{o b s}$ o erro devido aos erros das medidas de largura equivalente, e $\sigma_{T e f f}, \sigma_{\log g}, \sigma_{v_{t}}$ são os erros devido às incertezas na temperatura efetiva, gravidade superficial e velocidade de microturbulência, respectivamente.

\subsection{Verificação dos erros usando asteroides}

Como mencionado anteriormente é possível atingir um erro em temperatura de $\sim 10$ K e 0.01 dex em composição química. Com o fim de verificar esses erros podemos usar espectros do Sol (Iris e Vesta) que foram obtidos empregando o espectrógrafo 'MIKE' $(\mathrm{R}=65000)$ do telescópio Magellan de $6.5 \mathrm{~m}$.

Para estimar os parâmetros atmosféricos, usei o asteróide Vesta (Sol) como referência cujos parâmetros atmosféricos padrões adotados são: $T_{\text {eff }}=5777 \mathrm{~K}, \log g=4.44$ dex, $v_{t}=$ $1.00 \mathrm{kms}^{-1}$ e $[\mathrm{Fe} / \mathrm{H}]=0.00$ dex. Seguindo a metodologia explicada neste capítulo, estimei os parâmetros atmosféricos do asteróide Iris em: $T_{\text {eff }}=5776 \pm 4 \mathrm{~K}, \log g=4.43 \pm 0.01$ $\operatorname{dex}, v_{t}=1.03 \pm 0.01 \mathrm{kms}^{-1}, \mathrm{e}[\mathrm{Fe} / \mathrm{H}]=-0.004 \pm 0.004$ dex, que estão em excelente acordo dentro dos erros com os parâmetros adotados para o Solt

\footnotetext{
${ }^{4} \mathrm{Um}$ acordo similar foi obtido pelo estudo de Bedell et al. (2014) $\left(T_{\text {eff }}=5769 \pm 5 \mathrm{~K}, \log g=4.42 \pm 0.01\right.$ $\operatorname{dex}, v_{t}=1.01 \pm 0.01 \mathrm{kms}^{-1}$, e $\left.[\mathrm{Fe} / \mathrm{H}]=-0.01 \pm 0.01 \mathrm{dex}\right)$.
} 
A média das abundâncias químicas para Iris é -0.003 $(\sigma=0.008)$ dex, que sugere que é possível atingir uma precisão de $\sim 0.01$ dex. Na Figura 2.9 é mostrado a comparação de abundâncias estimadas neste trabalho e as determinadas por Bedell et al. (2014) (ela encontrou uma média de -0.006 ( $\sigma=0.008$ dex $)$ usando o mesmo par de asteroides. Conclui-se, então, que a técnica diferencial permite atingir uma precisão de $\sim 0.01$ dex. Os parâmetros atmosféricos e as abundâncias químicas do asteróide Iris foram estimadas usando o código $q^{2}$, que será explanado em detalhe na seguinte seção.

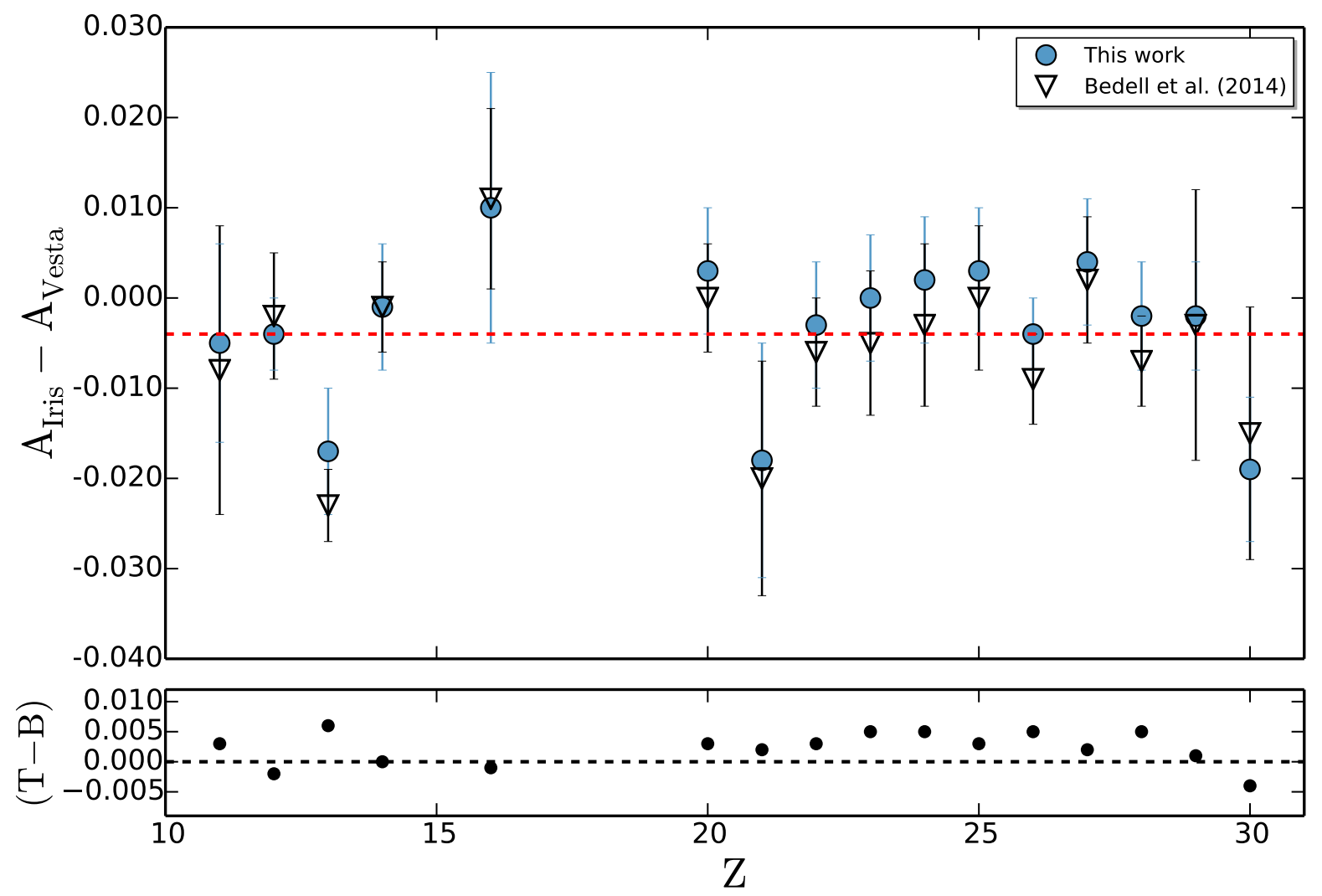

Figura 2.9: O painel superior mostra as abundâncias diferenciais do asteróide Iris e Vesta. A linha pontilhada vermelha representa o valor da abundância de $[\mathrm{Fe} / \mathrm{H}]$. O painel inferior mostra a diferença entre as abundâncias estimadas nesta dissertação e as de Bedell et al. (2014) (T-B). Esta diferença é de apenas $0.002(\sigma=0.003)$ dex.

\subsection{O código qoyllur-quipu $\left(\mathrm{q}^{2}\right)$}

Na Figura 2.10 é mostrado o processo de determinação dos parâmetros atmosféricos. O método consiste em atingir as condições explicadas nas seções 2.11 e 2.12. Nos painéis superiores pode-se ver que um aumento na temperatura do modelo gera uma inclinação negativa no plano $[\mathrm{Fe} / \mathrm{H}]$ vs. $\chi_{\text {exc }}$ e uma inclinação positiva no plano $[\mathrm{Fe} / \mathrm{H}]$ vs. $\log (E W / \lambda)$, 
já com o decréscimo da temperatura ocorre o contrário. Nos painéis do meio são mostrados os efeitos das variações da gravidade superficial no ajuste dos planos $[\mathrm{Fe} / \mathrm{H}]$ vs. $\chi_{\text {exc }} \mathrm{e}$ $[\mathrm{Fe} / \mathrm{H}]$ vs. $\log (E W / \lambda)$. Estas variações vão depender do equilíbrio de ionização (equação 2.29. Nos painéis inferiores são mostrados que um aumento na velocidade de microturbulência gera uma inclinação positiva no plano $[\mathrm{Fe} / \mathrm{H}]$ vs. $\chi_{e x c}$ e uma inclinação negativa no plano $[\mathrm{Fe} / \mathrm{H}]$ vs. $\log (E W / \lambda)$; com a diminuição da velocidade de microturbulência ocorre o contrário.

Como visto acima, encontrar os parâmetros atmosféricos torna-se um procedimento muito laborioso. Pela experiência obtida no cálculo de parâmetros atmosféricos, primeiro determina-se a temperatura efetiva, logo a gravidade superficial e por último a velocidade de microturbulência, sempre mantendo a condição do equilíbrio de ionização do Fe (equação 2.29). Todo este processo requer muitas iterações para determinar os parâmetros atmosféricos e seus erros de apenas uma estrela.

Levando em conta o explicado acima, o Dr. Ivan Ramírez desenvolveu o código nomeado qoyllur-quipu $\left(\mathrm{q}^{2}\right)^{5}$ e que está baseado na linguagem Python. Este código determina os parâmetros atmosféricos de forma iterativa seguindo a metodologia explicada nas seções 2.11 e 2.12. Para tal fim, $\mathrm{q}^{2}$ usa dois arquivos em formato csv como parâmetros de entrada, um deles contendo dados das estrelas $\left(T_{e f f}, v_{t}\right.$, etc) e o outro com dados das linhas espectrais $\left(\mathrm{EW}, \chi_{e x c}, C_{6}\right.$, etc). O código $\mathrm{q}^{2}$ oferece a possibilidade de escolher como modelo de atmosfera os modelos de Kurucz (Castelli e Kurucz, 2004) ou Marcs (Gustafsson et al., 2008).

Para determinar os parâmetros atmosféricos, primeiro $q^{2}$ adota para a estrela em análise os mesmos parâmetros atmosféricos do Sol, logo cada um destes valores vai mudando com passos sucessivamente menores como o fim de se aproximar ao equilíbrio espectroscópico. Depois de que os parâmetros convergem para um determinado passo, uma nova iteração começa, isto é realizado repetidamente até que os passos sejam de $1 \mathrm{~K}$ em temperatura e 0.01 dex para o resto. A solução final é atingida quando o equilíbrio espectroscópico é satisfeito. O tempo para determinar os parâmetros atmosféricos depende do número de passos e o número máximo de iterações estabelecidos antes de rodar o código.

O q $\mathrm{q}^{2}$ estima as abundâncias químicas através do código MOOG (Sneden, 1973) usando curvas de crescimento (seção 2.10). O código determina a idade e massa usando as isócronas

\footnotetext{
${ }^{5}$ Qoyllur-quipu pode ser traduzido como 'contador de estrelas' na língua quéchua.
} 

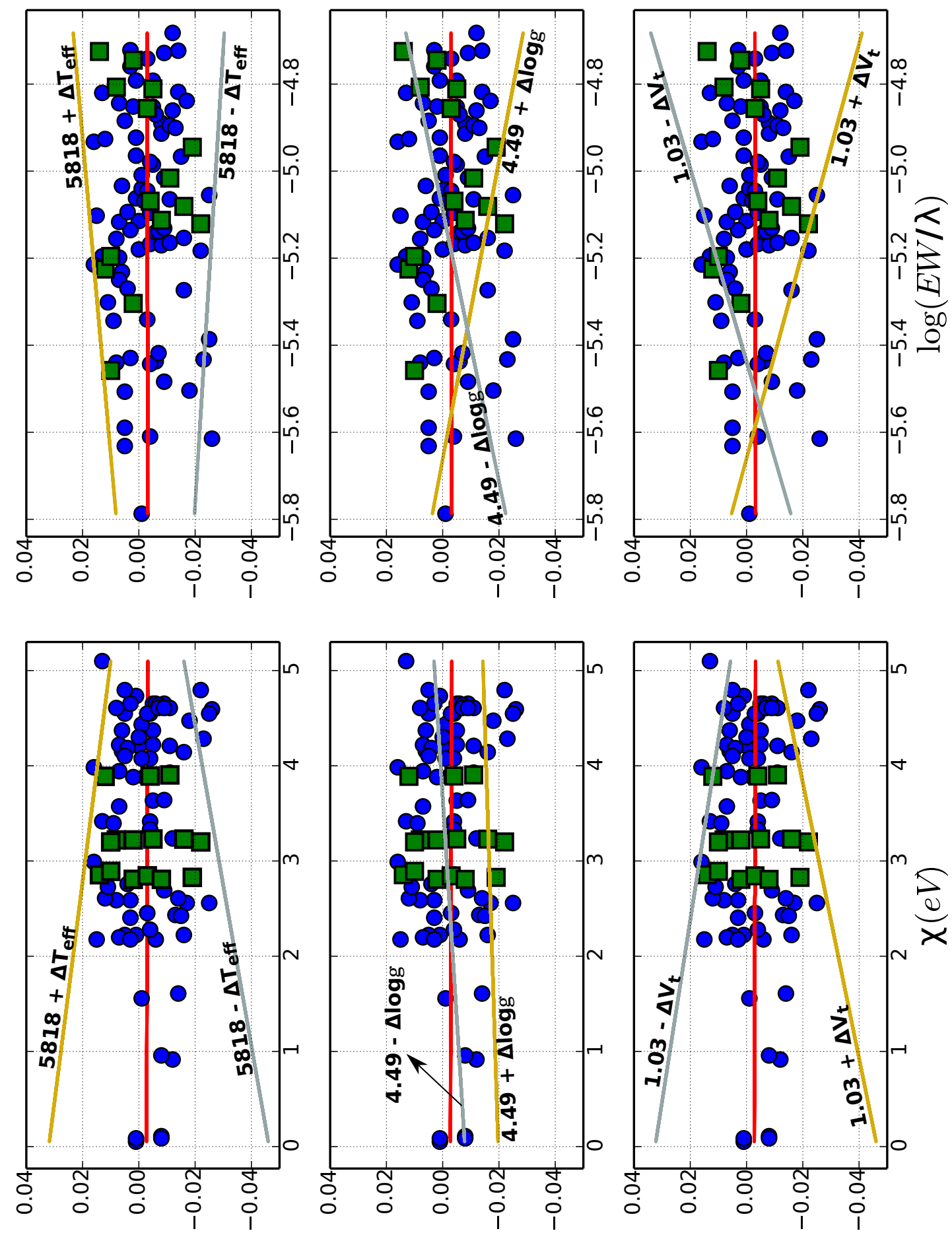

(хәр) $\left[\mathrm{H} / \partial_{\mathrm{H}}\right]$

Figura 2.10: Ilustração da estimativa dos parâmetros atmosféricos da gêmea solar HIP 100963. O equilíbrio espectroscópico é atingido quando a $T_{e f f}=5818 \mathrm{~K}, \log g=4.49 \mathrm{dex},[\mathrm{Fe} / \mathrm{H}]=-0.003$ dex e $v_{t}=1.03 \mathrm{kms}^{-1}$. A linha vermelha central representa a solução final. Os efeitos de variar $\Delta T_{\text {eff }}= \pm 30 \mathrm{~K}, \Delta \log g= \pm 0.10$ dex e $\Delta v_{t}= \pm 0.1 \mathrm{kms}^{-1}$ são mostrados nos painéis superiores, do meio e inferiores, respectivamente. 
de Yonsei-Yale (Yi et al., 2001), como também a luminosidade, magnitude absoluta e raio da estrela. A metodologia é explanada na secção 3.8 .

Os erros são determinados de acordo ao explicado na seção 2.12 , não obstante $q^{2}$ determina os erros totais realizando uma média dos valores máximos e mínimos dos erros dos parâmetros estelares. Mais detalhes do uso de $\mathrm{q}^{2}$ podem ser encontrados no site do Dr. Ivan Ramírez 6 .

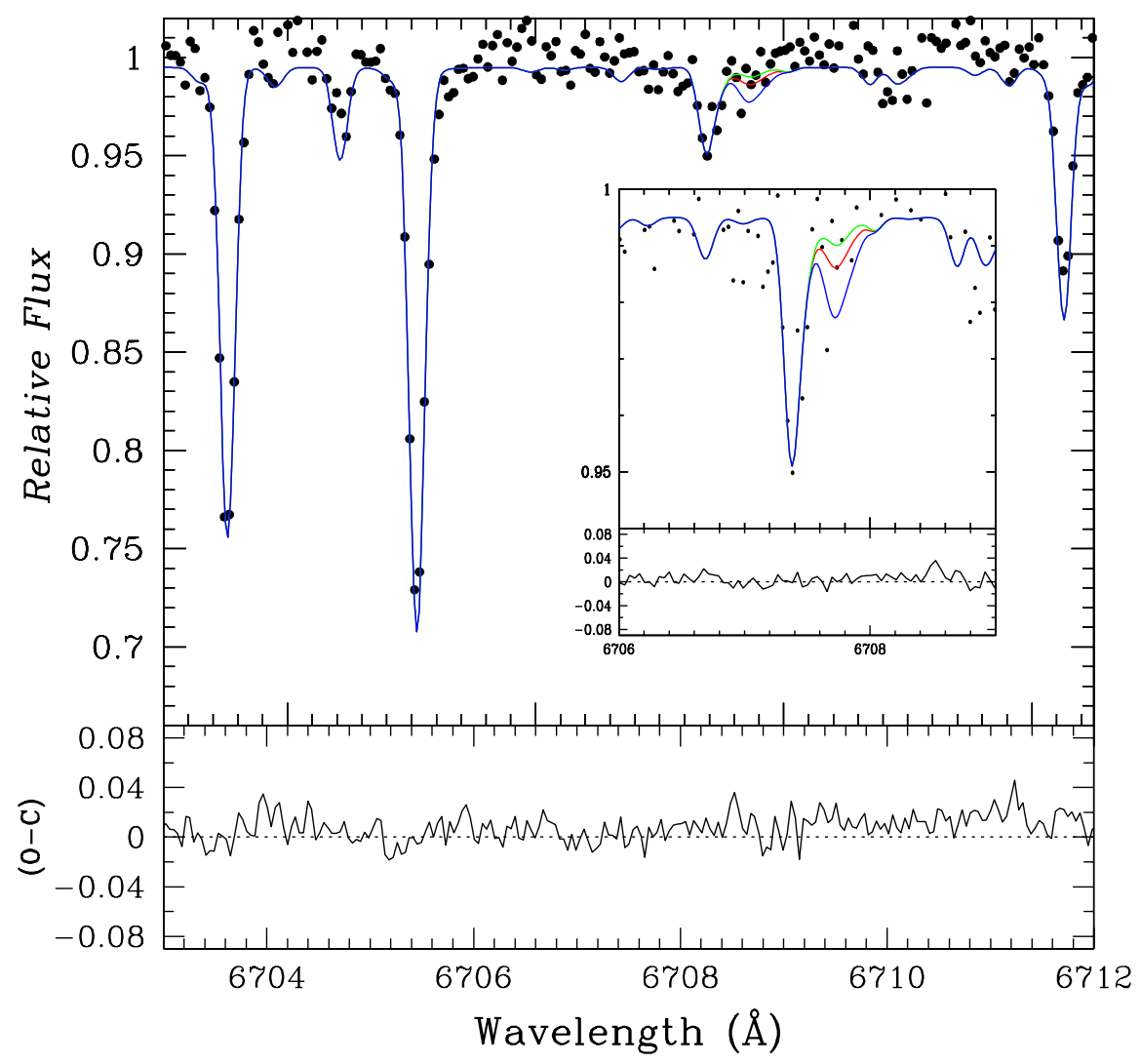

Figura 2.11: Síntese espectral do lítio em torno de 6707.8 Å. O espectro de ID 102684698 é representado pelos círculos pretos cheios, enquanto o melhor ajuste do perfil teórico pela linha sólida azul. Os diferentes valores de lítio (0.50, 0.85 e 1.2) são mostrados com os perfis de linha de cor verde, vermelho e azul, respectivamente. Fonte: do Nascimento et al. (2013).

\subsection{Síntese Espectral de Lítio}

A técnica da síntese espectral consiste em calcular um espectro teórico para reproduzir um espectro observado e assim obter a abundância do elemento estudado (ver Figura 2.11). MOOG é um código usado para a determinação da composição química estelar, assumindo equilíbrio termodinâmico local (LTE) em camadas plano-paralelas, e considera no

\footnotetext{
${ }^{6} \mathrm{O}$ código é de acesso livre no site https://github.com/astroChasqui/q2.
} 
cálculo das linhas fotosféricas os mecanismos de alargamento das linhas por efeito Doppler e amortecimento van der Waals. Adicionalmente tem que ser considerado o alargamento instrumental, rotacional e de macroturbulência.

Para gerar o espectro sintético correspondente a uma determinada composição química, usa-se a ferramenta 'synth' de MOOG com parâmetros de entrada como linhas atômicas e moleculares, e um modelo de atmosfera (com camadas tabeladas de valores de temperatura, densidade eletrônica, pressão do gás) correspondente aos parâmetros estelares. No apêndice C.0.1é descrito com detalhe a forma de estimar a abundância de lítio empregando o código MOOG. 
Capítulo 3

\section{A descoberta fortuita da gêmea solar fraca Inti 1}

As primeiras candidatas a análogas solares fracas foram encontradas por Pasquini et al. (2008) no aglomerado aberto M67. Posteriormente, no mesmo aglomerado, Önehag et al. (2011) descobriram a primeira gêmea solar fraca (M67-1194) que tem magnitude V=14.6. Depois, do Nascimento et al. (2013) foram os primeiros em encontrar a gêmea solar (CoRoT ID 102684698) mais distante $(\approx 830$ pc), que é a segunda gêmea solar fraca (V=14.1). Após estas descobertas, surgiram algumas questões sobre se estes objetos apresentam o mesmo padrão de abundâncias químicas que as gêmeas solares brilhantes. Não obstante, apesar de que Önehag et al. (2011) encontraram que o padrão de abundâncias de M67-1194 é semelhante ao do Sol, atualmente ainda não foram descobertas suficientes gêmeas solares fracas para ter uma conclusão definitiva.

Neste capítulo reportarei a descoberta da gêmea solar 2MASS J23263267-0239363, a qual nomeei de Inti $1^{1}$ por razões práticas. Inti 1 é a terceira gêmea solar fraca $(\mathrm{V}=12.8)$, e está localizada a uma distância de 390 pc. A gêmea solar HD 45184, observada na mesma missão, também foi analisada com o fim de verificar a precisão na determinação dos parâmetros atmosféricos e de abundâncias químicas da Inti 1.

Finalmente na seção 3.9 descrevo o meu código terra, para estimar o material rochoso correspondente ao material refratário que pode estar faltando na zona convectiva de estrelas de tipo solar.

\footnotetext{
${ }^{1}$ Inti é o nome quechua do Sol.
} 


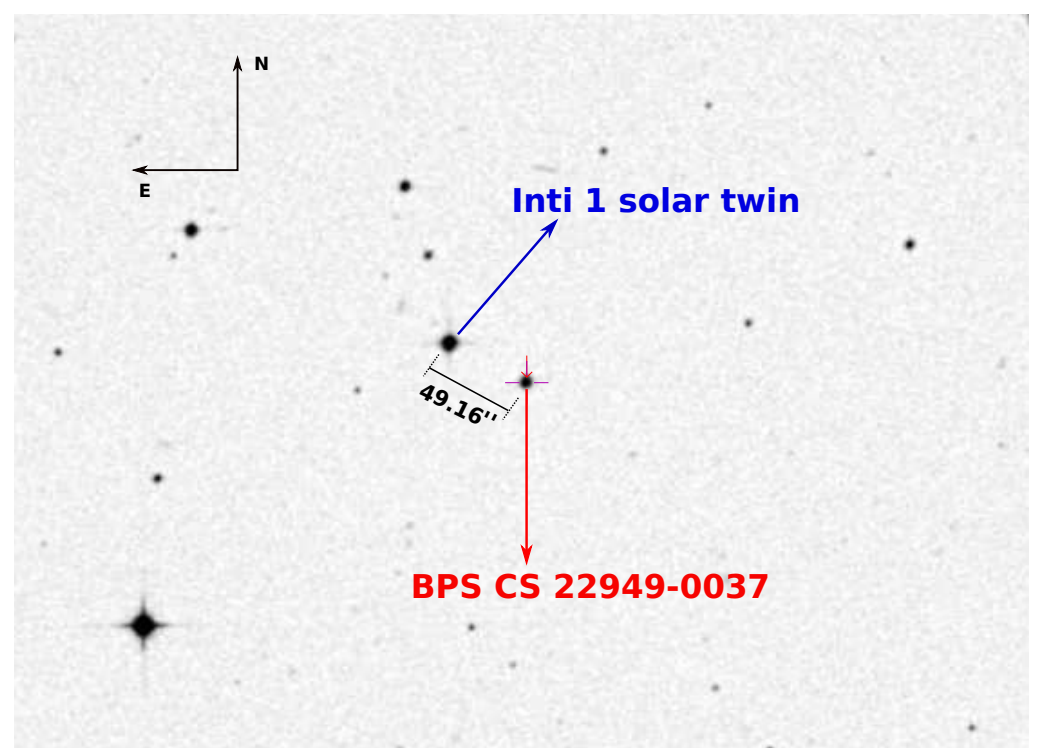

Figura 3.1: A separação entre a Inti 1 e a estrela BPS CS 22949-0037 é de apenas 49.16". A imagem foi tirada do Aladin Sky Atlas (http://aladin.ustrasbg.fr).

\subsection{Dados espectroscópicos}

Os espectros das estrelas HD 45184, Inti 1 e o Sol foram obtidos pelos professores Jorge Meléndez e Judith G. Cohen em Novembro 1-3 de 2004 no Observatório W. M. Keck, no Havaí. O espectro de Inti 1 foi parte do programa de observação 'The first Generation of Stars on the Galaxy', enquanto o Sol (asteroide Vesta) e HD 45184 foram objetos brilhantes do programa de gêmeas solares do professor Jorge Meléndez, para serem observados em condições de tempo ruim.

Para as observações, foi utilizado o espectrógrafo HIRES² (High Resolution Echelle Spectrometer) do telescópio Keck I de 10 metros de diâmetro. A cobertura de comprimento de onda destes espectros é de 3190 a $5980 \AA$ A , com o uso de um mosaico de dois CCDs. Os tempos de exposição para HD 45184, Inti 1 e Vesta foram $2 \times 300$ s, 1200 s e 100 s. A resolução espectral $(R=\lambda / \lambda \Delta)$ é 50000, enquanto a razão sinal-ruído (S/R) estimada para HD 45184, Inti 1 e Vesta é de 160, 110 e 240 por pixel, respectivamente.

A Inti 1 foi observada nas coordenadas $(\alpha=23: 26: 32.61, \delta=-2: 39: 35.3)$ porque ela foi confundida com a estrela pobre em metais e rica em carbono BPS CS 22949-0037, cujas coordenadas verdadeiras são $(\alpha=23: 26: 29.80, \delta=-2: 39: 57.94)$. Na Figura 3.1 é mostrado que a confusão foi devido à proximidade destas estrelas.

\footnotetext{
${ }^{2}$ O HIRES (Vogt et al. 1994 ) pode ser usando na região 3000-10000 Å, e tem um poder resolvente de
} $\mathrm{R} \sim 25000-95000$. 
Os professores Meléndez e Cohen tinham planejado realizar duas exposições de 1200 s cada uma, porém depois de efetuar a primeira exposição, eles perceberam que a estrela observada não foi a BPS CS 22949-0037, por conseguinte a sequência de exposição prevista foi encerrada depois de apenas uma exposição.

Felizmente, na mesma noite, observou-se o Sol empregando a mesma configuração que foi usada para as outras estrelas. Uma recente inspeção do alvo errado revelou uma similaridade com o espectro do Sol (ver Figura 3.2), tornando-o um bom candidato para ser uma gêmea solar. Posteriormente, isso foi confirmado depois de uma análise de alta precisão. Durante a mesma noite de observação, o espectro da gêmea solar brilhante HD 45184 (p. ex., Nissen, 2015) também foi obtido.

O pipeline MAKEE ${ }^{3}$ foi usado para a redução dos espectros; o procedimento padrão consiste em: subtração do bias, correção do flat field, correção da luz difusa, remoção dos raios cósmicos, subtração do céu, extração do espectro e calibração do comprimento de onda. MAKEE também efetua a correção heliocêntrica para o comprimento de onda.

\subsection{As cores de Inti 1}

A poeira interestelar aumenta a magnitude intrínseca $\left(m_{\mathrm{X} 0}\right)$ devido à extinção $\mathrm{A}_{\mathrm{X}}$. Assim, a magnitude aparente $m_{\mathrm{X}}$ pode ser escrita:

$$
m_{\mathrm{X}}=m_{\mathrm{X} 0}+\mathrm{A}_{\mathrm{X}}
$$

onde X representa a banda de um sistema fotométrico (p. ex. UBVRI, JHKL, etc.). A magnitude absoluta $\left(M_{\mathrm{X}}\right)$ de uma estrela é definida como a magnitude que a estrela teria se estivesse localizada a uma distância de 10 pc, isto é:

$$
M_{\mathrm{X}}=m_{\mathrm{X}}-5 \log _{10} d+5,
$$

sendo $d$ a distância à estrela. Não obstante, assumindo que a magnitude $m_{\mathrm{X}}$ está afetada por avermelhamento (equação 3.1), a equação 3.2 pode ser escrita:

$$
m_{\mathrm{X} 0}=M_{\mathrm{X}}+5 \log _{10} d-5-\mathrm{A}_{\mathrm{X}}
$$

\footnotetext{
${ }^{3}$ MAKEE foi desenvolvido por T. Barlow para a redução dos espectros Keck HIRES. O pipeline está disponível em wwww.astro.caltech.edu/ tb/
} 


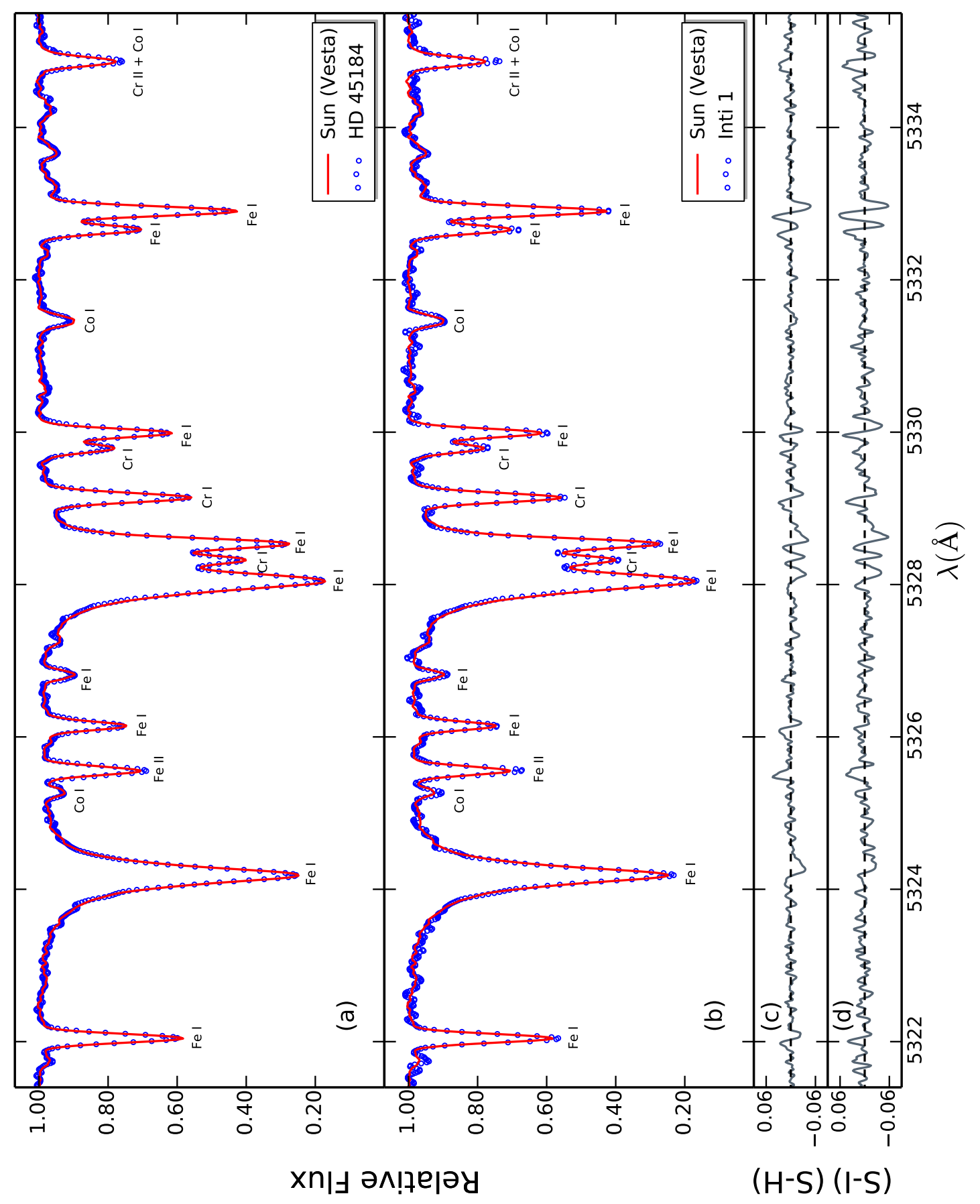

Figura 3.2: Comparação dos espectros de HD 45184, Inti 1 e o Sol na faixa entre 5321 e 5336 Å. O painel (a) ilustra o espectro de HD 45184 (círculos azuis abertos) e o Sol (linha vermelha sólida). O painel (b) mostra o espectro do Sol (linha vermelha sólida) e a candidata a gêmea solar Inti 1 (círculos azuis abertos); ambos têm uma notável semelhança. A diferente composição química é revelada através de medições cuidadosas linha a linha. Os resíduos entre o Sol e HD 45184 (S-H), e o Sol e Inti 1 (S-I) são exibidos nos painéis $(\mathrm{c})$ e $(\mathrm{d})$, respectivamente. 
Similarmente para uma banda $\mathrm{Y}$, a sua magnitude pode ser expressa como: $m_{\mathrm{Y} 0}=$ $M_{\mathrm{Y}}+5 \log _{10} d-5-\mathrm{A}_{\mathrm{Y}}$. Portanto, pode-se escrever:

$$
(X-Y)_{0}=(X-Y)-\left(A_{X}-A_{Y}\right)
$$

onde $(\mathrm{X}-\mathrm{Y})_{0}=\left(m_{\mathrm{X} 0}-m_{\mathrm{Y} 0}\right)$ é o índice de cor intrínseco, $(\mathrm{X}-\mathrm{Y})=\left(M_{\mathrm{X}}-M_{\mathrm{Y}}\right)$ é a cor observada da estrela e $\mathrm{E}(\mathrm{X}-\mathrm{Y})=\mathrm{A}_{\mathrm{X}}-\mathrm{A}_{\mathrm{Y}}$ é o excesso de cor. Por exemplo para o sistema UBV temos o excesso de cor $\mathrm{E}(\mathrm{B}-\mathrm{V})=\mathrm{A}_{\mathrm{B}}-\mathrm{A}_{\mathrm{V}}$. Outra relação importante é a extinção seletiva:

$$
\mathrm{k}_{\mathrm{X}}=\frac{\mathrm{A}_{\mathrm{X}}}{\mathrm{E}(\mathrm{B}-\mathrm{V})}
$$

A partir da equação 3.5 e a definição de excesso de cor, obtém-se:

$$
\mathrm{E}(\mathrm{X}-\mathrm{Y})=\left(\mathrm{k}_{\mathrm{X}}-\mathrm{k}_{\mathrm{Y}}\right) \mathrm{E}(\mathrm{B}-\mathrm{V})
$$

Logo, substituindo a equação 3.6 e 3.5 na equação 3.4 , a cor intrínseca para uma estrela pode ser escrita:

$$
(\mathrm{X}-\mathrm{Y})_{0}=(\mathrm{X}-\mathrm{Y})-\left(\mathrm{k}_{\mathrm{X}}-\mathrm{k}_{\mathrm{Y}}\right) \mathrm{E}(\mathrm{B}-\mathrm{V})
$$

A equação 3.7 é a forma geral de correção por avermelhamento para qualquer cor de um sistema fotométrico. Por outro lado, a extinção também afeta o cálculo de distâncias, portanto a distância é dada a partir da equação 3.3 .

$$
\log _{10} \mathrm{~d}=\frac{\left(\mathrm{m}_{\mathrm{X}}-\mathrm{M}_{\mathrm{X}}-\mathrm{A}_{\mathrm{X}}\right)}{5}+1
$$

Para verificar se Inti 1 é uma gêmea solar, comparou-se suas cores com as cores do Sol. As magnitudes $4^{4}$ de Inti 1 foram obtidas usando a base de dados do VizieR ${ }^{5} \mathrm{~V}=12.857 \pm$ $0.028, \mathrm{~B}=13.516 \pm 0.032, \mathrm{I}=12.045 \pm 0.072, \mathrm{~J}=11.559 \pm 0.023, \mathrm{H}=11.247 \pm 0.023$, $\mathrm{K}=11.168 \pm 0.024, \mathrm{~W} 1=11.125 \pm 0.023$ e W2 $=11.180 \pm 0.022$. A partir dessas magnitudes, as cores de Inti 1 foram determinadas, como mostrado na segunda coluna da Tabela 3.1. Usando os mapas de avermelhamento de Schlegel et al. (1998) e com o auxílio de IRSA 6 , notei que a estrela Inti 1 encontra-se numa região avermelhada (ver Figura 3.3), portanto foi necessária uma correção de avermelhamento. Para tal fim, usouse a equação 3.7 com os coeficientes de extinção fotométrica $(B-V),(V-I),(V-J)$,

\footnotetext{
${ }^{4}$ As magnitudes V,I foram adotadas de APASS (The AAVSO Photometric All-Sky Survey) e as magnitudes J, H, K de Cutri et al. (2003), enquanto as magnitudes W1, W2 de Cutri e et al. (2012).

${ }^{5} \mathrm{http}: / /$ vizier.u-strasbg.fr

${ }^{6}$ http://irsa.ipac.caltech.edu/frontpage
} 
Tabela 3.1 - Comparação das cores de Inti 1 e o Sol.

\begin{tabular}{cccc}
\hline \hline \multirow{2}{*}{ Cor } & \multicolumn{2}{c}{ Inti 1 } & Sol \\
& Observado & Desavermelhado & \\
\hline$(\mathrm{B}-\mathrm{V})^{a}$ & $0.659 \pm 0.042$ & $0.615 \pm 0.042$ & $0.653 \pm 0.005$ \\
$(\mathrm{~V}-\mathrm{I})^{a}$ & $0.812 \pm 0.077$ & $0.755 \pm 0.077$ & $0.702 \pm 0.010$ \\
$(\mathrm{~V}-\mathrm{J})^{b}$ & $1.298 \pm 0.036$ & $1.203 \pm 0.036$ & $1.198 \pm 0.005$ \\
$(\mathrm{~V}-\mathrm{H})^{b}$ & $1.610 \pm 0.036$ & $1.500 \pm 0.036$ & $1.484 \pm 0.009$ \\
$(\mathrm{~V}-\mathrm{K})^{b}$ & $1.689 \pm 0.036$ & $1.570 \pm 0.036$ & $1.560 \pm 0.008$ \\
$(\mathrm{~V}-\mathrm{W} 1)^{b}$ & $1.731 \pm 0.036$ & $1.603 \pm 0.036$ & $1.608 \pm 0.008$ \\
$(\mathrm{~V}-\mathrm{W} 2)^{b}$ & $1.676 \pm 0.035$ & $1.556 \pm 0.035$ & $1.583 \pm 0.008$ \\
\hline \hline
\end{tabular}

Notas.

a : cores solares estimadas por Ramírez et al. (2012)

b : cores solares calculadas por Casagrande et al. (2012)

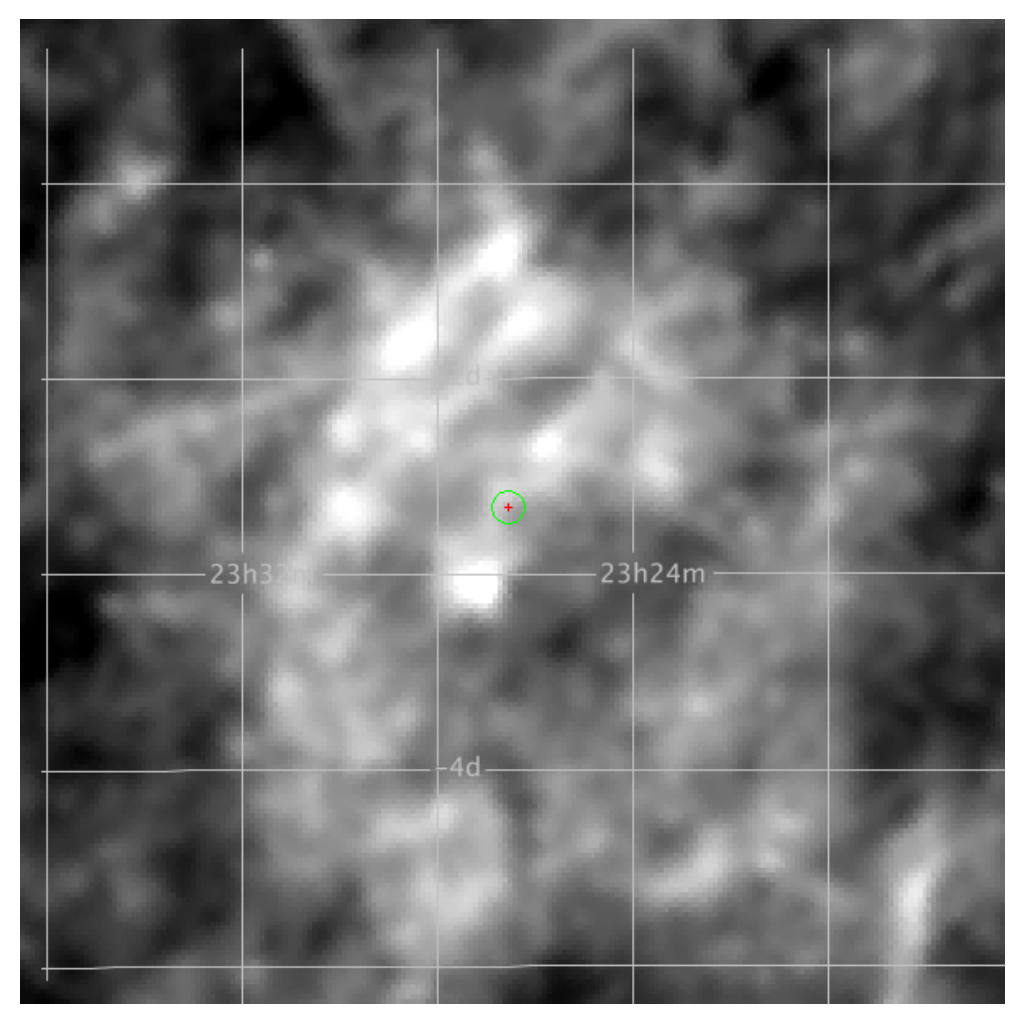

Figura 3.3: Mapa de avermelhamento de Inti 1. Fonte: IRSA. 
$(\mathrm{V}-\mathrm{H})$ e $(\mathrm{V}-\mathrm{K})$ tomados de Ramírez e Meléndez (2005), enquanto para (V - W1) e $(\mathrm{V}-\mathrm{W} 2)$ de Yuan et al. (2013). Para a correção adotou-se $\mathrm{E}(\mathrm{B}-\mathrm{V})=0.044 \pm 0.002$ a partir dos mapas de avermelhamento de Schlegel et al. (1998) e com a correção proposta por Schlafly e Finkbeiner (2011).

Os resultados das magnitudes corrigidas são mostrados na terceira coluna da Tabela 3.1 e comparadas com as do Sol na coluna 4. É importante notar a semelhança de cores entre a Inti 1 e o Sol; estes resultados reforçam a ideia de que a Inti 1 é uma gêmea solar. Empregando a equação 3.8 estimei a distância de Inti 1 em $390 \pm 60$ pc.

\subsection{Normalização do Contínuo}

Os espectros obtidos com o HIRES não são normalizados na redução de dados realizada pelo pipeline MAKEE (p. ex. ver os painéis superiores da Figura 3.4), por conseguinte é necessária a normalização das diferentes ordens dos espectros. Para tal fim, usei a tarefa continuum do pacote IRAF 7 . Nesta tarefa muda-se os valores de vários parâmetros tais como: function, order, low rejection, high rejection, grow, etc., para assim atingir a melhor normalização para os espectros. Antes de realizar este processo é importante definir os seguintes parâmetros 8 .

- O tipo de função que adotei é o spline cúbico (spline3), que fornece um excelente ajuste a um conjunto de pontos que formam uma função. Esta técnica consiste em dividir essa função em vários subintervalos para depois interpolá-los com um polinômio cúbico, de forma que o resultado seja uma função altamente suavizada.

- Os parâmetros de high rejection e low rejection são pontos a ser rejeitados pelo ajuste acima e abaixo do contínuo. De acordo com a experiência de nosso grupo, os melhores valores que adotamos para os parâmetros de high rejection e low rejection são 1 e 3. Estes valores ajudam a obter um menor valor da ordem (order) de ajuste da curva de normalização. Empregando estes valores, as ordens que usei para normalizar os espectros foram de grau inferior a 6 .

\footnotetext{
${ }^{7}$ O IRAF é distribuído pela National Optical Astronomy Observatory, que é dirigida pela Association of the Universities for Research in Astronomy, Inc. (AURA) sob acordo de cooperação pela National Science Foundation.

${ }^{8}$ Mais informações sobre todos os parâmetros da tarefa continuum são encontrados em http://www.stsci.edu/institute/software_hardware/stsdas
} 


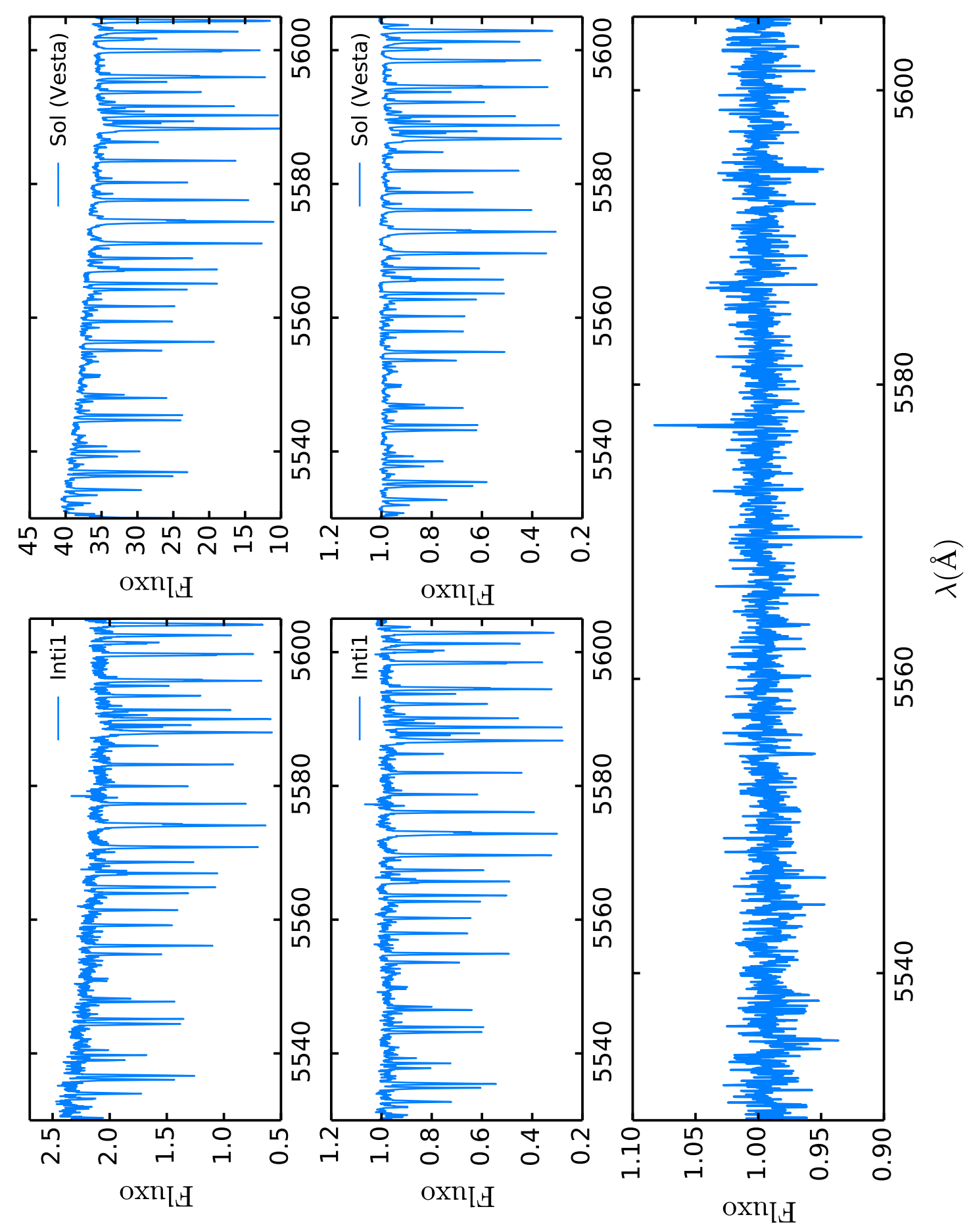

Figura 3.4: Os espectros sem normalizar de Inti 1 e o Sol (painéis superiores), normalizados (painéis do meio) e a razão dos espectros normalizados (painel inferior). 
A normalização consiste em ajustar uma função de forma mais suave possível ao contínuo usando os parâmetros mencionados acima. Para verificar se o ajuste é satisfatório, usei como referência o Atlas Solar de Wallace et al. (2011). Um exemplo de espectro normalizado é mostrado na Figura 3.4, onde nos painéis superiores são mostrados os espectros sem normalizar das estrelas Inti 1 e o Sol, nos painéis do meio os espectros já normalizados e nos painéis inferiores a razão dos espectros normalizados (Inti 1/Vesta). Se a normalização de ambos espectros é satisfatória, a sua razão no contínuo deveria ser 1.0. É importante notar que o trabalho foi realizado no espaço de pixeis, ou seja, usando a opção wavescale $=$ no, que fornece resultados melhores.

\subsection{Correção de velocidade radial}

Após a normalização de todos os espectros é necessário determinar a velocidade radial para corrigir os espectros que foram deslocados por causa do efeito Doppler. Para tal fim, usei a tarefa rvidlines (que faz parte da tarefa noao.rv do IRAF). O método consiste em identificar diversas linhas do espectro em análise; para isso usei o Atlas Solar de Wallace et al. (p. ex. 2011). Essas linhas são usadas para determinar os comprimentos de onda observados $\left(\lambda_{o b}\right)$, enquanto as linhas da lista de Meléndez et al. (2014) (Tabela A.2) são os comprimentos de onda de referência $\left(\lambda_{\text {ref }}\right)$. A tarefa rvidlines computa a velocidade radial da estrela aplicando uma média aritmética simples das velocidades radiais fornecidas por cada uma das linhas adotadas, e que são obtidas a partir da relação:

$$
v_{r a d}=\frac{c\left(\lambda_{o b}-\lambda_{r e f}\right)}{\lambda_{r e f}} .
$$

Para estimar a velocidade radial foi executado o seguinte comando de IRAF no terminal:

\$ rvidlines spectra coordli="list" maxfe=320 ftype=abs

No comando de cima, o spectra é o nome do espectro (em formato fits) onde serão identificados os $\lambda_{o b}$, list é a lista de linhas com os valores de $\lambda_{\text {ref }}$ (lista de linhas de Meléndez et al. (2014)), maxfe mostra o número de linhas a ser identificado e ftype indica se o espectro é de linhas de absorção ou de emissão. O pacote rvidlines gera um gráfico do espectro, onde as linhas podem ser identificadas com o auxílio do Atlas Solar (Wallace et al., 2011). Cada um dessas linhas foram identificadas pressionando a letra $m$ no terminal de IRAF; depois com as letras $l$ e $f$ a tarefa identifica automaticamente todas 
as linhas presentes no espectro usando as linhas do arquivo list. Essas linhas junto com as velocidades radiais são salvas num arquivo nomeado logfile. Por exemplo, para a estrela Inti 1 foram identificadas 5 linhas no primeiro CCD, 12 linhas no segundo CCD e 40 linhas no terceiro CCD. O mesmo procedimento foi realizado para cada um dos CCDs da gêmea solar HD 45184. Com as velocidades radiais obtidas o seguinte procedimento é corrigir cada um dos espectros de cada CCD usando a tarefa dopcor e escrevendo na terminal de IRAF:

\$ dopcor spectra spectra_corrected radial_velocity isvel+ add+

Onde spectra_corrected é o nome do espectro corrigido, radial_velocity é a velocidade radial $\left(\mathrm{em} \mathrm{kms}^{-1}\right)$, isvel+ indica que o parâmetro de deslocamento é uma velocidade e $a d d+$ indica a existência de uma correção Doppler para o espectro. A velocidade radial para cada estrela foi estimada tomando a média das velocidades radiais de cada CCD, essas velocidades são $66.5(\sigma=0.1)$ e $78.7(\sigma=0.1) \mathrm{kms}^{-1}$ para Inti1 e HD 45184 , respectivamente.

\subsection{Medição de larguras equivalentes}

As larguras equivalentes foram medidas manualmente usando a lista de linhas de Meléndez et al. (2014) (ver seções 2.6 e 2.8). Para tal fim, usou-se a tarefa splot do pacote IRAF efetuando um ajuste gaussiano para cada linha (equação 2.21), escolhendo-se os limites inferior e superior em comprimento de onda, bem como o nível do contínuo. Às vezes vários ajustes gaussianos foram necessários no caso de blends.

A precisão das medidas das larguras equivalentes vai depender da escolha do contínuo no espectro. Para isso, determinei o "pseudo-contínuo" escolhendo vários pontos (nas imediações da linha) que aparecem mais constantes nos diferentes espectros, pois estes pontos têm maior probabilidade de pertencer ao contínuo verdadeiro. A finalidade desta aproximação é medir as larguras equivalentes com a maior exatidão possível entre os espectros das diferentes estrelas.

A aproximação do pseudo-contínuo nem sempre é a melhor opção pois às vezes o contínuo pode ter alguma inclinação. Para quase todas as linhas de Fe I é fácil a escolha do pseudo-contínuo (ver painel superior a esquerda da Figura 3.5). Em outros casos, é melhor escolher apenas um ponto de contínuo (no lado azul ou vermelho) ao invés de 


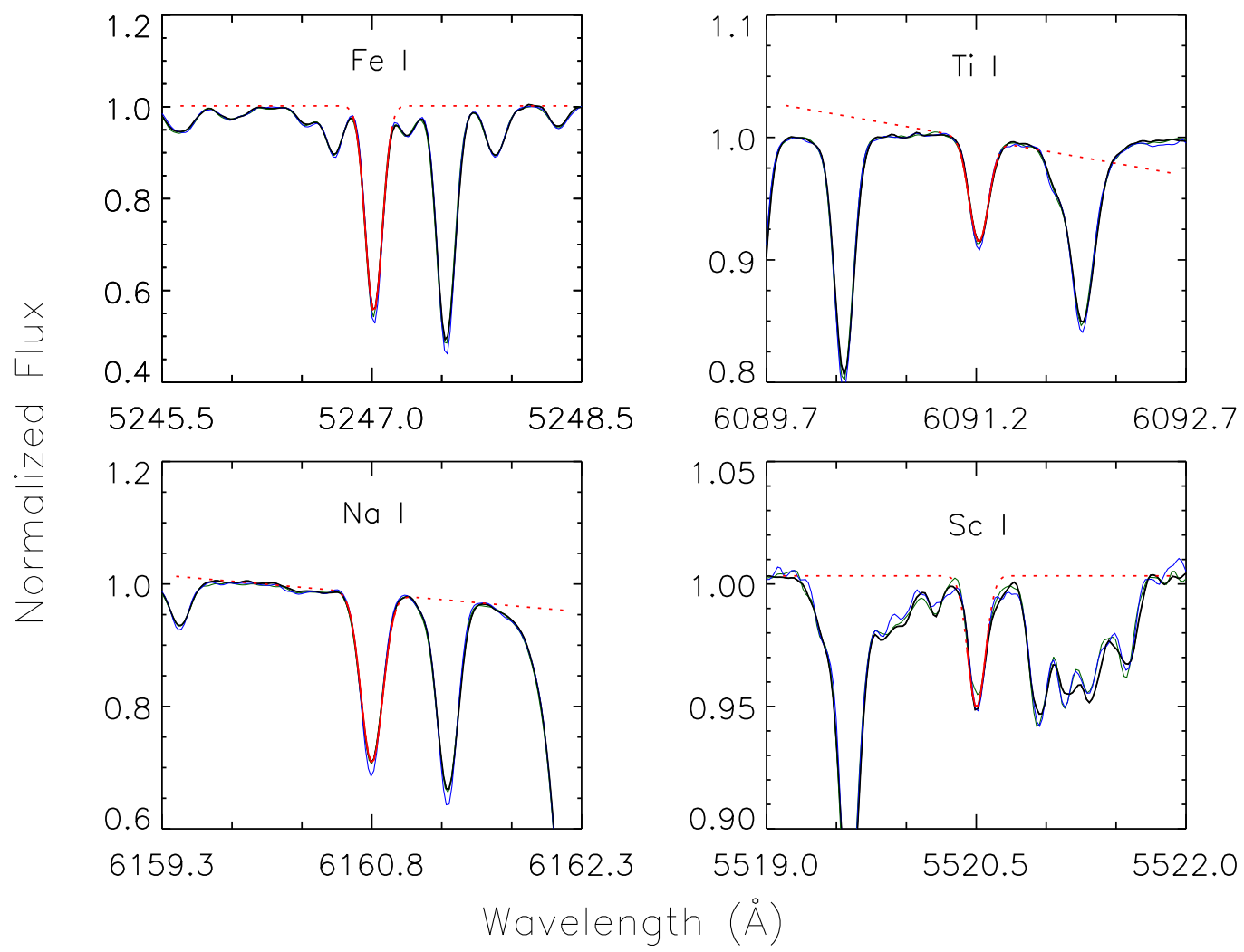

Figura 3.5: Exemplo de quatro linhas espectrais e as escolhas dos seus pseudos-contínuos, respectivamente. Fonte: Bedell et al. (2014).

dois pontos, pois algum desses pontos pode ter mais ruído (ver painel inferior a direita da Figura 3.5, onde pode-se notar que o contínuo 'azul' é mais estável do que o contínuo 'vermelho'). Também, a inclinação do pseudo-contínuo é importante nas regiões onde o espectro apresenta uma inclinação devido as asas das linhas vizinhas (ver painel superior direito e inferior esquerdo da Figura 3.5.

O segredo da alta precisão em abundâncias químicas diferenciais é medir as linhas de absorção seguindo exatamente os mesmos critérios para a estrela de interesse e para a estrela padrão, pois isso minimiza os erros de medida. Como já foi explanado na seção 2.10, a análise é baseada no método diferencial (p. ex. Meléndez et al., 2012, Monroe et al., 2013; Liu et al., 2014; Ramírez et al., 2014; Meléndez et al., 2014; Saffe et al., 2015; Nissen, 2015: Spina et al., 2016; Yana Galarza et al., 2016). É possível encontrar uma discussão mais detalhada sobre a escolha do pseudo-contínuo em Bedell et al. (2014). A lista de linhas que adotamos está descrita na subseção (2.8). 


\subsection{Determinação dos parâmetros estelares}

Como já foi explicado na seção 2.11, há duas formas de determinar os parâmetros atmosféricos: a primeira é através do método manual de equilíbrio espectroscópico que consiste em uma série de passos que descreverei nesta seção, enquanto a segunda, e mais rápida, é usando o código automático $q^{2}$ (ver seção 2.14). Os parâmetros atmosféricos e incluso as abundâncias da Inti 1 foram obtidos usando o método manual, enquanto para HD 45184 usei o código $\mathrm{q}^{2}$.

Para a Inti 1 e HD 45184 adotei os modelos de atmosfera de Marcs (Gustafsson et al. 2008) (seção 2.3). Para interpolar um modelo é necessário os parâmetros de entrada $T_{\text {eff }}$, $\log g, v_{t}$ e $[\mathrm{Fe} / \mathrm{H}]$.

Para modelar a atmosfera do Sol, adotou-se como padrão os seguintes parâmetros atmosféricos: $T_{\text {eff }}=5777 \mathrm{~K}, \log g=4.44 \mathrm{dex}(\overline{C o x}, 2000)$ e $v_{t}=1.00 \mathrm{~km} \mathrm{~s}^{-1}$ Ramírez et al. 2014). Estes parâmetros também foram adotados inicialmente para modelar a atmosfera da Inti 1. Seguidamente, a lista das larguras equivalentes e os modelos atmosféricos foram fornecidos como parâmetros de entrada do código MOOG através da ferramenta abfind? com o fim de estimar as abundâncias químicas de cada estrela.

Para determinar a $T_{\text {eff }}$, primeiro aplicou-se o método diferencial (ver seção 2.11), ou seja, tomou-se as diferenças das abundâncias de Inti 1 e do Sol (equação 2.26). Logo, analisou-se a dependência da abundância diferencial com o potencial de excitação. Se a temperatura efetiva do modelo de atmosfera para a Inti 1 fosse mais alta do que a sua temperatura real, então os níveis com potencial de excitação mais baixos resultariam em abundâncias acima da média (ver painel superior da Figura 3.6). No entanto, se a temperatura é menor do que a temperatura real da estrela, ocorre o inverso (ver painel inferior da Figura 3.6.

A $T_{e f f}$ é atingida quando o equilíbrio de excitação é satisfeito, ou seja, $d\left(\delta A_{F e, i}\right) / d X_{\text {exc }}=$ 0 (ver painel do meio da Figura 3.6). Na Figura 3.6 também são incluídos os valores de $d\left(\delta A_{F e, i}\right) / d X_{e x c}$, que muda com as variações da temperatura.

A $v_{t}$ foi determinada impondo a não dependência com o logaritmo da largura equivalente reduzida (equação 2.28). Na Figura 3.7 são mostradas as diferentes inclinações da reta ajustada devida as variações da velocidade de microturbulência. O painel superior mostra

\footnotetext{
${ }^{9}$ A ferramenta abfind é explanada em detalhe no apêndice C.0.2.
} 


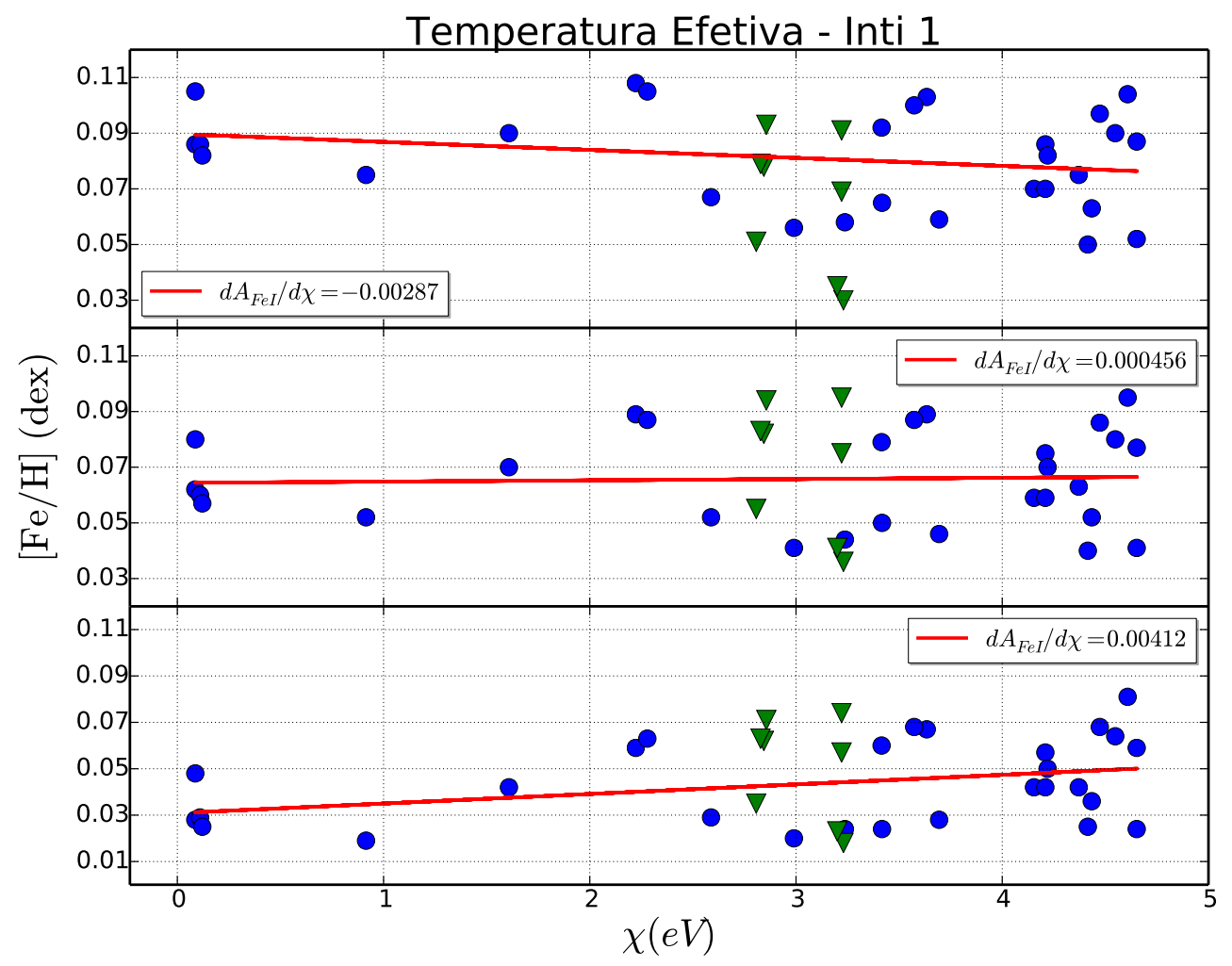

Figura 3.6: Efeitos no ajuste da $[\mathrm{Fe} / \mathrm{H}]$ vs $\chi$ com variações em temperatura de $+20 \mathrm{~K}$ (painel superior) e $-20 \mathrm{~K}$ (painel inferior). O painel do meio mostra o equilíbrio de excitação quando a $T_{\text {eff }}=5837 \mathrm{~K}$. Os círculos azuis representam o Fe I e os triângulos verdes representam o Fe II, enquanto a linha sólida vermelha é o ajuste.

a variação da microturbulência em +0.1 e $-0.1 \mathrm{kms}^{-1}$, enquanto o painel do meio exibe a melhor solução.

A gravidade superficial foi determinada atingindo o equilíbrio de ionização diferencial (equação 2.29), como mostrado na Figura 3.8. A determinação dos erros dos parâmetros atmosféricos foi efetuada segundo a subseção 2.12

Os parâmetros atmosféricos para a Inti 1 são: $T_{\text {eff }}=5837 \pm 11 \mathrm{~K}, \log g=4.42 \pm 0.03$ dex, $v_{t}=1.04 \pm 0.02 \mathrm{kms}^{-1} \mathrm{e}[\mathrm{Fe} / \mathrm{H}]=0.07 \pm 0.01$ dex. A fim de validar o método, também estudei a gêmea solar brilhante HD 45184, que foi observada na mesma missão; os parâmetros estelares foram obtidos com o código $\mathrm{q}^{2}: T_{\text {eff }}=5864 \pm 9 \mathrm{~K}, \log g=4.45 \pm 0.03$ $\operatorname{dex}, v_{t}=1.11 \pm 0.02 \mathrm{kms}^{-1} \mathrm{e}[\mathrm{Fe} / \mathrm{H}]=0.04 \pm 0.01 \mathrm{dex}$ (ver Figura 3.9). Estes valores para a gêmea solar HD 45184 estão em bom acordo com todos os trabalhos anteriores encontrados na literatura, como mostrado na Tabela 3.2. Os resultados estão em excelente acordo com a média ponderada dos valores da literatura: $T_{\text {eff }}=5863 \pm 5 \mathrm{~K}, \log g=4.44 \pm 0.01$ dex, 


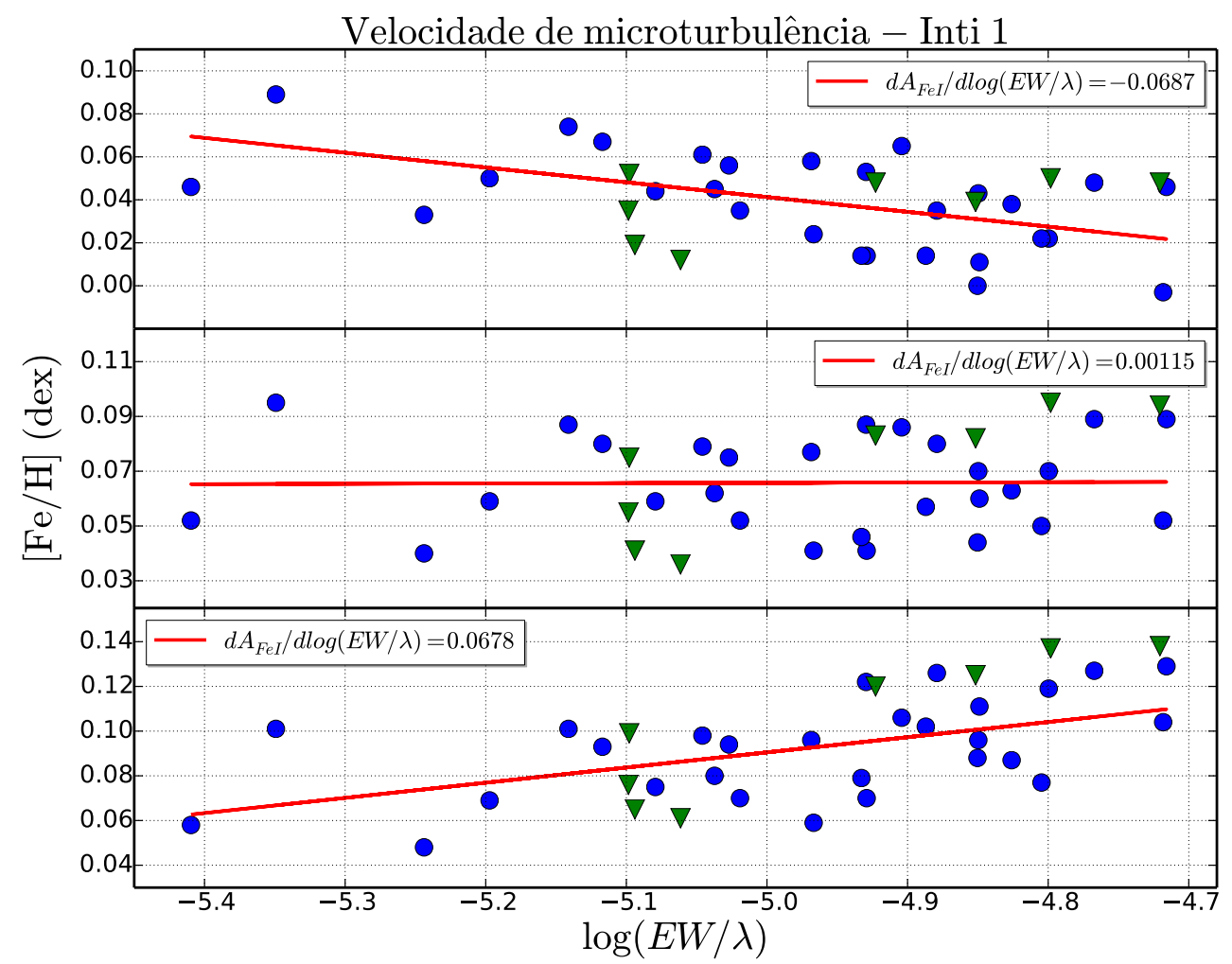

Figura 3.7: Variação da velocidade de microturbulência e seus efeitos sobre o ajuste ao variar $+0.1 \mathrm{kms}^{-1}$ (painel superior) e $-0.1 \mathrm{kms}^{-1}$ (painel inferior). O painel do meio mostra o equilíbrio de ionização quando $v_{t}=1.04 \mathrm{kms}^{-1}$. Os círculos, triângulos e linha sólida representam o mesmo que a Figura 3.6 .

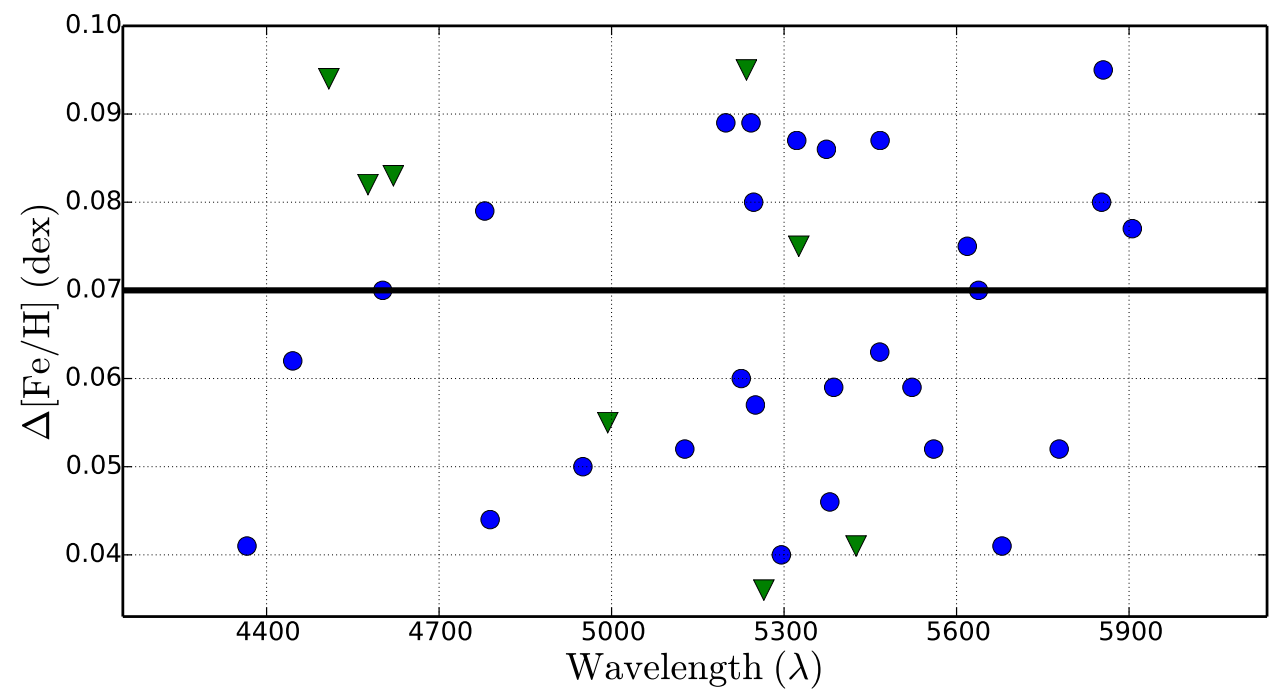

Figura 3.8: Abundância diferencial da Inti 1 em função do comprimento de onda. Os círculos, triângulos e linha sólida representam o mesmo que a Figura 3.6 e 3.7 
Tabela 3.2 - Comparação dos parâmetros estelares da gêmea solar HD 45184

\begin{tabular}{ccccccccccccc}
\hline \hline $\begin{array}{c}T_{\text {eff }} \\
(\mathrm{K})\end{array}$ & $\begin{array}{c}\text { erro } \\
(\mathrm{K})\end{array}$ & $\begin{array}{c}\log g \\
(\mathrm{dex})\end{array}$ & $\begin{array}{c}\text { erro } \\
(\mathrm{dex})\end{array}$ & $\begin{array}{c}{[\mathrm{Fe} / \mathrm{H}]} \\
(\mathrm{dex})\end{array}$ & $\begin{array}{c}\text { erro } \\
(\mathrm{dex})\end{array}$ & $\begin{array}{c}v_{t} \\
\left(\mathrm{kms}^{-1}\right)\end{array}$ & $\begin{array}{c}\text { erro } \\
\left(\mathrm{kms}^{-1}\right)\end{array}$ & $\begin{array}{c}\text { Idade } \\
(\mathrm{Gyr})\end{array}$ & $\begin{array}{c}\text { erro } \\
(\mathrm{Gyr})\end{array}$ & $\begin{array}{c}\text { Massa } \\
\mathrm{M}_{\odot}\end{array}$ & $\begin{array}{l}\text { erro } \\
\mathrm{M}_{\odot}\end{array}$ & Fonte \\
\hline 5864 & 9 & 4.45 & 0.03 & 0.040 & 0.010 & 1.11 & 0.02 & 3.0 & 1.2 & 1.05 & 0.01 & Este trabalho \\
\hline 5873 & 18 & 4.41 & 0.04 & 0.070 & 0.016 & 1.03 & 0.04 & 3.7 & 1.2 & 1.06 & 0.02 & $(1) \dagger$ \\
5871 & 6 & 4.45 & 0.01 & 0.047 & 0.006 & 1.06 & 0.02 & 2.7 & 0.5 & 1.06 & 0.01 & $(2) \dagger$ \\
5833 & 10 & 4.37 & 0.02 & 0.010 & 0.010 & 1.04 & 0.06 & $\ldots$ & $\ldots$ & $\ldots$ & $\ldots$ & $(3) \dagger$ \\
5849 & 86 & 4.45 & 0.11 & 0.040 & 0.090 & 1.11 & 0.09 & 4.4 & 2.3 & 1.03 & 0.05 & $(4) \dagger$ \\
5869 & 14 & 4.47 & 0.02 & 0.040 & 0.010 & 1.03 & 0.04 & 2.3 & $\ldots$ & 1.05 & $\ldots$ & $(5)^{*} \dagger$ \\
\hline 5863 & 5 & 4.44 & 0.01 & 0.040 & 0.004 & 1.05 & 0.02 & 2.9 & 0.5 & 1.06 & 0.01 & $(6)$ \\
\hline \hline
\end{tabular}

Notas:

(1) Spina et al. (2016); (2) Nissen (2015); (3) Maldonado et al. (2015b); (4) Bensby et al. (2014); (5) (Sousa et al., 2008, Delgado Mena et al., 2014); (6) média ponderada da literatura.

* Parâmetros estelares tomados de Sousa et al. (2008), idade e massa de Delgado Mena et al. (2014) e Schneider et al. (2011).

† Os parâmetros reportados nesta dissertação são baseados nos parâmetros estelares diferenciais e adotando para o Sol $T_{\text {eff }}=5777 \mathrm{~K}, \log g=4.44$ dex e $v_{t}=1.00 \mathrm{kms}^{-1}$.

$v_{t}=1.05 \pm 0.02 \mathrm{kms}^{-1}$ e $[\mathrm{Fe} / \mathrm{H}]=0.040 \pm 0.004$ dex. Os parâmetros atmosféricos de ambas estrelas estão dentro da definição de gêmea solar de Ramírez et al. (2009), por conseguinte pode-se concluir que a estrela Inti 1 é uma gêmea solar.

Para ratificar os resultados em $T_{\text {eff }}$ das gêmeas solares Inti 1 e HD 45184, usei a relação $T_{\text {eff }}$ vs. cor derivada por (Casagrande et al., 2010), que leva em consideração os efeitos da metalicidade (Alonso et al., 1996; Ramírez e Meléndez, 2005; Casagrande et al., 2006; González Hernández e Bonifacio, 2009):

$$
\theta_{\text {eff }}=a_{0}+a_{1} X+a_{2} X^{2}+a_{3} X[\mathrm{Fe} / \mathrm{H}]+\mathrm{a}_{4}[\mathrm{Fe} / \mathrm{H}]+\mathrm{a}_{5}[\mathrm{Fe} / \mathrm{H}]^{2},
$$

sendo $\theta_{\text {eff }}=5040 / T_{\text {eff }}, X$ a cor e $a_{i}(i=0, \ldots, 5)$ os coeficientes do ajuste. Na Figura 3.10 é mostrado o ajuste do plano $T_{\text {eff }}$ vs. cor para metalicidades de $-5 \leq[\mathrm{Fe} / \mathrm{H}] \leq 0.5$. Também são mostradas as estrelas que foram usadas para o ajuste. Os valores dos coeficientes são encontrados na Tabela 4 de Casagrande et al. (2010).

A $T_{\text {eff }}$ de Inti 1 usando a equação 3.10 foi estimada em $5765 \pm 67 \mathrm{~K}$ que está em razoável acordo dentro dos erros com o resultado obtido usando o equilíbrio de excitação $(5837 \pm 11 \mathrm{~K})$. Estes resultados não são tão próximos devido a que as cores de Inti 1 não são precisas. Para a gêmea solar HD 45184 adotou-se as seguintes magnitudes: ${ }^{10}$ : V =

\footnotetext{
${ }^{10}$ A magnitude $\mathrm{V}$ foi adotada de Mallama (2014) e as magnitudes $\mathrm{B}, \mathrm{R}_{\mathrm{C}}, \mathrm{I}_{\mathrm{C}}$ de Just e Jahrei (2008), enquanto as magnitudes $\mathrm{V}_{\mathrm{T}}, \mathrm{B}_{\mathrm{T}}, \mathrm{J}_{2}, \mathrm{H}_{2}$ e $\mathrm{K}_{2}$ de Ammons et al. (2006).
} 
HD45184 : 5864, 4.45, 0.035, 1.11 [Vesta]
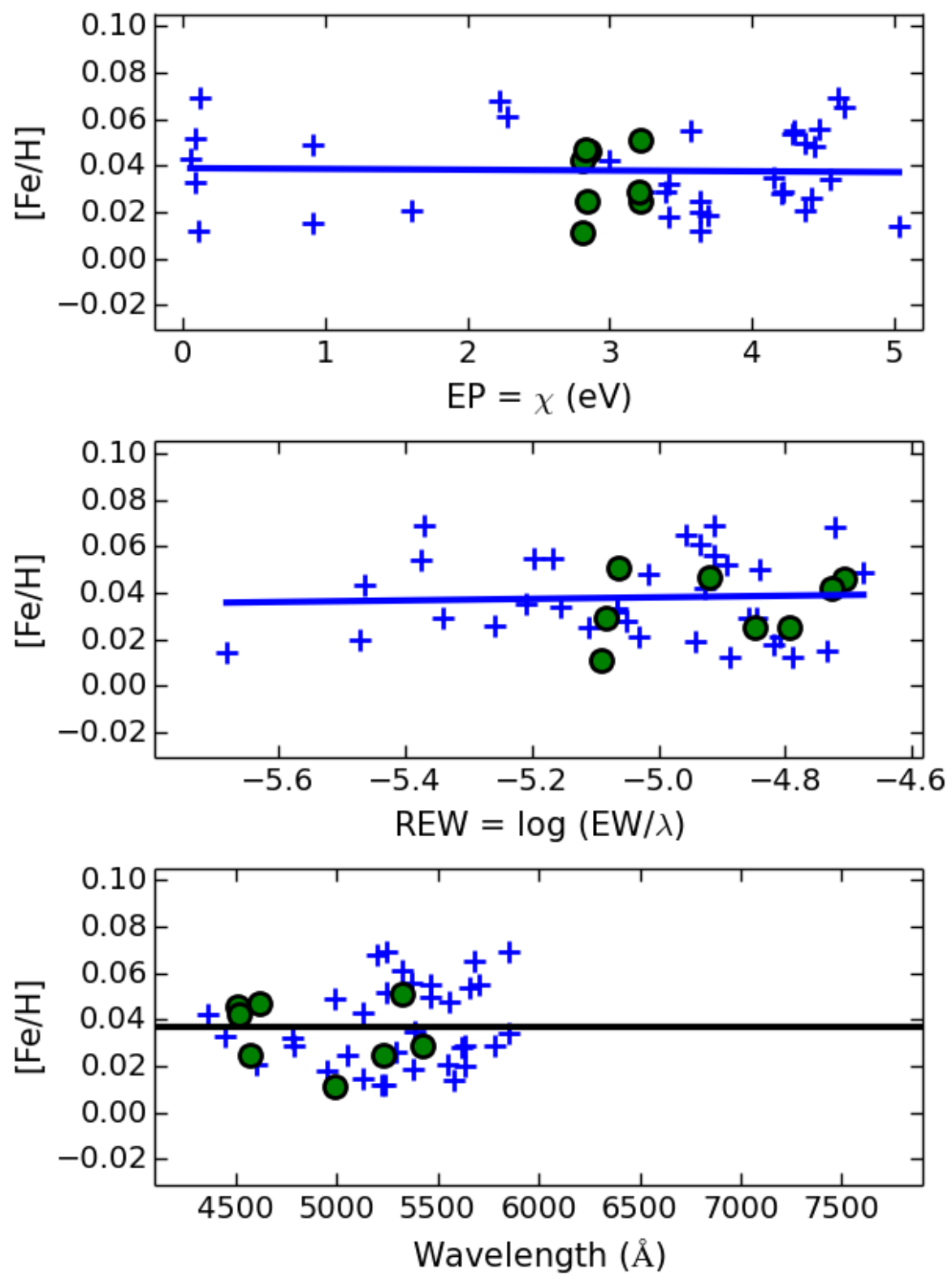

Figura 3.9: Abundância diferencial do ferro para a estrela HD 45184 em função do potencial de excitação (painel superior), largura equivalente reduzida (painel do meio) e comprimento de onda (painel inferior). As cruzes azuis e os círculos verdes representam o Fe I e Fe II, a linha sólida azul o ajuste (painel superior e central) e a linha preta o valor médio da abundância de ferro (painel inferior). 


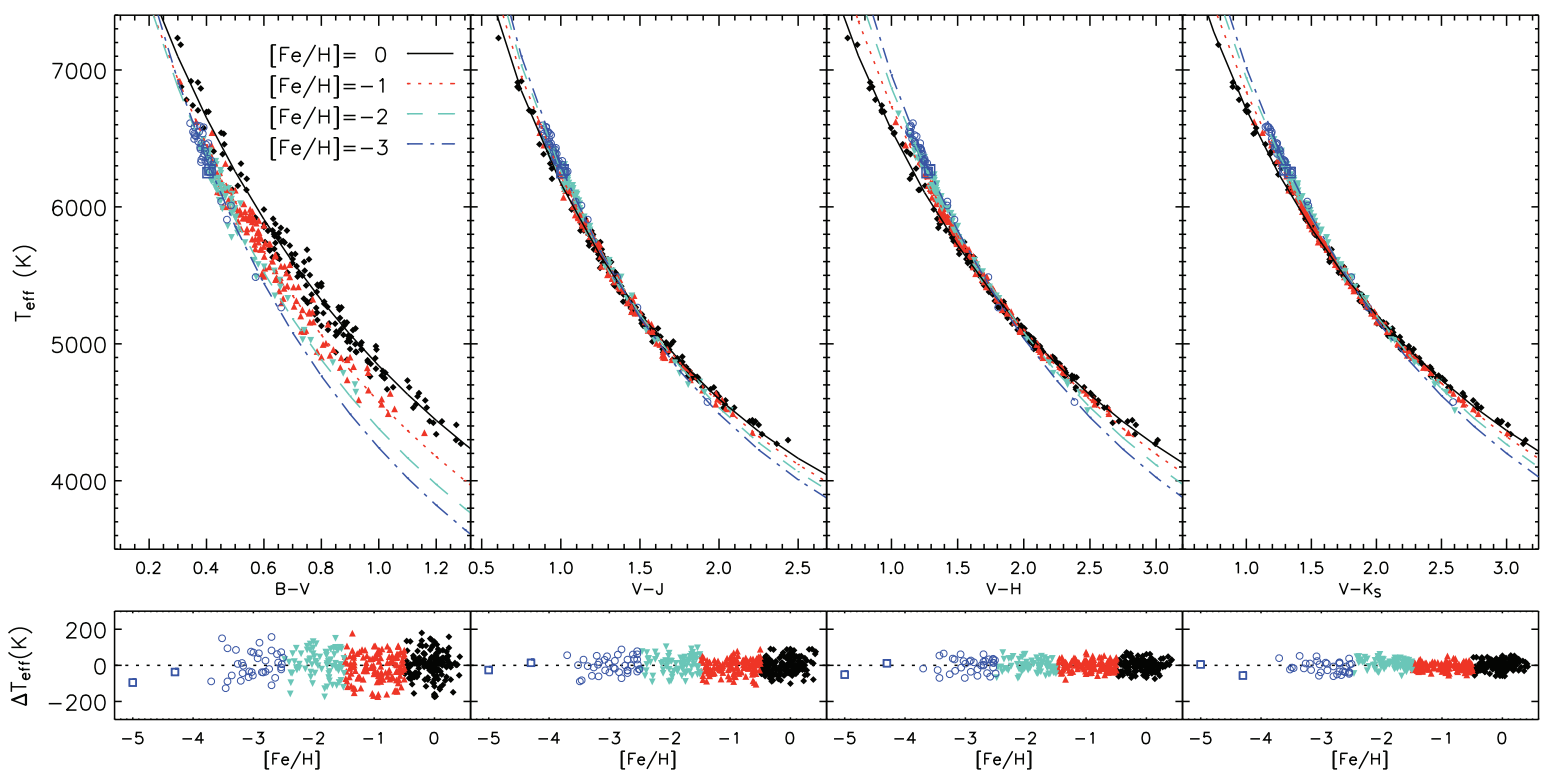

Figura 3.10: Painéis superiores: relação empírica do cor- $T_{\text {eff }}$. Diamantes cheios representam estrelas com $-0.5<[\mathrm{Fe} / \mathrm{H}] \leq 0.5$, triângulos voltados para acima a estrelas com $-1.5<[\mathrm{Fe} / \mathrm{H}] \leq-0.5$, triângulos voltados para abaixo a estrelas com $-2.5<[\mathrm{Fe} / \mathrm{H}] \leq-1.5$ e círculos abertos a estrelas com $[\mathrm{Fe} / \mathrm{H}] \leq-2.5$. Os quadrados abertos representam às estrelas muito pobres em metais HE0233-0343 e HE1327-2326. Painéis inferiores: os resíduos dos ajustes como uma função da metalicidade. Fonte: Casagrande et al. (2010)

Tabela 3.3 - Temperatura efetiva fotométrica de Inti 1 e HD 45184.

\begin{tabular}{|c|c|c|c|c|}
\hline \multirow{2}{*}{ Cor } & \multicolumn{2}{|c|}{ Inti 1} & \multicolumn{2}{|c|}{ HD 45184} \\
\hline & Observado & $T_{\text {eff }}$ & Observado & $T_{e f f}$ \\
\hline$(B-V)$ & 0.615 & 5881 & 0.620 & 5856 \\
\hline$\left(V-R_{C}\right)$ & $\ldots$ & $\ldots$ & 0.370 & 5710 \\
\hline$\left(\mathrm{V}-\mathrm{I}_{\mathrm{C}}\right)$ & $\ldots$ & $\ldots$ & 0.682 & 5804 \\
\hline$(\mathrm{V}-\mathrm{J})$ & 1.203 & 5729 & 1.171 & 5794 \\
\hline$(\mathrm{V}-\mathrm{H})$ & 1.500 & 5713 & 1.428 & 5820 \\
\hline$(\mathrm{V}-\mathrm{K})$ & 1.570 & 5737 & 1.519 & 5811 \\
\hline$(\mathrm{J}-\mathrm{K})$ & $\ldots$ & $\ldots$ & 0.348 & 5836 \\
\hline$(\mathrm{B}-\mathrm{V})_{T}$ & $\ldots$ & $\ldots$ & 0.681 & 5922 \\
\hline$\left(\mathrm{V}_{\mathrm{T}}-\mathrm{J}\right)$ & $\ldots$ & $\ldots$ & 1.225 & 5832 \\
\hline$\left(\mathrm{V}_{\mathrm{T}}-\mathrm{H}\right)$ & . & & 1.482 & 5847 \\
\hline$\left(\mathrm{V}_{\mathrm{T}}-\mathrm{K}\right)$ & $\ldots$ & $\ldots$ & 1.573 & 5841 \\
\hline$\left(\mathrm{R}_{\mathrm{C}}-\mathrm{I}_{\mathrm{C}}\right)$ & $\ldots$ & $\ldots$ & 0.312 & 5956 \\
\hline Média & da $T_{e f f}$ & 5765 & & 5835 \\
\hline Sigma & da $T_{e f f}$ & 67 & & 59 \\
\hline
\end{tabular}


$6.39,(\mathrm{~B}-\mathrm{V})=0.62,\left(\mathrm{~B}-\mathrm{R}_{\mathrm{C}}\right)=0.370,\left(\mathrm{R}_{\mathrm{C}}-\mathrm{I}_{\mathrm{C}}\right)=0.312, \mathrm{~V}_{\mathrm{T}}=6.444, \mathrm{~B}_{\mathrm{T}}=7.125, \mathrm{~J}_{2}=$ 5.219, $\mathrm{H}_{2}=4.962$ e $\mathrm{K}_{2}=4.871$. De igual modo que para a Inti 1 , a $T_{\text {eff }}$ de HD 45184 foi determinada em $5835 \pm 59 \mathrm{~K}$ que está em excelente acordo com o resultado obtido usando o equilíbrio de excitação $(5864 \pm 9 \mathrm{~K})$. Os resultados são apresentados na Tabela 3.3.

A gravidade superficial também foi estimada para HD 45184 seguindo a seção 2.1 (equação 2.9). A paralaxe usada é $\pi=45.7 \pm 0.4$ mas (van Leeuwen, 2007). A correção bolométrica $(B C)$ foi estimada em -0.062, resultando em uma gravidade superficial de $\log g$ $=4.44 \pm 0.01$ dex, que está em acordo com o resultado obtido a partir do equilíbrio de ionização diferencial $(\log g=4.45 \pm 0.03 \mathrm{dex})$. Não foi possível determinar a gravidade superficial trigonométrica da gêmea solar Inti 1 devido a que ainda não foi realizada a medida da sua paralaxe.

\subsection{Análise de abundâncias}

Uma vez que os parâmetros atmosféricos foram obtidos, usando o código MOOG (ver seção C.0.2 , estimei as abundâncias de 18 elementos diferentes do ferro, através de linhas atômicas dos seguintes elementos: C, Na, Mg, Si, Ca, Sc, Ti, Cr, Mn, Co, Ni, Cu, Zn, Y, Zr, Ce e Nd. Para o carbono usei as linhas da molécula $\mathrm{CH}$, e para o nitrogênio empreguei a molécula NH na região do ultravioleta. As correções hiperfinas foram efetuadas para Mn, Co, Y e Cu (segundo a seção 2.9), e também adotando os dados de CHF de Meléndez et al. (2014).

As abundâncias da gêmea solar brilhante HD 45184 foram comparadas com as abundâncias mais exatas disponíveis na literatura (ver Figura 3.11), e que são as de Nissen (2015). Encontrei uma diferença em abundância (este trabalho - Nissen $(2015)$ ) de $\Delta[\mathrm{X} / \mathrm{H}]=0.007$ $(\sigma=0.009 \mathrm{dex})$ e $\Delta[\mathrm{X} / \mathrm{Fe}]=0.000(\sigma=0.009 \mathrm{dex})$. Isso mostra que a precisão atingida é de aproximadamente 0.01 dex, por conseguente as abundâncias de Inti 1 são precisas. Também comparei com mais outros dois trabalhos da literatura de menor precisão do que o Nissen (2015), resultando em $\Delta[\mathrm{X} / \mathrm{H}]=0.023(\sigma=0.016 \mathrm{dex})$ e $\Delta[\mathrm{X} / \mathrm{Fe}]=-0.007(\sigma$ $=0.016$ dex $)$ para Spina et al. $(2016)$, e $\Delta[\mathrm{X} / \mathrm{H}]=0.014(\sigma=0.030$ dex $)$ e $\Delta[\mathrm{X} / \mathrm{Fe}]=$ 0.004 ( $\sigma=0.030$ dex) para González Hernández et al. (2010).

As abundâncias diferenciais de HD 45184 e Inti 1 são apresentadas na Tabela 3.4 , incluindo os erros de observação e sistemáticos (devido às incertezas nos parâmetros este- 
Tabela 3.4 - Abundâncias químicas de HD 45184 e Inti 1, e seus erros.

\begin{tabular}{|c|c|c|c|c|c|c|c|c|}
\hline \multirow[b]{2}{*}{ Elemento } & \multicolumn{8}{|c|}{ HD 45184} \\
\hline & $\begin{array}{r}\Delta[\mathrm{X} / \mathrm{H}] \\
\mathrm{LTE} \\
(\mathrm{dex})\end{array}$ & $\begin{array}{l}\Delta T_{\text {eff }} \\
\pm 9 \mathrm{~K} \\
(\text { dex })\end{array}$ & $\begin{array}{r}\Delta \log g \\
\pm 0.03 \text { dex } \\
(\text { dex })\end{array}$ & $\begin{array}{r}\Delta v_{t} \\
\pm 0.02 \mathrm{kms}^{-1} \\
(\text { dex })\end{array}$ & $\begin{array}{r}\Delta[\mathrm{Fe} / \mathrm{H}] \\
\pm 0.01 \mathrm{dex} \\
(\mathrm{dex})\end{array}$ & Param $^{a}$ & $\mathrm{Obs}^{\mathrm{b}}$ & Total $^{\mathrm{c}}$ \\
\hline $\mathrm{C}$ & -0.019 & 0.005 & 0.007 & 0.000 & 0.000 & 0.009 & 0.006 & 0.010 \\
\hline $\mathrm{Na}$ & -0.003 & 0.004 & 0.002 & 0.000 & 0.000 & 0.004 & 0.008 & 0.009 \\
\hline $\mathrm{Mg}$ & 0.040 & 0.007 & 0.003 & 0.004 & 0.000 & 0.009 & 0.007 & 0.011 \\
\hline $\mathrm{Si}$ & 0.042 & 0.002 & 0.002 & 0.000 & 0.001 & 0.003 & 0.001 & 0.015 \\
\hline $\mathrm{Ca}$ & 0.054 & 0.005 & 0.003 & 0.004 & 0.000 & 0.007 & 0.012 & 0.014 \\
\hline $\mathrm{Sc}$ & 0.041 & 0.007 & 0.003 & 0.000 & 0.000 & 0.008 & 0.006 & 0.010 \\
\hline $\mathrm{Ti}$ & 0.044 & 0.009 & 0.002 & 0.003 & 0.000 & 0.010 & 0.012 & 0.015 \\
\hline $\mathrm{Cr}$ & 0.048 & 0.007 & 0.001 & 0.004 & 0.000 & 0.008 & 0.008 & 0.011 \\
\hline $\mathrm{Mn}$ & 0.014 & 0.006 & 0.001 & 0.003 & 0.000 & 0.007 & 0.012 & 0.014 \\
\hline $\mathrm{Fe}$ & 0.040 & 0.007 & 0.001 & 0.006 & 0.000 & 0.010 & 0.003 & 0.010 \\
\hline $\mathrm{Co}$ & 0.006 & 0.006 & 0.003 & 0.001 & 0.000 & 0.007 & 0.014 & 0.016 \\
\hline $\mathrm{Ni}$ & 0.022 & 0.004 & 0.001 & 0.003 & 0.001 & 0.005 & 0.011 & 0.012 \\
\hline $\mathrm{Cu}$ & -0.005 & 0.004 & 0.002 & 0.002 & 0.001 & 0.005 & 0.007 & 0.009 \\
\hline $\mathrm{Zn}$ & 0.013 & 0.002 & 0.001 & 0.007 & 0.002 & 0.008 & 0.006 & 0.010 \\
\hline Y & 0.063 & 0.001 & 0.010 & 0.009 & 0.002 & 0.014 & 0.010 & 0.017 \\
\hline $\mathrm{Zr}$ & 0.076 & 0.001 & 0.013 & 0.004 & 0.002 & 0.015 & 0.014 & 0.020 \\
\hline $\mathrm{Ce}$ & 0.099 & 0.002 & 0.014 & 0.002 & 0.003 & 0.015 & 0.020 & 0.025 \\
\hline $\mathrm{Nd}$ & 0.124 & 0.002 & 0.014 & 0.001 & 0.003 & 0.014 & 0.032 & 0.035 \\
\hline $\mathrm{C}(\mathrm{CH})$ & -0.021 & 0.007 & 0.001 & 0.001 & 0.006 & 0.009 & 0.013 & 0.016 \\
\hline \multirow[t]{2}{*}{$\mathrm{N}(\mathrm{NH})$} & 0.003 & 0.009 & 0.001 & 0.000 & 0.006 & 0.011 & 0.011 & 0.015 \\
\hline & \multicolumn{8}{|c|}{ Inti 1} \\
\hline Elemento & $\begin{array}{r}\Delta[\mathrm{X} / \mathrm{H}] \\
\mathrm{LTE} \\
(\mathrm{dex}) \\
\end{array}$ & $\begin{array}{r}\Delta T_{\text {eff }} \\
\pm 11 \mathrm{~K} \\
(\mathrm{dex}) \\
\end{array}$ & $\begin{array}{r}\Delta \log g \\
\pm 0.03 \text { dex } \\
(\text { dex })\end{array}$ & $\begin{array}{r}\Delta v_{t} \\
\pm 0.02 \mathrm{kms}^{-1} \\
(\mathrm{dex})\end{array}$ & $\begin{array}{r}\Delta[\mathrm{Fe} / \mathrm{H}] \\
\pm 0.01 \mathrm{dex} \\
(\mathrm{dex})\end{array}$ & Param $^{a}$ & $\mathrm{Obs}^{\mathrm{b}}$ & Total $^{\mathrm{c}}$ \\
\hline $\mathrm{C}$ & 0.059 & 0.006 & 0.008 & 0.001 & 0.000 & 0.010 & 0.004 & 0.011 \\
\hline $\mathrm{Na}$ & 0.069 & 0.005 & 0.001 & 0.000 & 0.000 & 0.005 & 0.010 & 0.011 \\
\hline $\mathrm{Mg}$ & 0.076 & 0.009 & 0.005 & 0.004 & 0.001 & 0.011 & 0.003 & 0.011 \\
\hline $\mathrm{Si}$ & 0.075 & 0.003 & 0.002 & 0.001 & 0.001 & 0.004 & 0.007 & 0.008 \\
\hline $\mathrm{Ca}$ & 0.069 & 0.007 & 0.004 & 0.000 & 0.004 & 0.009 & 0.007 & 0.011 \\
\hline $\mathrm{Sc}$ & 0.083 & 0.009 & 0.003 & 0.001 & 0.000 & 0.010 & 0.007 & 0.012 \\
\hline $\mathrm{Ti}$ & 0.076 & 0.010 & 0.001 & 0.003 & 0.000 & 0.010 & 0.006 & 0.012 \\
\hline $\mathrm{Cr}$ & 0.066 & 0.010 & 0.003 & 0.006 & 0.000 & 0.012 & 0.006 & 0.013 \\
\hline $\mathrm{Mn}$ & 0.073 & 0.007 & 0.001 & 0.003 & 0.001 & 0.008 & 0.001 & 0.008 \\
\hline $\mathrm{Fe}$ & 0.070 & 0.009 & 0.001 & 0.005 & 0.000 & 0.010 & 0.003 & 0.011 \\
\hline Co & 0.074 & 0.009 & 0.003 & 0.001 & 0.001 & 0.010 & 0.010 & 0.014 \\
\hline $\mathrm{Ni}$ & 0.085 & 0.006 & 0.000 & 0.003 & 0.001 & 0.007 & 0.003 & 0.007 \\
\hline $\mathrm{Cu}$ & 0.067 & 0.006 & 0.002 & 0.002 & 0.001 & 0.007 & 0.010 & 0.012 \\
\hline $\mathrm{Zn}$ & 0.066 & 0.002 & 0.000 & 0.007 & 0.003 & 0.008 & 0.007 & 0.011 \\
\hline Y & 0.086 & 0.001 & 0.011 & 0.009 & 0.003 & 0.015 & 0.006 & 0.016 \\
\hline $\mathrm{Zr}$ & 0.085 & 0.001 & 0.014 & 0.003 & 0.003 & 0.016 & 0.008 & 0.017 \\
\hline $\mathrm{Ce}$ & 0.084 & 0.003 & 0.015 & 0.002 & 0.003 & 0.016 & 0.007 & 0.017 \\
\hline $\mathrm{Nd}$ & 0.088 & 0.003 & 0.015 & 0.002 & 0.003 & 0.016 & 0.003 & 0.016 \\
\hline $\mathrm{C}(\mathrm{CH})$ & 0.062 & 0.009 & 0.000 & 0.001 & 0.008 & 0.012 & 0.010 & 0.016 \\
\hline $\mathrm{N}(\mathrm{NH})$ & 0.063 & 0.010 & 0.001 & 0.001 & 0.008 & 0.013 & 0.002 & 0.013 \\
\hline
\end{tabular}

Notas.

a Erros sistemáticos devido à incerteza dos parâmetros estelares.

b Erros observacionais.

c Erros totais (parâmetros estelares e observacionais). 

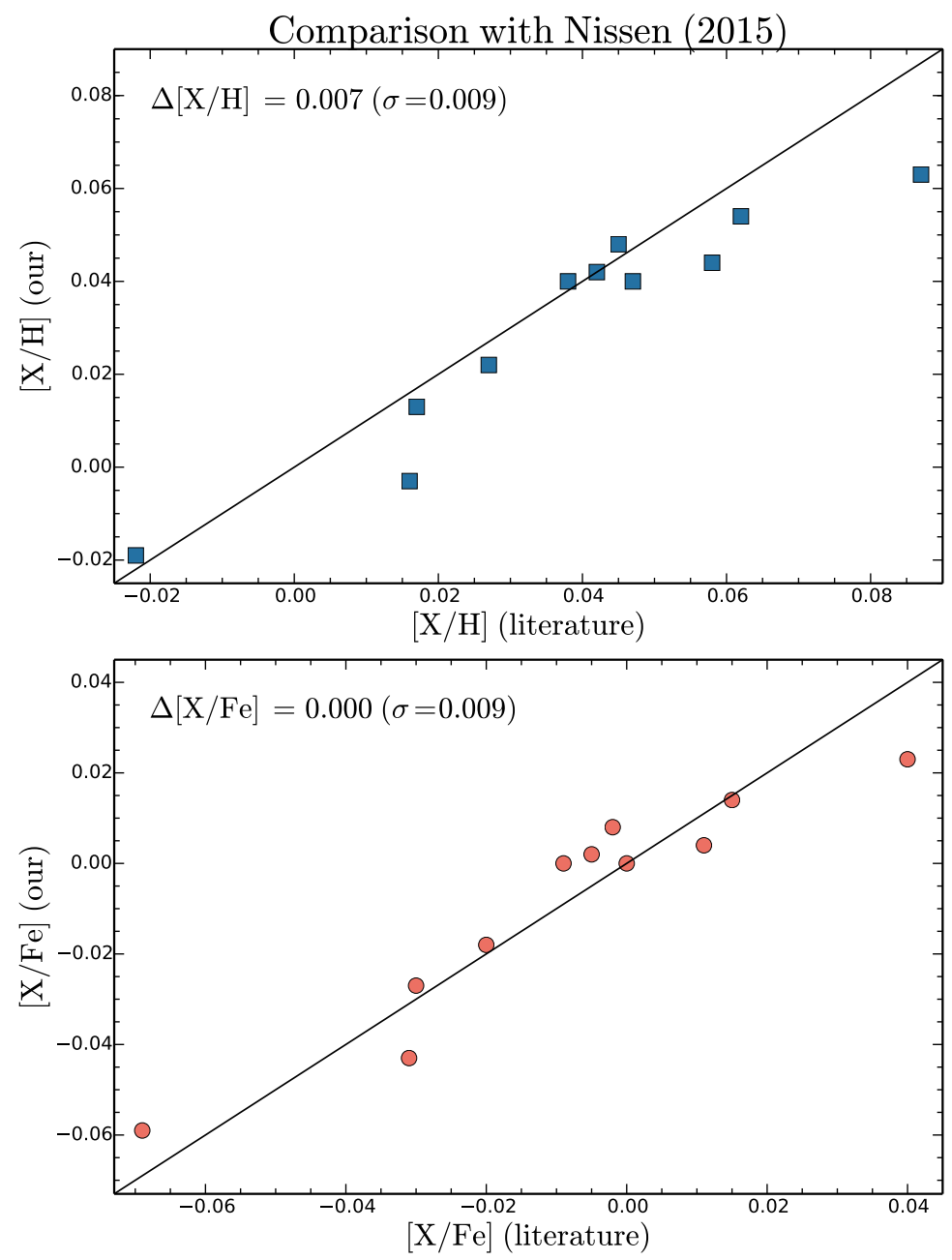

Figura 3.11: Painel superior: Comparação entre as abundâncias $[\mathrm{X} / \mathrm{H}]$ estimadas nesta dissertação e as determinadas por Nissen (2015). Painel inferior: De modo igual que para o painel superior, no entanto para a razão $[\mathrm{X} / \mathrm{Fe}]$.

lares), e também incluí o erro total obtido de somar quadraticamente os erros sistemáticos e estatísticos (ver seção 2.12).

\subsection{Idade e Massa}

Lachaume et al. (1999) demonstraram que é possível determinar a idade e a massa de uma estrela localizando sua posição no diagrama de cor-magnitude e comparando-a com isócronas teóricas de evolução estelar, usando dados estelares como: a magnitude absoluta $\left(M_{V}\right)$, temperatura efetiva $\left(T_{e f f}\right)$ e metalicidade $[\mathrm{Fe} / \mathrm{H}]$. Este método foi amplamente estudado por Reddy et al. (2003); Nordström et al. (2004); Meléndez et al. (2012); Chanamé e Ramírez (2012); Ramírez et al. (2013) e Ramírez et al. (2014). 
A determinação com alta precisão da idade é possível pelo uso da gravidade superficial espectroscópica $(\log g)$ ao invés de uma incerta magnitude absoluta $\left(M_{V}\right.$, ou paralaxe) como parâmetro de entrada. Ao contrario de $M_{V}$, o log $g$ espectroscópico pode ser estimado com altíssima precisão atingindo assim idades mais precisas. Atualmente apenas para estrelas muito brilhantes e próximas o erro da paralaxe resulta em $\log g$ mais preciso do que o $\log g$ espectroscópico para gêmeas solares; no futuro a alta precisão das paralaxes Gaia permitirá obter $\log g$ trigonométricos com altíssima precisão. Por exemplo, Meléndez et al. (2012) mostraram que usando $M_{V}$ a idade isocronal de HIP 56948 está entre 0 a 8 Gyr (devido ao erro da paralaxe Hipparcos), no entanto usando o $\log g$ espectroscópico a idade estimada foi entre 2.3 e 4.1 Gyr.

Nesta dissertação adotarei a metodologia de Meléndez et al. (2012) e Ramírez et al. (2013) para determinar a idade e massa das gêmeas solares. Para os modelos de isócronas foram adotadas as grades de isócronas de Yonsei-Yale (p. ex. Yi et al., 2001). Estas grades estão divididas em passos de $\Delta[\mathrm{Fe} / \mathrm{H}]=0.01$ dex para intervalos de metalicidade de -0.15 $\leq[\mathrm{Fe} / \mathrm{H}] \leq 0.15$, enquanto para os demais intervalos de metalicidades os passos são de $\Delta[\mathrm{Fe} / \mathrm{H}]=0.02$ dex. Adotou-se também $[\alpha / \mathrm{Fe}]=0$ para metalicidades $[\mathrm{Fe} / \mathrm{H}] \geq 0$ e $[\alpha / \mathrm{Fe}]$ $=-0.3 \times[\mathrm{Fe} / \mathrm{H}]$ para metalicidades no intervalo de $1 \leq[\mathrm{Fe} / \mathrm{H}] \leq 0$. As isócronas foram normalizadas para reproduzir a massa e idade do Sol usando como entrada os parâmetros estelares do Sol $\left(T_{\text {eff }}=5777 \mathrm{~K}, \log g=4.44\right.$ dex e $\left.[\mathrm{Fe} / \mathrm{H}]=0.0\right)$; para isso foi necessário uma correção de apenas -0.04 dex na metalicidade. Esta normalização deu como resultado uma massa solar de $\mathrm{M}_{\odot}=1.000 \pm 0.003$ e uma idade de Age $_{\odot}=4.5 \pm 0.2$ Gyr.

Com o fim de determinar quais isócronas representam melhor a idade de uma estrela, foi desenvolvida a distribuição de probabilidade de uma idade estelar calculando a probabilidade de que alguma isócrona passe perto dos correspondentes conjuntos de parâmetros. Assumindo que os erros nos parâmetros estelares observados $\left(\sigma T_{e f f}, \sigma[\mathrm{Fe} / \mathrm{H}]\right.$ e $\left.\sigma M_{V}\right)$ têm distribuição de probabilidade gaussiana, a probabilidade de que um ponto seja parte de uma isócrona dada, pode ser escrita como:

$$
\begin{aligned}
p \propto & \exp \left[-\left(T_{\text {eff }}-T\right)^{2} /\left(\sqrt{2} \sigma\left(T_{\text {eff }}\right)^{2}\right]\right) \\
& \left.\exp \left[-(\log g-G)^{2}\right] /\left(\sqrt{2} \sigma \log (g)^{2}\right)\right) \\
& \exp \left[-([\mathrm{Fe} / \mathrm{H}]-\mathrm{M})^{2}\right] /\left(\sqrt{2} \sigma([\mathrm{Fe} / \mathrm{H}])^{2}\right)
\end{aligned}
$$

A distribuição de probabilidade sobre todos os parâmetros espaciais de um conjunto de 
isócronas resulta na distribuição de probabilidade em idade:

$$
d P(\text { age })=\frac{1}{\Delta(\text { age })} \sum_{\Delta(\text { age })} p\left(T_{e f f}, \log g,[\mathrm{Fe} / \mathrm{H}], \mathrm{T}, \mathrm{G}, \mathrm{M}\right)
$$

onde $T_{\text {eff }}, \log g$ e $[\mathrm{Fe} / \mathrm{H}]$ são os parâmetros observados, enquanto T, G e M são os parâmetros da isócrona. É importante notar que na equação 3.12 a soma foi realizada sobre um intervalo de isócronas de idade e limitada aos pontos da isócrona dentro de um raio de 3 vezes o erro ao redor dos parâmetros observados. Incluindo pontos de isócronas mais distantes destes limites não têm impacto significativo sobre o resultado final. Um formalismo semelhante é usado para determinar a massa.

A idade e massa mais prováveis são obtidas dos picos das distribuições, enquanto 1 sigma e 2 sigma são os limites superiores e inferiores que podem ser derivados a partir da forma da distribuição de probabilidade.

A luminosidade também é estimada a partir de:

$$
\log \frac{L}{L_{\odot}}=\log \left(\frac{M}{M_{\odot}}\right)-(\log g-4.44)+4 \log \left(\frac{T_{\text {eff }}}{5777}\right),
$$

e o raio através de:

$$
R=\left(\frac{L}{4 \pi \sigma T_{e f f}^{4}}\right)^{1 / 2}
$$

Usando o código $\mathrm{q}^{2}$, a idade, massa, luminosidade, magnitude absoluta e raio foram determinadas para ambas gêmeas solares (ver Figura 3.12).

Os resultados mostram uma massa de $1.05 \mathrm{M}_{\odot}$ e $1.04 \mathrm{M}_{\odot}$ e uma idade de 3 Gyr e 4 Gyr para HD 45184 e Inti 1, respectivamente (ver Figura 3.13). A massa e idade de HD 45184 estão em excelente acordo com as médias encontradas na literatura (ver Tabela 3.2). Note que as grades dos modelos estelares de Yonsei-Yale não incluem non-standard physics, como incluídas nos estudos de depleção do lítio do Nascimento et al., 2009, Denissenkov, 2010 Li et al. 2012). Para testar se as isócronas calculadas com non-standard physics podem causar algum efeito, realizei um teste para a gêmea solar 18 Sco, que foi analisada usando os modelos non-standard por Li et al. (2012), que determinaram uma massa e idade de $1.04 \pm 0.03 \mathrm{M}_{\odot}$ e $3.11_{-2.56}^{+2.08} \mathrm{Gyr}$, enquanto nesta dissertação encontrei valores praticamente idênticos: $1.04_{-0.02}^{+0.01} \mathrm{M}_{\odot}$ e $3.10_{-1.01}^{+1.10}$ Gyr. Além disso, Meléndez et al. (2014) mostraram que a escolha exata de uma isócrona não tem um impacto importante para a determinação da massa e idade em relação ao Sol. 
HD 45184
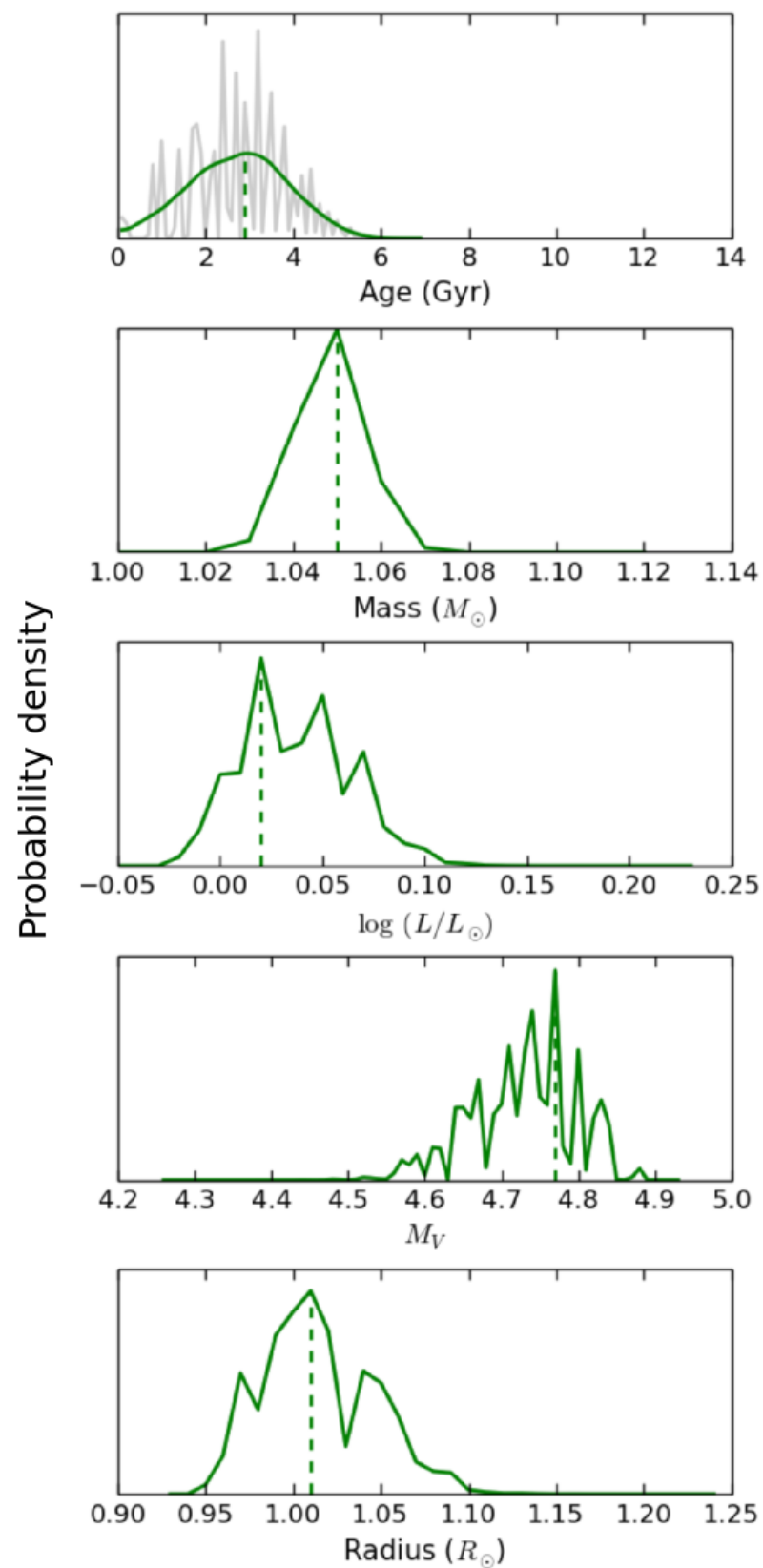

Inti 1
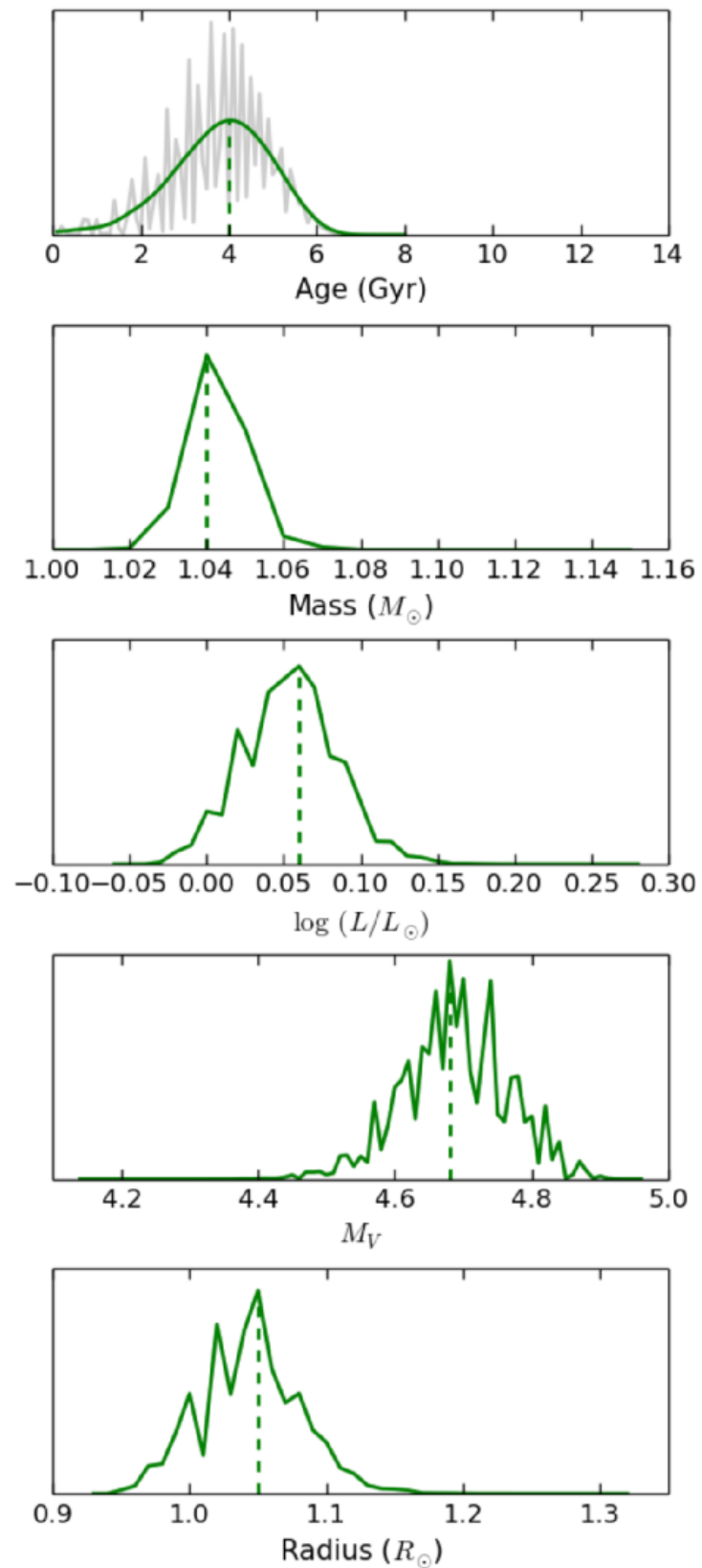

Figura 3.12: Estimativas da idade, massa, luminosidade, magnitude absoluta e raio para as gêmeas solares HD 45184 e Inti 1. As linhas pontilhadas representam os resultados mais prováveis. 

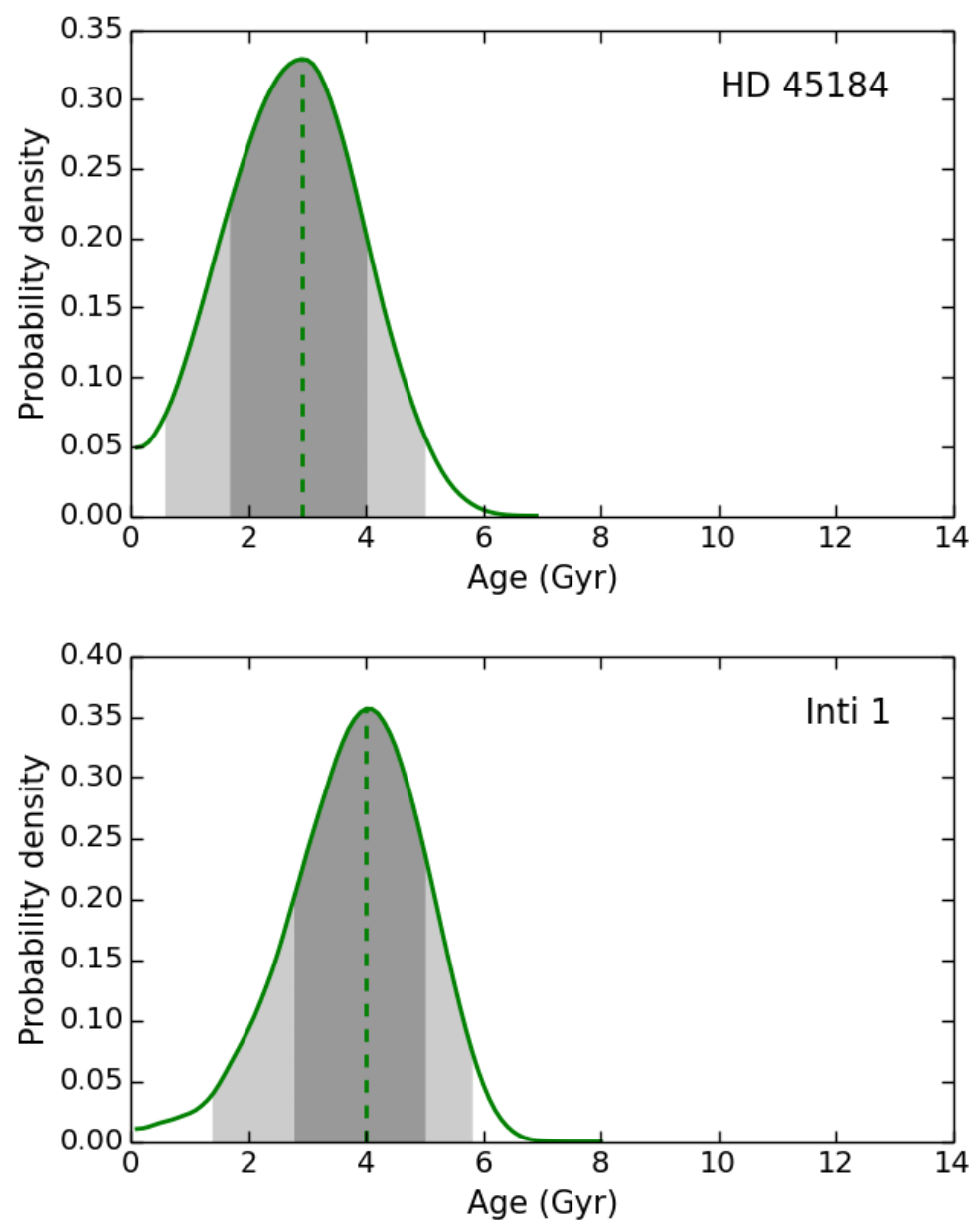

Figura 3.13: Distribuição de probabilidade da idade de HD 45184 (painel superior) e Inti 1 (painel inferior). As linhas pontilhadas representam a idade mais provável. As diferentes regiões representam \pm 1 sigma e \pm 2 sigma de incerteza.

Para reforçar os resultados, também estimei as idades das gêmeas solares empregando a relação [Y/Mg] (Nissen, 2015):

$$
[\mathrm{Y} / \mathrm{Mg}]=0.175( \pm 0.011)-0.0404( \pm 0.0019) \times \text { Age }[\mathrm{Gyr}]
$$

Usando a equação 3.15, as idades estimadas para as gêmeas solares HD 45184 e Inti 1 foram de $3.7 \pm 0.6$ Gyr e $4.1 \pm 0.6$ Gyr, respectivamente. Estes resultados estão de acordo com as idades isocronais calculadas usando o código $\mathrm{q}^{2}$.

\subsection{Metodologia para a determinação da massa rochosa faltante}

Meléndez et al. (2009) descobriram um padrão peculiar nas abundâncias das gêmeas solares em relação ao Sol; eles observaram que o Sol é mais abundante em elementos 


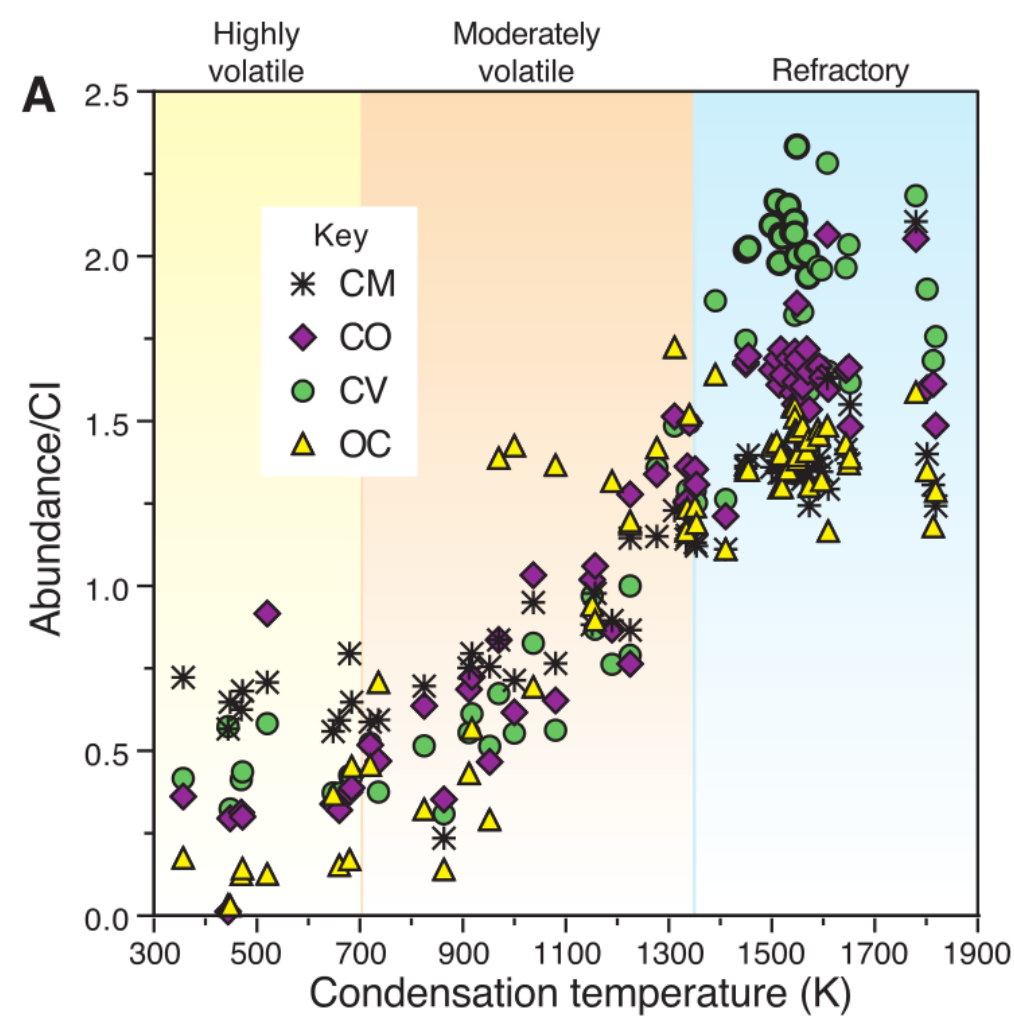

Figura 3.14: Abundâncias normalizadas dos condritos CI carbonáceos (CM, CO e CV) e condritos ordinários (OC) em relação a sua temperatura de condensação. Note que os elementos estão divididos em refratários $(>1500 \mathrm{~K})$, moderadamente voláteis (entre 700 e $1350 \mathrm{~K}$ ) e altamente voláteis $(<700 \mathrm{~K})$. Fonte: Alexander et al. (2001).

voláteis do que os elementos refratários (seção 1.2). Eles argumentaram que esse padrão de abundâncias químicas é devido a que certa massa dos elementos refratários foi usada para formar os planetas de tipo terrestre. Essa massa dos elementos refratários faltante no Sol (zona convectiva) é da mesma ordem de grandeza que a massa dos planetas rochosos no Sistema Solar.

É sabido que os objetos que estão nas regiões internas do Sistema Solar, tais como os meteoritos e os planetas de tipo rochoso são ricos em elementos refratários quando são comparados com os elementos voláteis (Palme, 2000). O padrão de abundâncias destes objetos são aproximadamente constantes até os $1000 \mathrm{~K}$, no entanto aumentam acentualmente para temperaturas maiores a $1000 \mathrm{~K}$ (Alexander et al., 2001), como mostrado na Figura (3.14).

Nesta seção detalharei o cálculo realizado para determinar os padrões de abundâncias das gêmeas solares HD 45184 e Inti 1, e por conseguinte estimar a massa faltante nas suas 


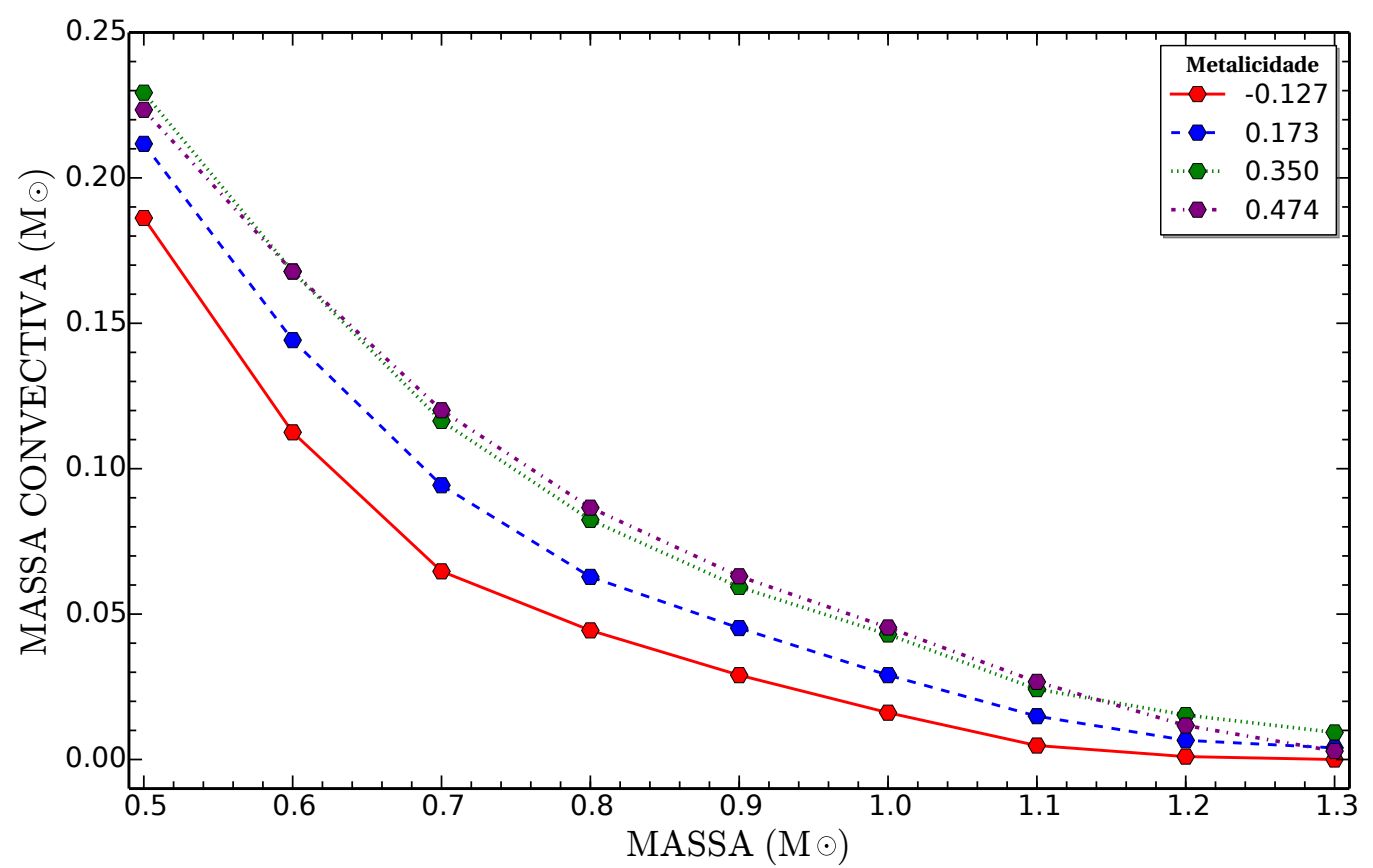

Figura 3.15: Variação da massa estelar em relação a sua massa convectiva e metalicidade usando os modelos de evolução estelar de Siess et al. (2000).

zonas convectivas seguindo o procedimento de Chambers (2010) (ver Figura 1.13).

\subsubsection{Massa convectiva}

As massas convectivas das gêmeas solares foram estimadas usando os modelos de evolução estelar de Siess et al. (2000). Estes modelos apresentam grades da pré-sequência principal para estrelas com massas entre $0.1 \mathrm{M}_{\odot}$ e $7.0 \mathrm{M}_{\odot}$, para quatro metalicidades $(\mathrm{Z}$ $=0.01,0.02,0.03$ e $0.04 \mathrm{dex})$.

O código de Siess et al. (2000) determina o caminho evolutivo de uma estrela no diagrama Hertzsprung-Russell (HR), fornecendo informação sobre a estrutura interna, e em particular sobre a camada convectiva. A composição solar adotada nesta dissertação é de Asplund et al. (2009), cujos valores são: $Z_{\odot}=0.0134, \mathrm{Y}=0.2485$ e $\mathrm{X}=0.7381$. Não obstante a metalicidade solar adotada por Siess et al. (2000) é $Z_{\odot}=0.02$. Por conseguinte, as metalicidades foram transformadas usando:

$$
\left[\frac{\mathrm{Fe}}{\mathrm{H}}\right]=\log _{10}\left(\frac{Z}{Z_{\odot}}\right) .
$$

Para o cálculo da massa convectiva, foi usada uma grade com massas entre 0.5 e 1.3 $\mathrm{M}_{\odot}$, com metalicidades $[\mathrm{Fe} / \mathrm{H}]$ de $-0.13,0.17,0.35$ e 0.47 dex (usando a equação 3.16). 
Tabela 3.5 - Parâmetros fundamentais de Inti 1

\begin{tabular}{cc}
\hline \hline Inti 1 & Parâmetro \\
\hline$T_{\text {eff }}$ & $5837 \pm 11 \mathrm{~K}$ \\
$\log g$ & $4.42 \pm 0.03 \mathrm{dex}$ \\
{$[\mathrm{Fe} / \mathrm{H}]$} & $0.07 \pm 0.01 \mathrm{dex}$ \\
$v_{t}$ & $1.04 \pm 0.02 \mathrm{kms}^{-1}$ \\
Massa & $1.04_{-0.08}^{+0.01} \mathrm{M}_{\odot}^{* *}$ \\
Distância & $390 \pm 36 \mathrm{pc}^{*}$ \\
Massa convectiva & $0.019 \mathrm{M}_{\odot}^{* * *}$ \\
Idade & $4.00_{-1.26}^{+1.00} \mathrm{Gyr}^{* *}$ \\
logL & $0.06 \pm 0.032 \mathrm{~L}_{\odot}^{* *}$ \\
$M_{V}$ & $4.68_{-0.07}^{+0.08} \mathrm{mag}^{* *}$ \\
Raio & $1.05 \pm 0.04 \mathrm{R}_{\odot}^{* *}$ \\
\hline \hline
\end{tabular}

Notas:

* O erro de módulo de distância foi estimado assumindo uma incerteza de 0.2 mags.

** Usando o código q2.

*** Usando os código terra.

A variação da zona convectiva é mostrada na Figura 3.15. Para sistematizar o cálculo, desenvolvi um código na linguagem Python nomeado terra ${ }^{11}$, que estima a massa convectiva de uma estrela fazendo uma dupla interpolação entre a massa, metalicidade e a massa convectiva, com os valores obtidos dos modelos teóricos de Siess et al. (2000). Usando o código terra a massa convectiva do Sol foi estimada em $0.020 \mathrm{M}_{\odot}$, que está em acordo com outros modelos que calculam uma massa convectiva de $0.023 \mathrm{M}_{\odot}$. O código é apresentado no apêndice B.0.1. Na Tabela 3.5 são apresentados os parâmetros estelares para a gêmea solar fraca Inti 1 obtidos usando os códigos $\mathrm{q}^{2}$ e terra.

\subsubsection{Massa rochosa faltante}

Adotando as abundâncias de Asplund et al. (2009) para a composição química do Sol $\left(\mathrm{A}_{\odot}\right)$, e usando a metalicidade $([\mathrm{Fe} / \mathrm{H}])$ da estrela, é possível estimar a massa do material rochoso faltante na zona convectiva de uma estrela de tipo solar. Para tal fim, primeiro calculei a massa de cada elemento, que é dada por:

$$
\left.\mathrm{X}_{\text {conv_mass }}=\mathrm{A} \times 10^{(\mathrm{A} \odot}+[\mathrm{Fe} / \mathrm{H}]\right),
$$

\footnotetext{
11 terra é um código livre, e está disponível em https://github.com/ramstojh/terra
} 


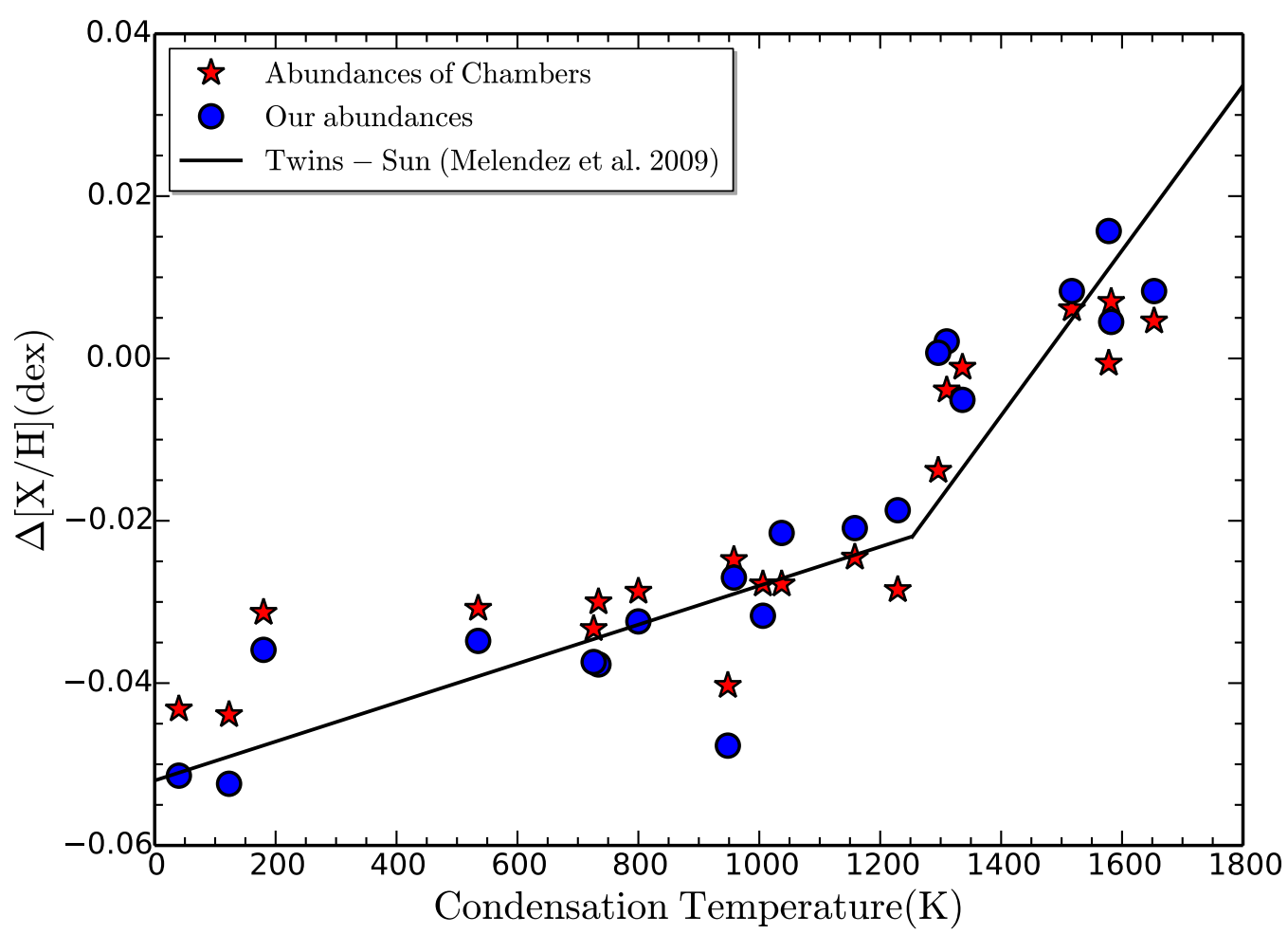

Figura 3.16: Composição da fotosfera solar adicionando $4 \mathrm{M}_{\oplus}$ de uma mistura de material rochoso (terrestre mais meteorítica) à zona convectiva do Sol. As abundâncias de Chambers (2010) e as estimadas nesta dissertação são representadas por estrelas vermelhas e círculos azuis, respectivamente.

onde A é o peso atômico. A massa convectiva de cada elemento é dada por:

$$
\text { Convective }_{\text {mass }}=\mathrm{M}_{\text {conv }} \times \mathrm{M}_{\odot} \times \frac{\mathrm{X}_{\text {conv_mass }}}{\sum \mathrm{X}_{\text {conv_mass }}}
$$

onde $\mathrm{M}_{\text {conv }}$ é a massa convectiva do Sol. Para calcular a massa com composição meteorítica, adotei as abundâncias de Wasson e Kallemeyn (1988) como composição de condritos, e para a massa com composição química terrestre as de Allègre et al.(2001). A massa meteorítica e terrestre podem ser escritas:

$$
\begin{aligned}
\text { Meteoritic }_{\text {mass }} & =\mathrm{M}_{\oplus} \times \frac{\mathrm{X}_{\text {met_mass }}}{\sum \mathrm{X}_{\text {met_mass }}} \\
\text { Terrestrial } & \\
\text { mass } & =\mathrm{M}_{\oplus} \times \frac{\mathrm{X}_{\text {terr_mass }}}{\sum \mathrm{X}_{\text {terr_mass }}},
\end{aligned}
$$

onde $\mathrm{X}_{\text {met_mass }}$ e $\mathrm{X}_{\text {terr_mass }}$ são as massas de cada elemento em massas terrestres. A massa de um dado elemento no envelope convectivo, necessária para explicar a diferença de abundância observada, é dada por:

$$
\Delta M=\log \left(\frac{\text { Convective }_{\text {mass }}+M_{\text {rock }}}{\text { Convective }_{\text {mass }}}\right),
$$


onde $M_{\text {rock }}$ é a massa do material rochoso faltante e que é dado por $M_{\text {rock }}=\alpha \times$ Meteoritical $_{\text {mass }}+\beta \times$ Terrestrial $_{\text {mass }}$, onde $\alpha$ e $\beta$ estão em unidades de massas terrestres. O código terra realiza todos os cálculos acima para os coeficientes $\alpha$ e $\beta$, e mostra os resultados em função da temperatura de condensação.

Para verificar o resultado, na Figura (3.16) é apresentado o cálculo de Chambers (2010) acrescentando uma mistura de $2 \mathrm{M}_{\oplus}$ massas de material tipo Terra e $2 \mathrm{M}_{\oplus}$ massas de material condrítico. As abundâncias estimadas nesta dissertação são representadas por círculos azuis, enquanto as abundâncias de Chambers (2010) por estrelas de cor vermelha. O resultado obtido com o meu código terra concorda bem com os cálculos de Chambers (2010), que usou a mesma composição meteorítica que eu adotei. Não obstante, para as abundâncias terrestres ele adotou uma referência mais antiga (Waenke e Dreibus, 1988). É importante notar que os meus resultados ajustam melhor os elementos voláteis do que os de Chambers (2010).

\subsection{Padrão de abundâncias e resultados}

Uma comparação entre o padrão de abundâncias químicas da gêmea solar HD 45184 estimadas neste trabalho e as determinadas por Nissen (2015) é mostrada na Figura 3.17. É importante notar que os meus resultados concordam muito bem dentro dos erros com os de Nissen (2015). Na Figura 3.18 são mostradas as abundâncias diferenciais normalizadas ao carbono para a gêmea solar HD 45184 (painel superior) e a Inti 1 (painel inferior) como uma função da temperatura de condensação (Lodders, 2003). O padrão químico de HD 45184 segue o padrão de abundâncias do ajuste da média das 11 gêmeas solares estudadas por Meléndez et al. (2009), como mostrado pelas linhas pontilhadas após de um deslocamento vertical. Inti 1 tem um padrão de abundâncias similar ao do Sol, embora ligeiramente rica em elementos refratários. Os deslocamentos entre os elementos refratários e voláteis de HD 45184 e Inti 1 são 0.076 dex e 0.025 dex, respectivamente.

Seguindo Chambers (2010) e usando o código terra, estimei a massa de material rochoso necessário para reproduzir o padrão de abundâncias de HD 45184 e Inti 1. Os resultados mostram um valor de $3.5 \pm 1.0 \mathrm{M}_{\oplus}$ de elementos refratários usando uma mistura de material terrestre e condrítica para $\mathrm{HD} 45184$, e $1.5 \pm 1.0 \mathrm{M}_{\oplus}$ para Inti 1. Estes padrões são representados por triângulos azuis na Figura 3.18 . 


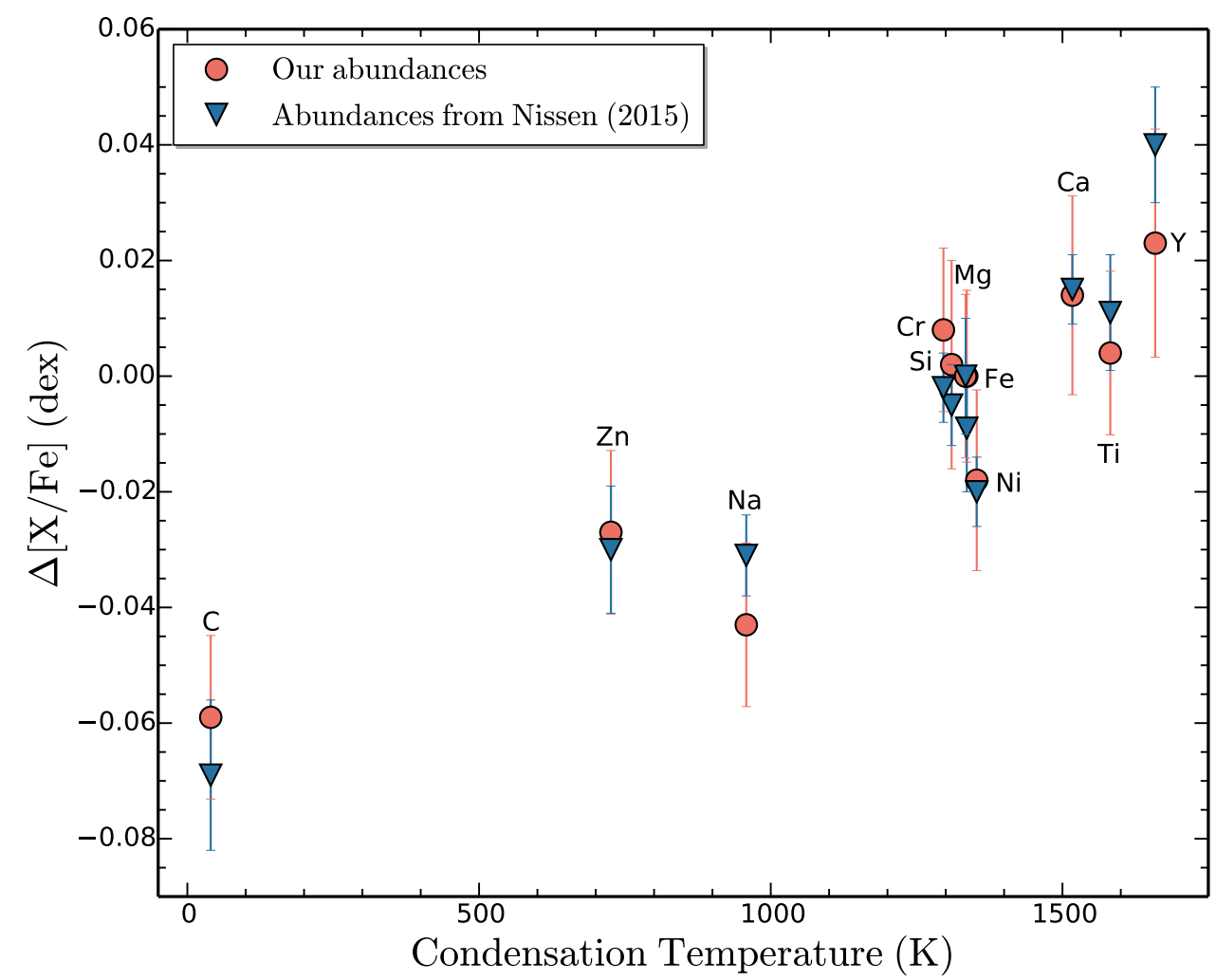

Figura 3.17: Comparação entre as abundâncias determinadas nesta dissertação e as de Nissen (2015), em função da temperatura de condensação (Lodders, 2003).

É importante notar que o código terra adota o carbonáceo CM como material condrítico devido a que representa melhor a composição do cinturão de asteróide (Wasson e Kallemeyn, 1988). No entanto, terra oferece a escolha dos diferentes tipos de carbonáceos CI, CM, CO e CV. Uma comparação entre estes carbonáceos é apresentada na Figura 3.19 . A média de abundâncias das 11 gêmeas solares estudadas por Meléndez et al. (2009) é representada pela linha preta sólida, após um deslocamento vertical.

O melhor ajuste é dado pelos carbonáceos CM (círculos azuis), enquanto os carbonáceos CI (triângulos) ajustam apenas os elementos refratários. Os carbonáceos CV (quadrados de cor verde) mostram um bom ajuste dos elementos voláteis e os carbonáceos CO (estrelas de cor púrpura) são mal ajustados para quase toda a linha. O padrão de abundâncias da Figura 3.19 foi estimado usando o código terra adicionando $2 \mathrm{M}_{\oplus}$ de material com composição da Terra e $2 \mathrm{M}_{\oplus}$ com composição carbonácea à zona convectiva $\left(0.02 \mathrm{M}_{\odot}\right)$ do Sol. Foram usados 56 elementos entre voláteis e refratários. 


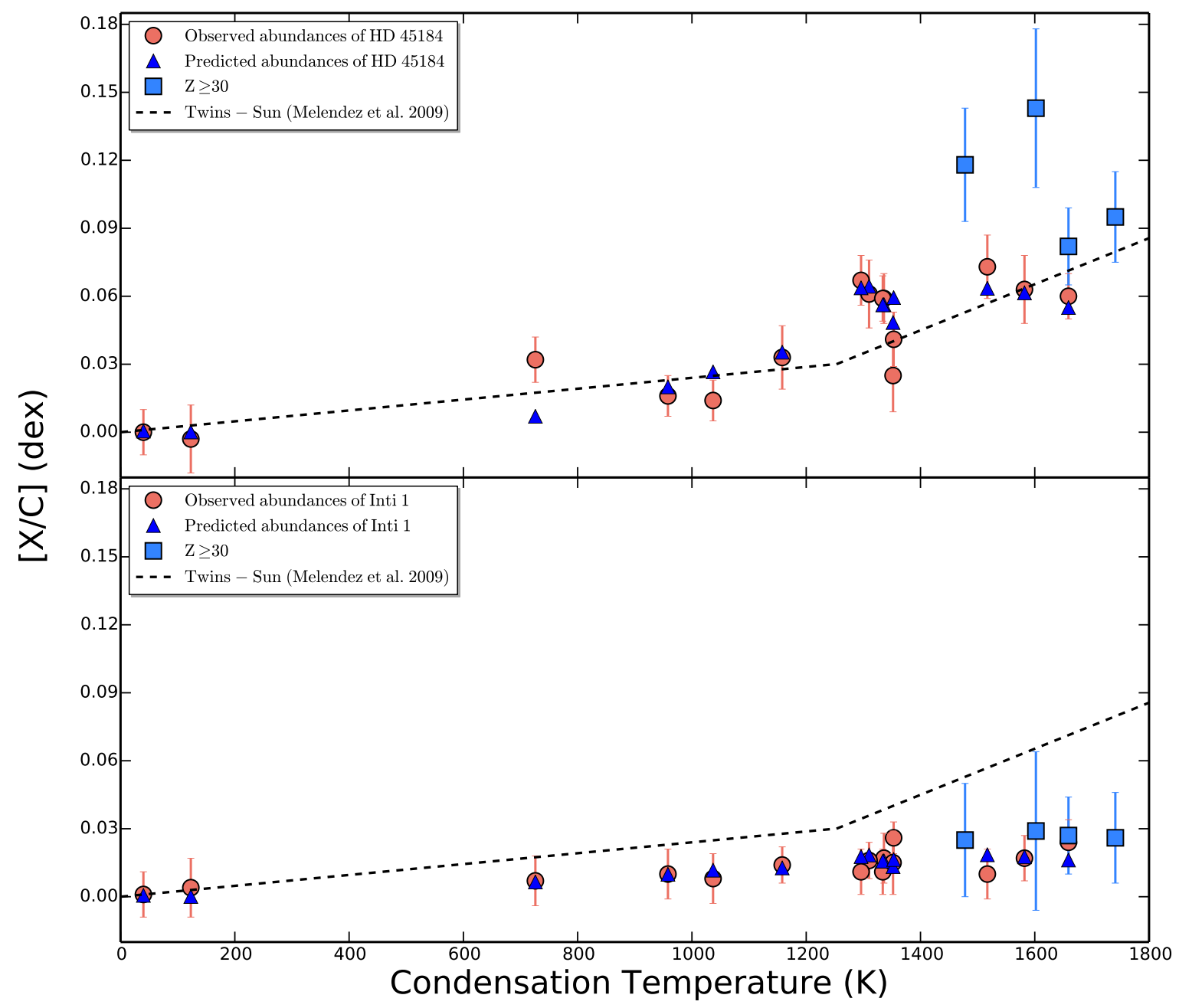

Figura 3.18: Painel superior: Padrão de abundância de HD 45184 (círculos vermelhos) em relação à temperatura de condensação. O padrão químico de HD 45184 (triângulos azuis) foi determinado adicionando $3.5 \mathrm{M}_{\oplus}$ de material rochoso à zona convectiva do Sol. Painel inferior: A razão de abundâncias diferenciais de Inti 1 (círculos vermelhos) relativa ao Sol em função da temperatura de condensação. A média do padrão de abundância das 11 gêmeas solares estudadas por Meléndez et al. (2009) é representada pela linha pontilhada. O padrão de abundâncias de Inti 1 (triângulos azuis) foi determinado adicionando $1.5 \mathrm{M}_{\oplus}$ de material rochoso à zona convectiva do Sol. Os elementos de captura de nêutrons são representados por quadrados em ambos painéis. 


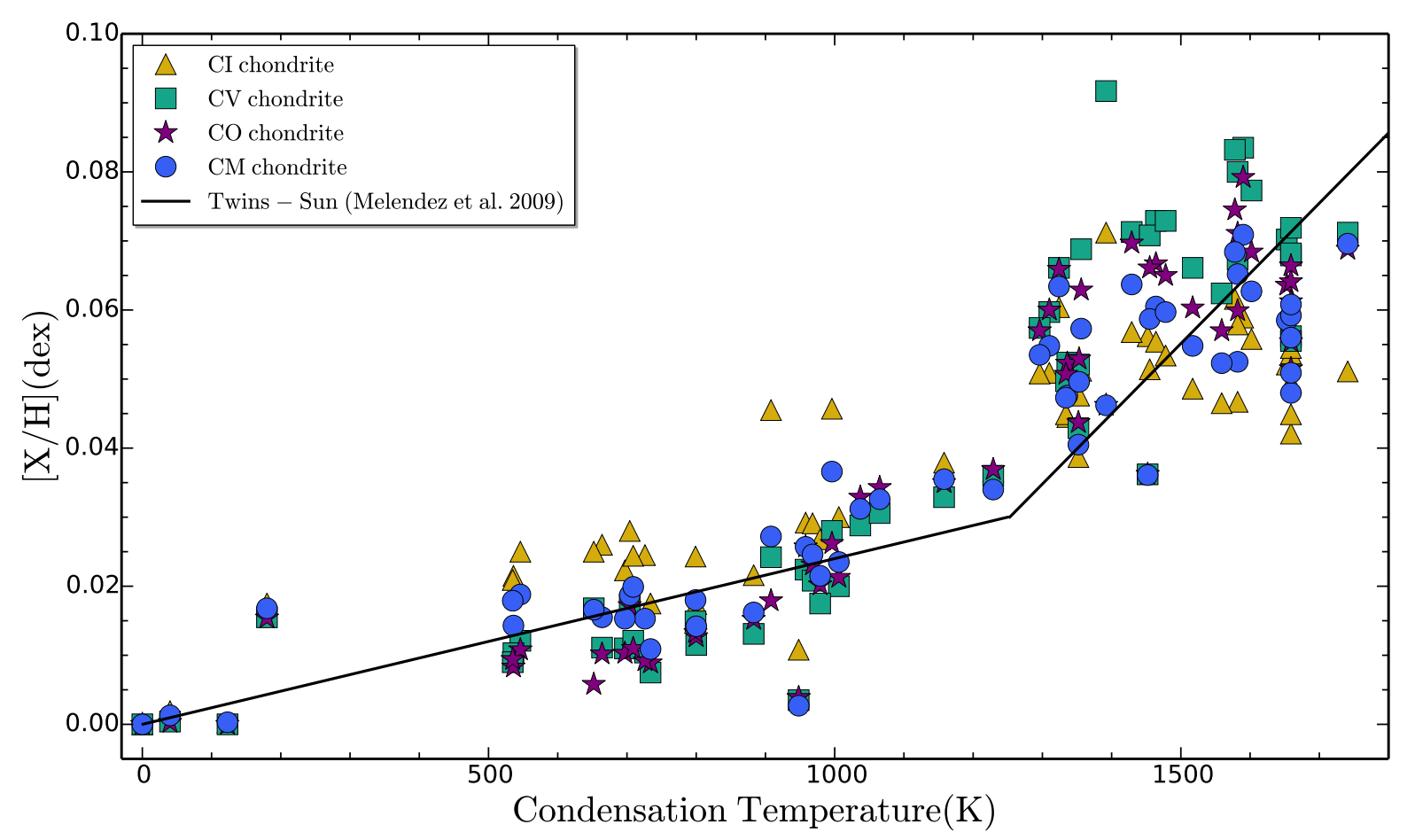

Figura 3.19: Comparação entre os 4 tipos de carbonáceos (CI, CV, CO e CM) em função da temperatura de condensação, para o padrão de abundâncias de Meléndez et al. (2009), representada pela linha. A massa meteorítica adoptada é $2 \mathrm{M}_{\oplus}$, e a massa de composição terrestre é $2 \mathrm{M}_{\oplus}$.

\subsection{Conclusões}

Os parâmetros atmosféricos determinados em relação ao Sol para HD 45184 são $T_{\text {eff }}=$ $5864 \pm 9 \mathrm{~K}, \log g=4.45 \pm 0.03 \mathrm{dex}, v_{t}=1.11 \pm 0.02 \mathrm{kms}^{-1} \mathrm{e}[\mathrm{Fe} / \mathrm{H}]=0.04 \pm 0.01 \mathrm{dex}$ e para a Inti 1 são $T_{\text {eff }}=5837 \pm 11 \mathrm{~K}, \log g=4.42 \pm 0.03 \mathrm{dex}, v_{t}=1.04 \pm 0.02 \mathrm{kms}^{-1}$ e $[\mathrm{Fe} / \mathrm{H}]=0.07 \pm 0.01$ dex. Estes resultados indicam que Inti 1 é uma gêmea solar fraca (Ramírez et al., 2009). Na Tabela 3.1, mostrei que as cores de Inti 1 são idênticas às do Sol dentro dos erros. Assim, a gêmea solar fraca Inti 1 e a gêmea solar distante encontrada por do Nascimento et al. (2013) poderiam ser usadas para calibrar diferentes sistemas fotométricos ou para subtrair a luz solar refletida em asteroides.

As abundâncias de HD 45184 mostram um excelente acordo com o trabalho de Nissen (2015) indicando que atingimos uma precisão de 0.01 dex. HD 45184 e Inti 1 apresentam enriquecimento nos elementos refratários em relação aos elementos voláteis, com um deslocamento de 0.076 dex e 0.025 dex, respetivamente. Isso demonstra que anomalias químicas também são encontradas quando o Sol é comparado com gêmeas solares distantes, não obstante o enriquecimento refratário de Inti 1 é menor do que a gêmea solar local 
HD 45184. Usando o código terra e os modelos teóricos de Siess et al. (2000), estimei a massa do material rochoso necessário para reproduzir o padrão de abundâncias de HD $45184\left(\approx 3.5 \mathrm{M}_{\oplus}\right)$ e Inti $1\left(\approx 1.5 \mathrm{M}_{\oplus}\right)$.

A abundância de lítio (linha em $6708 \AA$ ) não foi determinada devido à cobertura espectral limitada (3190-5980 ^) das observações. 
Capítulo 4

\section{Análise de alta precisão da gêmea solar HIP 100963}

\subsection{Estudos prévios de HIP 100963}

HIP 100963 foi uma das 118 análogas solares observadas por Takeda et al. (2007). Estes autores determinaram parâmetros estelares, velocidade rotacional, abundância de lítio, luminosidade, massa e idade. Estes dois últimos parâmetros foram estimados comparando a posição da luminosidade $(\mathrm{L})$ e a temperatura efetiva $\left(T_{\text {eff }}\right)$ no diagrama HertzprungRussell; o resultado desta comparação indicou um valor de aproximadamente 5 Gyr. Também concluíram que HIP 100963 tem parâmetros estelares bastante similares ao Sol, descobrindo assim a terceira gêmea solar. Dois anos depois, Takeda e Tajitsu (2009) obtiveram os parâmetros estelares de HIP 100963 com maior precisão. Estes resultados mostram uma maior temperatura $(+40 \mathrm{~K})$ e abundância de lítio $(+0.7$ dex $)$ em relação ao do Sol. Também analisaram as linhas de Be II (3130.42 A e $3131.07 \AA)$ e concluíram que a sua abundância de Be presumivelmente é semelhante à do Sol dentro de 0.1 dex ${ }^{1}$,

do Nascimento et al. (2009) determinaram a idade e a massa de HIP 100963 empregando o código de evolução estelar de Toulouse-Geneva (Hui-Bon-Hoa, 2008), usando os parâmetros estelares obtidos por Takeda et al. (2007) e Takeda e Tajitsu (2009). Seus resultados estão em acordo com a massa estimada por Takeda et al. (2007), não obstante a idade é 3 Gyr, que é consideravelmente menor do que o valor determinado por Takeda et al. (2007) usando parâmetros estelares menos precisos. Posteriormente, Isaacson e Fischer (2010) estimaram uma idade de 1.7 Gyr usando um indicador de atividade cromosférica.

\footnotetext{
${ }^{1}$ Notar que não foram dadas as abundâncias do Be, apenas há uma comparação qualitativa entre o espectro observado e o sintético.
} 
Em trabalhos recentes baseados em espectroscopia de estrelas de tipo solar superflares, Notsu et al. (2015a) executaram observações de espectroscopia de alta dispersão para uma amostra de 50 estrelas de tipo solar e 8 gêmeas solares; entre a amostra encontrase HIP 100963. Eles determinaram os parâmetros estelares de HIP 100963 (ver Tabela 4.1) segundo a metodologia de Takeda et al. (2005). A velocidade rotacional, atividade cromosférica (Notsu et al., 2015b) e a abundância de lítio (Honda et al., 2015) também foram estimadas pelo mesmo grupo.

Neste capítulo, determinarei os parâmetros estelares de HIP 100963 com alta precisão, para obter a sua massa e idade, e desta forma esclarecer seu estado evolutivo. Também estimarei as abundâncias químicas de 27 elementos e investigarei as possíveis assinaturas de planetas, evolução estelar e evolução química da Galáxia (GCE), para explicar o padrão de abundâncias químicas desta gêmea solar.

\subsection{Observação e redução de dados}

O espectro de HIP 100963 e o Sol (usando luz solar refletida no asteroide Iris) foram obtidos usando o espectrógrafo HIRES (Vogt et al., 1994) do telescópio Keck I de 10 metros de diâmetro no Observatório W. M. Keck, no Havaí. As observações foram realizadas pelo Professor Jorge Meléndez e Fan Liu (Australian National University) em 13 de Agosto de 2013, com tempos de exposição de 180 s para HIP 100963 e 720 s para Iris. A cobertura de comprimento de onda destes espectros está na região entre 3940 e $8350 \AA$, usando um mosaico de três CCDs otimizados nas regiões do azul, verde e vermelho. A largura da fenda foi de 0.57 segundos de arco, dando assim um poder de resolução espectral de $\mathrm{R}=\lambda / \Delta \lambda=70000$ (3.2 pixeis por elemento de resolução). Os espectros têm uma alta razão sinal ruído (S/R); na região de $\sim 6000 \AA$ é aproximadamente 400 pixel $^{-1}$ para HIP 100963, enquanto para o Sol é 650 pixel $^{-1}$.

A redução do espectro e a normalização do contínuo foi realizada de modo igual que para a gêmea solar fraca Inti 1 (seção 3.1). Parte dos espectros reduzidos de HIP 100963 e o asteroide Iris são mostrados na Figura 4.1. 


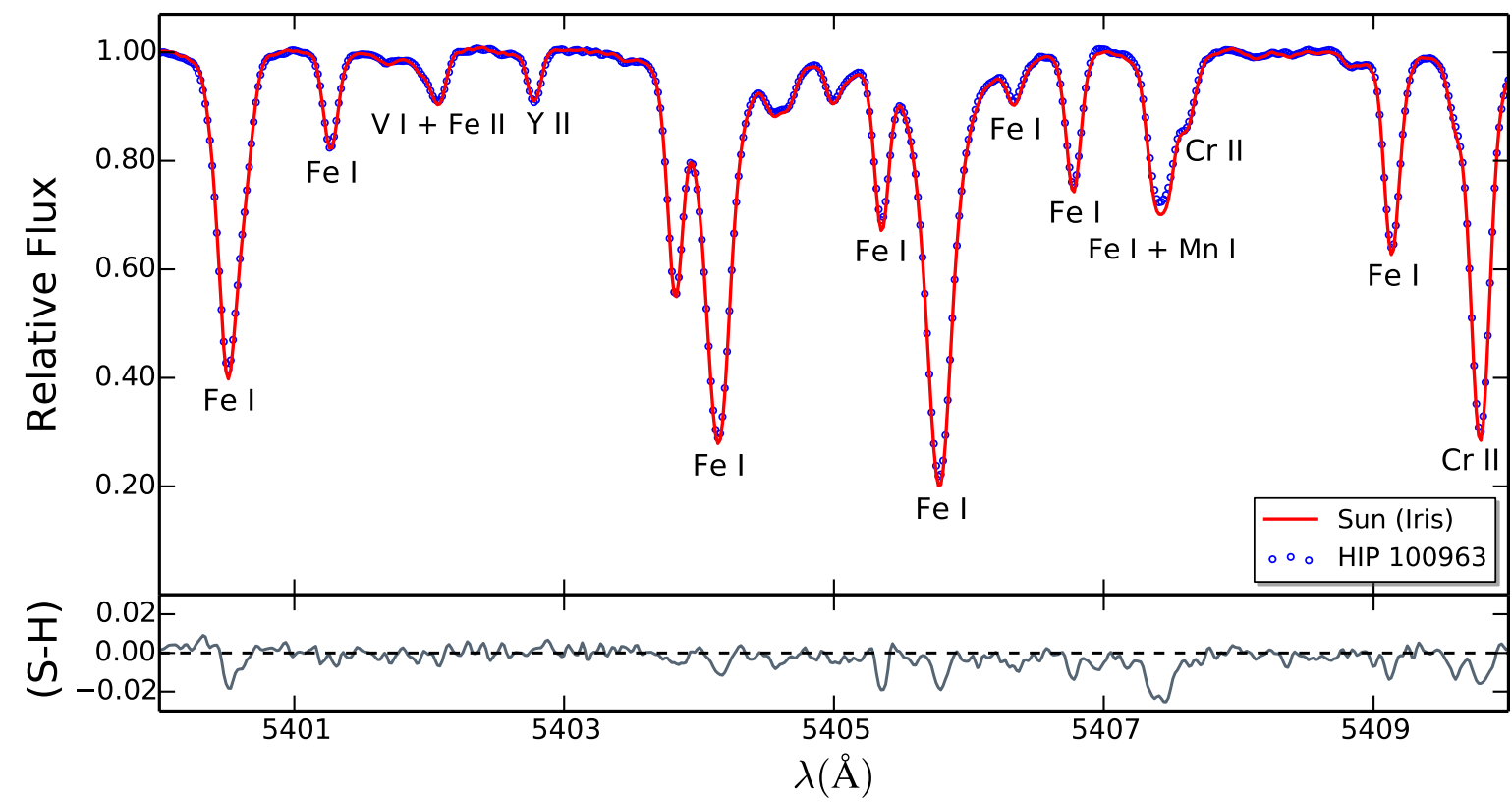

Figura 4.1: Espectro HIRES de HIP 100963 (círculos azuis) e o Sol (linha sólida vermelha) na faixa entre 5400 e 5410 Å. Os resíduos entre o Sol e HIP 100963 (S-H) são exibidos no painel inferior.

\subsection{Análise de abundâncias}

\subsubsection{Parâmetros estelares}

A análise é baseada no método diferencial (ver seção 2.10). As larguras equivalentes (EWs) foram medidas manualmente usando a tarefa splot do pacote IRAF, ajustando os perfis com gaussianas (ver seção 2.6 e 3.5). As regiões de pseduo-contínuo foram escolhidas segundo Bedell et al. (2014), em intervalos de $6 \AA$ (p. ex. ver seção 3.5.

Para determinar os parâmetros atmosféricos e as abundâncias químicas, usei o modelo de atmosfera de Kurucz ODFNEW (Castelli e Kurucz, 2004) e a versão 2014 do código MOOG (Sneden, 1973). Determinei as abundâncias elementais do Sol adotando parâmetros estelares padrões: $T_{\text {eff }}=5777 \mathrm{~K}, \log g=4.44 \operatorname{dex}(\operatorname{Cox}, 2000)$ e $v_{t}=1.00 \mathrm{~km} \mathrm{~s}^{-1}$, como realizado em Ramírez et al. (2014). Foi empregado o equilíbrio espectroscópico diferencial2 para HIP 100963 em relação ao Sol (ver Figura 4.2), obtendo como resultado os seguintes parâmetros atmosféricos: $T_{\text {eff }}=5818 \mathrm{~K}, \log g=4.49 \mathrm{dex}, v_{t}=1.03 \mathrm{~km} \mathrm{~s}^{-1}$, e $[\mathrm{Fe} / \mathrm{H}]=-0.003$ dex. Os erros dos parâmetros estelares foram determinados seguindo

\footnotetext{
${ }^{2} \mathrm{O}$ equilíbrio espectroscópico é atingido quando o equilíbrio de excitação, equilíbrio de ionização e a
} não dependência do diferencial de ferro com a largura equivalente reduzida $(\mathrm{EW} / \lambda)$ é satisfeito (ver seção 2.11 . 


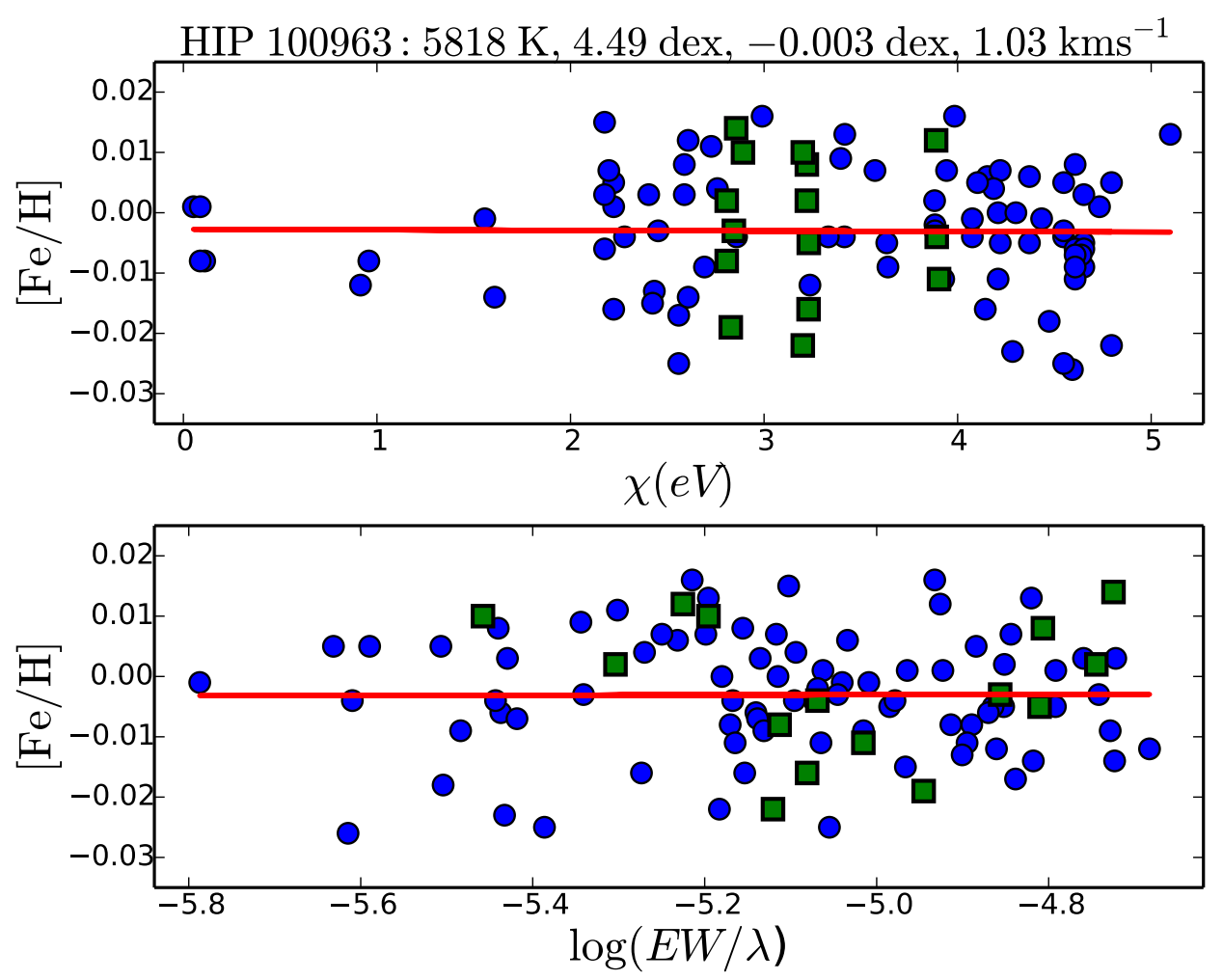

Figura 4.2: Abundância diferencial de HIP 100963 em relação ao Sol em função do potencial de excitação (painel superior) e largura equivalente reduzida (painel inferior). Em ambas figuras os círculos azuis representam o Fe I, os quadrados verdes o Fe II e a linha sólida vermelha o ajuste.

Epstein et al. (2010) e Bensby et al. (2014). Estes erros são provenientes das incertezas e degenerescências nos parâmetros estelares (ver seção 2.12). Foi atingida uma altíssima precisão nos parâmetros atmosféricos para este objeto: $\sigma\left(T_{\text {eff }}\right)=4 \mathrm{~K}, \sigma(\log g)=0.012$ dex, $\sigma\left(v_{t}\right)=0.01 \mathrm{~km} \mathrm{~s}^{-1}$ e $\sigma([\mathrm{Fe} / \mathrm{H}])=0.004$ dex. Na Tabela 4.1 são mostradas as comparações entre os parâmetros estelares obtidos nesta dissertação e estudos anteriores, verificando-se um bom acordo entre estes.

Para determinar a $T_{\text {eff }}$ fotométrica, procurou-se as cores de HIP 100963 usando a base de dados de VIZIER ${ }^{3}$. As magnitudes $\mathrm{V}, \mathrm{B} \mathrm{I}_{\mathrm{C}}$ e $\mathrm{R}_{\mathrm{C}}$ foram adotadas de Ramírez et al. (2012) e as magnitudes $\mathrm{V}_{T}, \mathrm{~B}_{T}, \mathrm{~J}_{2}, \mathrm{H}_{2}, \mathrm{~K}_{2}$ de Pickles e Depagne (2010); Høg et al. (2000), enquanto as magnitudes $b$ e $y$ de Paunzen (2015). A $T_{\text {eff }}$ fotométrica foi estimada em 5804 $\pm 62 \mathrm{~K}$ e está em excelente acordo com a $T_{\text {eff }}$ estimada neste trabalho $(5818 \pm 4 \mathrm{~K})$. As cores de HIP 100963 e seus respectivos valores de $T_{\text {eff }}$ são mostrados na Tabela. 4.2.

A gravidade superficial também foi estimada seguindo o método trigonométrico (seção 2.1. equação 2.9. Os parâmetros estelares usados para HIP 100963 são: massa $=1.03 \pm$

\footnotetext{
${ }^{3}$ http://vizier.u-strasbg.fr
} 
Tabela 4.1 - Comparação dos parâmetros atmosféricos da gêmea solar HIP 100963

\begin{tabular}{lrrrrrrrl}
\hline \hline $\begin{array}{l}T_{\text {eff }} \\
(\mathrm{K})\end{array}$ & $\begin{array}{r}\text { erro } \\
(\mathrm{K})\end{array}$ & $\begin{array}{r}\log g \\
(\mathrm{dex})\end{array}$ & $\begin{array}{r}\text { erro } \\
(\mathrm{dex})\end{array}$ & $\begin{array}{r}{[\mathrm{Fe} / \mathrm{H}]} \\
(\mathrm{dex})\end{array}$ & $\begin{array}{r}\text { erro } \\
(\mathrm{dex})\end{array}$ & $\begin{array}{r}v_{t} \\
\left(\mathrm{kms}^{-1}\right)\end{array}$ & $\begin{array}{r}\text { erro } \\
\left(\mathrm{kms}^{-1}\right)\end{array}$ & Fonte \\
\hline 5818 & 4 & 4.49 & 0.01 & -0.003 & 0.004 & 1.03 & 0.01 & Este trabalho, espectroscópico. \\
5775 & $17-51$ & 4.41 & $0.04-0.12$ & -0.012 & $0.02-0.06$ & 0.98 & $0.09-0.27$ & Takeda et al. $(2007) *$ \\
5815 & 10 & 4.46 & 0.01 & -0.010 & 0.005 & 1.01 & 0.04 & Takeda e Tajitsu $(2009) \dagger$ \\
5815 & 50 & 4.49 & 0.07 & 0.018 & 0.019 & $\ldots$ & $\ldots$ & Ramírez et al. (2009) \\
5834 & 25 & 4.56 & 0.06 & 0.010 & 0.020 & 1.07 & 0.09 & Notsu et al. $(2015 \mathrm{a})$ \\
\hline \hline
\end{tabular}

* Os erros individuais não foram reportados por Takeda et al. (2007); os erros variam no intervalo mostrado. † Os parâmetros reportados nesta dissertação são baseados nos parâmetros estelares diferenciais e adotando para o Sol $T_{\text {eff }}=5777 \mathrm{~K}, \log g=4.44 \mathrm{dex}$, e $v_{t}=1.00 \mathrm{~km} \mathrm{~s}^{-1}$.

Tabela 4.2 - Temperatura efetiva fotométrica de HIP 100963.

\begin{tabular}{ccc}
\hline \hline Cor & Observado & $T_{\text {eff }}$ \\
\hline$(\mathrm{B}-\mathrm{V})$ & 0.651 & 5746 \\
$\left(\mathrm{~V}-\mathrm{R}_{\mathrm{C}}\right)$ & 0.342 & 5885 \\
$\left(\mathrm{~V}-\mathrm{I}_{\mathrm{C}}\right)$ & 0.703 & 5730 \\
$(\mathrm{~V}-\mathrm{J})$ & 1.188 & 5762 \\
$(\mathrm{~V}-\mathrm{H})$ & 1.457 & 5781 \\
$(\mathrm{~V}-\mathrm{K})$ & 1.510 & 5827 \\
$(\mathrm{~J}-\mathrm{K})$ & 0.322 & 5962 \\
$(\mathrm{~B}-\mathrm{V})_{T}$ & 0.718 & 5808 \\
$\left(\mathrm{~V}_{\mathrm{T}}-\mathrm{J}\right)$ & 1.261 & 5763 \\
$\left(\mathrm{~V}_{\mathrm{T}}-\mathrm{H}\right)$ & 1.530 & 5782 \\
$\left(\mathrm{~V}_{\mathrm{T}}-\mathrm{K}\right)$ & 1.583 & 5828 \\
$(\mathrm{~b}-\mathrm{y})$ & 0.409 & 5776 \\
\hline \multicolumn{2}{c}{ Média da $T_{\text {eff }}$} & 5804 \\
Sigma da & $T_{\text {eff }}$ & 62 \\
\hline \hline
\end{tabular}


$0.02 \mathrm{M}_{\odot}$ (ver seção 4.3.2), $T_{\text {eff }}=5818 \pm 4 \mathrm{~K}, \mathrm{~V}=7.089 \pm 0.021$ mag (Ramírez et al. 2012) e a paralaxe $\pi=35.42 \pm 0.59$ mas (van Leeuwen, 2007). A correção bolométrica $(B C)$ foi estimada em -0.068, resultando em $\log g=4.47 \pm 0.02$ dex, que está em bom acordo com os meus resultados ( $\log g=4.49 \pm 0.01 \mathrm{dex})$.

\subsubsection{Idade e massa}

Meléndez et al. (2012) e Nissen (2015) demonstraram que é possível estimar idades confiáveis de estrelas tipo solar usando a técnica das isócronas (e.g. Lachaume et al., 1999). Isso foi possível graças às medições extremamente precisas dos parâmetros estelares e, em particular, usando precisos $\log g$ (ao invés de uma incerta magnitude absoluta $M_{v}$ ) como parâmetros de entrada. Levando em conta as considerações acima, Ramírez et al. (2014) desenvolveram um código em Python nomeado q²(qoyllur-quipu). Este código estima a massa, idade, luminosidade e raio de estrelas de tipo solar. Para calcular a idade, o código $\mathrm{q}^{2}$ usa a técnica da comparação com isócronas, adotando uma fina grade de isócronas de Yonsei-Yale (e.g. Yi et al., 2001). Os resultados são listados na Tabela 4.3.

Outra forma de estimar a idade é através da atividade cromosférica. A técnica consiste em medir a emissão das linhas de $H$ e $K$ de Ca II (Wilson, 1968). Definiu-se o índice S como o parâmetro padrão de atividade cromosférica, que mede o coeficiente do fluxo em dois filtros triangulares centrados nas linhas de emissão de $H$ e $K$ e dois fluxos contínuos $R$ e $V$, estes dois últimos são as bandas do contínuo das bandas $H$ e $K$ nas faixas vermelhas e azuis (ver Figura 4.3). Na Figura 4.4 é mostrada a banda $K$ de HIP 100963 e a sua atividade cromosférica. O índice $\mathrm{S}$ é definido como:

$$
S=\alpha\left(\frac{H+K}{R+V}\right)
$$

onde $H, K, R$ e $V$ são os fluxos nos correspondentes filtros e $\alpha$ é determinado a partir de observações das estrelas padrões observadas por Wilson (1978); esse coeficiente é 2.4. Existem várias técnicas para determinar o índice \$4 por exemplo Wright et al. (2004) encontraram através de um ajuste:

$$
S=\frac{1.68 H+0.585 K}{0.497 R+1.72 V}
$$

\footnotetext{
${ }^{4}$ Para os dados desta dissertação pode-se encontrar a maneira em que foram determinados os índices $\mathrm{S}$ em Wright et al. (2004), White et al. (2007) e Isaacson e Fischer (2010).
} 
Tabela 4.3 - Parâmetros fundamentais

\begin{tabular}{cc}
\hline \hline HIP 100963 & Parâmetros \\
\hline Massa & $1.03_{-0.01}^{+0.02} \mathrm{M}_{\odot}$ \\
Distância & $28.2 \pm 0.5 \mathrm{pc}$ \\
Massa convectiva & $0.018 \mathrm{M}_{\odot}$ \\
Idade & $2.0 \pm 0.4 \mathrm{Gyr}$ \\
$\operatorname{logL}$ & $-0.02_{-0.01}^{+0.01} \mathrm{~L}_{\odot}$ \\
$M_{V}$ & $4.83_{-0.03}^{+0.04} \mathrm{mag}$ \\
Raio & $0.97_{-0.02}^{+0.01} \mathrm{R}_{\odot}$ \\
\hline \hline
\end{tabular}

Notas: A massa, idade, luminosidade e raio foram estimados usando o código $\mathrm{q}^{2}$, enquanto a massa convectiva foi determinada usando o código terra (ver seção 3.9 p e empregando as isócronas teóricas de Siess et al. (2000). A $M_{V}$ e a distância foram estimadas usando a paralaxe Hipparcos (van Leeuwen, 2007).
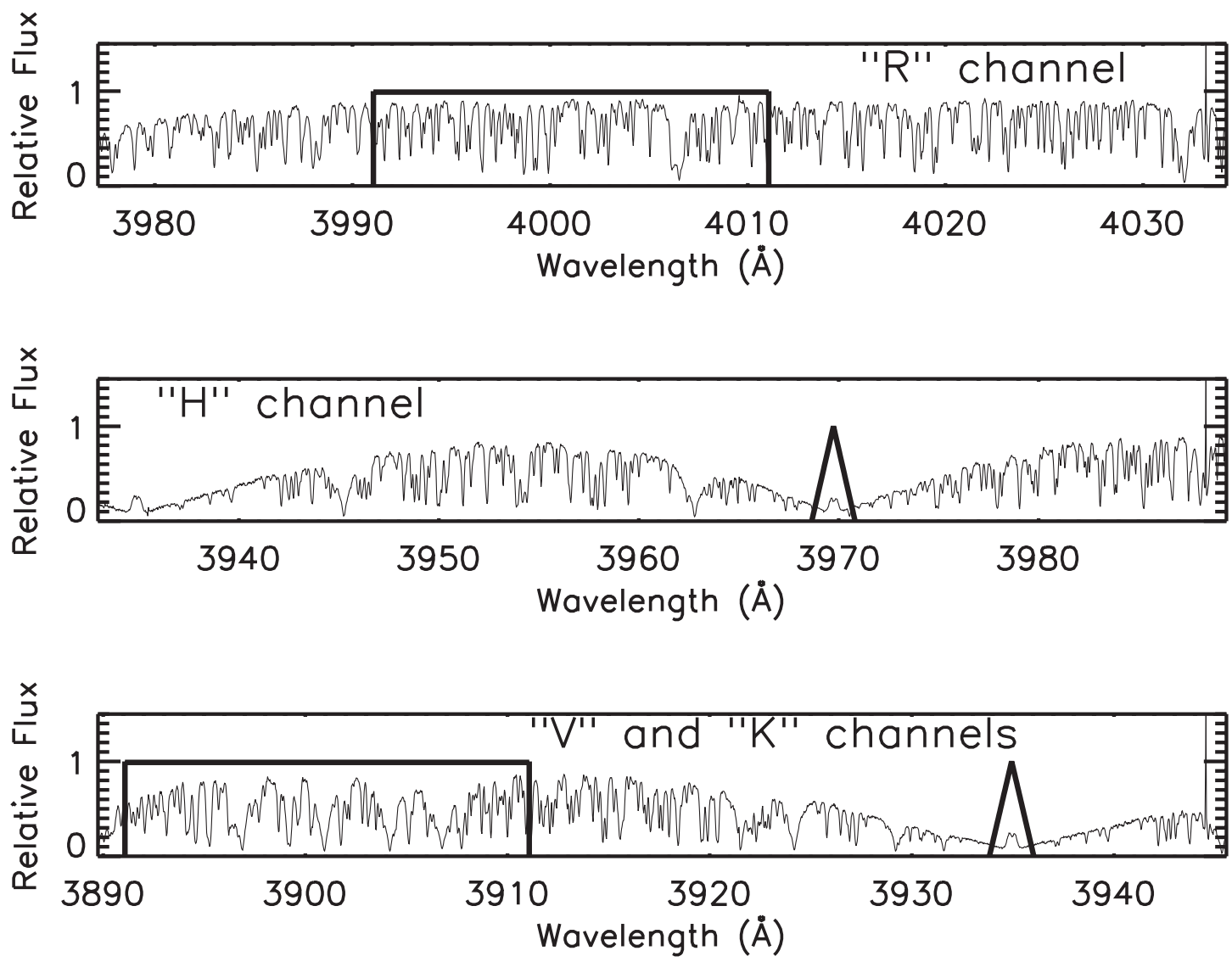

Figura 4.3: Representação das bandas $R, H, K$ e $V$ em um espectro obtido pelo observatório Keck. Note nas bandas $H$ e $K$ a alta atividade cromosférica. Imagem tirada de Wright et al. (2004). 


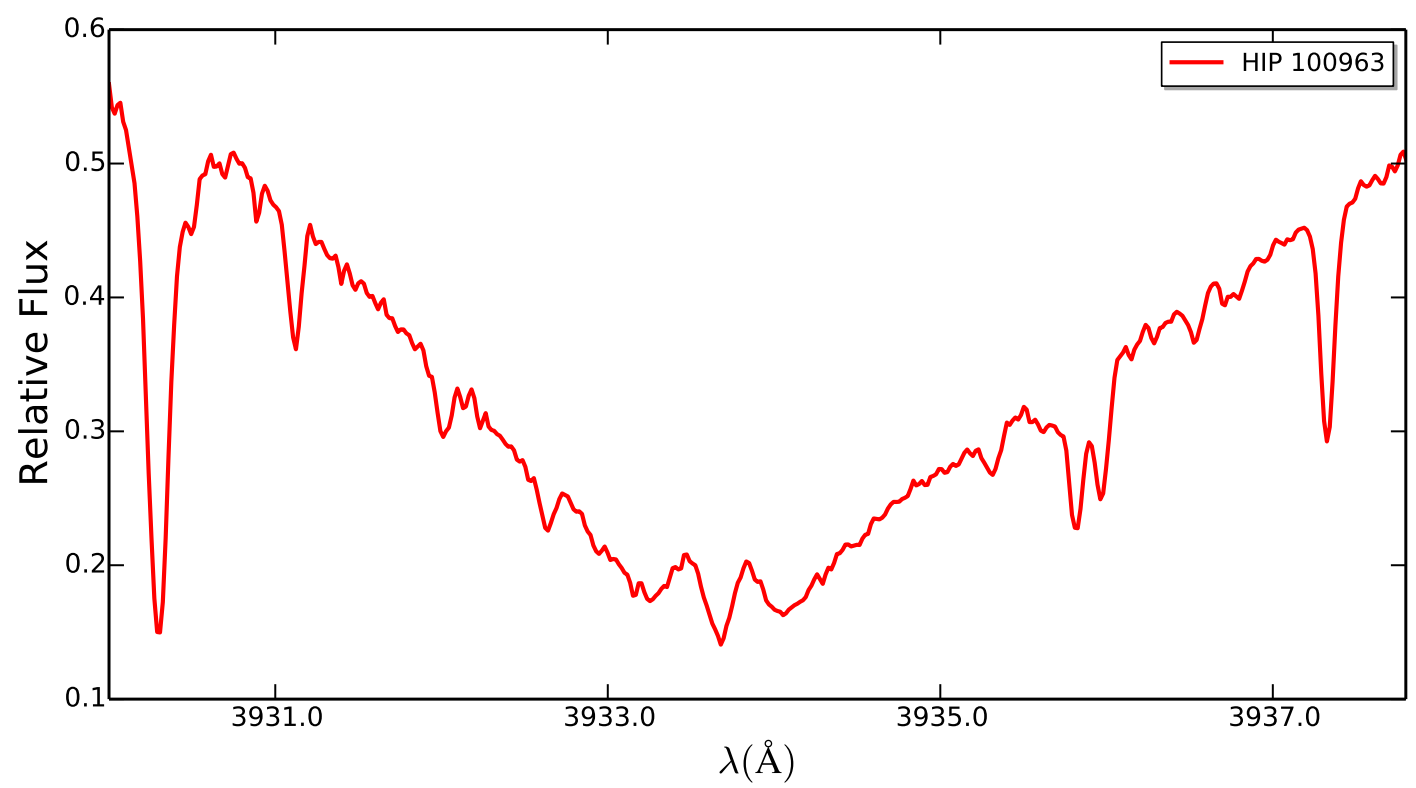

Figura 4.4: Espectro de HIP 100963 na faixa entre 3928 e 3945 Å mostrando emissão cromosférica no centro da linha.

O índice S inclui as contribuições fotosféricas e cromosféricas. Com o fim de subtrair a componente fotosférica e obter o índice cromosférico $R_{H K}^{\prime}$, adotei o procedimento de Wright et al. (2004) e Noyes et al. (1984), que consiste em transformar o índice S em fluxo, usando uma calibração em função de $(B-V)$, válida para o intervalo $0.44<B-V<0.90$ :

$$
R_{H K}=1.340 \times 10^{-4} C_{c f} S,
$$

onde

$$
\log C_{c f}=1.13(B-V)^{3}-3.91(B-V)^{2}+2.84(B-V)-0.47 .
$$

A equação 4.3 transforma o índice S em fluxo, porém esse é o fluxo total da emissão cromosférica e da fotosfera. É necessário corrigir para a contribuição do fluxo fotosférico na parte central das linhas de $H$ e $K$ (Noyes et al., 1984), usando o fluxo fotosférico:

$$
\log R_{f o t}=-4.898+1.918(B-V)^{2}-2.893(B-V)^{3} .
$$

O fluxo cromosférico é:

$$
R_{H K}^{\prime}=R_{H K}-R_{f o t} .
$$

Adicionalmente, a idade pode ser determinada por uma calibração empírica entre a idade e índice de atividade cromosférica (Donahue, 1993; Henry et al., 1996):

$$
\log t=10.725-1.334 R_{5}+0.4085 R_{5}^{2}-0.0522 R_{5}^{3},
$$


onde $R_{5}=R_{H K}^{\prime} \times 10^{5}$, e $t$ é a idade estelar em anos.

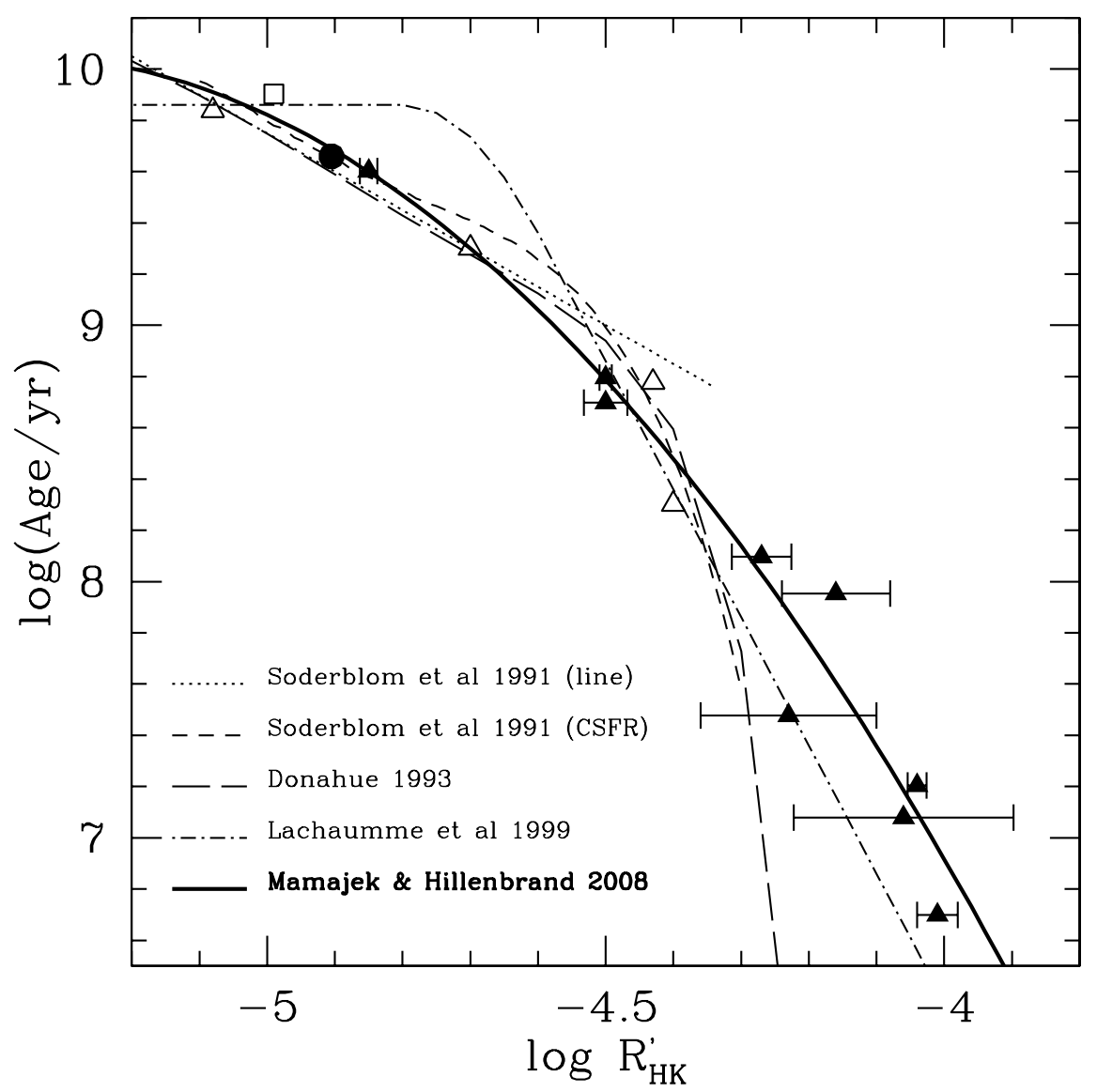

Figura 4.5: Valores médios de $\log R_{H K}^{\prime}$ em função da idade de aglomerados. Os triângulos cheios e abertos representam a média dos valores $\log R_{H K}^{\prime}$ nos aglomerados (Tabela 7 em Mamajek e Hillenbrand (2008)). $\mathrm{O}$ círculo cheio é o Sol e o quadrado aberto representa à média de anãs de tipo solar tomadas da amostra de Valenti e Fischer (2005). Imagem tirada de Mamajek e Hillenbrand (2008)

Mamajek e Hillenbrand (2008) calibraram a relação do índice $\log R_{H K}^{\prime}$ e a idade usando aglomerados abertos (Figura 4.5):

$$
\log t=-38.053-17.912 \log R_{H K}^{\prime}-1.6675 \log \left(R_{H K}^{\prime}\right)^{2}
$$

onde $t$ é a idade em anos.

Encontrei sete dados do índice de atividade $\log R_{H K}^{\prime}$; esses dados foram obtidos de Wright et al. (2004), White et al. (2007) e Isaacson e Fischer (2010). O indicador de atividade médio é $\log R_{H K}^{\prime}=-4.74(\sigma=0.11)$. Usei essas medições individuais de $\log R_{H K}^{\prime}$ disponíveis nas referências indicadas acima, com a cor $(B-V)=0.651$ (Ramírez et al. 2012) a fim de determinar a idade a partir desse indicador cromosférico. Usando as equações 4.7 e 4.8, encontrei uma média de idades de $2.3 \pm 0.4$ Gyr e $2.6 \pm 0.6$ Gyr, respectivamente, 


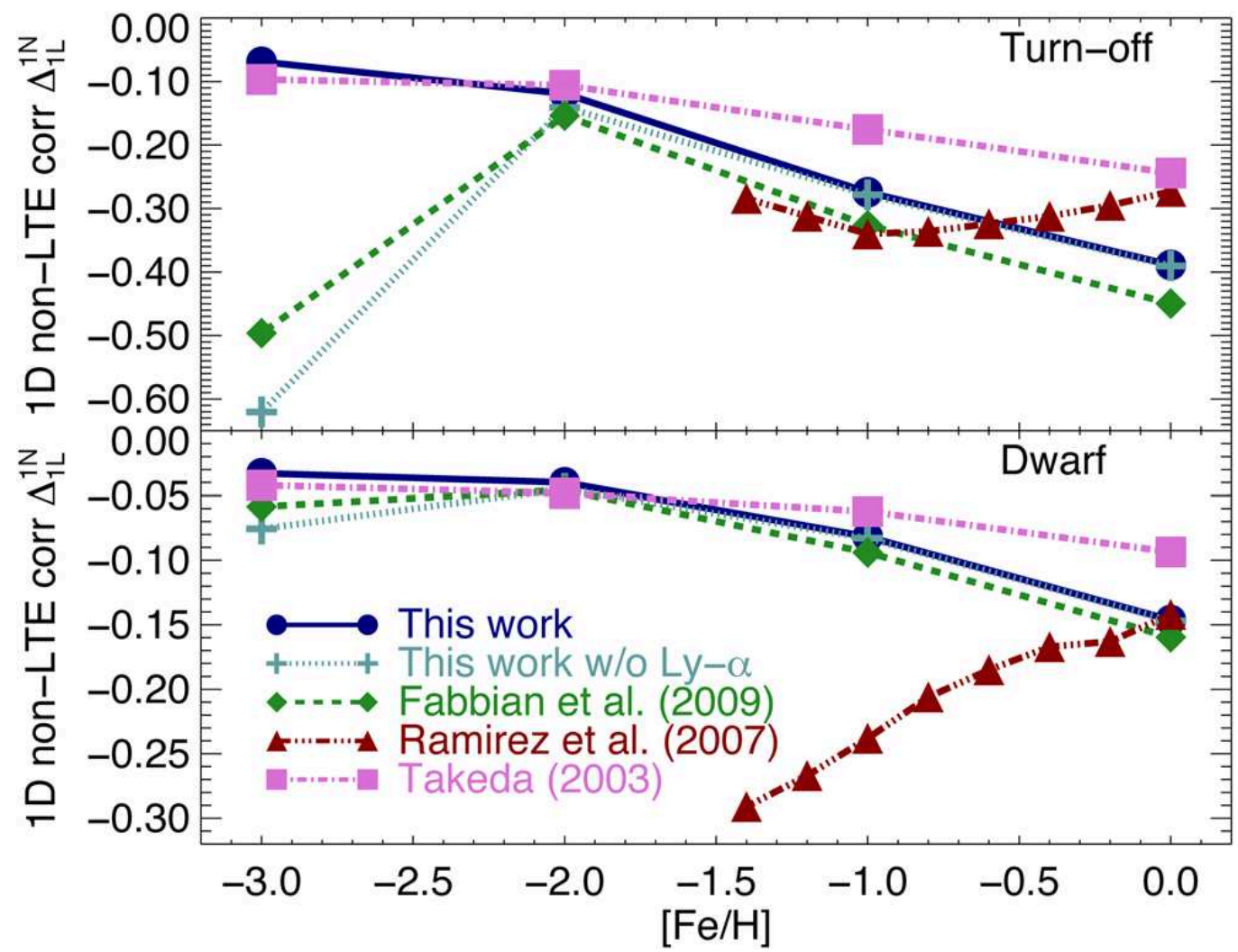

Figura 4.6: Ambos painéis mostram as correções de abundância para o O I 777 em modelos de NLTE. O painel superior representa as correções para uma estrela que deixa a sequência principal (turn-off star) $\operatorname{com} T_{\text {eff }}=6500 \mathrm{~K}$ e $\log g=4.0 \mathrm{dex}$, enquanto para o painel inferior são para uma estrela anã com $T_{\text {eff }}$ $=5500 \mathrm{~K}$ e $\log g=4.0$ dex. Fonte: Amarsi et al. (2015).

e uma média ponderada de $2.4 \pm 0.3$ Gyr. Estes valores estão em bom acordo com a idade isocronal, estimada através de $q^{2}(2.0 \pm 0.4$ Gyr $)$.

\subsubsection{Padrão de abundâncias}

Estimei com alta precisão as abundâncias químicas de 26 elementos diferentes do lítio usando EWs: C, O, Na, Mg, Al, Si, Ca, Sc, Ti, V, Cr, Mn, Fe, Co, Ni, Cu, Zn, Sr, Y, Zr, Ba, La, Ce, Nd, Sm e Eu, em relação ao Sol. Adotei os dados de estrutura hiperfina usados por Meléndez et al. (2014) para os elementos V, Mn, Co, Cu, Y, Ba, La e Eu, com frações isotópicas que são dadas em Asplund et al. (2009), McWilliam (1998) e Cohen et al. (2003) para Cu, Ba e Eu, respectivamente (ver seção 2.9). A estimativa das abundâncias foi estritamente diferencial em comparação ao Sol, onde as medições foram feitas manualmente linha a linha. O total de linhas medidas é de 500 para ambas gêmeas solares (HIP 100963 e Iris). 


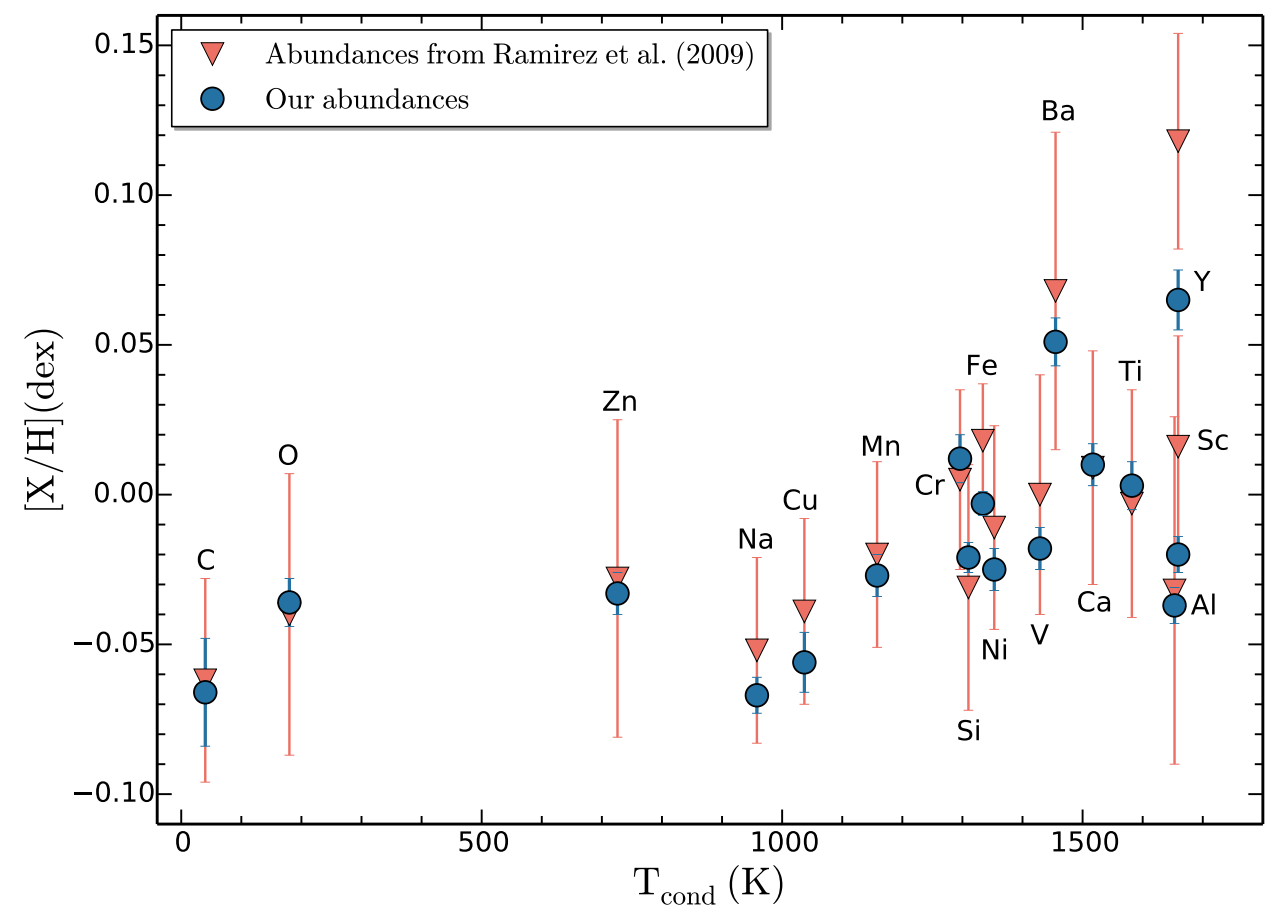

Figura 4.7: Comparação entre o padrão de abundâncias estimadas nesta dissertação e o padrão determinado por Ramírez et al. (2009) em função da temperatura de condensação, T $T_{\text {cond }}$ Lodders, 2003).

No geral, efeitos de NLTE em gêmeas solares são desprezíveis (Meléndez et al., 2012; Monroe et al., 2013), não obstante poderiam ser de importância para o tripleto de O I. Portanto, empreguei as correções diferenciais NLTE para o O I usando a grade de NLTE de Ramírez et al. (2007). Cálculos recentes de NLTE para o oxigênio (Amarsi et al., 2015), predizem correções absolutas de NLTE bastantes diferentes do que as correções de NLTE de Ramírez et al. (2007) (Figura 4.6). Porém para metalicidade solar o acordo é razoável. Note-se que para gêmeas solares os efeitos de aplicar uma ou outra correção NLTE são desprezíveis devido a que todos os cálculos são estritamente diferenciais. Por exemplo, adotando a grade NLTE de Amarsi et al. (2015), a diferença em abundância com as correções NLTE de Ramírez et al. (2007), é de apenas 0.004 dex.

Na tabela 4.4 são mostradas as abundâncias diferenciais em relação ao Sol, incluindo erros observacionais, sistemáticos e os totais obtidos de somar quadraticamente os erros sistemáticos e estatísticos (ver seção 2.12). Os resultados estão de acordo com as abundâncias estimadas por Ramírez et al. (2009), como mostrado na Figura 4.7, não obstante os meus resultados são mais precisos devido à melhor qualidade dos dados. A diferença média é $\Delta[\mathrm{X} / \mathrm{H}]($ Ramírez et al. $(2009)$ - este trabalho $)=0.011(\sigma=0.016$ dex $)$.

Nissen (2015) atingiu uma alta precisão em abundância química de 21 gêmeas solares, 
Tabela 4.4 - Abundâncias químicas de HIP 100963, e seus erros.

\begin{tabular}{lrlrrrrrrr}
\hline \hline Elemento & $\Delta[\mathrm{X} / \mathrm{H}]$ & $\Delta T_{\text {eff }}$ & $\Delta \log g$ & $\Delta v_{t}$ & $\Delta[\mathrm{Fe} / \mathrm{H}]$ & Param $^{\mathrm{a}}$ & Obs $^{\mathrm{b}}$ & Total $^{\mathrm{c}}$ & \\
& $\mathrm{LTE}$ & $\pm 9 \mathrm{~K}$ & $\pm 0.03 \mathrm{dex}$ & $\pm 0.02 \mathrm{kms}^{-1}$ & $\pm 0.01 \mathrm{dex}$ & & & & \\
& $(\mathrm{dex})$ & $(\mathrm{dex})$ & $(\mathrm{dex})$ & $(\mathrm{dex})$ & $(\mathrm{dex})$ & $(\mathrm{dex})$ & $(\mathrm{dex})$ & $\mathrm{dex}$ & \\
\hline $\mathrm{C}$ & -0.066 & 0.002 & 0.003 & 0.000 & 0.000 & 0.004 & 0.018 & 0.018 & 0.015 \\
$\mathrm{O}$ & -0.036 & 0.004 & 0.002 & 0.001 & 0.000 & 0.005 & 0.006 & 0.008 & 0.038 \\
$\mathrm{Na}$ & -0.067 & 0.002 & 0.001 & 0.000 & 0.000 & 0.002 & 0.006 & 0.006 & 0.008 \\
$\mathrm{Mg}$ & -0.024 & 0.004 & 0.001 & 0.002 & 0.001 & 0.005 & 0.007 & 0.008 & 0.022 \\
$\mathrm{Al}$ & -0.037 & 0.002 & 0.000 & 0.000 & 0.000 & 0.002 & 0.006 & 0.006 & -0.006 \\
$\mathrm{Si}$ & -0.021 & 0.001 & 0.001 & 0.000 & 0.001 & 0.002 & 0.005 & 0.005 & 0.004 \\
$\mathrm{Ca}$ & 0.010 & 0.003 & 0.001 & 0.002 & 0.001 & 0.004 & 0.006 & 0.007 & -0.009 \\
$\mathrm{Sc}{ }^{*}$ & -0.020 & 0.000 & 0.004 & 0.002 & 0.001 & 0.005 & 0.004 & 0.006 & 0.048 \\
$\mathrm{Ti}{ }^{*}$ & 0.003 & 0.000 & 0.005 & 0.002 & 0.001 & 0.005 & 0.006 & 0.008 & 0.028 \\
$\mathrm{~V}$ & -0.018 & 0.004 & 0.001 & 0.000 & 0.000 & 0.004 & 0.006 & 0.007 & 0.002 \\
$\mathrm{Cr} *$ & 0.012 & 0.001 & 0.004 & 0.002 & 0.001 & 0.005 & 0.006 & 0.008 & 0.002 \\
$\mathrm{Mn}$ & -0.027 & 0.003 & 0.000 & 0.001 & 0.001 & 0.003 & 0.006 & 0.007 & 0.021 \\
$\mathrm{Fe}{ }^{*}$ & -0.003 & 0.003 & 0.000 & 0.002 & 0.001 & 0.004 & 0.001 & 0.004 & -0.003 \\
$\mathrm{Co}$ & -0.046 & 0.003 & 0.002 & 0.000 & 0.000 & 0.004 & 0.011 & 0.012 & 0.017 \\
$\mathrm{Ni}$ & -0.025 & 0.002 & 0.000 & 0.002 & 0.001 & 0.003 & 0.006 & 0.007 & 0.024 \\
$\mathrm{Cu}$ & -0.056 & 0.002 & 0.001 & 0.002 & 0.001 & 0.003 & 0.009 & 0.010 & 0.027 \\
$\mathrm{Zn}$ & -0.033 & 0.000 & 0.001 & 0.002 & 0.001 & 0.002 & 0.007 & 0.007 & 0.033 \\
$\mathrm{Sr}$ & 0.055 & 0.004 & 0.001 & 0.001 & 0.001 & 0.004 & 0.007 & 0.008 & $\ldots$ \\
$\mathrm{Y}$ & 0.065 & 0.001 & 0.005 & 0.004 & 0.002 & 0.007 & 0.008 & 0.010 & $\ldots$ \\
$\mathrm{Zr}$ & 0.074 & 0.001 & 0.005 & 0.002 & 0.001 & 0.006 & 0.006 & 0.008 & $\ldots$ \\
$\mathrm{Ba}$ & 0.051 & 0.001 & 0.001 & 0.004 & 0.002 & 0.005 & 0.008 & 0.009 & $\ldots$ \\
$\mathrm{La}$ & 0.072 & 0.001 & 0.006 & 0.000 & 0.001 & 0.006 & 0.011 & 0.013 & $\ldots$ \\
$\mathrm{Ce}$ & 0.054 & 0.001 & 0.005 & 0.001 & 0.002 & 0.006 & 0.007 & 0.009 & $\ldots$ \\
$\mathrm{Nd}$ & 0.066 & 0.001 & 0.006 & 0.000 & 0.002 & 0.006 & 0.006 & 0.009 & $\ldots$ \\
$\mathrm{Sm}$ & 0.086 & 0.001 & 0.005 & 0.001 & 0.001 & 0.005 & 0.007 & 0.009 & $\ldots$ \\
$\mathrm{Eu}$ & 0.069 & 0.001 & 0.006 & 0.001 & 0.001 & 0.006 & 0.007 & 0.009 & $\ldots$ \\
\hline & & & & & & & & &
\end{tabular}

Notas.

a Erros sistemáticos devido à incerteza dos parâmetros estelares.

b Erros observacionais.

c Erros totais (parâmetros estelares e observacionais).

com o fim de investigar a relação entre o padrão de abundâncias com a idade e a temperatura de condensação. Ele encontrou que a razão [Y/Mg] está correlacionada com a idade, proporcionando um novo método para estimar a idade (seção 3.8). Usando esta relação, estimei $[\mathrm{Y} / \mathrm{Mg}]=0.089$ dex e portanto uma idade de $2.1 \pm 0.4 \mathrm{Gyr}$, que esta em acordo com a idade isocronal estimada usando $\mathrm{q}^{2}(2.0 \pm 0.4 \mathrm{Gyr})$ e a idade determinada a partir dos diagnósticos cromosféricos (2.4 $\pm 0.3 \mathrm{Gyr})$. 


\subsection{Discussão}

\subsubsection{Os elementos leves $(Z \leq 30)$}

O padrão de abundâncias de HIP 100963 em relação ao Sol é mostrado na Figura 4.8 (círculos azuis no painel superior). O ajuste dos elementos leves $(\mathrm{Z} \leq 30$ ) resulta em uma inclinação positiva com uma dispersão de 0.019 dex, que é maior do que a média da barra do erro das abundâncias (0.008 dex). A diferença poderia ser devida à dispersão introduzida pela evolução química da Galáxia (GCE).

A correlação entre o padrão de $\mathrm{T}_{\text {cond }}$ e a idade, foi observada primeiro por Ramírez et al. (2014). Adibekyan et al. (2014) também mostraram a correlação entre o padrão de abundância e a temperatura de condensação e as idades estelares. Eles analisaram uma amostra de 148 estrelas de tipo solar e observaram que as estrelas jovens são mais ricas em elementos refratários do que as estrelas velhas. Eles sugeriram que este comportamento é devido aos efeitos da evolução química do disco fino da Galáxia. Posteriormente, Nissen (2015) e Spina et al. (2016) confirmaram esta correlação e concluíram que a inclinação da

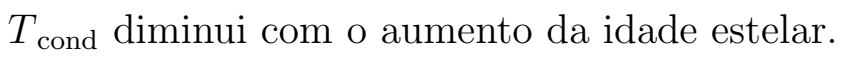

Para estudar o efeito da evolução química da galáxia, usou-se a relação de $[\mathrm{X} / \mathrm{Fe}]$ vs idade de Spina et al. (2016) para corrigir os elementos Z $\leq 30$ por GCE. Como HIP 100963 é mais jovem do que o Sol, adicionei os efeitos de GCE a suas abundâncias devido a que as abundâncias diferenciais são relativas às abundâncias do Sol, que tem idade de 4.6 Gyr. Isto é:

$$
[\mathrm{X} / \mathrm{H}]_{\mathrm{GCE}}=[\mathrm{X} / \mathrm{H}]+b \times\left(\text { Age }_{\mathrm{Sun}}-\mathrm{Age}_{\mathrm{twin}}\right),
$$

onde $b$ é a inclinação encontrada por Spina et al. (2016) Na Figura 4.8 (painel inferior) é mostrada a diferença da abundância dos elementos $\left([\mathrm{X} / \mathrm{H}]_{\mathrm{GCE}}\right)$ adicionando os efeitos de GCE entre HIP 100963 e o Sol (círculos vermelhos) em função da temperatura de condensação (Lodders, 2003). Os elementos de captura de nêutrons (quadrados de cor cinza) não foram corrigidos devido a que Spina et al. (2016) não incluíram a maioria destes elementos. A média da dispersão do ajuste é 0.016 dex, que está de acordo com a média da barra de erro (0.015 dex), que agora inclui as incertezas da correção por GCE

\footnotetext{
${ }^{5}$ Spina et al. (2016) efetuaram um ajuste lineal $([\mathrm{X} / \mathrm{Fe}]=$ age $\times \mathrm{b}+\mathrm{a})$ com seus parâmetros listados na Tabela 3 do seu trabalho. Os ajustes são usados para realizar correções por GCE como uma função da idade.
} 


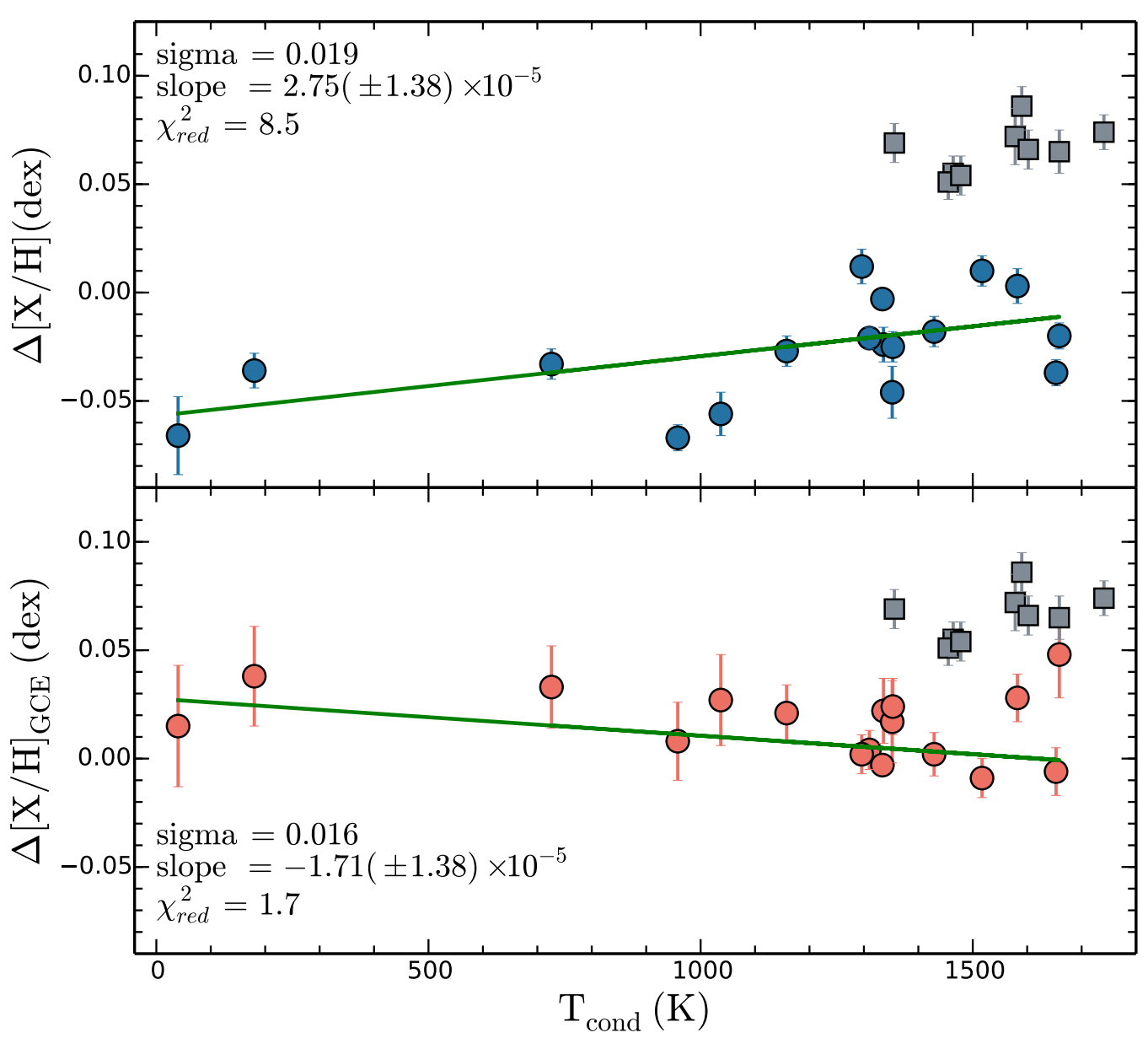

Figura 4.8: Painel superior: Abundâncias diferenciais observadas em relação ao Sol e em função da temperatura de condensação. Painel inferior: Padrão de abundâncias depois de corrigir por GCE à idade solar. Ajustes lineares aos dados (excluindo os elementos de captura de nêutrons) são representados graficamente em cada painel com uma linha sólida verde. Os elementos de captura de nêutrons são representados por quadrados de cor cinza em ambos painéis. Sigma representa a dispersão sobre o ajuste linear.

(incluindo também o erro em idade). Note que o $\chi_{\text {red }}^{2}$ diminui de 8.5 (abundâncias sem correção) para 1.7 (abundâncias corrigidas). Dentro dos erros, o padrão de abundâncias de HIP 100963 corrigida por GCE (para idade solar), é semelhante ao Sol, ou talvez levemente mais pobre em elementos refratários do que o Sol. Note que a inclinação muda de 2.8 a -1.7, e que a diferença é significante no nível $\sim 3$ sigma, ou seja, a contribuição de GCE é importante.

Meléndez et al. (2009) foram os primeiros em encontrar que o padrão de abundâncias do Sol é deficiente em elementos refratários quando comparado com a abundância média da 11 gêmeas solares. Eles argumentaram que o peculiar padrão de abundância do Sol é uma imagem espelho do padrão de abundâncias dos meteoritos e planetas rochosos internos no 
Sistema Solar. Isto sugere que o padrão de elementos refratários poderia estar ligado à formação de planetas terrestres no Sistema Solar. Se o cenário de Meléndez et al. (2009) estiver correto, o padrão de abundâncias de HIP 100963 (similar ao do Sol) implicaria que teria as condições para a formação de planetas rochosos.

HIP 100963 é incluída no California Planet Search (Isaacson e Fischer, 2010), não obstante ainda não foi detetado nenhum planeta. Apenas uns poucos dados foram reportados até hoje, o que não é suficiente para excluir planetas.

\subsubsection{Elementos de captura de nêutrons $(Z>30)$}

Pode-se ver na Figura 4.8, que HIP 100963 apresenta considerável enriquecimento nos elementos de captura de nêutrons (quadrados de cor cinza) devido aos processos-s e $-r$. Para a gêmea solar 18 Sco, Meléndez et al. (2014) argumentaram que este enriquecimento poderia ser devido à poluição por estrelas do ramo gigante assintótico (AGB) e fontes de processo- $r$, que enriqueceram o meio interestelar ao longo do tempo. Apesar de que estrelas massivas dominam a produção de elementos leves originados pelo processo-s $(\mathrm{Sr}, \mathrm{Y}$, e Zr) em baixas metalicidades, na metalicidade solar a produção destes elementos é dominada pelas estrelas AGB (Bisterzo et al., 2014).

Nesta dissertação, seguirei o procedimento adotado por Meléndez et al. (2014) para estudar elementos de captura de nêutrons na gêmea solar 18 Sco. Primeiro ajustei os elementos leves $[\mathrm{X} / \mathrm{H}]_{\mathrm{Z} \leq 30}$, com o fim de subtrair o padrão de abundância com a temperatura de condensação dos elementos pesados $[\mathrm{X} / \mathrm{H}]_{\mathrm{Z}>30}$ :

$$
[\mathrm{X} / \mathrm{H}]_{\mathrm{Tcond}}=[\mathrm{X} / \mathrm{H}]_{\mathrm{Z}>30}-\left(-0.056+2.753 \times 10^{-5} \mathrm{~T}_{\text {cond }}\right),
$$

onde $[\mathrm{X} / \mathrm{H}]_{\text {Tcond }}$ representa a abundância dos elementos de captura de nêutrons corrigida pelos efeitos da temperatura de condensação, enquanto os últimos dois termos vem do ajuste do padrão de abundâncias de elementos com $Z \leq 30$ em função da temperatura de condensação sem GCE (ver Figura 4.8). Para estimar a quantidade de poluição da protonuvem por estrelas AGB $\left([\mathrm{X} / \mathrm{H}]_{\mathrm{AGB}}\right)$, usei o mesmo modelo adotado por Meléndez et al. (2014) com a diluição de pequenas frações de material ejetado pela AGB na proto-nuvem de $1 \mathrm{M}_{\odot}$ de composição solar (Asplund et al. 2009).

\footnotetext{
${ }^{6}$ Este é um modelo da produção de elementos químicos por uma estrela AGB com $3 \mathrm{M}_{\odot}$ de massa inicial e $\mathrm{Z}=0.01$ de metalicidade (Karakas et al., 2010; Meléndez et al., 2014).
} 


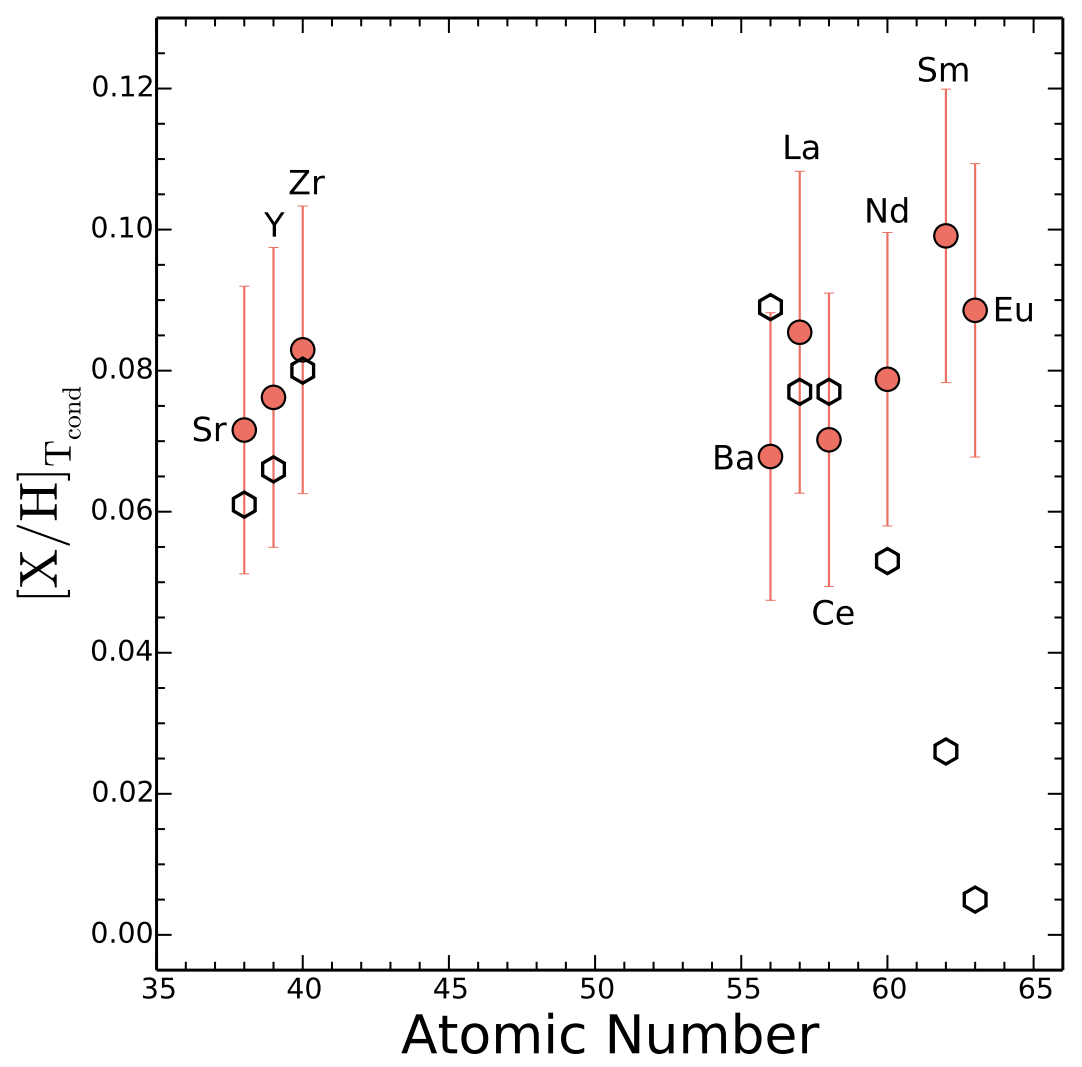

Figura 4.9: Comparação da razão de $[\mathrm{X} / \mathrm{H}]_{\mathrm{T}_{\text {cond }}}$ (círculos vermelhos cheios) com as abundâncias preditas a partir da poluição de estrelas AGB (hexágonos abertos).

Estimei uma diluição de $0.34 \%$ de massa de material da AGB para igualar o enriquecimento médio observado nos elementos do processo -s (Sr, Y, Zr, Ba, La, e Ce). As duas abundâncias, $[\mathrm{X} / \mathrm{H}]_{\text {Tcond }} \mathrm{e}[\mathrm{X} / \mathrm{H}]_{\mathrm{AGB}}$ são dadas na Tabela 4.5 . Na Figura 4.9 é mostrado que os elementos gerados pelo processo-s (Y, Ba, La, e Ce) são bem reproduzidos, mas os elementos do processo-r (Sm e Eu) não. Por conseguinte, a contribuição de AGBs não explica completamente o enriquecimento de todos os elementos pesados. Outra fonte de enriquecimento é a contribuição devida ao processo-r. Para estimar este enriquecimento, primeiro foi subtraída a contribuição AGB na abundância dos elementos pesados:

$$
[\mathrm{X} / \mathrm{H}]_{\mathrm{r}-\text { process }}=[\mathrm{X} / \mathrm{H}]_{\mathrm{Tcond}}-[\mathrm{X} / \mathrm{H}]_{\mathrm{AGB}} \text {. }
$$

Depois, comparei essas razões com o enriquecimento predito baseado no processo- $r$ no Sistema Solar (Simmerer et al., 2004; Bisterzo et al., 2014). Meléndez et al. (2014) determinaram a contribuição do processo- $r$, que é dada por:

$$
[\mathrm{X} / \mathrm{H}]_{\mathrm{SS}-\mathrm{r}}=\Delta \tau \log _{10} \mathrm{r}_{\mathrm{SS}}+[\mathrm{X} / \mathrm{H}]_{\mathrm{Tcond}}
$$


Tabela 4.5 - Abundância dos elementos de captura de nêutrons e sua decomposição em HIP 100963

\begin{tabular}{lrrrr}
\hline \hline $\mathrm{Z}$ & Elemento & $\begin{array}{r}{[X / H]_{\text {Tcond }}} \\
(\mathrm{dex})\end{array}$ & $\begin{array}{r}{[X / H]_{\text {AGB }}} \\
(\mathrm{dex})\end{array}$ & $\begin{array}{r}{[X / H]_{\text {r-process }}} \\
(\mathrm{dex})\end{array}$ \\
\hline 38 & $\mathrm{Sr}$ & 0.071 & 0.061 & 0.010 \\
39 & $\mathrm{Y}$ & 0.076 & 0.066 & 0.010 \\
40 & $\mathrm{Zr}$ & 0.083 & 0.080 & 0.003 \\
56 & $\mathrm{Ba}$ & 0.067 & 0.089 & -0.020 \\
57 & $\mathrm{La}$ & 0.085 & 0.077 & 0.008 \\
58 & $\mathrm{Ce}$ & 0.070 & 0.077 & -0.007 \\
60 & $\mathrm{Nd}$ & 0.078 & 0.053 & 0.025 \\
62 & $\mathrm{Sm}$ & 0.099 & 0.026 & 0.073 \\
63 & $\mathrm{Eu}$ & 0.088 & 0.005 & 0.083 \\
\hline
\end{tabular}

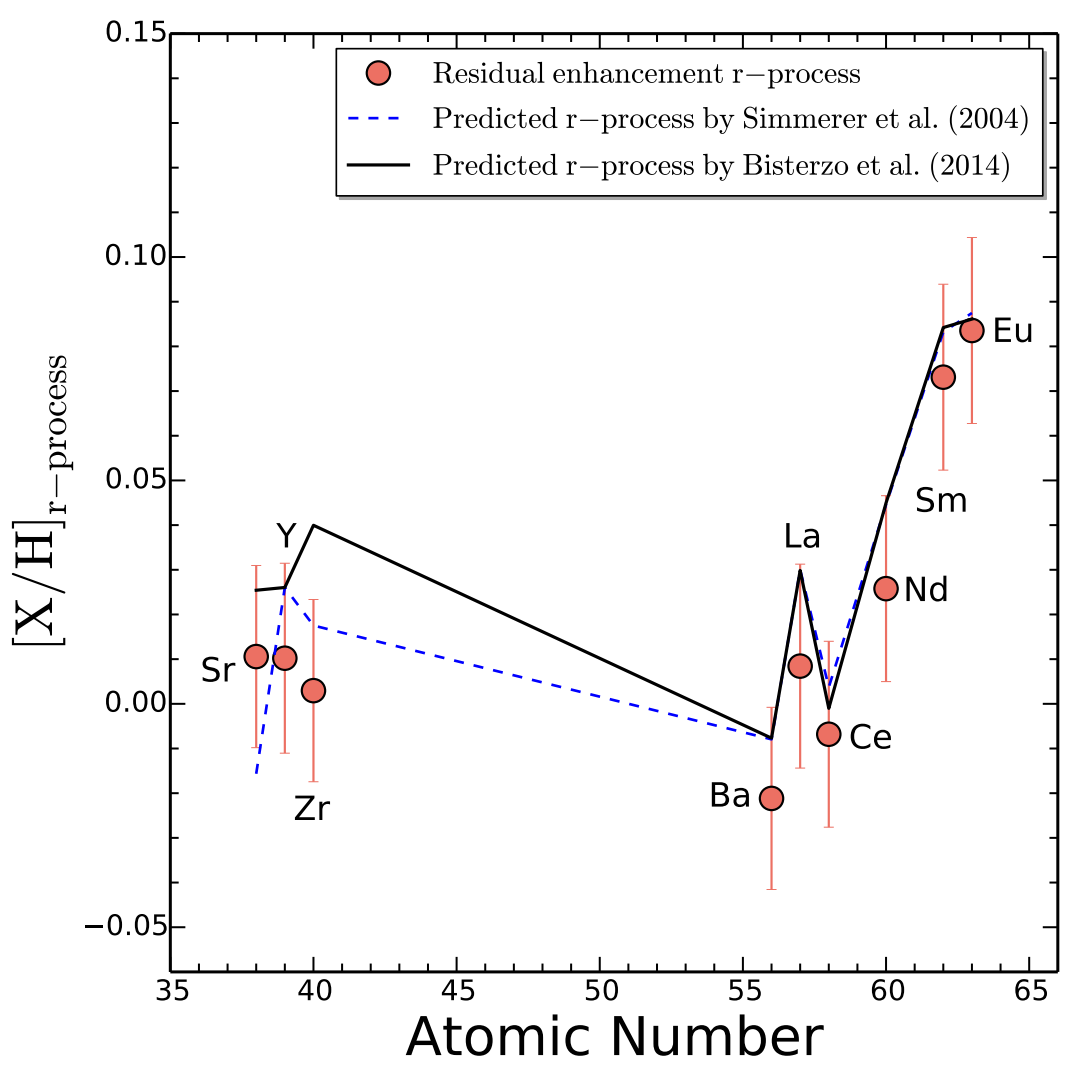

Figura 4.10: Abundâncias residuais $[\mathrm{X} / \mathrm{H}]_{\mathrm{r}-\text { process }}$ devido à contribuição do processo- $r$. Abundâncias preditas usando o padrão de abundâncias do processo- $r$ no Sistema Solar por Bisterzo et al. (2014) e Simmerer et al. (2004), são também representadas graficamente com linhas sólidas e pontilhadas, respectivamente. 
onde $\Delta \tau$ é a média dos dois elementos mais enriquecidos por processos- $s$ e $-r(\Delta \tau=$

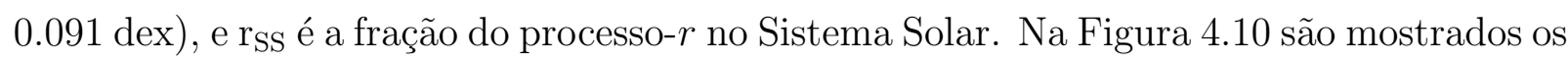
resultados, que estão razoavelmente em acordo com o padrão de abundância do processo-r predito no Sistema Solar (Simmerer et al., 2004; Bisterzo et al., 2014). Inclusive para os elementos que são parcialmente produzidos através da contribuição do processo $r$ (p.ex., $\mathrm{Nd}$ ), obtive um bom acordo dentro dos erros. Os resultados, junto com os obtidos para 18 Sco (Meléndez et al., 2014), sugerem um enriquecimento em estrelas jovens dos elementos do processo- $r$ e $-s$. Os resultados desta dissertação são também similares ao encontrado por D'Orazi et al. (2009), Maiorca et al. (2011), e D'Orazi et al. (2012), que mostraram que estrelas jovens em aglomerados abertos apresentam enriquecimento em elementos do processo- $s$.

\subsubsection{Abundância de Lítio}

Trabalhos anteriores indicam uma forte conexão entre a abundância de lítio e a idade estelar (Soderblom, 1983; Charbonnel e Talon, 2005; Denissenkov, 2010; Baumann et al. 2010; Monroe et al., 2013; Meléndez et al., 2014), com estrelas jovens tendo maiores abundâncias de lítio. Para determinar se HIP 100963 segue essa relação, estimei a abundância de lítio seguindo o procedimento explanado em Meléndez et al. (2012), que consiste primeiro na estimativa de alargamento da linha devido a efeitos instrumentais, de macroturbulência e de rotação. Logo é efetuada a síntese espectral (ver apêndice C.0.1) da região de lítio.

Foi determinada a velocidade de macroturbulência estelar através da relação (Tucci Maia et al., 2015):

$$
v_{\text {macro }}=v_{\text {macro }, \odot}+\left(T_{\text {eff }}-5777\right) / 486 .
$$

Fixei o $v \sin i \odot=1.9 \mathrm{kms}^{-1}$ (Bruning, 1984, Saar e Osten, 1997) e obtive por síntese espectral de seis linhas (ver abaixo) $v_{\text {macro, } \odot}=3.34 \mathrm{kms}^{-1}$, que foi empregada na equação 4.13 para estimar a $v_{\text {macro }}$ de HIP 100963 , que resultou em $v_{\text {macro }}=3.43 \mathrm{kms}^{-1}$. Depois a velocidade de rotação projetada $(v \sin i)$ foi medida pelo ajuste dos perfis de cinco linhas de ferro: $6027.050 \AA$ (p. ex. ver Figura 4.11), $6093.644 \AA, 6151.618 \AA, 6165.360 \AA, 6705.102$ $\AA$, e uma linha de Ni I em $6767.772 \AA$. Encontrei $v \sin i=1.93 \pm 0.21 \mathrm{~km} \mathrm{~s}^{-1}$, similar ao que foi determinado por Takeda e Tajitsu $(2009)\left(v \sin i=2.04 \mathrm{~km} \mathrm{~s}^{-1}\right.$; os erros não foram reportados), e em bom acordo com o valor de $1.9 \pm 0.3 \mathrm{kms}^{-1}$ de Honda et al. (2015) 7 .

\footnotetext{
${ }^{7} \mathrm{O}$ valor estimado por Honda et al. (2015) para HIP 100963 é $2.4 \pm 0.3 \mathrm{~km} \mathrm{~s}^{-1}$, com $v \sin i_{\odot}=2.4$
} 


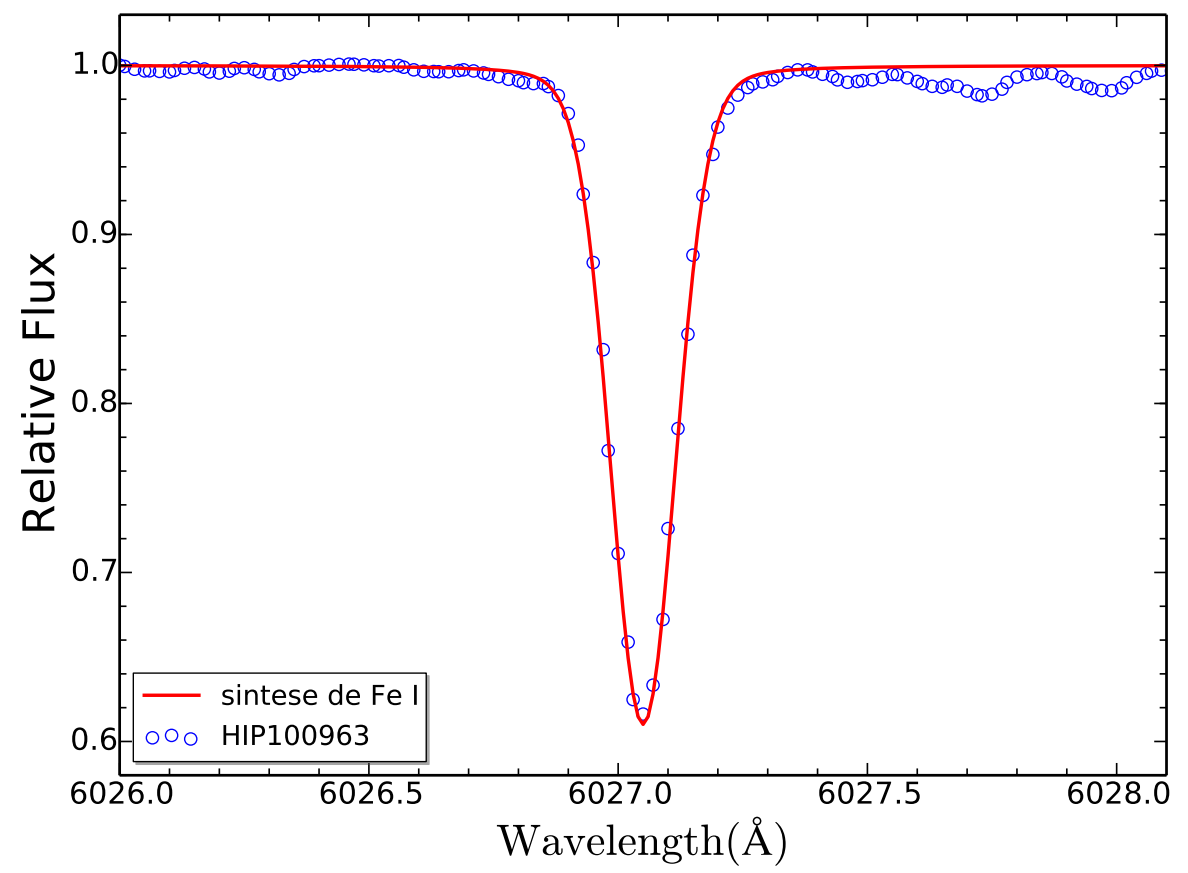

Figura 4.11: Síntese espectral da linha de Fe I $(6727.050 \AA)$, que foi usada para estimar o $v \sin i$. Para ajustar o perfil necessitou-se de uma largura gaussiana (FWHM) de $0.086 \AA$, $v \sin i=1.5 \mathrm{kms}^{-1}$, fator de escurecimento de limbo de 0.6 e $v_{\text {macro }}=3.43 \mathrm{kms}^{-1}$.

Recentemente, Dos Santos et al. (2016) demonstraram que a $v_{\text {macro }}$ não depende apenas da $T_{\text {eff }}$, mas também do $\log g$ através da relação:

$$
v_{\text {macro }}=v_{\text {macro }, \odot}-0.00707 T_{\text {eff }}+9.2422 T_{\text {eff }}^{2}+10.0+k 1(\log g-4.44)+k 2,
$$

onde $k 1$ e $k 2$ são estimados por meio de um ajuste linear (ver Figura 1 de Dos Santos et al. (2016)), cujos valores são $-1.81 \pm 0.26$ e $-0.05 \pm 0.03$, respectivamente. Usando a equação 4.14 estimei a $v_{\text {macro }}$ em $3.40 \mathrm{kms}^{-1}$. Este valor está em excelente acordo com a $v_{\text {macro }}$ estimada inicialmente usando a equação $4.13\left(3.43 \mathrm{kms}^{-1}\right)$.

HIP 100963 (círculos azuis abertos) apresenta um profundo traço de Li (Figura 4.12) em comparação à linha fraca de lítio no Sol (círculos pretos cheios). Baseado na $v_{\text {macro }} \mathrm{e}$ $v \sin i$ estimados acima, realizei a síntese espectral da linha de Li adotando a lista de linhas de Meléndez et al. (2012) e usando a tarefa synth de MOOG. Isso proporcionou uma abundância (LTE) de 1.67 dex. A abundância de lítio em NLTE é $1.70 \pm 0.03$ dex; esta foi obtida usando a correção NLTE de Lind et al. (2009) 8 . A incerteza em A(Li) foi obtida levando em conta os erros devido ao $\mathrm{S} / \mathrm{N}$, escolha do contínuo, e erros dos parâmetros $\mathrm{km} \mathrm{s}^{-1}$. Deste modo, o resultado em relação ao Sol é $\Delta v \sin i=0.0 \mathrm{~km} \mathrm{~s}^{-1}$. O mesmo é verdadeiro para Takeda e Tajitsu (2009), onde $v \sin i_{\odot}=2.13 \mathrm{~km} \mathrm{~s}^{-1}$ e $v \sin i=2.27 \mathrm{~km} \mathrm{~s}^{-1}$ para HIP 100963.

${ }^{8}$ A base de dados de correções NLTE INSPECT esta disponível em wwww.inspect-stars.com 


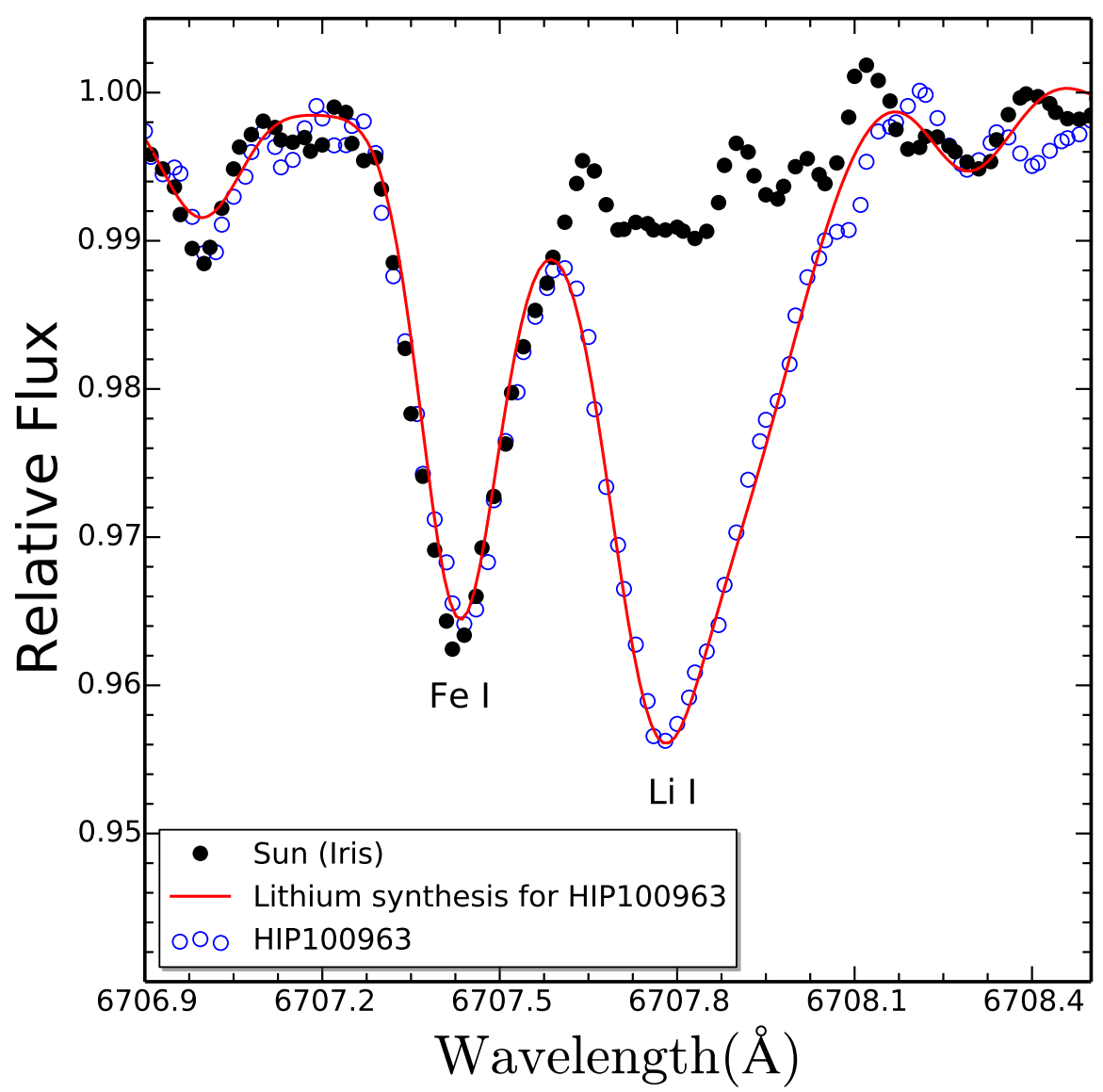

Figura 4.12: Síntese espectral de lítio em 6708 A. Círculos abertos e fechados representam o espectro de HIP 100963 e o Sol, respectivamente, enquanto o espectro sintético é representado pela linha sólida vermelha.

estelares. A soma quadrática das três fontes de incertezas dá um erro de 0.03 dex. Os resultados estão em acordo com as abundâncias de Li de 1.72 dex e 1.7 dex 9 determinadas por Takeda et al. (2007) e Honda et al. (2015), respectivamente.

Meléndez et al. (2012) analisaram a correlação da idade e Li usando o Sol e duas gêmeas solares (18 Sco e HIP 56948). Eles concluíram que o lítio decai com a idade. Outros trabalhos (Baumann et al., 2010; Ramírez et al., 2011; Monroe et al., 2013; Meléndez et al., 2014) confirmaram seus resultados. Na Figura 4.13 é mostrado que HIP 100963 segue a correlação de Li e idade de trabalhos anteriores, estendendo o resultado para idades estelares mais jovens do que o Sol. Também comparei os resultados com modelos non-standard de depleção de Li desenvolvidos para o Sol (Charbonnel e Talon, 2005; do Nascimento et al., 2009; Xiong e Deng, 2009; Denissenkov, 2010; Andrássy e Spruit, 2015). Como pode ser visto, o acordo é bom. Estes modelos anteriores incluem mecanismos de

\footnotetext{
${ }^{9}$ Os erros não foram reportados por Takeda et al. (2007) e Honda et al. (2015).
} 


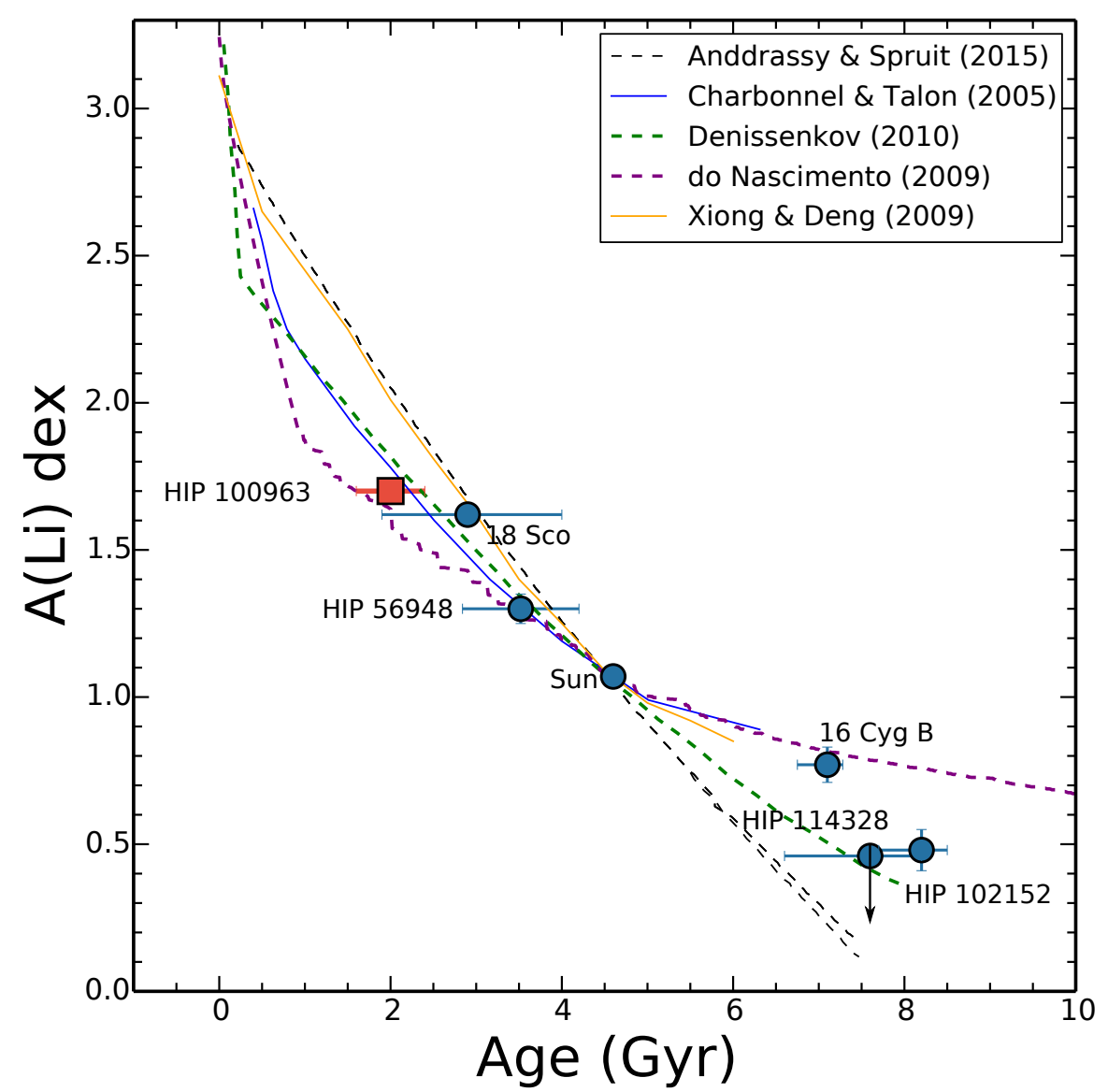

Figura 4.13: Li vs. idade para HIP 100963 (quadrado vermelho) baseado em análise NLTE e idade isocronal. A abundância de Li para outras estrelas analisadas pelo nosso grupo em anteriores trabalhos (Ramírez et al., 2011; Meléndez et al., 2012, Monroe et al., 2013, Meléndez et al., 2014) é mostrado com círculos azuis. Os erros das abundâncias de lítio são menores do que o tamanho do círculo. Os modelos de depleção de Li são também mostrados com diferentes linhas.

transporte fora do modelo solar padrão, permitindo atingir regiões mais profundas do que o limite inferior da camada convectiva.

\subsubsection{Conclusões}

Foi realizado um estudo diferencial de alta precisão para a gêmea solar HIP 100963, baseado em um espectro de alta resolução obtido com o espectrógrafo HIRES no telescópio Keck. Os parâmetros atmosféricos encontrados são: $T_{\text {eff }}=5818 \pm 4 \mathrm{~K}, \log g=4.49 \pm 0.01$ dex, $v_{t}=1.03 \pm 0.01 \mathrm{~km} \mathrm{~s}^{-1}$, e $[\mathrm{Fe} / \mathrm{H}]=-0.003 \pm 0.004$ dex. Embora estes valores estão de acordo com estudos anteriores, atingiu-se uma precisão maior e confirmou-se que HIP 100963 é uma gêmea solar.

Foi obtida uma idade precisa $(2.0 \pm 0.4 \mathrm{Gyr})$, este resultado está em bom acordo com 
a idade obtida através da atividade cromosférica (2.4 \pm 0.3 Gyr) e a idade obtida usando a relação $[\mathrm{Y} / \mathrm{Mg}](2.1 \pm 0.4 \mathrm{Gyr})$.

O padrão de abundâncias com $\mathrm{T}_{\text {cond }}$ antes da correção por GCE é comparável com o enriquecimento dos elementos refratários encontrado em outras gêmeas solares. No entanto, considerando correções por GCE à mesma idade ao Sol, o padrão de abundâncias é parecido ao solar. Isso significa que a HIP 100963 poderia ter formado planetas rochosos, assim como em nosso Sistema Solar. As abundâncias dos elementos dos processos-s e $-r$ são enriquecidas em relação ao Sol. Isto é provavelmente devido a que HIP 100963 é mais jovem do que o Sol.

Finalmente, a abundância de lítio de HIP 100963 segue a correlação entre o Li e idade sugerida na literatura, estendendo a cobertura da idade, para testar modelos de depleção, para estrelas relativamente jovens. 
Capítulo 5

\section{Conclusões e perspectivas}

Nesta dissertação realizei uma análise espectroscópica das gêmeas solares Inti 1, HD 45184 e HIP 100963. Estes espectros foram obtidos usando o espectrógrafo HIRES do telescópio Keck I. A resolução espectral para a Inti 1 e HD 45184 foi de 50000, enquanto para a gêmea solar HIP 100963 foi de 70000. Os espectros foram normalizados e corrigidos por efeito Doppler, para depois medir as larguras equivalentes manualmente.

As temperaturas efetivas foram estimadas (via equilíbrio de excitação diferencial) em $5864 \pm 9,5837 \pm 11$ e $5818 \pm 4$ K, para HD 45184, Inti 1 e HIP 100963, respectivamente. Para validar estes resultados usei as calibrações fotométricas dadas por Casagrande et al. (2010), cujas estimativas são $5835 \pm 59,5765 \pm 67$, e $5804 \pm 62 \mathrm{~K}$, para HD 45184, Inti 1 e HIP 100963, respectivamente. Ambos métodos estão em bom acordo dentro dos erros, validando assim os meus resultados. Note-se que a temperatura efetiva de Inti 1 estimada com as calibrações fotométricas é um pouco menor do que a determinada usando a espectroscopia, provavelmente devido a que as cores desta estrela não são muito precisas.

As gravidades superficiais espectroscópicas para HD 45184, Inti 1 e HIP 100963 foram estimadas em $4.45 \pm 0.03,4.42 \pm 0.03$ e $4.49 \pm 0.01$ dex, respectivamente. Empregou-se também o método trigonométrico, resultando em $4.45 \pm 0.03$ e $4.47 \pm 0.02$ dex, respectivamente, para HD 45184 e HIP 100963. Estes resultados estão em bom acordo com os valores obtidos através do equilíbrio de ionização. O valor da paralaxe da Inti 1 ainda não foi medida, portanto não foi possível estimar a sua gravidade superficial trigonométrica.

As velocidades de microturbulência foram obtidas impondo a não dependência com o logaritmo da largura equivalente reduzida, obtendo para HD 45184, Inti 1 e HIP 100963 os valores de $1.11 \pm 0.02,1.04 \pm 0.02$ e $1.03 \pm 0.01 \mathrm{~km} \mathrm{~s}^{-1}$, e com metalicidades de $0.04 \pm 0.01$, $0.07 \pm 0.01$ e $-0.003 \pm 0.004$, respectivamente. 
Os parâmetros atmosféricos obtidos para a Inti 1 encontram-se dentro da definição de gêmea solar de Ramírez et al. (2009), portanto confirmou-se que esta estrela é uma gêmea solar. Inti 1 é a terceira gêmea solar fraca e junto às gêmeas solares de Önehag et al. (2011) e do Nascimento et al. (2013), poderiam ser usadas para calibrar diferentes sistemas fotométricos. Para a gêmea solar HD 45184, encontrei um excelente acordo quando comparei a média ponderada dos parâmetros atmosféricos encontrados na literatura e os obtidos neste trabalho (ver Tabela 3.2). Os parâmetros atmosféricos de HIP 100963 estão em excelente acordo com estudos anteriores (ver Tabela 4.1). Não obstante, atingiu-se uma maior precisão e confirmou-se que HIP 100963 é uma gêmea solar.

As idades foram obtidas usando o código $\mathrm{q}^{2}$, que emprega as isócronas de Yi et al. (2001). Estas idades foram estimadas em $3.0 \pm 1.0$ e $4.0 \pm 1.1$ e $2.0 \pm 0.4$ Gyr para as gêmeas solares HD 45184, Inti 1 e HIP 100963, respectivamente. As idades também foram determinadas usando a relação $[\mathrm{Y} / \mathrm{Mg}$ ] dada por Nissen (2015), resultando em $3.7 \pm 0.6$ Gyr (HD 45184), $4.1 \pm 0.6$ Gyr (Inti 1) e $2.1 \pm 0.4$ Gyr (HIP 100963). Usei os dados de atividade cromosférica obtidos por Wright et al. (2004), White et al. (2007) e Isaacson e Fischer (2010), para estimar a idade de HIP 100963 em $2.4 \pm 0.3$ Gyr. Estes resultados indicam que a técnica de isócronas é adequada para o cálculo de idades. Apesar dos modelos de Yonsei-Yale não incluem non-standard physics, foi demonstrado que isto não tem efeito nenhum nas isócronas de gêmeas solares. Confirmou-se também que a escolha exata de uma isócrona não tem impacto importante na determinação de idade e massa em relação ao Sol (ver também Meléndez et al., 2014; Tucci Maia et al., 2016).

As abundâncias químicas de 19 elementos foram estimadas para HD 45184 e Inti 1, enquanto para HIP 100963 foram 26 elementos. As abundâncias de HD 45184 mostram um excelente acordo com o trabalho de Nissen (2015), com uma diferença de $\Delta[\mathrm{X} / \mathrm{Fe}]=$ $0.000(\sigma=0.009)$ dex (este trabalho - Nissen (2015)). Este resultado indica que foi atingida uma precisão de 0.01 dex, validando assim os resultados da Inti 1. Para a gêmea solar HIP 100963, suas abundâncias foram comparadas com os resultados de Ramírez et al. (2009), e encontrou-se uma diferença de $\Delta[\mathrm{X} / \mathrm{H}]=0.011(\sigma=0.016)$ dex (Ramírez et al. $(2009)$ - este trabalho). No entanto, dada a qualidade dos dados obtidos para HIP 100963, os meus resultados são mais precisos. Calculou-se a abundância do tripleto de O I usando as grades de NLTE de Ramírez et al. (2007) e Amarsi et al. (2015) e encontrei uma diferença de apenas 0.004 dex. Isso demonstra que a escolha de diferentes grades para correções 
NLTE diferenciais do O I, é desprezível em gêmeas solares. Empregando os modelos de atmosfera de Marcs e Kurucz foram estimadas as abundâncias de HIP 100963, encontrando uma diferença de apenas $0.003(\sigma=0.002)$ dex. Isto confirma que a escolha do modelo de atmosfera não influi significativamente nas abundâncias químicas.

As gêmeas solares HD 45184 e Inti 1 mostram um enriquecimento de 0.076 e 0.025 dex nos elementos refratários em relação aos voláteis. Com o resultado da Inti 1 demonstrei que as anomalias químicas também são encontradas quando o Sol é comparado com gêmeas solares distantes.

Desenvolvi o código terra que emprega os modelos teóricos de Siess et al. (2000) para estimar a massa convectiva de estrelas tipo solar $\left(0.017 \mathrm{M}_{\odot}\right.$ e $0.019 \mathrm{M}_{\odot}$ para HD 45184 e Inti1). Este código adota as abundâncias de Wasson e Kallemeyn (1988) e Allègre et al. (2001) como composições químicas de material condrítico e terrestre, respectivamente. Usando terra estime a massa do material rochoso necessário para reproduzir o padrão de abundâncias de HD $45184\left(\approx 3.5 \mathrm{M}_{\oplus}\right)$ e Inti $1\left(\approx 1.5 \mathrm{M}_{\oplus}\right)$. Chambers $(2010)$ reproduziu o padrão de abundâncias da média das 11 gêmeas solares estudadas por Meléndez et al. (2009), não obstante ele não consegue um bom ajuste dos elementos voláteis, ao contrario do código $q^{2}$ que consegue um melhor ajuste em todo o padrão de abundâncias (ver Figura 3.16). Também foi confirmado através do código terra que o carbonáceo CM representa melhor o padrão de abundâncias observado por Meléndez et al. (2009) (ver Figura 3.19).

O padrão de abundâncias químicas de HIP 100963 mostra um ajuste de inclinação positiva com a temperatura de condensação com uma dispersão de 0.019 dex, que é maior do que a média da barra do erro das abundâncias (0.008 dex). Depois de corrigir por GCE à mesma idade do Sol, o resultado mostra um padrão de abundâncias similar ao do Sol, com uma dispersão de 0.016 dex, que está em excelente acordo com a média da barra do erro (0.015 dex). No cenário de Meléndez et al. (2009), isso significa que HIP 100963 e a Inti 1 poderiam ter formado planetas rochosos, assim como em nosso Sistema Solar. Com estes resultados foi confirmado que as estrelas jovens são mais ricas em elementos refratários do que as estrelas velhas (Ramírez et al., 2014; Adibekyan et al., 2014; Nissen, 2015; Spina et al., 2016).

De modo igual que para a 18 Sco (Meléndez et al. 2014), com o estudo de abundâncias de HIP 100963, foi confirmado que os elementos de captura de nêutrons são enriquecidos em estrelas jovens. Este comportamento também é observado em estrelas jovens de 
aglomerados abertos (D'Orazi et al., 2009; Maiorca et al., 2011; D'Orazi et al., 2012).

A velocidade de macroturbulência de HIP 100963 foi estimada em $3.43 \mathrm{kms}^{-1}$ (Tucci Maia et al., 2015). Este resultado foi comparado com a velocidade de macroturbulência derivada usando a calibração de Dos Santos et al. (2016), que envolve a $T_{\text {eff }}$ e a $\log g$, resultando em $3.40 \mathrm{kms}^{-1}$, e mostrando assim um excelente acordo.

A abundância de lítio de HIP 100963 foi estimada com alta precisão através da síntese espectral $(1.67 \pm 0.03 \mathrm{dex})$, e mostra um bom acordo com os resultados da literatura. Com a abundância de lítio em NLTE $(1.70 \pm 0.03$ dex $)$ e a idade isocronal, foi possível confirmar a correlação lítio e idade observada anteriormente por Baumann et al. (2010); Ramírez et al. (2011); Meléndez et al. (2012); Monroe et al. (2013); Meléndez et al. (2014). A abundância de Li nas gêmeas solares Inti 1 e HD 45184 não foi medida devido à cobertura espectral limitada (3190-5980 ^) desses dados. Futuras observações permitirão determinar a abundância de Li de Inti 1 e verificar se as gêmeas solares fracas seguem a correlação de Li e idade.

Recentemente, os astrônomos do projeto do Gaia-ESA têm observado 400000 asteroides, e estão calculando as refletâncias destes asteroides empregando análogas solares. Não obstante, há problemas com a lista de análogas solares devido a que são muito brilhantes para serem observadas com o mesmo detetor. O grupo de Gaia-ESA está procurando análogas solares com magnitudes $\mathrm{V}>11$, e a gêmea solar Inti $1(\mathrm{~V}=12.8)$ vai ser usada para determinar estas refletâncias. Seria importante fazer uma procura de mais gêmeas solares fracas.

As técnicas aprendidas ao longo deste trabalho podem ser aplicadas para diferentes objetivos, tais como para estudar efeitos da evolução estelar na composição química de estrelas (depleção do lítio), na procura de planetas de tipo terrestre analisando as abundâncias de gêmeas solares (pela assinatura de deficiencia de elementos refratários), e para estudar a evolução química da Galáxia. 


\section{Referências Bibliográficas}

Adibekyan V. Z., González Hernández J. I., Delgado Mena E., Sousa S. G., Figueira P., Santos N. C., Israelian G., Solar analogs with and without planets: $T_{c}$ trends and Galactic evolution. In EAS Publications Series, vol. 67 of EAS Publications Series, 2014, p. 105

Alexander C. M. O., Boss A. P., Carlson R. W., The Early Evolution of the Inner Solar System: A Meteoritic Perspective, Science, 2001, vol. 293, p. 64

Allègre C., Manhès G., Lewin É., Chemical composition of the Earth and the volatility control on planetary genetics, Earth and Planetary Science Letters, 2001, vol. 185, p. 49

Allende Prieto C., Barklem P. S., Lambert D. L., Cunha K., $\mathrm{S}^{4} \mathrm{~N}$ : A spectroscopic survey of stars in the solar neighborhood. The Nearest 15 pc, A\&A, 2004, vol. 420, p. 183

Alonso A., Arribas S., Martinez-Roger C., The empirical scale of temperatures of the low main sequence (F0V-K5V)., A\&A, 1996, vol. 313, p. 873

Amarsi A. M., Asplund M., Collet R., Leenaarts J., Non-LTE oxygen line formation in 3D hydrodynamic model stellar atmospheres, ArXiv e-prints, 2015

Ammons S. M., Robinson S. E., Strader J., Laughlin G., Fischer D., Wolf A., The N2K Consortium. IV. New Temperatures and Metallicities for More than 100,000 FGK Dwarfs, ApJ, 2006, vol. 638, p. 1004

Andrássy R., Spruit H. C., Convective settling in main sequence stars: Li and Be depletion, A\&A, 2015, vol. 579, p. A122 
Andre P., Ward-Thompson D., Barsony M., From Prestellar Cores to Protostars: the Initial Conditions of Star Formation, Protostars and Planets IV, 2000, p. 59

Andrews S. M., Wilner D. J., Zhu Z., Birnstiel T., Carpenter J. M., Perez L. M., Bai X.-N., Oberg K. I., Hughes A. M., Isella A., Ricci L., Ringed Substructure and a Gap at 1 AU in the Nearest Protoplanetary Disk, ArXiv e-prints, 2016

Asplund M., Grevesse N., Sauval A. J., Scott P., The Chemical Composition of the Sun, ARA\&A, 2009, vol. 47, p. 481

Barbuy B., , PhD thesis, Université de Paris VII, (1982), 1982, Tese de Doutorado

Barklem P. S., Piskunov N., O'Mara B. J., A list of data for the broadening of metallic lines by neutral hydrogen collisions, A\&AS, 2000, vol. 142, p. 467

Baumann P., Ramírez I., Meléndez J., Asplund M., Lind K., Lithium depletion in solar-like stars: no planet connection, A\&A, 2010, vol. 519, p. A87

Bedell M., Meléndez J., Bean J. L., Ramírez I., Asplund M., Alves-Brito A., Casagrande L., Dreizler S., Monroe T., Spina L., Tucci Maia M., The Solar Twin Planet Search. II. A Jupiter twin around a solar twin, A\&A, 2015, vol. 581, p. A34

Bedell M., Meléndez J., Bean J. L., Ramírez I., Leite P., Asplund M., Stellar Chemical Abundances: In Pursuit of the Highest Achievable Precision, ApJ, 2014, vol. 795, p. 23

Bensby T., Feltzing S., Oey M. S., Exploring the Milky Way stellar disk. A detailed elemental abundance study of $714 \mathrm{~F}$ and $\mathrm{G}$ dwarf stars in the solar neighbourhood, A\&A, 2014, vol. 562, p. A71

Bertout C., T Tauri stars - Wild as dust, ARA\&A, 1989, vol. 27, p. 351

Bessell M. S., Castelli F., Plez B., Erratum: Model atmospheres broad-band colors, bolometric corrections and temperature calibrations for O-M stars, A\&A, 1998, vol. 337, p. 321

Bisterzo S., Travaglio C., Gallino R., Wiescher M., Käppeler F., Galactic Chemical Evolution and Solar s-process Abundances: Dependence on the ${ }^{13} \mathrm{C}$-pocket Structure, ApJ, 2014, vol. 787, p. 10 
Booth A. J., Blackwell D. E., Shallis M. J., Analysis of MN I lines in the solar spectrum using accurate oscillator strengths, MNRAS, 1984, vol. 209, p. 77

Bruning D. H., The applicability of the Fourier convolution theorem to the analysis of late-type stellar spectra, ApJ, 1984, vol. 281, p. 830

Caffe M. W., Hohenberg C. M., Swindle T. D., Goswami J. N., Evidence in meteorites for an active early sun, ApJ, 1987, vol. 313, p. L31

Carlos M., Análise química diferencial detalhada de estrelas de tipo solar pobres em metais com e sem planetas', São Paulo: Instituto Nacional de Pesquisas Espaciais - INPE, 2015, Dissertação de Mestrado

Carlos M., Nissen P. E., Meléndez J., Correlation between lithium abundances and ages of solar twin stars, A\&A, 2016, vol. 587, p. A100

Casagrande L., Portinari L., Flynn C., Accurate fundamental parameters for lower mainsequence stars, MNRAS, 2006, vol. 373, p. 13

Casagrande L., Ramírez I., Meléndez J., Asplund M., The Infrared Colors of the Sun, ApJ, 2012, vol. 761, p. 16

Casagrande L., Ramírez I., Meléndez J., Bessell M., Asplund M., An absolutely calibrated $\mathrm{T}_{\text {eff }}$ scale from the infrared flux method. Dwarfs and subgiants, A\&A, 2010, vol. 512, p. A54

Castelli F., Kurucz R. L., New Grids of ATLAS9 Model Atmospheres, ArXiv Astrophysics e-prints, 2004

Cayrel de Strobel G., Stars resembling the Sun, A\&A Rev., 1996, vol. 7, p. 243

Chambers J. E., Stellar Elemental Abundance Patterns: Implications for Planet Formation, ApJ, 2010, vol. 724, p. 92

Chambers J. E., Wetherill G. W., Making the Terrestrial Planets: N-Body Integrations of Planetary Embryos in Three Dimensions, Icarus, 1998, vol. 136, p. 304 
Chanamé J., Ramírez I., Toward Precise Ages for Single Stars in the Field. Gyrochronology Constraints at Several Gyr Using Wide Binaries. I. Ages for Initial Sample, ApJ, 2012, vol. 746 , p. 102

Charbonnel C., Talon S., New generation stellar models with rotation and internal gravity waves: The Li dip revisited. In EAS Publications Series, vol. 17 of EAS Publications Series, 2005, p. 167

Cochran W. D., Hatzes A. P., Butler R. P., Marcy G. W., The Discovery of a Planetary Companion to 16 Cygni B, ApJ, 1997, vol. 483, p. 457

Cohen J. G., Christlieb N., Qian Y.-Z., Wasserburg G. J., Abundance Analysis of HE 2148-1247, A Star with Extremely Enhanced Neutron Capture Elements, ApJ, 2003, vol. 588 , p. 1082

Cox A. N., Allen's astrophysical quantities, 2000

Cutri R. M., et al. VizieR Online Data Catalog: WISE All-Sky Data Release (Cutri+ 2012), VizieR Online Data Catalog, 2012, vol. 2311, p. 0

Cutri R. M., Skrutskie M. F., van Dyk S., Beichman C. A., Carpenter J. M., Chester T., Cambresy L., Evans T., Fowler J., Gizis J., Howard E., VizieR Online Data Catalog: 2MASS All-Sky Catalog of Point Sources (Cutri+ 2003), VizieR Online Data Catalog, 2003, vol. 2246, p. 0

Datson J., Flynn C., Portinari L., New solar twins and the metallicity and temperature scales of the Geneva-Copenhagen Survey, MNRAS, 2012, vol. 426, p. 484

Datson J., Flynn C., Portinari L., Solar analogues and solar twins in the HARPS archive, MNRAS, 2014, vol. 439, p. 1028

Delgado Mena E., Israelian G., González Hernández J. I., Sousa S. G., Mortier A., Santos N. C., Adibekyan V. Z., Fernandes J., Rebolo R., Udry S., Mayor M., Li depletion in solar analogues with exoplanets. Extending the sample, A\&A, 2014, vol. 562, p. A92

Denissenkov P. A., A Model of Magnetic Braking of Solar Rotation that Satisfies Observational Constraints, ApJ, 2010, vol. 719, p. 28 
di Francesco J., Evans II N. J., Caselli P., Myers P. C., Shirley Y., Aikawa Y., Tafalla M., An Observational Perspective of Low-Mass Dense Cores I: Internal Physical and Chemical Properties, Protostars and Planets V, 2007, pp 17-32

do Nascimento Jr. J. D., Castro M., Meléndez J., Bazot M., Théado S., Porto de Mello G. F., de Medeiros J. R., Age and mass of solar twins constrained by lithium abundance, A\&A, 2009, vol. 501, p. 687

do Nascimento Jr. J.-D., García R. A., Mathur S., Anthony F., Barnes S. A., Meibom S., da Costa J. S., Castro M., Salabert D., Ceillier T., Rotation Periods and Ages of Solar Analogs and Solar Twins Revealed by the Kepler Mission, ApJ, 2014, vol. 790, p. L23 do Nascimento Jr. J.-D., Takeda Y., Meléndez J., da Costa J. S., Porto de Mello G. F., Castro M., The Future of the Sun: An Evolved Solar Twin Revealed by CoRoT, ApJ, 2013, vol. 771, p. L31

Donahue R. A., Surface differential rotation in a sample of cool dwarf stars, New Mexico State University, University Park., 1993, Tese de Doutorado

D’Orazi V., Biazzo K., Desidera S., Covino E., Andrievsky S. M., Gratton R. G., The chemical composition of nearby young associations: s-process element abundances in AB Doradus, Carina-Near and Ursa Major, MNRAS, 2012, vol. 423, p. 2789

D’Orazi V., Magrini L., Randich S., Galli D., Busso M., Sestito P., Enhanced Production of Barium in Low-Mass Stars: Evidence from Open Clusters, ApJ, 2009, vol. 693, p. L31

Dos Santos L., Meléndez J., Do Nascimento J. D., Bedell M., Ramírez I., Jacob L., Asplund M., Spina L., Dreizler S., Alves-Brito A., Casagrande L., The Solar Twin Planet Search. V. The Sun as a regular rotator and evidence for a new rotational braking law for Sun-like stars, ApJS, 2016, p. submitted

Ehrenfreund P., Charnley S. B., Organic Molecules in the Interstellar Medium, Comets, and Meteorites: A Voyage from Dark Clouds to the Early Earth, ARA\&A, 2000, vol. 38, p. 427

Epstein C. R., Johnson J. A., Dong S., Udalski A., Gould A., Becker G., Chemical Composition of Faint (I 21 mag) Microlensed Bulge Dwarf OGLE-2007-BLG-514S, ApJ, 2010, vol. 709, p. 447 
Feigelson E. D., Montmerle T., High-Energy Processes in Young Stellar Objects, ARA\&A, 1999, vol. 37 , p. 363

Freedman R. A., Kaufmann W. J., Universe, 2005

Gonzalez G., Carlson M. K., Tobin R. W., Parent stars of extrasolar planets - XI. Trends with condensation temperature revisited, MNRAS, 2010, vol. 407, p. 314

González Hernández J. I., Bonifacio P., A new implementation of the infrared flux method using the 2MASS catalogue, A\&A, 2009, vol. 497, p. 497

González Hernández J. I., Israelian G., Santos N. C., Sousa S., Delgado-Mena E., Neves V., Udry S., Searching for the Signatures of Terrestrial Planets in Solar Analogs, ApJ, 2010, vol. 720, p. 1592

Gray D. F., The Observation and Analysis of Stellar Photospheres, 2005

Greaves J. S., Disks Around Stars and the Growth of Planetary Systems, Science, 2005, vol. 307 , p. 68

Gustafsson B., Edvardsson B., Eriksson K., Jørgensen U. G., Nordlund Å., Plez B., A grid of MARCS model atmospheres for late-type stars. I. Methods and general properties, A\&A, 2008, vol. 486, p. 951

Hayashi C., Evolution of Protostars, ARA\&A, 1966, vol. 4, p. 171

Hayashi C., Nakazawa K., Nakagawa Y., Formation of the solar system. In Protostars and Planets II , 1985, p. 1100

Henry T. J., Soderblom D. R., Donahue R. A., Baliunas S. L., A Survey of Ca II H and K Chromospheric Emission in Southern Solar-Type Stars, AJ, 1996, vol. 111

Høg E., Fabricius C., Makarov V. V., Urban S., Corbin T., Wycoff G., Bastian U., Schwekendiek P., Wicenec A., The Tycho-2 catalogue of the 2.5 million brightest stars, A\&A, 2000, vol. 355 , p. L27

Holmberg J., Flynn C., Portinari L., The colours of the Sun, MNRAS, 2006, vol. 367, p. 449 
Honda S., Notsu Y., Maehara H., Notsu S., Shibayama T., Nogami D., Shibata K., High dispersion spectroscopy of solar-type superflare stars. III. Lithium abundances, PASJ, 2015 , vol. 67 , p. 85

Hui-Bon-Hoa A., The Toulouse Geneva Evolution Code (TGEC), Ap\&SS, 2008, vol. 316, p. 55

Isaacson H., Fischer D., Chromospheric Activity and Jitter Measurements for 2630 Stars on the California Planet Search, ApJ, 2010, vol. 725, p. 875

Jasmim F. L., Lazzaro D., Carvano J. M. F., Mothé-Diniz T., Hasselmann P. H., Mineralogical investigation of several $\mathrm{Q}_{p}$ asteroids and their relation to the Vesta family, $\mathrm{A} \& \mathrm{~A}$, 2013, vol. 552, p. A85

Jofré P., Mädler T., Gilmore G., Casey A. R., Soubiran C., Worley C., Climbing the cosmic ladder with stellar twins, MNRAS, 2015, vol. 453, p. 1428

Just A., Jahrei H., The main sequence from $\mathrm{F}$ to $\mathrm{K}$ stars of the solar neighbourhood in SDSS colours, Astronomische Nachrichten, 2008, vol. 329, p. 790

Karakas A. I., Campbell S. W., Stancliffe R. J., Is Extra Mixing Really Needed in Asymptotic Giant Branch Stars?, ApJ, 2010, vol. 713, p. 374

King J. R., Boesgaard A. M., Schuler S. C., Keck HIRES Spectroscopy of Four Candidate Solar Twins, AJ, 2005, vol. 130, p. 2318

Kiselman D., Pereira T. M. D., Gustafsson B., Asplund M., Meléndez J., Langhans K., Is the solar spectrum latitude-dependent?. An investigation with SST/TRIPPEL, A\&A, 2011, vol. 535, p. A14

Lachaume R., Dominik C., Lanz T., Habing H. J., Age determinations of main-sequence stars: combining different methods, A\&A, 1999, vol. 348, p. 897

Lawton A. T., Wright P., A planetary system for Gamma Cephei?, Journal of the British Interplanetary Society, 1989, vol. 42, p. 335

Lazzaro D., Angeli C. A., Carvano J. M., Mothé-Diniz T., Duffard R., Florczak M., S ${ }^{3}$ OS 2: the visible spectroscopic survey of 820 asteroids, Icarus, 2004, vol. 172, p. 179 
Li T. D., Bi S. L., Liu K., Tian Z. J., Shuai G. Z., Stellar parameters and seismological analysis of the star 18 Scorpii, A\&A, 2012, vol. 546, p. A83

Lind K., Asplund M., Barklem P. S., Departures from LTE for neutral Li in late-type stars, A\&A, 2009, vol. 503, p. 541

Liu F., Asplund M., Ramírez I., Yong D., Meléndez J., A high-precision chemical abundance analysis of the HAT-P-1 stellar binary: constraints on planet formation, MNRAS, 2014, vol. 442, p. L51

Lodders K., Solar System Abundances and Condensation Temperatures of the Elements, ApJ, 2003, vol. 591, p. 1220

Lodders K., Solar System Abundances of the Elements. In Principles and Perspectives in Cosmochemistry , 2010, p. 379

Lodders K., Palme H., Gail H.-P., Abundances of the Elements in the Solar System, Landolt Börnstein, 2009

Mahdi D., Soubiran C., Blanco-Cuaresma S., Chemin L., Solar twins in the ELODIE archive, ArXiv e-prints, 2016

Maiorca E., Randich S., Busso M., Magrini L., Palmerini S., s-processing in the Galactic Disk. I. Super-solar Abundances of Y, Zr, La, and Ce in Young Open Clusters, ApJ, 2011, vol. 736, p. 120

Maldonado J., Eiroa C., Villaver E., Montesinos B., Mora A., Searching for signatures of planet formation in stars with circumstellar debris discs, A\&A, 2015a, vol. 579, p. A20

Maldonado J., Eiroa C., Villaver E., Montesinos B., Mora A., Searching for signatures of planet formation in stars with circumstellar debris discs, A\&A, 2015b, vol. 579, p. A20

Mallama A., Sloan Magnitudes for the Brightest Stars, Journal of the American Association of Variable Star Observers (JAAVSO), 2014, vol. 42, p. 443

Mamajek E. E., Hillenbrand L. A., Improved Age Estimation for Solar-Type Dwarfs Using Activity-Rotation Diagnostics, ApJ, 2008, vol. 687, p. 1264 
Mayor M., Queloz D., A Jupiter-mass companion to a solar-type star, Nature, 1995, vol. 378 , p. 355

McWilliam A., Barium Abundances in Extremely Metal-poor Stars, AJ, 1998, vol. 115, p. 1640

Meléndez J., Espectroscopia no infravermelho abundâncias de oxigênio em estrelas pobres em metais, São Paulo: Universidade de São Paulo, 2001, Tese de Doutorado

Meléndez J., Abundâncias de alta precisão em estrelas gêmeas do Sol: impacto em calibrações fundamentais, planetas e evolução estelar., São Paulo: Universidade de São Paulo, 2014, Tese de Doutorado

Meléndez J., Asplund M., Gustafsson B., Yong D., The Peculiar Solar Composition and Its Possible Relation to Planet Formation, ApJ, 2009, vol. 704, p. L66

Meléndez J., Bergemann M., Cohen J. G., Endl M., Karakas A. I., Ramírez I., Cochran W. D., Yong D., MacQueen P. J., Kobayashi C., Asplund M., The remarkable solar twin HIP 56948: a prime target in the quest for other Earths, A\&A, 2012, vol. 543, p. A29

Meléndez J., Dodds-Eden K., Robles J. A., HD 98618: A Star Closely Resembling Our Sun, ApJ, 2006a, vol. 641, p. L133

Meléndez J., Dodds-Eden K., Robles J. A., HD 98618: A Star Closely Resembling Our Sun, ApJ, 2006b, vol. 641, p. L133

Meléndez J., Ramírez I., HIP 56948: A Solar Twin with a Low Lithium Abundance, ApJ, 2007, vol. 669, p. L89

Meléndez J., Ramírez I., Karakas A. I., Yong D., Monroe T. R., Bedell M., Bergemann M., Asplund M., Tucci Maia M., Bean J., do Nascimento Jr. J.-D., Bazot M., Alves-Brito A., Freitas F. C., Castro M., 18 Sco: A Solar Twin Rich in Refractory and Neutron-capture Elements. Implications for Chemical Tagging, ApJ, 2014, vol. 791, p. 14

Meléndez J., Schirbel L., Monroe T. R., Yong D., Ramírez I., Asplund M., HIP 114328: a new refractory-poor and Li-poor solar twin, A\&A, 2014, vol. 567, p. L3 
Meléndez J., Schuster W. J., Silva J. S., Ramírez I., Casagrande L., Coelho P., uvby- $\beta$ photometry of solar twins . The solar colors, model atmospheres, and the $\mathrm{T}_{\text {eff }}$ and metallicity scales, A\&A, 2010, vol. 522, p. A98

Monroe T. R., Meléndez J., Ramírez I., Yong D., Bergemann M., Asplund M., Bedell M., Tucci Maia M., Bean J., Lind K., Alves-Brito A., Casagrande L., Castro M., do Nascimento J.-D., Bazot M., Freitas F. C., High Precision Abundances of the Old Solar Twin HIP 102152: Insights on Li Depletion from the Oldest Sun, ApJ, 2013, vol. 774, p. L32

Montmerle T., Augereau J.-C., Chaussidon M., Gounelle M., Marty B., Morbidelli A., From Suns to Life: A Chronological Approach to the History of Life on Earth 3. Solar System Formation and Early Evolution: the First 100 Million Years, Earth Moon and Planets, 2006, vol. 98, p. 39

Murray N., Star Formation Efficiencies and Lifetimes of Giant Molecular Clouds in the Milky Way, ApJ, 2011, vol. 729, p. 133

Neves V., Santos N. C., Sousa S. G., Correia A. C. M., Israelian G., Chemical abundances of 451 stars from the HARPS GTO planet search program. Thin disc, thick disc, and planets, A\&A, 2009, vol. 497, p. 563

Nissen P. E., High-precision abundances of elements in solar twin stars. Trends with stellar age and elemental condensation temperature, A\&A, 2015, vol. 579, p. A52

Nissen P. E., Hoeg E., Schuster W. J., Surface Gravities of Metal-Poor Stars Derived from HIPPARCOS Parallaxes. In Hipparcos - Venice '97, vol. 402 of ESA Special Publication, 1997 , p. 225

Nordström B., Mayor M., Andersen J., Holmberg J., Pont F., Jørgensen B. R., Olsen E. H., Udry S., Mowlavi N., The Geneva-Copenhagen survey of the Solar neighbourhood. Ages, metallicities, and kinematic properties of $14000 \mathrm{~F}$ and G dwarfs, A\&A, 2004, vol. 418, p. 989

Notsu Y., Honda S., Maehara H., Notsu S., Shibayama T., Nogami D., Shibata K., High dispersion spectroscopy of solar-type superflare stars. I. Temperature, surface gravity, metallicity, and vsin i, PASJ, 2015a, vol. 67, p. 32 
Notsu Y., Honda S., Maehara H., Notsu S., Shibayama T., Nogami D., Shibata K., High dispersion spectroscopy of solar-type superflare stars. II. Stellar rotation, starspots, and chromospheric activities, PASJ, 2015b, vol. 67, p. 33

Noyes R. W., Hartmann L. W., Baliunas S. L., Duncan D. K., Vaughan A. H., Rotation, convection, and magnetic activity in lower main-sequence stars, ApJ, 1984, vol. 279, p. 763

Önehag A., Korn A., Gustafsson B., Stempels E., Vandenberg D. A., M67-1194, an unusually Sun-like solar twin in M67, A\&A, 2011, vol. 528, p. A85

Palme H., Are There Chemical Gradients in the Inner Solar System?, Space Sci. Rev., 2000, vol. 92 , p. 237

Pasquini L., Biazzo K., Bonifacio P., Randich S., Bedin L. R., Solar twins in M 67, A\&A, 2008, vol. 489 , p. 677

Paunzen E., A new catalogue of Strömgren-Crawford uvby $\beta$ photometry, A\&A, 2015, vol. 580, p. A23

Petit P., Dintrans B., Solanki S. K., Donati J.-F., Aurière M., Lignières F., Morin J., Paletou F., Ramirez Velez J., Catala C., Fares R., Toroidal versus poloidal magnetic fields in Sun-like stars: a rotation threshold, MNRAS, 2008, vol. 388, p. 80

Pickles A., Depagne É., All-Sky Spectrally Matched UBVRI-ZY and u' g' r' i' z' Magnitudes for Stars in the Tycho2 Catalog, PASP, 2010, vol. 122, p. 1437

Planck Collaboration Adam R., Ade P. A. R., Aghanim N., Akrami Y., Alves M. I. R., Arnaud M., Arroja F., Aumont J., Baccigalupi C., et al. Planck 2015 results. I. Overview of products and scientific results, ArXiv e-prints, 2015

Pollack J. B., Hubickyj O., Bodenheimer P., Lissauer J. J., Podolak M., Greenzweig Y., Formation of the Giant Planets by Concurrent Accretion of Solids and Gas, Icarus, 1996, vol. 124 , p. 62

Porto de Mello G. F., da Silva L., HR 6060: The Closest Ever Solar Twin?, ApJ, 1997, vol. 482 , p. L89 
Porto de Mello G. F., da Silva R., da Silva L., de Nader R. V., A photometric and spectroscopic survey of solar twin stars within 50 parsecs of the Sun. I. Atmospheric parameters and color similarity to the Sun, A\&A, 2014, vol. 563, p. A52

Ramírez I., Allende Prieto C., Lambert D. L., Oxygen abundances in nearby stars. Clues to the formation and evolution of the Galactic disk, A\&A, 2007, vol. 465, p. 271

Ramírez I., Allende Prieto C., Lambert D. L., Oxygen Abundances in Nearby FGK Stars and the Galactic Chemical Evolution of the Local Disk and Halo, ApJ, 2013, vol. 764, p. 78

Ramírez I., Asplund M., Baumann P., Meléndez J., Bensby T., A possible signature of terrestrial planet formation in the chemical composition of solar analogs, A\&A, 2010, vol. 521, p. A33

Ramírez I., Khanal S., Aleo P., Sobotka A., Liu F., Casagrande L., Meléndez J., Yong D., Lambert D. L., Asplund M., The Dissimilar Chemical Composition of the Planet-hosting Stars of the XO-2 Binary System, ApJ, 2015, vol. 808, p. 13

Ramírez I., Meléndez J., The Effective Temperature Scale of FGK Stars. II. $\mathrm{T}_{\text {eff }}$ :Color: $[\mathrm{Fe} / \mathrm{H}]$ Calibrations, ApJ, 2005, vol. 626, p. 465

Ramírez I., Meléndez J., Asplund M., Accurate abundance patterns of solar twins and analogs. Does the anomalous solar chemical composition come from planet formation?, A\&A, 2009, vol. 508, p. L17

Ramírez I., Meléndez J., Asplund M., Chemical signatures of planets: beyond solar-twins, A\&A, 2014, vol. 561, p. A7

Ramírez I., Meléndez J., Bean J., Asplund M., Bedell M., Monroe T., Casagrande L., Schirbel L., Dreizler S., Teske J., Tucci Maia M., Alves-Brito A., Baumann P., The Solar Twin Planet Search. I. Fundamental parameters of the stellar sample, A\&A, 2014, vol. 572 , p. A48

Ramírez I., Meléndez J., Cornejo D., Roederer I. U., Fish J. R., Elemental Abundance Differences in the 16 Cygni Binary System: A Signature of Gas Giant Planet Formation?, ApJ, 2011, vol. 740, p. 76 
Ramírez I., Michel R., Sefako R., Tucci Maia M., Schuster W. J., van Wyk F., Meléndez J., Casagrande L., Castilho B. V., The UBV $(\mathrm{RI})_{C}$ Colors of the Sun, ApJ, 2012, vol. 752, p. 5

Reddy B. E., Tomkin J., Lambert D. L., Allende Prieto C., The chemical compositions of Galactic disc F and G dwarfs, MNRAS, 2003, vol. 340, p. 304

Reipurth B., Jewitt D., Keil K., Protostars and Planets V, Protostars and Planets V, 2007

Rutten R. J., Radiative Transfer in Stellar Atmospheres, 2003

Saar S. H., Osten R. A., Rotation, turbulence and evidence for magnetic fields in southern dwarfs, MNRAS, 1997, vol. 284, p. 803

Saffe C., Flores M., Buccino A., HD 80606: searching for the chemical signature of planet formation, A\&A, 2015, vol. 582, p. A17

Schlafly E. F., Finkbeiner D. P., Measuring Reddening with Sloan Digital Sky Survey Stellar Spectra and Recalibrating SFD, ApJ, 2011, vol. 737, p. 103

Schlegel D. J., Finkbeiner D. P., Davis M., Maps of Dust Infrared Emission for Use in Estimation of Reddening and Cosmic Microwave Background Radiation Foregrounds, ApJ, 1998, vol. 500, p. 525

Schneider J., Dedieu C., Le Sidaner P., Savalle R., Zolotukhin I., Defining and cataloging exoplanets: the exoplanet.eu database, A\&A, 2011, vol. 532, p. A79

Schuler S. C., Flateau D., Cunha K., King J. R., Ghezzi L., Smith V. V., Abundances of Stars with Planets: Trends with Condensation Temperature, ApJ, 2011, vol. 732, p. 55

Shu F. H., Adams F. C., Lizano S., Star formation in molecular clouds - Observation and theory, ARA\&A, 1987, vol. 25, p. 23

Siess L., Dufour E., Forestini M., An internet server for pre-main sequence tracks of lowand intermediate-mass stars, A\&A, 2000, vol. 358, p. 593

Simmerer J., Sneden C., Cowan J. J., Collier J., Woolf V. M., Lawler J. E., The Rise of the s-Process in the Galaxy, ApJ, 2004, vol. 617, p. 1091 
Sneden C. A., Carbon and Nitrogen Abundances in Metal-Poor Stars., THE UNIVERSITY OF TEXAS AT AUSTIN., 1973, Tese de Doutorado

Soderblom D. R., Rotational studies of late-type stars. II - Ages of solar-type stars and the rotational history of the sun, ApJS, 1983, vol. 53, p. 1

Sousa S. G., Santos N. C., Mayor M., Udry S., Casagrande L., Israelian G., Pepe F., Queloz D., Monteiro M. J. P. F. G., Spectroscopic parameters for 451 stars in the HARPS GTO planet search program. Stellar $[\mathrm{Fe} / \mathrm{H}]$ and the frequency of exo-Neptunes, A\&A, 2008, vol. 487 , p. 373

Spina L., Meléndez J., Ramírez I., Planet signatures and effect of the chemical evolution of the Galactic thin-disk stars, A\&A, 2016, vol. 585, p. A152

Takeda Y., Fundamental Parameters and Elemental Abundances of 160 F-G-K Stars Based on OAO Spectrum Database, PASJ, 2007, vol. 59, p. 335

Takeda Y., Hashimoto O., Taguchi H., Yoshioka K., Takada-Hidai M., Saito Y., Honda S., Non-LTE Line-Formation and Abundances of Sulfur and Zinc in F, G, and K Stars, PASJ, 2005, vol. 57, p. 751

Takeda Y., Kawanomoto S., Honda S., Ando H., Sakurai T., Behavior of Li abundances in solar-analog stars. Evidence for line-width dependence, A\&A, 2007, vol. 468, p. 663

Takeda Y., Tajitsu A., High-Dispersion Spectroscopic Study of Solar Twins: HIP 56948, HIP 79672, and HIP 100963, PASJ, 2009, vol. 61, p. 471

Tucci Maia M., Meléndez J., Castro M., Asplund M., Ramírez I., Monroe T. R., do Nascimento Jr. J. D., Yong D., Shallow extra mixing in solar twins inferred from Be abundances, A\&A, 2015, vol. 576, p. L10

Tucci Maia M., Meléndez J., Ramírez I., High Precision Abundances in the 16 Cyg Binary System: A Signature of the Rocky Core in the Giant Planet, ApJ, 2014, vol. 790, p. L25

Tucci Maia M., Ramírez I., Meléndez J., Bedell M., Bean J. L., Asplund M., The Solar Twin Planet Search III. The $[\mathrm{Y} / \mathrm{Mg}]$ clock: estimating stellar ages of solar-type stars, ArXiv e-prints, 2016 
Unsold A., Physik der Sternatmospharen, MIT besonderer Berucksichtigung der Sonne., 1955

Valenti J. A., Fischer D. A., Spectroscopic Properties of Cool Stars (SPOCS). I. 1040 F, G, and K Dwarfs from Keck, Lick, and AAT Planet Search Programs, ApJS, 2005, vol. 159, p. 141

van Leeuwen F., Validation of the new Hipparcos reduction, A\&A, 2007, vol. 474, p. 653

Vogt S. S., Allen S. L., Bigelow B. C., Bresee L., Brown B., Cantrall T., Conrad A., Couture M., Delaney C., Epps H. W., Hilyard D., Hilyard D. F., Horn E., Jern N., Kanto D., Keane M. J., Kibrick R. I., Lewis J. W., Osborne J., Pardeilhan G. H., HIRES: the high-resolution echelle spectrometer on the Keck 10-m Telescope. In Instrumentation in Astronomy VIII , vol. 2198 of Society of Photo-Optical Instrumentation Engineers (SPIE) Conference Series, 1994, p. 362

Waenke H., Dreibus G., Chemical composition and accretion history of terrestrial planets, Philosophical Transactions of the Royal Society of London Series A, 1988, vol. 325, p. 545

Wallace L., Hinkle K. H., Livingston W. C., Davis S. P., An Optical and Near-infrared (2958-9250 A) Solar Flux Atlas, ApJS, 2011, vol. 195, p. 6

Wasson J. T., Kallemeyn G. W., Compositions of chondrites, Royal Society of London Philosophical Transactions Series A, 1988, vol. 325, p. 535

Weidenschilling S. J., Aerodynamics of solid bodies in the solar nebula, MNRAS, 1977, vol. 180 , p. 57

Weidenschilling S. J., Cuzzi J. N., Formation of planetesimals in the solar nebula. In Protostars and Planets III , 1993, p. 1031

Wetherill G. W., Stewart G. R., Accumulation of a swarm of small planetesimals, Icarus, 1989, vol. 77, p. 330

White R. J., Gabor J. M., Hillenbrand L. A., High-Dispersion Optical Spectra of Nearby Stars Younger Than the Sun, AJ, 2007, vol. 133, p. 2524 
Williams J., The astrophysical environment of the solar birthplace, Contemporary Physics, 2010, vol. 51, p. 381

Williams J. P., Blitz L., McKee C. F., The Structure and Evolution of Molecular Clouds: from Clumps to Cores to the IMF, Protostars and Planets IV, 2000, p. 97

Wilson O. C., Flux Measurements at the Centers of Stellar h- and K-Lines, ApJ, 1968, vol. 153 , p. 221

Wilson O. C., Chromospheric variations in main-sequence stars, ApJ, 1978, vol. 226, p. 379

Wolszczan A., PSR1257+12: A Neutron Star with Planetary Companions. In AAS/Division for Planetary Sciences Meeting Abstracts \#24, vol. 24 of Bulletin of the American Astronomical Society, 1992, p. 969

Wright J. T., Marcy G. W., Butler R. P., Vogt S. S., Chromospheric Ca II Emission in Nearby F, G, K, and M Stars, ApJS, 2004, vol. 152, p. 261

Xiong D. R., Deng L., Lithium depletion in late-type dwarfs, MNRAS, 2009, vol. 395, p. 2013

Yana Galarza J., Meléndez J., Cohen J. G., Serendipitous discovery of the faint solar twin Inti 1, A\&A, 2016, vol. 589, p. A65

Yana Galarza J., Meléndez J., Ramírez I., Yong D., Karakas A. I., Asplund M., Liu F., High-precision analysis of the solar twin HIP 100963, A\&A, 2016, vol. 589, p. A17

Yeghikyan A. G., Irradiation of dust in molecular clouds. II. Doses produced by cosmic rays, Astrophysics, 2011, vol. 54, p. 87

Yi S., Demarque P., Kim Y.-C., Lee Y.-W., Ree C. H., Lejeune T., Barnes S., Toward Better Age Estimates for Stellar Populations: The $\mathrm{Y}^{2}$ Isochrones for Solar Mixture, ApJS, 2001, vol. 136, p. 417

Yuan H. B., Liu X. W., Xiang M. S., Empirical extinction coefficients for the GALEX, SDSS, 2MASS and WISE passbands, MNRAS, 2013, vol. 430, p. 2188 
Apêndice 



\section{Apêndice A}

\section{Tabelas}

\section{A.1 Abundâncias químcas do Sol}

Tabela A.1 - As abundancias da fotosfera, meteoritos e a temperatura de condensação são de Asplund et al. (2009), Lodders (2010) e Lodders (2003).

\begin{tabular}{|c|c|c|c|c|c|c|c|c|c|}
\hline Z & Elemento & Fotosfera & Meteoritos & $\mathrm{T}_{\text {cond }}$ & Z & Elemento & Fotosfera & Meteoritos & $\mathrm{T}_{\text {cond }}$ \\
\hline 1 & $\mathrm{H}$ & 12.00 & $8.22 \pm 0.04$ & - & 30 & $\mathrm{Zn}$ & $4.56 \pm 0.05$ & $4.63 \pm 0.04$ & 726 \\
\hline 2 & $\mathrm{He}$ & $10.93 \pm 0.01$ & 1.29 & - & 31 & $\mathrm{Ga}$ & $3.04 \pm 0.09$ & $3.08 \pm 0.02$ & 968 \\
\hline 3 & $\mathrm{Li}$ & $1.050 \pm 0.10$ & $3.26 \pm 0.05$ & 1142 & 32 & $\mathrm{Ge}$ & $3.65 \pm 0.10$ & $3.58 \pm 0.04$ & 883 \\
\hline 4 & $\mathrm{Be}$ & $1.38 \pm 0.09$ & $1.30 \pm 0.03$ & 1452 & 33 & As & $2.30 \pm$ & $2.30 \pm 0.04$ & 1065 \\
\hline 5 & $\mathrm{~B}$ & $2.70 \pm 0.20$ & $2.79 \pm 0.04$ & 908 & 34 & $\mathrm{Se}$ & $3.34 \pm$ & $3.34 \pm 0.03$ & 697 \\
\hline 6 & $\mathrm{C}$ & $8.43 \pm 0.05$ & $7.39 \pm 0.04$ & 40 & 35 & $\mathrm{Br}$ & $2.54 \pm$ & $2.54 \pm 0.06$ & 546 \\
\hline 7 & $\mathrm{~N}$ & $7.83 \pm 0.05$ & $6.26 \pm 0.06$ & 123 & 36 & $\mathrm{Kr}$ & $3.25 \pm 0.06$ & -2.27 & 52 \\
\hline 8 & $\mathrm{O}$ & $8.69 \pm 0.05$ & $8.40 \pm 0.04$ & 180 & 37 & $\mathrm{Rb}$ & $2.52 \pm 0.10$ & $2.36 \pm 0.03$ & 800 \\
\hline 9 & $\mathrm{~F}$ & $4.56 \pm 0.30$ & $4.42 \pm 0.06$ & 734 & 38 & $\mathrm{Sr}$ & $2.87 \pm 0.07$ & $2.88 \pm 0.03$ & 1464 \\
\hline 10 & $\mathrm{Ne}$ & $7.93 \pm 0.10$ & -1.12 & 9.1 & 39 & $\mathrm{Y}$ & $2.21 \pm 0.05$ & $2.17 \pm 0.04$ & 1659 \\
\hline 11 & $\mathrm{Na}$ & $6.24 \pm 0.04$ & $6.27 \pm 0.02$ & 958 & 40 & $\mathrm{Zr}$ & $2.58 \pm 0.04$ & $2.53 \pm 0.04$ & 1741 \\
\hline 12 & $\mathrm{Mg}$ & $7.60 \pm 0.04$ & $7.53 \pm 0.01$ & 1336 & 41 & $\mathrm{Nb}$ & $1.46 \pm 0.04$ & $1.41 \pm 0.04$ & 1559 \\
\hline 13 & $\mathrm{Al}$ & $6.45 \pm 0.03$ & $6.43 \pm 0.01$ & 1653 & 42 & Mo & $1.88 \pm 0.08$ & $1.94 \pm 0.04$ & 1590 \\
\hline 14 & $\mathrm{Si}$ & $7.51 \pm 0.03$ & $7.51 \pm 0.01$ & 1310 & 44 & $\mathrm{Ru}$ & $1.75 \pm 0.08$ & $1.76 \pm 0.03$ & 1551 \\
\hline 15 & $\mathrm{P}$ & $5.41 \pm 0.03$ & $5.43 \pm 0.04$ & 1229 & 45 & $\mathrm{Rh}$ & $0.91 \pm 0.10$ & $1.06 \pm 0.04$ & 1392 \\
\hline 16 & S & $7.12 \pm 0.03$ & $7.15 \pm 0.02$ & 664 & 46 & $\mathrm{Pd}$ & $1.57 \pm 0.10$ & $1.65 \pm 0.02$ & 1324 \\
\hline 17 & $\mathrm{Cl}$ & $5.50 \pm 0.30$ & $5.23 \pm 0.06$ & 948 & 47 & $\mathrm{Ag}$ & $0.94 \pm 0.10$ & $1.20 \pm 0.02$ & 996 \\
\hline 18 & $\mathrm{Ar}$ & $6.40 \pm 0.13$ & -0.50 & 47 & 48 & $\mathrm{Cd}$ & $1.71 \pm$ & $1.71 \pm 0.03$ & 652 \\
\hline 19 & $\mathrm{~K}$ & $5.03 \pm 0.09$ & $5.08 \pm 0.02$ & 1006 & 49 & In & $0.80 \pm 0.20$ & $0.76 \pm 0.03$ & 536 \\
\hline 20 & $\mathrm{Ca}$ & $6.34 \pm 0.04$ & $6.29 \pm 0.02$ & 1517 & 50 & Sn & $2.04 \pm 0.10$ & $2.07 \pm 0.06$ & 704 \\
\hline 21 & $\mathrm{Sc}$ & $3.15 \pm 0.04$ & $3.05 \pm 0.02$ & 1659 & 51 & $\mathrm{Sb}$ & $1.01 \pm$ & $1.01 \pm 0.06$ & 979 \\
\hline 22 & $\mathrm{Ti}$ & $4.95 \pm 0.05$ & $4.91 \pm 0.03$ & 1582 & 52 & $\mathrm{Te}$ & $2.18 \pm$ & $2.18 \pm 0.03$ & 709 \\
\hline 23 & $\mathrm{~V}$ & $3.93 \pm 0.08$ & $3.96 \pm 0.02$ & 1429 & 53 & I & $1.55 \pm$ & $1.55 \pm 0.08$ & 535 \\
\hline 24 & $\mathrm{Cr}$ & $5.64 \pm 0.04$ & $5.64 \pm 0.01$ & 1296 & 54 & $\mathrm{Xe}$ & $2.24 \pm 0.06$ & -1.95 & 68 \\
\hline 25 & Mn & $5.43 \pm 0.05$ & $5.48 \pm 0.01$ & 1158 & 55 & Cs & $1.08 \pm$ & $1.08 \pm 0.02$ & 799 \\
\hline 26 & $\mathrm{Fe}$ & $7.50 \pm 0.04$ & $7.45 \pm 0.01$ & 1334 & 56 & $\mathrm{Ba}$ & $2.18 \pm 0.09$ & $2.18 \pm 0.03$ & 1455 \\
\hline
\end{tabular}

Continua na próxima página... 
Tabela A.1 - Continuação

\begin{tabular}{lcccc|ccccc}
\hline \hline $\mathrm{Z}$ & Elemento & Fotosfera & Meteoritos & $\mathrm{T}_{\text {cond }}$ & $\mathrm{Z}$ & Elemento & Fotosfera & Meteoritos & $\mathrm{T}_{\text {cond }}$ \\
\hline 27 & $\mathrm{Co}$ & $4.99 \pm 0.07$ & $4.87 \pm 0.01$ & 1352 & 57 & $\mathrm{La}$ & $1.10 \pm 0.04$ & $1.17 \pm 0.02$ & 1578 \\
28 & $\mathrm{Ni}$ & $6.22 \pm 0.04$ & $6.20 \pm 0.01$ & 1353 & 58 & $\mathrm{Ce}$ & $1.58 \pm 0.04$ & $1.58 \pm 0.02$ & 1478 \\
29 & $\mathrm{Cu}$ & $4.19 \pm 0.04$ & $4.25 \pm 0.04$ & 1037 & 59 & $\mathrm{Pr}$ & $0.72 \pm 0.04$ & $0.76 \pm 0.03$ & 1582 \\
60 & $\mathrm{Nd}$ & $1.42 \pm 0.04$ & $1.45 \pm 0.02$ & 1602 & 74 & $\mathrm{~W}$ & $0.85 \pm 0.12$ & $0.65 \pm 0.04$ & 1789 \\
62 & $\mathrm{Sm}$ & $0.96 \pm 0.04$ & $0.94 \pm 0.02$ & 1590 & 75 & $\mathrm{Re}$ & $0.26 \pm$ & $0.26 \pm 0.04$ & 1821 \\
63 & $\mathrm{Eu}$ & $0.52 \pm 0.04$ & $0.51 \pm 0.02$ & 1356 & 76 & $\mathrm{Os}$ & $1.40 \pm 0.08$ & $1.35 \pm 0.03$ & 1812 \\
64 & $\mathrm{Gd}$ & $1.07 \pm 0.04$ & $1.05 \pm 0.02$ & 1659 & 77 & $\mathrm{Ir}$ & $1.38 \pm 0.07$ & $1.32 \pm 0.02$ & 1603 \\
65 & $\mathrm{~Tb}$ & $0.30 \pm 0.10$ & $0.32 \pm 0.03$ & 1659 & 78 & $\mathrm{Pt}$ & $1.62 \pm$ & $1.62 \pm 0.03$ & 1408 \\
66 & $\mathrm{Dy}$ & $1.10 \pm 0.04$ & $1.13 \pm 0.02$ & 1659 & 79 & $\mathrm{Au}$ & $0.92 \pm 0.10$ & $0.80 \pm 0.04$ & 1060 \\
67 & $\mathrm{Ho}$ & $0.48 \pm 0.11$ & $0.47 \pm 0.03$ & 1659 & 80 & $\mathrm{Hg}$ & $1.17 \pm$ & $1.17 \pm 0.08$ & 252 \\
68 & $\mathrm{Er}$ & $0.92 \pm 0.05$ & $0.92 \pm 0.02$ & 1659 & 81 & $\mathrm{Tl}$ & $0.90 \pm 0.20$ & $0.77 \pm 0.03$ & 532 \\
69 & $\mathrm{Tm}$ & $0.10 \pm 0.04$ & $0.12 \pm 0.03$ & 1659 & 82 & $\mathrm{~Pb}$ & $1.75 \pm 0.10$ & $2.04 \pm 0.03$ & 727 \\
70 & $\mathrm{Yb}$ & $0.84 \pm 0,11$ & $0.92 \pm 0.02$ & 1487 & 83 & $\mathrm{Bi}$ & $0.65 \pm$ & $0.65 \pm 0.04$ & 746 \\
71 & $\mathrm{Lu}$ & $0.10 \pm 0.09$ & $0.09 \pm 0.02$ & 1659 & 90 & $\mathrm{Th}$ & $0.02 \pm 0.10$ & $0.06 \pm 0.03$ & 1659 \\
72 & $\mathrm{Hf}$ & $0.85 \pm 0.04$ & $0.71 \pm 0.02$ & 1684 & 92 & $\mathrm{U}$ & $-0.54 \pm$ & $-0.54 \pm 0.03$ & 1610 \\
73 & $\mathrm{Ta}$ & $-0.12 \pm$ & $-0.12 \pm 0.04$ & 1573 & $\ldots$ & $\ldots$ & $\ldots$ & $\ldots$ & $\ldots$ \\
& & & & & & & & $\ldots$ \\
\hline \hline
\end{tabular}

\section{A.2 Lista de linhas}

Tabela A.2 - Lista de linhas atómicas adotadas

\begin{tabular}{ccccc|ccccc}
\hline \hline$\lambda(\AA)$ & Íon & $X_{\text {exc }}(\mathrm{eV})$ & log gf & $\mathrm{C}_{6}$ & $\lambda(\AA)$ & Íon & $X_{\text {exc }}(\mathrm{eV})$ & $\log$ gf & $\mathrm{C}_{6}$ \\
\hline 4365.896 & 26.0 & 2.990 & -2.250 & $0.445 \mathrm{E}-31$ & 5466.987 & 26.0 & 3.573 & -2.23 & 2.8 \\
4389.245 & 26.0 & 0.052 & -4.583 & $0.139 \mathrm{E}-31$ & 5522.446 & 26.0 & 4.209 & -1.31 & $0.302 \mathrm{E}-30$ \\
4445.471 & 26.0 & 0.087 & -5.441 & 2.8 & 5546.506 & 26.0 & 4.371 & -1.18 & $0.391 \mathrm{E}-30$ \\
4602.001 & 26.0 & 1.608 & -3.154 & $0.301 \mathrm{E}-31$ & 5560.211 & 26.0 & 4.434 & -1.16 & $0.479 \mathrm{E}-30$ \\
4779.439 & 26.0 & 3.415 & -2.020 & $0.358 \mathrm{E}-31$ & 5577.02 & 26.0 & 5.0331 & -1.455 & 2.8 \\
4788.757 & 26.0 & 3.237 & -1.763 & $0.175 \mathrm{E}-31$ & 5618.633 & 26.0 & 4.209 & -1.276 & $0.290 \mathrm{E}-30$ \\
4950.106 & 26.0 & 3.417 & -1.56 & $0.459 \mathrm{E}-30$ & 5636.696 & 26.0 & 3.640 & -2.56 & $0.519 \mathrm{E}-31$ \\
4994.129 & 26.0 & 0.915 & -3.080 & $0.190 \mathrm{E}-31$ & 5638.262 & 26.0 & 4.220 & -0.81 & $0.288 \mathrm{E}-30$ \\
5044.211 & 26.0 & 2.8512 & -2.058 & $0.271 \mathrm{E}-30$ & 5649.987 & 26.0 & 5.0995 & -0.8 & $0.277 \mathrm{E}-30$ \\
5054.642 & 26.0 & 3.640 & -1.921 & $0.468 \mathrm{E}-31$ & 5651.469 & 26.0 & 4.473 & -1.75 & $0.483 \mathrm{E}-30$ \\
5127.359 & 26.0 & 0.915 & -3.307 & $0.184 \mathrm{E}-31$ & 5661.348 & 26.0 & 4.2843 & -1.756 & $0.324 \mathrm{E}-30$ \\
5127.679 & 26.0 & 0.052 & -6.125 & $0.12 \mathrm{E}-31$ & 5679.023 & 26.0 & 4.652 & -0.75 & $0.813 \mathrm{E}-30$ \\
5198.711 & 26.0 & 2.223 & -2.135 & $0.461 \mathrm{E}-31$ & 5696.089 & 26.0 & 4.548 & -1.78 & $0.578 \mathrm{E}-30$ \\
5225.525 & 26.0 & 0.1101 & -4.789 & $0.123 \mathrm{E}-31$ & 5701.544 & 26.0 & 2.559 & -2.216 & $0.495 \mathrm{E}-31$ \\
5242.491 & 26.0 & 3.634 & -0.967 & $0.495 \mathrm{E}-31$ & 5705.464 & 26.0 & 4.301 & -1.355 & $0.302 \mathrm{E}-30$ \\
5247.050 & 26.0 & 0.0872 & -4.946 & $0.122 \mathrm{E}-31$ & 5778.453 & 26.0 & 2.588 & -3.430 & $0.495 \mathrm{E}-31$
\end{tabular}

Continua na próxima página. . . 
Tabela A.2 - Continuação

\begin{tabular}{|c|c|c|c|c|c|c|c|c|c|}
\hline$\lambda(\AA)$ & Íon & $X_{e x c}(\mathrm{eV})$ & $\log g f$ & $\mathrm{C}_{6}$ & $\lambda(\AA)$ & Íon & $X_{e x c}(\mathrm{eV})$ & $\log g f$ & $\mathrm{C}_{6}$ \\
\hline 5250.208 & 26.0 & 0.1212 & -4.938 & $0.123 \mathrm{E}-31$ & 5784.658 & 26.0 & 3.396 & -2.532 & $0.357 \mathrm{E}-30$ \\
\hline 5295.312 & 26.0 & 4.415 & -1.49 & $0.654 \mathrm{E}-30$ & 5793.914 & 26.0 & 4.220 & -1.619 & $0.272 \mathrm{E}-30$ \\
\hline 5322.041 & 26.0 & 2.279 & -2.80 & $0.429 \mathrm{E}-31$ & 5809.218 & 26.0 & 3.883 & -1.609 & $0.565 \mathrm{E}-30$ \\
\hline 5373.709 & 26.0 & 4.473 & -0.77 & $0.704 \mathrm{E}-30$ & 5852.219 & 26.0 & 4.548 & -1.17 & $0.480 \mathrm{E}-30$ \\
\hline 5379.574 & 26.0 & 3.694 & -1.514 & $0.502 \mathrm{E}-31$ & 5855.076 & 26.0 & 4.6075 & -1.478 & $0.574 \mathrm{E}-30$ \\
\hline 5386.334 & 26.0 & 4.154 & -1.74 & $0.527 \mathrm{E}-30$ & 5905.672 & 26.0 & 4.652 & -0.69 & $0.623 \mathrm{E}-30$ \\
\hline 5466.396 & 26.0 & 4.371 & -0.565 & $0.440 \mathrm{E}-30$ & 5916.247 & 26.0 & 2.453 & -2.936 & $0.429 \mathrm{E}-31$ \\
\hline 5927.789 & 26.0 & 4.652 & -1.04 & $0.607 \mathrm{E}-30$ & 6750.152 & 26.0 & 2.4241 & -2.621 & $0.411 \mathrm{E}-31$ \\
\hline 5934.655 & 26.0 & 3.928 & -1.07 & $0.569 \mathrm{E}-30$ & 6752.707 & 26.0 & 4.638 & -1.204 & $0.337 \mathrm{E}-30$ \\
\hline 5956.694 & 26.0 & 0.8589 & -4.605 & $0.155 \mathrm{E}-31$ & 6793.259 & 26.0 & 4.076 & -2.326 & 2.8 \\
\hline 5987.065 & 26.0 & 4.795 & -0.212 & $0.155 \mathrm{E}-31$ & 6806.845 & 26.0 & 2.727 & -3.11 & $0.346 \mathrm{E}-31$ \\
\hline 6003.012 & 26.0 & 3.881 & -1.06 & $0.483 \mathrm{E}-30$ & 6810.263 & 26.0 & 4.607 & -0.986 & $0.450 \mathrm{E}-30$ \\
\hline 6005.541 & 26.0 & 2.588 & -3.43 & 2.8 & 6837.006 & 26.0 & 4.593 & -1.687 & $0.246 \mathrm{E}-31$ \\
\hline 6024.058 & 26.0 & 4.548 & -0.02 & $0.388 \mathrm{E}-30$ & 6839.830 & 26.0 & 2.559 & -3.35 & $0.395 \mathrm{E}-31$ \\
\hline 6027.050 & 26.0 & 4.0758 & -1.09 & 2.8 & 6843.656 & 26.0 & 4.548 & -0.86 & $0.294 \mathrm{E}-30$ \\
\hline 6056.005 & 26.0 & 4.733 & -0.45 & $0.679 \mathrm{E}-30$ & 6858.150 & 26.0 & 4.607 & -0.930 & $0.324 \mathrm{E}-30$ \\
\hline 6065.482 & 26.0 & 2.6085 & -1.530 & $0.471 \mathrm{E}-31$ & 4508.288 & 26.1 & 2.8557 & -2.44 & $0.956 \mathrm{E}-32$ \\
\hline 6079.009 & 26.0 & 4.652 & -1.10 & $0.513 \mathrm{E}-30$ & 4520.224 & 26.1 & 2.8068 & -2.65 & $0.857 \mathrm{E}-32$ \\
\hline 6082.711 & 26.0 & 2.223 & -3.573 & $0.327 \mathrm{E}-31$ & 4576.340 & 26.1 & 2.8443 & -2.95 & $0.943 \mathrm{E}-32$ \\
\hline 6093.644 & 26.0 & 4.607 & -1.30 & $0.441 \mathrm{E}-30$ & 4620.521 & 26.1 & 2.8283 & -3.21 & $0.930 \mathrm{E}-32$ \\
\hline 6096.665 & 26.0 & 3.9841 & -1.81 & $0.575 \mathrm{E}-30$ & 4993.358 & 26.1 & 2.8066 & -3.62 & $0.775 \mathrm{E}-32$ \\
\hline 6151.618 & 26.0 & 2.1759 & -3.299 & $0.255 \mathrm{E}-31$ & 5197.577 & 26.1 & 3.2306 & -2.22 & $0.869 \mathrm{E}-32$ \\
\hline 6157.728 & 26.0 & 4.076 & -1.22 & 2.8 & 5234.625 & 26.1 & 3.2215 & -2.18 & $0.869 \mathrm{E}-32$ \\
\hline 6165.360 & 26.0 & 4.1426 & -1.46 & 2.8 & 5264.812 & 26.1 & 3.2304 & -3.13 & $0.943 \mathrm{E}-32$ \\
\hline 6173.335 & 26.0 & 2.223 & -2.880 & $0.265 \mathrm{E}-31$ & 5325.553 & 26.1 & 3.2215 & -3.16 & $0.857 \mathrm{E}-32$ \\
\hline 6187.990 & 26.0 & 3.943 & -1.67 & $0.490 \mathrm{E}-30$ & 5414.073 & 26.1 & 3.2215 & -3.58 & $0.930 \mathrm{E}-32$ \\
\hline 6200.313 & 26.0 & 2.6085 & -2.437 & $0.458 \mathrm{E}-31$ & 5425.257 & 26.1 & 3.1996 & -3.22 & $0.845 \mathrm{E}-32$ \\
\hline 6213.430 & 26.0 & 2.2227 & -2.52 & $0.262 \mathrm{E}-31$ & 6084.111 & 26.1 & 3.1996 & -3.79 & $0.787 \mathrm{E}-32$ \\
\hline 6219.281 & 26.0 & 2.198 & -2.433 & $0.258 \mathrm{E}-31$ & 6149.258 & 26.1 & 3.8894 & -2.69 & $0.943 \mathrm{E}-32$ \\
\hline 6226.736 & 26.0 & 3.883 & -2.1 & $0.415 \mathrm{E}-30$ & 6247.557 & 26.1 & 3.8918 & -2.30 & $0.943 \mathrm{E}-32$ \\
\hline 6240.646 & 26.0 & 2.2227 & -3.233 & $0.314 \mathrm{E}-31$ & 6369.462 & 26.1 & 2.8912 & -4.11 & $0.742 \mathrm{E}-32$ \\
\hline 6252.555 & 26.0 & 2.4040 & -1.687 & $0.384 \mathrm{E}-31$ & 6416.919 & 26.1 & 3.8918 & -2.64 & $0.930 \mathrm{E}-32$ \\
\hline 6265.134 & 26.0 & 2.1759 & -2.550 & $0.248 \mathrm{E}-31$ & 6432.680 & 26.1 & 2.8912 & -3.57 & $0.742 \mathrm{E}-32$ \\
\hline 6270.225 & 26.0 & 2.8580 & -2.54 & $0.458 \mathrm{E}-31$ & 6456.383 & 26.1 & 3.9036 & -2.05 & $0.930 \mathrm{E}-32$ \\
\hline 6271.279 & 26.0 & 3.332 & -2.703 & $0.278 \mathrm{E}-30$ & 5052.167 & 06.0 & 7.685 & -1.24 & 2.8 \\
\hline 6380.743 & 26.0 & 4.186 & -1.376 & 2.8 & 5380.337 & 06.0 & 7.685 & -1.57 & 2.8 \\
\hline 6392.539 & 26.0 & 2.279 & -4.03 & $0.338 \mathrm{E}-31$ & 6587.61 & 06.0 & 8.537 & -1.05 & 2.8 \\
\hline 6430.846 & 26.0 & 2.1759 & -2.006 & $0.242 \mathrm{E}-31$ & 7111.47 & 06.0 & 8.640 & -1.07 & $0.291 \mathrm{E}-29$ \\
\hline 6498.939 & 26.0 & 0.9581 & -4.699 & $0.153 \mathrm{E}-31$ & 7113.179 & 06.0 & 8.647 & -0.76 & $0.297 \mathrm{E}-29$ \\
\hline 6593.871 & 26.0 & 2.4326 & -2.422 & $0.369 \mathrm{E}-31$ & 7771.944 & 08.0 & 9.146 & 0.37 & $0.841 \mathrm{E}-31$ \\
\hline 6597.561 & 26.0 & 4.795 & -0.98 & $0.476 \mathrm{E}-30$ & 7774.166 & 08.0 & 9.146 & 0.22 & $0.841 \mathrm{E}-31$ \\
\hline 6625.022 & 26.0 & 1.011 & -5.336 & 2.8 & 7775.388 & 08.0 & 9.146 & 0.00 & $0.841 \mathrm{E}-31$ \\
\hline 6677.987 & 26.0 & 2.692 & -1.418 & $0.346 \mathrm{E}-31$ & 4751.822 & 11.0 & 2.1044 & -2.078 & 2.8 \\
\hline 6703.567 & 26.0 & 2.7585 & -3.023 & $0.366 \mathrm{E}-31$ & 5148.838 & 11.0 & 2.1023 & -2.044 & 2.8 \\
\hline
\end{tabular}

Continua na próxima página... 
Tabela A.2 - Continuação

\begin{tabular}{|c|c|c|c|c|c|c|c|c|c|}
\hline$\lambda(\AA)$ & Íon & $X_{\text {exc }}(\mathrm{eV})$ & $\log g f$ & $\mathrm{C}_{6}$ & $\lambda(\AA)$ & Íon & $X_{e x c}(\mathrm{eV})$ & $\log g f$ & $\mathrm{C}_{6}$ \\
\hline 6705.102 & 26.0 & 4.607 & -0.98 & 2.8 & 6154.225 & 11.0 & 2.1023 & -1.547 & 2.8 \\
\hline 6710.319 & 26.0 & 1.485 & -4.88 & $0.201 \mathrm{E}-31$ & 6160.747 & 11.0 & 2.1044 & -1.246 & 2.8 \\
\hline 6713.745 & 26.0 & 4.795 & -1.40 & $0.430 \mathrm{E}-30$ & 4571.095 & 12.0 & 0.000 & -5.623 & 2.8 \\
\hline 6725.357 & 26.0 & 4.103 & -2.19 & $0.482 \mathrm{E}-30$ & 4730.040 & 12.0 & 4.340 & -2.389 & 2.8 \\
\hline 6726.667 & 26.0 & 4.607 & -1.03 & $0.482 \mathrm{E}-30$ & 5711.088 & 12.0 & 4.345 & -1.729 & 2.8 \\
\hline 6733.151 & 26.0 & 4.638 & -1.47 & $0.341 \mathrm{E}-30$ & 6318.717 & 12.0 & 5.108 & -1.945 & 2.8 \\
\hline 6739.522 & 26.0 & 1.557 & -4.79 & $0.210 \mathrm{E}-31$ & 6319.236 & 12.0 & 5.108 & -2.165 & 2.8 \\
\hline 6696.018 & 13.0 & 3.143 & -1.481 & 2.8 & 5684.19 & 21.1 & 1.507 & -0.95 & 2.8 \\
\hline 6698.667 & 13.0 & 3.143 & -1.782 & 2.8 & 6245.63 & 21.1 & 1.507 & -1.030 & 2.8 \\
\hline 7835.309 & 13.0 & 4.021 & -0.68 & 2.8 & 6320.843 & 21.1 & 1.500 & -1.85 & 2.8 \\
\hline 7836.134 & 13.0 & 4.021 & -0.45 & 2.8 & 6604.578 & 21.1 & 1.3569 & -1.15 & 2.8 \\
\hline 8772.866 & 13.0 & 4.0215 & -0.38 & $0.971 \mathrm{E}-29$ & 4465.802 & 22.0 & 1.7393 & -0.163 & $0.398 \mathrm{E}-31$ \\
\hline 8773.896 & 13.0 & 4.0216 & -0.22 & $0.971 \mathrm{E}-29$ & 4555.485 & 22.0 & 0.8484 & -0.488 & $0.442 \mathrm{E}-31$ \\
\hline 5488.983 & 14.0 & 5.614 & -1.69 & 2.8 & 4758.120 & 22.0 & 2.2492 & 0.425 & $0.384 \mathrm{E}-31$ \\
\hline 5517.540 & 14.0 & 5.080 & -2.496 & 2.8 & 4759.272 & 22.0 & 2.2555 & 0.514 & $0.386 \mathrm{E}-31$ \\
\hline 5645.611 & 14.0 & 4.929 & -2.04 & 2.8 & 4820.410 & 22.0 & 1.5024 & -0.439 & $0.378 \mathrm{E}-31$ \\
\hline 5665.554 & 14.0 & 4.920 & -1.94 & 2.8 & 4913.616 & 22.0 & 1.8731 & 0.161 & $0.386 \mathrm{E}-31$ \\
\hline 5684.484 & 14.0 & 4.953 & -1.55 & 2.8 & 5022.871 & 22.0 & 0.8258 & -0.434 & $0.358 \mathrm{E}-31$ \\
\hline 5690.425 & 14.0 & 4.929 & -1.77 & 2.8 & 5113.448 & 22.0 & 1.4431 & -0.783 & $0.306 \mathrm{E}-31$ \\
\hline 5701.104 & 14.0 & 4.930 & -1.95 & 2.8 & 5147.479 & 22.0 & 0.0000 & -2.012 & $0.208 \mathrm{E}-31$ \\
\hline 5793.073 & 14.0 & 4.929 & -1.96 & 2.8 & 5219.700 & 22.0 & 0.0211 & -2.236 & $0.208 \mathrm{E}-31$ \\
\hline 6125.021 & 14.0 & 5.614 & -1.50 & 2.8 & 5295.774 & 22.0 & 1.0665 & -1.633 & $0.258 \mathrm{E}-31$ \\
\hline 6145.015 & 14.0 & 5.616 & -1.41 & 2.8 & 5490.150 & 22.0 & 1.4601 & -0.933 & $0.541 \mathrm{E}-31$ \\
\hline 6243.823 & 14.0 & 5.616 & -1.27 & 2.8 & 5739.464 & 22.0 & 2.249 & -0.60 & $0.386 \mathrm{E}-31$ \\
\hline 6244.476 & 14.0 & 5.616 & -1.32 & 2.8 & 5866.452 & 22.0 & 1.066 & -0.840 & $0.216 \mathrm{E}-31$ \\
\hline 6721.848 & 14.0 & 5.862 & -1.12 & 2.8 & 6091.174 & 22.0 & 2.2673 & -0.423 & $0.389 \mathrm{E}-31$ \\
\hline 6741.63 & 14.0 & 5.984 & -1.65 & 2.8 & 6126.217 & 22.0 & 1.066 & -1.424 & $0.206 \mathrm{E}-31$ \\
\hline 6046.000 & 16.0 & 7.868 & -0.15 & 2.8 & 6258.104 & 22.0 & 1.443 & -0.355 & $0.481 \mathrm{E}-31$ \\
\hline 6052.656 & 16.0 & 7.870 & -0.4 & 2.8 & 6261.101 & 22.0 & 1.429 & -0.479 & $0.468 \mathrm{E}-31$ \\
\hline 6743.54 & 16.0 & 7.866 & -0.6 & 2.8 & 4470.857 & 22.1 & 1.1649 & -2.06 & 2.8 \\
\hline 6757.153 & 16.0 & 7.870 & -0.15 & 2.8 & 4544.028 & 22.1 & 1.2429 & -2.53 & 2.8 \\
\hline 8693.93 & 16.0 & 7.870 & -0.44 & $0.151 \mathrm{E}-29$ & 4583.408 & 22.1 & 1.165 & -2.87 & 2.8 \\
\hline 8694.62 & 16.0 & 7.870 & 0.1 & $0.151 \mathrm{E}-29$ & 4636.33 & 22.1 & 1.16 & -3.152 & 2.8 \\
\hline 7698.974 & 19.0 & 0.000 & -0.168 & $0.104 \mathrm{E}-30$ & 4657.212 & 22.1 & 1.243 & -2.47 & 2.8 \\
\hline 4512.268 & 20.0 & 2.526 & -1.901 & 2.80 & 4779.985 & 22.1 & 2.0477 & -1.26 & 2.8 \\
\hline 5260.387 & 20.0 & 2.521 & -1.719 & $0.727 \mathrm{E}-31$ & 4865.611 & 22.1 & 1.116 & -2.81 & 2.8 \\
\hline 5512.980 & 20.0 & 2.933 & -0.464 & 2.8 & 4874.014 & 22.1 & 3.095 & -0.9 & 2.8 \\
\hline 5581.965 & 20.0 & 2.5229 & -0.555 & $0.640 \mathrm{E}-31$ & 4911.193 & 22.1 & 3.123 & -0.537 & 2.8 \\
\hline 5590.114 & 20.0 & 2.521 & -0.571 & $0.636 \mathrm{E}-31$ & 5211.54 & 22.1 & 2.59 & -1.49 & 2.8 \\
\hline 5867.562 & 20.0 & 2.933 & -1.57 & 2.8 & 5336.778 & 22.1 & 1.582 & -1.630 & 2.8 \\
\hline 6166.439 & 20.0 & 2.521 & -1.142 & $0.595 \mathrm{E}-30$ & 5381.015 & 22.1 & 1.565 & -1.97 & 2.8 \\
\hline 6169.042 & 20.0 & 2.523 & -0.797 & $0.595 \mathrm{E}-30$ & 5418.767 & 22.1 & 1.582 & -2.11 & 2.8 \\
\hline 6455.598 & 20.0 & 2.523 & -1.34 & $0.509 \mathrm{E}-31$ & 4875.486 & 23.0 & 0.040 & -0.81 & $0.198 \mathrm{E}-31$ \\
\hline 6471.662 & 20.0 & 2.525 & -0.686 & $0.509 \mathrm{E}-31$ & 5670.85 & 23.0 & 1.080 & -0.42 & $0.358 \mathrm{E}-31$ \\
\hline
\end{tabular}

Continua na próxima página... 
Tabela A.2 - Continuação

\begin{tabular}{|c|c|c|c|c|c|c|c|c|c|}
\hline$\lambda(\AA)$ & Íon & $X_{\text {exc }}(\mathrm{eV})$ & $\log g f$ & $\mathrm{C}_{6}$ & $\lambda(\AA)$ & Íon & $X_{e x c}(\mathrm{eV})$ & $\log g f$ & $\mathrm{C}_{6}$ \\
\hline 6499.650 & 20.0 & 2.523 & -0.818 & $0.505 \mathrm{E}-31$ & 5727.046 & 23.0 & 1.081 & -0.011 & $0.435 \mathrm{E}-31$ \\
\hline 4743.821 & 21.0 & 1.4478 & 0.35 & $0.597 \mathrm{E}-31$ & 6039.73 & 23.0 & 1.063 & -0.65 & $0.398 \mathrm{E}-31$ \\
\hline 5081.57 & 21.0 & 1.4478 & 0.30 & 2.8 & 6081.44 & 23.0 & 1.051 & -0.578 & $0.389 \mathrm{E}-31$ \\
\hline 5520.497 & 21.0 & 1.8649 & 0.55 & 2.8 & 6090.21 & 23.0 & 1.080 & -0.062 & $0.398 \mathrm{E}-31$ \\
\hline 5671.821 & 21.0 & 1.4478 & 0.55 & 2.8 & 6119.528 & 23.0 & 1.064 & -0.320 & $0.389 \mathrm{E}-31$ \\
\hline 5526.820 & 21.1 & 1.770 & 0.140 & 2.8 & 6199.20 & 23.0 & 0.286 & -1.28 & $0.196 \mathrm{E}-31$ \\
\hline 5657.87 & 21.1 & 1.507 & -0.30 & 2.8 & 6251.82 & 23.0 & 0.286 & -1.34 & $0.196 \mathrm{E}-31$ \\
\hline 4801.047 & 24.0 & 3.1216 & -0.130 & $0.452 \mathrm{E}-31$ & 6086.282 & 28.0 & 4.2661 & -0.51 & $0.406 \mathrm{E}-30$ \\
\hline 4936.335 & 24.0 & 3.1128 & -0.25 & $0.432 \mathrm{E}-31$ & 6108.116 & 28.0 & 1.6764 & -2.44 & $0.248 \mathrm{E}-31$ \\
\hline 5214.140 & 24.0 & 3.3694 & -0.74 & $0.206 \mathrm{E}-31$ & 6130.135 & 28.0 & 4.2661 & -0.96 & $0.391 \mathrm{E}-30$ \\
\hline 5238.964 & 24.0 & 2.709 & -1.27 & $0.519 \mathrm{E}-31$ & 6176.811 & 28.0 & 4.0881 & -0.26 & $0.392 \mathrm{E}-30$ \\
\hline 5247.566 & 24.0 & 0.960 & -1.59 & $0.392 \mathrm{E}-31$ & 6177.242 & 28.0 & 1.8261 & -3.51 & 2.8 \\
\hline 5272.007 & 24.0 & 3.449 & -0.42 & $0.315 \mathrm{E}-30$ & 6186.711 & 28.0 & 4.1054 & -0.96 & 2.8 \\
\hline 5287.19 & 24.0 & 3.438 & -0.87 & $0.309 \mathrm{E}-30$ & 6204.604 & 28.0 & 4.0881 & -1.14 & $0.277 \mathrm{E}-30$ \\
\hline 5296.691 & 24.0 & 0.983 & -1.36 & $0.392 \mathrm{E}-31$ & 6223.984 & 28.0 & 4.1054 & -0.98 & $0.393 \mathrm{E}-30$ \\
\hline 5300.744 & 24.0 & 0.982 & -2.13 & $0.392 \mathrm{E}-31$ & 6378.25 & 28.0 & 4.1535 & -0.90 & $0.391 \mathrm{E}-30$ \\
\hline 5345.801 & 24.0 & 1.0036 & -0.95 & $0.392 \mathrm{E}-31$ & 6643.630 & 28.0 & 1.6764 & -2.0 & $0.214 \mathrm{E}-31$ \\
\hline 5348.312 & 24.0 & 1.0036 & -1.21 & $0.392 \mathrm{E}-31$ & 6767.772 & 28.0 & 1.8261 & -2.17 & 2.8 \\
\hline 5783.08 & 24.0 & 3.3230 & -0.43 & $0.802 \mathrm{E}-30$ & 6772.315 & 28.0 & 3.6576 & -0.99 & $0.356 \mathrm{E}-30$ \\
\hline 5783.87 & 24.0 & 3.3223 & -0.295 & $0.798 \mathrm{E}-30$ & 7727.624 & 28.0 & 3.6784 & -0.4 & $0.343 \mathrm{E}-30$ \\
\hline 6661.08 & 24.0 & 4.1926 & -0.19 & $0.467 \mathrm{E}-30$ & 7797.586 & 28.0 & 3.89 & -0.34 & 2.8 \\
\hline 4588.199 & 24.1 & 4.071 & -0.594 & 2.8 & 5105.541 & 29.0 & 1.39 & -1.516 & 2.8 \\
\hline 4592.049 & 24.1 & 4.073 & -1.252 & 2.8 & 5218.197 & 29.0 & 3.816 & 0.476 & 2.8 \\
\hline 5237.328 & 24.1 & 4.073 & -1.087 & 2.8 & 5220.066 & 29.0 & 3.816 & -0.448 & 2.8 \\
\hline 5246.767 & 24.1 & 3.714 & -2.436 & 2.8 & 7933.13 & 29.0 & 3.79 & -0.368 & 2.8 \\
\hline 5305.870 & 24.1 & 3.827 & -1.97 & 2.8 & 4722.159 & 30.0 & 4.03 & -0.38 & 2.8 \\
\hline 5308.41 & 24.1 & 4.0712 & -1.846 & 2.8 & 4810.534 & 30.0 & 4.08 & -0.16 & 2.8 \\
\hline 5502.067 & 24.1 & 4.1682 & -2.049 & 2.8 & 6362.35 & 30.0 & 5.79 & 0.14 & 2.8 \\
\hline 4082.939 & 25.0 & 2.1782 & -0.354 & $0.255 \mathrm{E}-31$ & 7800.268 & 37.0 & 0.000 & 0.144 & 2.8 \\
\hline 4709.712 & 25.0 & 2.8884 & -0.339 & $0.341 \mathrm{E}-31$ & 4607.338 & 38.0 & 0.00 & 0.283 & $6.557 \mathrm{E}-32$ \\
\hline 4739.10 & 25.0 & 2.9408 & -0.490 & $0.352 \mathrm{E}-31$ & 4854.867 & 39.1 & 0.9923 & -0.38 & 2.8 \\
\hline 5004.891 & 25.0 & 2.9197 & -1.63 & $0.314 \mathrm{E}-31$ & 4883.685 & 39.1 & 1.0841 & 0.07 & 2.8 \\
\hline 5399.470 & 25.0 & 3.85 & -0.104 & 2.8 & 4900.110 & 39.1 & 1.0326 & -0.09 & 2.8 \\
\hline 6013.49 & 25.0 & 3.073 & -0.251 & 2.8 & 5087.420 & 39.1 & 1.0841 & -0.17 & 2.8 \\
\hline 6016.64 & 25.0 & 3.073 & -0.084 & 2.8 & 5200.413 & 39.1 & 0.9923 & -0.57 & 2.8 \\
\hline 6021.79 & 25.0 & 3.076 & +0.034 & 2.8 & 4050.320 & 40.1 & 0.713 & -1.06 & 2.8 \\
\hline 5212.691 & 27.0 & 3.5144 & -0.11 & $0.339 \mathrm{E}-30$ & 4208.980 & 40.1 & 0.713 & -0.51 & 2.8 \\
\hline 5247.911 & 27.0 & 1.785 & -2.08 & $0.327 \mathrm{E}-31$ & 4442.992 & 40.1 & 1.486 & -0.42 & 2.8 \\
\hline 5301.039 & 27.0 & 1.710 & -1.99 & $0.301 \mathrm{E}-31$ & 3158.16 & 42.0 & 0.000 & -0.31 & 2.8 \\
\hline 5342.695 & 27.0 & 4.021 & 0.54 & 2.8 & 3193.97 & 42.0 & 0.000 & 0.07 & 2.8 \\
\hline 5483.352 & 27.0 & 1.7104 & -1.49 & $0.289 \mathrm{E}-31$ & 3436.736 & 44.0 & 0.148 & 0.165 & 2.8 \\
\hline 5530.774 & 27.0 & 1.710 & -2.23 & $0.226 \mathrm{E}-31$ & 3498.942 & 44.0 & 0.000 & 0.322 & 2.8 \\
\hline 5647.23 & 27.0 & 2.280 & -1.56 & $0.414 \mathrm{E}-31$ & 3583.10 & 45.0 & 0.19 & -0.16 & 2.8 \\
\hline 6189.00 & 27.0 & 1.710 & -2.46 & $0.206 \mathrm{E}-31$ & 3692.36 & 45.0 & 0.00 & 0.15 & 2.8 \\
\hline
\end{tabular}

Continua na próxima página... 
Tabela A.2 - Continuação

\begin{tabular}{|c|c|c|c|c|c|c|c|c|c|}
\hline$\lambda(\AA)$ & Íon & $X_{e x c}(\mathrm{eV})$ & $\log g f$ & $\mathrm{C}_{6}$ & $\lambda(\AA)$ & Íon & $X_{e x c}(\mathrm{eV})$ & $\log g f$ & $\mathrm{C}_{6}$ \\
\hline 6454.995 & 27.0 & 3.6320 & -0.25 & $0.378 \mathrm{E}-30$ & 3242.698 & 46.0 & 0.8138 & 0.07 & 2.8 \\
\hline 4953.208 & 28.0 & 3.7397 & -0.66 & $0.325 \mathrm{E}-30$ & 3404.576 & 46.0 & 0.8138 & 0.33 & 2.8 \\
\hline 5010.938 & 28.0 & 3.6353 & -0.87 & $0.390 \mathrm{E}-30$ & 3516.944 & 46.0 & 0.9615 & -0.21 & 2.8 \\
\hline 5176.560 & 28.0 & 3.8982 & -0.44 & $0.384 \mathrm{E}-30$ & 3280.68 & 47.0 & 0.0000 & -0.022 & 2.8 \\
\hline 5589.358 & 28.0 & 3.8982 & -1.14 & $0.398 \mathrm{E}-30$ & 3382.89 & 47.0 & 0.0000 & -0.334 & 2.8 \\
\hline 5643.078 & 28.0 & 4.1646 & -1.25 & $0.379 \mathrm{E}-30$ & 5853.67 & 56.1 & 0.604 & -0.91 & $0.53 \mathrm{E}-31$ \\
\hline 5805.217 & 28.0 & 4.1672 & -0.64 & $0.410 \mathrm{E}-30$ & 6141.71 & 56.1 & 0.704 & -0.08 & $0.53 \mathrm{E}-31$ \\
\hline 6496.90 & 56.1 & 0.604 & -0.38 & $0.53 \mathrm{E}-31$ & 3712.704 & 64.1 & 0.382 & 0.04 & 2.8 \\
\hline 4662.50 & 57.1 & 0.0000 & -1.24 & 2.8 & 3768.396 & 64.1 & 0.078 & 0.21 & 2.8 \\
\hline 4748.73 & 57.1 & 0.9265 & -0.54 & 2.8 & 4251.731 & 64.1 & 0.382 & -0.22 & 2.8 \\
\hline 5303.53 & 57.1 & 0.3213 & -1.35 & 2.8 & 3531.71 & 66.1 & 0.000 & 0.77 & 2.8 \\
\hline 3942.151 & 58.1 & 0.000 & -0.22 & 2.8 & 3536.02 & 66.1 & 0.538 & 0.53 & 2.8 \\
\hline 3999.237 & 58.1 & 0.295 & 0.06 & 2.8 & 3694.81 & 66.1 & 0.103 & -0.11 & 2.8 \\
\hline 4042.581 & 58.1 & 0.495 & 0.00 & 2.8 & 4077.97 & 66.1 & 0.103 & -0.04 & 2.8 \\
\hline 4073.474 & 58.1 & 0.477 & 0.21 & 2.8 & 4103.31 & 66.1 & 0.103 & -0.38 & 2.8 \\
\hline 4364.653 & 58.1 & 0.495 & -0.17 & 2.8 & 4449.70 & 66.1 & 0.000 & -1.03 & 2.8 \\
\hline 4523.075 & 58.1 & 0.516 & -0.08 & 2.8 & 3694.19 & 70.1 & 0.000 & -0.30 & 2.8 \\
\hline 4562.359 & 58.1 & 0.477 & 0.21 & 2.8 & 4951.415 & 606.0 & 1.055 & 0.823 & 2.8 \\
\hline 5274.229 & 58.1 & 1.044 & 0.13 & 2.8 & 4955.94 & 606.0 & 1.029 & 0.817 & 2.8 \\
\hline 5259.73 & 59.1 & 0.633 & 0.114 & 2.8 & 5009.45 & 606.0 & 0.736 & 0.729 & 2.8 \\
\hline 4021.33 & 60.1 & 0.320 & -0.10 & 2.8 & 5141.23 & 606.0 & 0.446 & 0.574 & 2.8 \\
\hline 4059.95 & 60.1 & 0.204 & -0.52 & 2.8 & 5143.324 & 606.0 & 0.127 & -0.409 & 2.8 \\
\hline 4446.38 & 60.1 & 0.204 & -0.35 & 2.8 & 4218.723 & 106.0 & 0.413 & -1.008 & 2.8 \\
\hline 5234.19 & 60.1 & 0.550 & -0.51 & 2.8 & 4253.003 & 106.0 & 0.523 & -1.523 & 2.8 \\
\hline 5293.16 & 60.1 & 0.822 & 0.10 & 2.8 & 4253.209 & 106.0 & 0.523 & -1.486 & 2.8 \\
\hline 5319.81 & 60.1 & 0.550 & -0.14 & 2.8 & 4263.976 & 106.0 & 0.460 & -1.593 & 2.8 \\
\hline 3760.70 & 62.1 & 0.18 & -0.42 & 2.8 & 3399.790 & 107.0 & 0.2637 & -1.358 & 0.0 \\
\hline 4318.936 & 62.1 & 0.277 & -0.25 & 2.8 & 3307.898 & 107.0 & 0.4164 & -1.189 & 0.0 \\
\hline 4467.341 & 62.1 & 0.659 & 0.15 & 2.8 & 3342.996 & 107.0 & 0.4957 & -1.386 & 0.0 \\
\hline 4519.630 & 62.1 & 0.543 & -0.35 & 2.8 & 3365.184 & 107.0 & 1.1429 & -0.714 & 0.0 \\
\hline 4676.902 & 62.1 & 0.040 & -0.87 & 2.8 & 3152.455 & 108.0 & 0.485 & -2.491 & 0.0 \\
\hline 3819.67 & 63.1 & 0.000 & 0.51 & 2.8 & 3167.169 & 108.0 & 1.109 & -1.544 & 0.0 \\
\hline 3907.11 & 63.1 & 0.207 & 0.17 & 2.8 & 3172.992 & 108.0 & 1.202 & -1.526 & 0.0 \\
\hline 4129.72 & 63.1 & 0.000 & 0.22 & 2.8 & 3173.198 & 108.0 & 0.842 & -1.888 & 0.0 \\
\hline 6645.10 & 63.1 & 1.379 & 0.12 & 2.8 & 3189.311 & 108.0 & 1.032 & -1.842 & 0.0 \\
\hline 3331.387 & 64.1 & 0.000 & -0.28 & 2.8 & 3218.061 & 108.0 & 0.897 & -2.095 & 0.0 \\
\hline 3697.733 & 64.1 & 0.032 & -0.34 & 2.8 & 3255.493 & 108.0 & 1.300 & -1.829 & 0.0 \\
\hline
\end{tabular}




\section{A.3 Correção hiperfina}

Tabela A.3 - Correção hiperfina das linnhas para as quais foi aplicada.

\begin{tabular}{|c|c|c|c|c|c|c|c|c|c|}
\hline$\lambda(\AA)$ & Íon & $X_{e x c}(\mathrm{eV})$ & $\log g f$ & Elemento & $\lambda(\AA)$ & Íon & $X_{e x c}(\mathrm{eV})$ & $\log g f$ & Elemento \\
\hline 4594.093 & 23.0 & 0.068 & -2.096 & VI & 5670.832 & 23.0 & 1.080 & -1.093 & \\
\hline 4594.096 & 23.0 & 0.068 & -2.548 & & 5670.844 & 23.0 & 1.080 & -3.004 & \\
\hline 4594.096 & 23.0 & 0.068 & -1.978 & & 5670.844 & 23.0 & 1.080 & -1.891 & \\
\hline 4594.101 & 23.0 & 0.068 & -3.548 & & 5670.844 & 23.0 & 1.080 & -1.198 & \\
\hline 4594.101 & 23.0 & 0.068 & -2.337 & & 5670.854 & 23.0 & 1.080 & -2.800 & \\
\hline 4594.101 & 23.0 & 0.068 & -1.860 & & 5670.854 & 23.0 & 1.080 & -1.817 & \\
\hline 4594.107 & 23.0 & 0.068 & -3.342 & & 5670.854 & 23.0 & 1.080 & -1.314 & \\
\hline 4594.107 & 23.0 & 0.068 & -2.241 & & 5670.863 & 23.0 & 1.080 & -2.703 & \\
\hline 4594.107 & 23.0 & 0.068 & -1.748 & & 5670.863 & 23.0 & 1.080 & -1.811 & \\
\hline 4594.115 & 23.0 & 0.068 & -3.313 & & 5670.863 & 23.0 & 1.080 & -1.443 & \\
\hline 4594.115 & 23.0 & 0.068 & -2.205 & & 5670.870 & 23.0 & 1.080 & -2.703 & \\
\hline 4594.115 & 23.0 & 0.068 & -1.644 & & 5670.870 & 23.0 & 1.080 & -1.858 & \\
\hline 4594.125 & 23.0 & 0.068 & -3.393 & & 5670.870 & 23.0 & 1.080 & -1.589 & \\
\hline 4594.125 & 23.0 & 0.068 & -2.221 & & 5670.875 & 23.0 & 1.080 & -2.858 & \\
\hline 4594.125 & 23.0 & 0.068 & -1.548 & & 5670.875 & 23.0 & 1.080 & -1.963 & \\
\hline 4594.136 & 23.0 & 0.068 & -3.585 & & 5670.875 & 23.0 & 1.080 & -1.759 & \\
\hline 4594.136 & 23.0 & 0.068 & -2.303 & & 5670.878 & 23.0 & 1.080 & -2.159 & \\
\hline 4594.136 & 23.0 & 0.068 & -1.458 & & 5670.878 & 23.0 & 1.080 & -1.963 & \\
\hline 4594.149 & 23.0 & 0.068 & -3.974 & & 5670.880 & 23.0 & 1.080 & -2.226 & \\
\hline 4594.149 & 23.0 & 0.068 & -2.521 & & 5727.027 & 23.0 & 1.081 & -2.993 & VI \\
\hline 4594.149 & 23.0 & 0.068 & -1.374 & & 5727.027 & 23.0 & 1.081 & -1.692 & \\
\hline 4875.462 & 23.0 & 0.040 & -2.616 & VI & 5727.027 & 23.0 & 1.081 & -0.684 & \\
\hline 4875.464 & 23.0 & 0.040 & -2.331 & & 5727.039 & 23.0 & 1.081 & -2.595 & \\
\hline 4875.464 & 23.0 & 0.040 & -2.586 & & 5727.039 & 23.0 & 1.081 & -1.481 & \\
\hline 4875.468 & 23.0 & 0.040 & -2.586 & & 5727.039 & 23.0 & 1.081 & -0.789 & \\
\hline 4875.468 & 23.0 & 0.040 & -2.143 & & 5727.049 & 23.0 & 1.081 & -2.391 & \\
\hline 4875.468 & 23.0 & 0.040 & -2.637 & & 5727.049 & 23.0 & 1.081 & -1.408 & \\
\hline 4875.474 & 23.0 & 0.040 & -2.198 & & 5727.049 & 23.0 & 1.081 & -0.905 & \\
\hline 4875.474 & 23.0 & 0.040 & -2.052 & & 5727.058 & 23.0 & 1.081 & -2.294 & \\
\hline 4875.474 & 23.0 & 0.040 & -2.762 & & 5727.058 & 23.0 & 1.081 & -1.402 & \\
\hline 4875.481 & 23.0 & 0.040 & -1.943 & & 5727.058 & 23.0 & 1.081 & -1.034 & \\
\hline 4875.481 & 23.0 & 0.040 & -2.030 & & 5727.065 & 23.0 & 1.081 & -2.294 & \\
\hline 4875.481 & 23.0 & 0.040 & -2.984 & & 5727.065 & 23.0 & 1.081 & -1.449 & \\
\hline 4875.491 & 23.0 & 0.040 & -1.745 & & 5727.065 & 23.0 & 1.081 & -1.180 & \\
\hline 4875.491 & 23.0 & 0.040 & -2.084 & & 5727.070 & 23.0 & 1.081 & -2.449 & \\
\hline 4875.491 & 23.0 & 0.040 & -3.394 & & 5727.070 & 23.0 & 1.081 & -1.554 & \\
\hline 4875.503 & 23.0 & 0.040 & -1.581 & & 5727.070 & 23.0 & 1.081 & -1.350 & \\
\hline 4875.503 & 23.0 & 0.040 & -2.280 & & 5727.074 & 23.0 & 1.081 & -1.750 & \\
\hline 4875.517 & 23.0 & 0.040 & -1.440 & & 5727.074 & 23.0 & 1.081 & -1.554 & \\
\hline 5670.832 & 23.0 & 1.080 & -3.402 & VI & 5727.076 & 23.0 & 1.081 & -1.817 & \\
\hline 5670.832 & 23.0 & 1.080 & -2.101 & & 6039.727 & 23.0 & 1.063 & -1.854 & VI \\
\hline
\end{tabular}


Tabela A.3 - Continuação

\begin{tabular}{|c|c|c|c|c|c|c|c|c|c|}
\hline$\lambda(\AA)$ & Íon & $X_{e x c}(\mathrm{eV})$ & $\log g f$ & Elemento & $\lambda(\AA)$ & Íon & $X_{e x c}(\mathrm{eV})$ & $\log g f$ & Elemento \\
\hline 6039.729 & 23.0 & 1.063 & -1.854 & & 6119.527 & 23.0 & 1.064 & -0.887 & \\
\hline 6039.730 & 23.0 & 1.063 & -2.030 & & 6119.528 & 23.0 & 1.064 & -1.352 & \\
\hline 6039.733 & 23.0 & 1.063 & -1.690 & & 6119.535 & 23.0 & 1.064 & -1.950 & \\
\hline 6039.733 & 23.0 & 1.063 & -2.155 & & 6119.537 & 23.0 & 1.064 & -1.513 & \\
\hline 6039.734 & 23.0 & 1.063 & -2.280 & & 6119.546 & 23.0 & 1.064 & -2.378 & \\
\hline 6039.738 & 23.0 & 1.063 & -1.682 & & 6199.155 & 23.0 & 0.286 & -1.958 & VI \\
\hline 6039.738 & 23.0 & 1.063 & -1.716 & & 6199.173 & 23.0 & 0.286 & -2.063 & \\
\hline 6039.739 & 23.0 & 1.063 & -2.708 & & 6199.188 & 23.0 & 0.286 & -2.179 & \\
\hline 6039.744 & 23.0 & 1.063 & -1.843 & & 6199.203 & 23.0 & 0.286 & -2.308 & \\
\hline 6039.744 & 23.0 & 1.063 & -1.433 & & 6199.207 & 23.0 & 0.286 & -2.966 & \\
\hline 6039.751 & 23.0 & 1.063 & -1.217 & & 6199.215 & 23.0 & 0.286 & -2.454 & \\
\hline 6081.417 & 23.0 & 1.051 & -1.660 & VI & 6199.218 & 23.0 & 0.286 & -2.755 & \\
\hline 6081.417 & 23.0 & 1.051 & -1.484 & & 6199.226 & 23.0 & 0.286 & -2.624 & \\
\hline 6081.427 & 23.0 & 1.051 & -1.484 & & 6199.227 & 23.0 & 0.286 & -2.682 & \\
\hline 6081.428 & 23.0 & 1.051 & -1.359 & & 6199.235 & 23.0 & 0.286 & -2.676 & \\
\hline 6081.442 & 23.0 & 1.051 & -1.359 & & 6199.236 & 23.0 & 0.286 & -2.828 & \\
\hline 6081.442 & 23.0 & 1.051 & -1.677 & & 6199.241 & 23.0 & 0.286 & -2.723 & \\
\hline 6081.442 & 23.0 & 1.051 & -1.472 & & 6199.244 & 23.0 & 0.286 & -3.091 & \\
\hline 6081.460 & 23.0 & 1.051 & -1.472 & & 6199.246 & 23.0 & 0.286 & -2.828 & \\
\hline 6090.199 & 23.0 & 1.080 & -0.692 & VI & 6199.249 & 23.0 & 0.286 & -3.024 & \\
\hline 6090.207 & 23.0 & 1.080 & -0.833 & & 6199.252 & 23.0 & 0.286 & -4.267 & \\
\hline 6090.213 & 23.0 & 1.080 & -0.997 & & 6199.256 & 23.0 & 0.286 & -3.869 & \\
\hline 6090.213 & 23.0 & 1.080 & -1.532 & & 6199.259 & 23.0 & 0.286 & -3.723 & \\
\hline 6090.218 & 23.0 & 1.080 & -1.195 & & 6199.259 & 23.0 & 0.286 & -3.665 & \\
\hline 6090.218 & 23.0 & 1.080 & -1.336 & & 6199.260 & 23.0 & 0.286 & -3.568 & \\
\hline 6090.223 & 23.0 & 1.080 & -1.450 & & 6199.261 & 23.0 & 0.286 & -3.568 & \\
\hline 6090.223 & 23.0 & 1.080 & -1.282 & & 6251.771 & 23.0 & 0.286 & -2.924 & VI \\
\hline 6090.225 & 23.0 & 1.080 & -2.646 & & 6251.788 & 23.0 & 0.286 & -2.720 & \\
\hline 6090.226 & 23.0 & 1.080 & -1.304 & & 6251.804 & 23.0 & 0.286 & -2.655 & \\
\hline 6090.227 & 23.0 & 1.080 & -1.838 & & 6251.806 & 23.0 & 0.286 & -2.021 & \\
\hline 6090.228 & 23.0 & 1.080 & -2.236 & & 6251.817 & 23.0 & 0.286 & -2.662 & \\
\hline 6090.229 & 23.0 & 1.080 & -1.394 & & 6251.818 & 23.0 & 0.286 & -2.208 & \\
\hline 6090.231 & 23.0 & 1.080 & -1.583 & & 6251.829 & 23.0 & 0.286 & -2.728 & \\
\hline 6090.231 & 23.0 & 1.080 & -2.014 & & 6251.829 & 23.0 & 0.286 & -2.427 & \\
\hline 6090.232 & 23.0 & 1.080 & -1.889 & & 6251.837 & 23.0 & 0.286 & -2.690 & \\
\hline 6090.233 & 23.0 & 1.080 & -1.868 & & 6251.839 & 23.0 & 0.286 & -2.866 & \\
\hline 6090.233 & 23.0 & 1.080 & -1.838 & & 6251.844 & 23.0 & 0.286 & -3.021 & \\
\hline 6119.510 & 23.0 & 1.064 & -1.825 & VI & 6251.848 & 23.0 & 0.286 & -3.146 & \\
\hline 6119.514 & 23.0 & 1.064 & -1.386 & & 6251.849 & 23.0 & 0.286 & -3.468 & \\
\hline 6119.516 & 23.0 & 1.064 & -1.524 & & 6251.853 & 23.0 & 0.286 & -4.167 & \\
\hline 6119.519 & 23.0 & 1.064 & -1.524 & & 6251.853 & 23.0 & 0.286 & -2.924 & \\
\hline 6119.519 & 23.0 & 1.064 & -1.103 & & 6251.859 & 23.0 & 0.286 & -3.146 & \\
\hline 6119.521 & 23.0 & 1.064 & -1.360 & & 6251.859 & 23.0 & 0.286 & -2.720 & \\
\hline 6119.527 & 23.0 & 1.064 & -1.700 & & 6251.862 & 23.0 & 0.286 & -2.655 & \\
\hline
\end{tabular}

Continua na próxima página... 
Tabela A.3 - Continuação

\begin{tabular}{|c|c|c|c|c|c|c|c|c|c|}
\hline$\lambda(\AA)$ & Íon & $X_{e x c}(\mathrm{eV})$ & $\log g f$ & Elemento & $\lambda(\AA)$ & Íon & $X_{\text {exc }}(\mathrm{eV})$ & $\log g f$ & Elemento \\
\hline 6251.863 & 23.0 & 0.286 & -2.866 & & 5247.897 & 27.0 & 1.785 & -2.564 & \\
\hline 6251.864 & 23.0 & 0.286 & -2.728 & & 5247.936 & 27.0 & 1.785 & -2.564 & \\
\hline 6251.864 & 23.0 & 0.286 & -2.662 & & 5247.962 & 27.0 & 1.785 & -3.041 & \\
\hline 6274.607 & 23.0 & 0.267 & -2.932 & VI & 5301.008 & 27.0 & 1.710 & -3.335 & CoI \\
\hline 6274.629 & 23.0 & 0.267 & -2.455 & & 5301.017 & 27.0 & 1.710 & -2.636 & \\
\hline 6274.641 & 23.0 & 0.267 & -2.476 & & 5301.026 & 27.0 & 1.710 & -3.154 & \\
\hline 6274.655 & 23.0 & 0.267 & -2.134 & & 5301.034 & 27.0 & 1.710 & -2.927 & \\
\hline 6274.657 & 23.0 & 0.267 & -2.455 & & 5301.041 & 27.0 & 1.710 & -3.123 & \\
\hline 6274.678 & 23.0 & 0.267 & -2.601 & & 5301.043 & 27.0 & 1.710 & -3.335 & \\
\hline 6285.098 & 23.0 & 0.275 & -3.568 & VI & 5301.048 & 27.0 & 1.710 & -3.334 & \\
\hline 6285.117 & 23.0 & 0.275 & -3.140 & & 5301.052 & 27.0 & 1.710 & -3.187 & \\
\hline 6285.122 & 23.0 & 0.275 & -2.703 & & 5301.056 & 27.0 & 1.710 & -3.154 & \\
\hline 6285.134 & 23.0 & 0.275 & -2.890 & & 5301.058 & 27.0 & 1.710 & -4.051 & \\
\hline 6285.137 & 23.0 & 0.275 & -2.542 & & 5301.061 & 27.0 & 1.710 & -3.386 & \\
\hline 6285.148 & 23.0 & 0.275 & -2.714 & & 5301.065 & 27.0 & 1.710 & -5.295 & \\
\hline 6285.149 & 23.0 & 0.275 & -2.550 & & 5301.065 & 27.0 & 1.710 & -3.123 & \\
\hline 6285.152 & 23.0 & 0.275 & -2.077 & & 5301.070 & 27.0 & 1.710 & -3.641 & \\
\hline 6285.157 & 23.0 & 0.275 & -2.714 & & 5301.071 & 27.0 & 1.710 & -3.187 & \\
\hline 6285.162 & 23.0 & 0.275 & -2.293 & & 5301.074 & 27.0 & 1.710 & -3.386 & \\
\hline 6285.168 & 23.0 & 0.275 & -2.576 & & 5342.693 & 27.0 & 4.021 & -0.743 & CoI \\
\hline 6285.172 & 23.0 & 0.275 & -3.015 & & 5342.693 & 27.0 & 4.021 & -0.660 & \\
\hline 5212.591 & 27.0 & 3.514 & -1.882 & CoI & 5342.693 & 27.0 & 4.021 & -0.574 & \\
\hline 5212.618 & 27.0 & 3.514 & -1.667 & & 5342.694 & 27.0 & 4.021 & -0.490 & \\
\hline 5212.642 & 27.0 & 3.514 & -1.590 & & 5342.696 & 27.0 & 4.021 & -0.408 & \\
\hline 5212.649 & 27.0 & 3.514 & -0.819 & & 5342.699 & 27.0 & 4.021 & -0.331 & \\
\hline 5212.664 & 27.0 & 3.514 & -1.579 & & 5342.701 & 27.0 & 4.021 & -1.468 & \\
\hline 5212.669 & 27.0 & 3.514 & -0.955 & & 5342.702 & 27.0 & 4.021 & -0.257 & \\
\hline 5212.683 & 27.0 & 3.514 & -1.622 & & 5342.704 & 27.0 & 4.021 & -1.250 & \\
\hline 5212.687 & 27.0 & 3.514 & -1.103 & & 5342.706 & 27.0 & 4.021 & -0.187 & \\
\hline 5212.700 & 27.0 & 3.514 & -1.725 & & 5342.707 & 27.0 & 4.021 & -1.156 & \\
\hline 5212.701 & 27.0 & 3.514 & -1.262 & & 5342.712 & 27.0 & 4.021 & -1.124 & \\
\hline 5212.713 & 27.0 & 3.514 & -1.431 & & 5342.713 & 27.0 & 4.021 & -2.681 & \\
\hline 5212.714 & 27.0 & 3.514 & -1.946 & & 5342.716 & 27.0 & 4.021 & -1.144 & \\
\hline 5212.722 & 27.0 & 3.514 & -1.598 & & 5342.718 & 27.0 & 4.021 & -2.447 & \\
\hline 5212.728 & 27.0 & 3.514 & -1.882 & & 5342.722 & 27.0 & 4.021 & -1.231 & \\
\hline 5212.729 & 27.0 & 3.514 & -1.736 & & 5342.725 & 27.0 & 4.021 & -2.401 & \\
\hline 5212.734 & 27.0 & 3.514 & -1.750 & & 5342.728 & 27.0 & 4.021 & -1.454 & \\
\hline 5212.738 & 27.0 & 3.514 & -1.667 & & 5342.732 & 27.0 & 4.021 & -2.468 & \\
\hline 5212.745 & 27.0 & 3.514 & -1.590 & & 5342.739 & 27.0 & 4.021 & -2.651 & \\
\hline 5212.748 & 27.0 & 3.514 & -1.946 & & 5342.748 & 27.0 & 4.021 & -3.033 & \\
\hline 5212.750 & 27.0 & 3.514 & -1.579 & & 5483.309 & 27.0 & 1.710 & -2.120 & CoI \\
\hline 5212.751 & 27.0 & 3.514 & -1.725 & & 5483.334 & 27.0 & 1.710 & -2.261 & \\
\hline 5212.752 & 27.0 & 3.514 & -1.622 & & 5483.344 & 27.0 & 1.710 & -2.961 & \\
\hline 5247.872 & 27.0 & 1.785 & -2.710 & CoI & 5483.354 & 27.0 & 1.710 & -2.425 & \\
\hline
\end{tabular}


Tabela A.3 - Continuação

\begin{tabular}{|c|c|c|c|c|c|c|c|c|c|}
\hline$\lambda(\AA)$ & Íon & $X_{e x c}(\mathrm{eV})$ & $\log g f$ & Elemento & $\lambda(\AA)$ & Íon & $X_{e x c}(\mathrm{eV})$ & $\log g f$ & Elemento \\
\hline 5483.363 & 27.0 & 1.710 & -2.764 & & 6188.925 & 27.0 & 1.710 & -3.805 & CoI \\
\hline 5483.370 & 27.0 & 1.710 & -2.623 & & 6188.937 & 27.0 & 1.710 & -3.106 & \\
\hline 5483.372 & 27.0 & 1.7104 & -4.074 & & 6188.968 & 27.0 & 1.710 & -3.624 & \\
\hline 5483.378 & 27.0 & 1.7104 & -2.710 & & 6188.979 & 27.0 & 1.710 & -3.398 & \\
\hline 5483.383 & 27.0 & 1.7104 & -2.878 & & 6188.991 & 27.0 & 1.710 & -3.805 & \\
\hline 5483.387 & 27.0 & 1.7104 & -3.664 & & 6189.003 & 27.0 & 1.710 & -3.593 & \\
\hline 5483.389 & 27.0 & 1.7104 & -2.732 & & 6189.012 & 27.0 & 1.710 & -3.804 & \\
\hline 5483.393 & 27.0 & 1.7104 & -3.266 & & 6189.024 & 27.0 & 1.710 & -3.624 & \\
\hline 5483.397 & 27.0 & 1.7104 & -2.822 & & 6189.030 & 27.0 & 1.710 & -3.657 & \\
\hline 5483.397 & 27.0 & 1.7104 & -3.442 & & 6189.038 & 27.0 & 1.710 & -4.521 & \\
\hline 5483.402 & 27.0 & 1.7104 & -3.011 & & 6189.048 & 27.0 & 1.710 & -3.593 & \\
\hline 5483.403 & 27.0 & 1.7104 & -3.317 & & 6189.052 & 27.0 & 1.710 & -3.856 & \\
\hline 5483.407 & 27.0 & 1.7104 & -3.296 & & 6189.057 & 27.0 & 1.710 & -5.764 & \\
\hline 5483.407 & 27.0 & 1.7104 & -3.266 & & 6189.065 & 27.0 & 1.710 & -3.657 & \\
\hline 5530.734 & 27.0 & 1.711 & -2.860 & CoI & 6189.069 & 27.0 & 1.710 & -4.111 & \\
\hline 5530.757 & 27.0 & 1.711 & -3.001 & & 6189.075 & 27.0 & 1.710 & -3.856 & \\
\hline 5530.767 & 27.0 & 1.711 & -3.700 & & 6454.934 & 27.0 & 3.632 & -2.056 & CoI \\
\hline 5530.776 & 27.0 & 1.711 & -3.165 & & 6454.944 & 27.0 & 3.632 & -1.989 & \\
\hline 5530.785 & 27.0 & 1.711 & -3.504 & & 6454.933 & 27.0 & 3.632 & -1.792 & \\
\hline 5530.791 & 27.0 & 1.711 & -3.363 & & 6454.965 & 27.0 & 3.632 & -2.688 & \\
\hline 5530.794 & 27.0 & 1.711 & -4.814 & & 6454.954 & 27.0 & 3.632 & -1.792 & \\
\hline 5530.799 & 27.0 & 1.711 & -3.450 & & 6454.937 & 27.0 & 3.632 & -1.588 & \\
\hline 5530.803 & 27.0 & 1.711 & -3.618 & & 6454.985 & 27.0 & 3.632 & -2.533 & \\
\hline 5530.808 & 27.0 & 1.711 & -4.404 & & 6454.968 & 27.0 & 3.632 & -1.688 & \\
\hline 5530.809 & 27.0 & 1.711 & -3.472 & & 6454.946 & 27.0 & 3.632 & -1.419 & \\
\hline 5530.812 & 27.0 & 1.711 & -4.006 & & 6455.010 & 27.0 & 3.632 & -2.533 & \\
\hline 5530.816 & 27.0 & 1.711 & -3.563 & & 6454.987 & 27.0 & 3.632 & -1.641 & \\
\hline 5530.817 & 27.0 & 1.711 & -4.182 & & 6454.959 & 27.0 & 3.632 & -1.273 & \\
\hline 5530.820 & 27.0 & 1.711 & -3.751 & & 6455.040 & 27.0 & 3.632 & -2.630 & \\
\hline 5530.822 & 27.0 & 1.711 & -4.057 & & 6455.012 & 27.0 & 3.632 & -1.646 & \\
\hline 5530.825 & 27.0 & 1.711 & -4.006 & & 6454.978 & 27.0 & 3.632 & -1.144 & \\
\hline 5530.825 & 27.0 & 1.711 & -4.036 & & 6455.074 & 27.0 & 3.632 & -2.834 & \\
\hline 5647.207 & 27.0 & 2.280 & -2.127 & CoI & 6455.041 & 27.0 & 3.632 & -1.720 & \\
\hline 5647.220 & 27.0 & 2.280 & -2.343 & & 6455.002 & 27.0 & 3.632 & -1.028 & \\
\hline 5647.232 & 27.0 & 2.280 & -2.626 & & 6455.114 & 27.0 & 3.632 & -3.232 & \\
\hline 5647.239 & 27.0 & 2.280 & -2.753 & & 6455.075 & 27.0 & 3.632 & -1.931 & \\
\hline 5647.243 & 27.0 & 2.280 & -3.065 & & 6455.030 & 27.0 & 3.632 & -0.922 & \\
\hline 5647.246 & 27.0 & 2.280 & -2.592 & & 5105.505 & 29.0 & 1.390 & -3.880 & $\mathrm{CuI}$ \\
\hline 5647.253 & 27.0 & 2.280 & -2.600 & & 5105.509 & 29.0 & 1.390 & -2.926 & \\
\hline 5647.259 & 27.0 & 2.280 & -2.764 & & 5105.511 & 29.0 & 1.390 & -2.880 & \\
\hline 5647.265 & 27.0 & 2.280 & -3.618 & & 5105.512 & 29.0 & 1.390 & -4.056 & \\
\hline 5647.267 & 27.0 & 2.280 & -3.190 & & 5105.517 & 29.0 & 1.390 & -2.813 & \\
\hline 5647.269 & 27.0 & 2.280 & -2.764 & & 5105.520 & 29.0 & 1.390 & -2.558 & \\
\hline 5647.269 & 27.0 & 2.280 & -2.940 & & 5105.531 & 29.0 & 1.390 & -2.910 & \\
\hline
\end{tabular}


Tabela A.3 - Continuação

\begin{tabular}{|c|c|c|c|c|c|c|c|c|c|}
\hline$\lambda(\AA)$ & Íon & $X_{\text {exc }}(\mathrm{eV})$ & $\log g f$ & Elemento & $\lambda(\AA)$ & Íon & $X_{e x c}(\mathrm{eV})$ & $\log g f$ & Elemento \\
\hline 5105.536 & 29.0 & 1.390 & -2.308 & & 5220.097 & 29.0 & 3.816 & -2.015 & \\
\hline 5105.558 & 29.0 & 1.390 & -2.102 & & 5220.103 & 29.0 & 3.816 & -2.015 & \\
\hline 5105.503 & 29.0 & 1.390 & -4.232 & & 5220.100 & 29.0 & 3.816 & -1.412 & \\
\hline 5105.506 & 29.0 & 1.390 & -3.277 & & 7933.092 & 29.0 & 3.790 & -1.383 & $\mathrm{CuI}$ \\
\hline 5105.509 & 29.0 & 1.390 & -3.232 & & 7933.101 & 29.00 & 3.790 & -1.035 & \\
\hline 5105.510 & 29.0 & 1.390 & -4.408 & & 7933.115 & 29.00 & 3.790 & -1.383 & \\
\hline 5105.515 & 29.0 & 1.390 & -3.165 & & 7933.122 & 29.00 & 3.790 & -1.035 & \\
\hline 5105.519 & 29.0 & 1.390 & -2.909 & & 7933.131 & 29.00 & 3.790 & -2.082 & \\
\hline 5105.530 & 29.0 & 1.390 & -3.262 & & 7933.136 & 29.00 & 3.790 & -1.734 & \\
\hline 5105.536 & 29.0 & 1.390 & -2.659 & & 7933.154 & 29.00 & 3.790 & -1.383 & \\
\hline 5105.560 & 29.0 & 1.390 & -2.453 & & 7933.157 & 29.00 & 3.790 & -1.035 & \\
\hline 5218.191 & 29.0 & 3.816 & -1.094 & $\mathrm{CuI}$ & 4854.867 & 39.1 & 0.992 & -0.857 & YII \\
\hline 5218.193 & 29.0 & 3.816 & -1.140 & & 4854.867 & 39.1 & 0.9923 & -0.602 & \\
\hline 5218.193 & 29.0 & 3.816 & -0.772 & & 4854.868 & 39.1 & 0.9923 & -1.556 & \\
\hline 5218.196 & 29.0 & 3.816 & -2.094 & & 4883.685 & 39.1 & 1.084 & -0.298 & YII \\
\hline 5218.196 & 29.0 & 3.816 & -1.027 & & 4883.685 & 39.1 & 1.0841 & -1.729 & \\
\hline 5218.196 & 29.0 & 3.816 & -0.522 & & 4883.685 & 39.1 & 1.0841 & -0.185 & \\
\hline 5218.202 & 29.0 & 3.816 & -2.270 & & 4900.110 & 39.1 & 1.032 & -0.488 & YII \\
\hline 5218.202 & 29.0 & 3.816 & -1.124 & & 4900.110 & 39.1 & 1.0326 & -1.634 & \\
\hline 5218.202 & 29.0 & 3.816 & -0.316 & & 4900.110 & 39.1 & 1.0326 & -0.333 & \\
\hline 5218.190 & 29.0 & 3.816 & -1.446 & & 5087.418 & 39.1 & 1.084 & -0.534 & YII \\
\hline 5218.192 & 29.0 & 3.816 & -1.491 & & 5087.418 & 39.1 & 1.0841 & -2.078 & \\
\hline 5218.192 & 29.0 & 3.816 & -1.123 & & 5087.420 & 39.1 & 1.0841 & -2.078 & \\
\hline 5218.196 & 29.0 & 3.816 & -2.446 & & 5087.420 & 39.1 & 1.0841 & -0.435 & \\
\hline 5218.196 & 29.0 & 3.816 & -1.379 & & 5200.411 & 39.1 & 0.992 & -1.968 & YII \\
\hline 5218.196 & 29.0 & 3.816 & -0.874 & & 5200.413 & 39.1 & 0.9923 & -1.014 & \\
\hline 5218.202 & 29.0 & 3.816 & -2.622 & & 5200.413 & 39.1 & 0.9923 & -0.822 & \\
\hline 5218.202 & 29.0 & 3.816 & -1.475 & & 5200.414 & 39.1 & 0.9923 & -1.968 & \\
\hline 5218.202 & 29.0 & 3.816 & -0.667 & & 3819.562 & 63.1 & 0.000 & -0.921 & EuII \\
\hline 5220.065 & 29.0 & 3.816 & -1.813 & $\mathrm{CuI}$ & 3819.581 & 63.1 & 0.000 & -1.590 & \\
\hline 5220.067 & 29.0 & 3.816 & -1.813 & & 3819.582 & 63.1 & 0.000 & -0.812 & \\
\hline 5220.066 & 29.0 & 3.816 & -2.211 & & 3819.607 & 63.1 & 0.000 & -2.807 & \\
\hline 5220.064 & 29.0 & 3.816 & -1.609 & & 3819.608 & 63.1 & 0.000 & -1.399 & \\
\hline 5220.068 & 29.0 & 3.816 & -1.609 & & 3819.608 & 63.1 & 0.000 & -0.702 & \\
\hline 5220.066 & 29.0 & 3.816 & -1.512 & & 3819.641 & 63.1 & 0.000 & -2.661 & \\
\hline 5220.063 & 29.0 & 3.816 & -1.667 & & 3819.641 & 63.1 & 0.000 & -1.346 & \\
\hline 5220.069 & 29.0 & 3.816 & -1.667 & & 3819.639 & 63.1 & 0.000 & -0.597 & \\
\hline 5220.066 & 29.0 & 3.816 & -1.064 & & 3819.683 & 63.1 & 0.000 & -2.748 & \\
\hline 5220.099 & 29.0 & 3.816 & -2.161 & & 3819.680 & 63.1 & 0.000 & -1.387 & \\
\hline 5220.101 & 29.0 & 3.816 & -2.161 & & 3819.675 & 63.1 & 0.000 & -0.499 & \\
\hline 5220.100 & 29.0 & 3.816 & -2.559 & & 3819.729 & 63.1 & 0.000 & -3.076 & \\
\hline 5220.098 & 29.0 & 3.816 & -1.957 & & 3819.724 & 63.1 & 0.000 & -1.578 & \\
\hline 5220.102 & 29.0 & 3.816 & -1.957 & & 3819.713 & 63.1 & 0.000 & -0.406 & \\
\hline 5220.100 & 29.0 & 3.816 & -1.860 & & 3819.623 & 63.1 & 0.000 & -0.921 & \\
\hline
\end{tabular}

Continua na próxima página... 
Tabela A.3 - Continuação

\begin{tabular}{|c|c|c|c|c|c|c|c|c|c|}
\hline$\lambda(\AA)$ & Íon & $X_{e x c}(\mathrm{eV})$ & $\log g f$ & Elemento & $\lambda(\AA)$ & Íon & $X_{e x c}(\mathrm{eV})$ & $\log g f$ & Elemento \\
\hline 3819.631 & 63.1 & 0.000 & -1.590 & & 4129.631 & 63.1 & 0.000 & -1.812 & \\
\hline 3819.639 & 63.1 & 0.000 & -0.812 & & 4129.626 & 63.1 & 0.000 & -1.277 & \\
\hline 3819.643 & 63.1 & 0.000 & -2.807 & & 4129.620 & 63.1 & 0.000 & -1.616 & \\
\hline 3819.650 & 63.1 & 0.000 & -1.399 & & 4129.657 & 63.1 & 0.000 & -1.616 & \\
\hline 3819.657 & 63.1 & 0.000 & -0.702 & & 4129.650 & 63.1 & 0.000 & -1.146 & \\
\hline 3819.665 & 63.1 & 0.000 & -2.661 & & 4129.644 & 63.1 & 0.000 & -1.557 & \\
\hline 3819.672 & 63.1 & 0.000 & -1.346 & & 4129.689 & 63.1 & 0.000 & -1.557 & \\
\hline 3819.674 & 63.1 & 0.000 & -0.597 & & 4129.683 & 63.1 & 0.000 & -0.996 & \\
\hline 3819.690 & 63.1 & 0.000 & -2.748 & & 4129.677 & 63.1 & 0.000 & -1.593 & \\
\hline 3819.693 & 63.1 & 0.000 & -1.387 & & 4129.731 & 63.1 & 0.000 & -1.593 & \\
\hline 3819.688 & 63.1 & 0.000 & -0.499 & & 4129.725 & 63.1 & 0.000 & -0.845 & \\
\hline 3819.714 & 63.1 & 0.000 & -3.076 & & 4129.721 & 63.1 & 0.000 & -1.780 & \\
\hline 3819.710 & 63.1 & 0.000 & -1.578 & & 4129.782 & 63.1 & 0.000 & -1.780 & \\
\hline 3819.694 & 63.1 & 0.000 & -0.406 & & 4129.778 & 63.1 & 0.000 & -0.701 & \\
\hline 3907.164 & 63.1 & 0.207 & -1.562 & EuII & 4129.693 & 63.1 & 0.000 & -1.335 & \\
\hline 3907.169 & 63.1 & 0.207 & -2.106 & & 4129.687 & 63.1 & 0.000 & -1.812 & \\
\hline 3907.151 & 63.1 & 0.207 & -1.659 & & 4129.703 & 63.1 & 0.000 & -1.812 & \\
\hline 3907.156 & 63.1 & 0.207 & -1.397 & & 4129.696 & 63.1 & 0.000 & -1.277 & \\
\hline 3907.164 & 63.1 & 0.207 & -2.073 & & 4129.688 & 63.1 & 0.000 & -1.616 & \\
\hline 3907.135 & 63.1 & 0.207 & -1.294 & & 4129.710 & 63.1 & 0.000 & -1.616 & \\
\hline 3907.143 & 63.1 & 0.207 & -1.310 & & 4129.702 & 63.1 & 0.000 & -1.146 & \\
\hline 3907.153 & 63.1 & 0.207 & -2.219 & & 4129.696 & 63.1 & 0.000 & -1.557 & \\
\hline 3907.113 & 63.1 & 0.207 & -1.043 & & 4129.720 & 63.1 & 0.000 & -1.557 & \\
\hline 3907.123 & 63.1 & 0.207 & -1.321 & & 4129.713 & 63.1 & 0.000 & -0.996 & \\
\hline 3907.136 & 63.1 & 0.207 & -2.583 & & 4129.712 & 63.1 & 0.000 & -1.593 & \\
\hline 3907.085 & 63.1 & 0.207 & -0.843 & & 4129.735 & 63.1 & 0.000 & -1.593 & \\
\hline 3907.097 & 63.1 & 0.207 & -1.486 & & 4129.733 & 63.1 & 0.000 & -0.845 & \\
\hline 3907.051 & 63.1 & 0.207 & -0.675 & & 4129.739 & 63.1 & 0.000 & -1.780 & \\
\hline 3907.148 & 63.1 & 0.207 & -1.562 & & 4129.758 & 63.1 & 0.000 & -1.780 & \\
\hline 3907.152 & 63.1 & 0.207 & -2.106 & & 4129.765 & 63.1 & 0.000 & -0.701 & \\
\hline 3907.143 & 63.1 & 0.207 & -1.659 & & 6645.148 & 63.1 & 1.379 & -1.222 & EuII \\
\hline 3907.146 & 63.1 & 0.207 & -1.397 & & 6645.151 & 63.1 & 1.379 & -2.130 & \\
\hline 3907.151 & 63.1 & 0.207 & -2.073 & & 6645.151 & 63.1 & 1.379 & -3.545 & \\
\hline 3907.137 & 63.1 & 0.207 & -1.294 & & 6645.137 & 63.1 & 1.379 & -1.139 & \\
\hline 3907.142 & 63.1 & 0.207 & -1.310 & & 6645.137 & 63.1 & 1.379 & -1.936 & \\
\hline 3907.147 & 63.1 & 0.207 & -2.219 & & 6645.130 & 63.1 & 1.379 & -3.377 & \\
\hline 3907.128 & 63.1 & 0.207 & -1.043 & & 6645.123 & 63.1 & 1.379 & -1.055 & \\
\hline 3907.134 & 63.1 & 0.207 & -1.321 & & 6645.116 & 63.1 & 1.379 & -1.884 & \\
\hline 3907.137 & 63.1 & 0.207 & -2.583 & & 6645.099 & 63.1 & 1.379 & -3.450 & \\
\hline 3907.116 & 63.1 & 0.207 & -0.843 & & 6645.105 & 63.1 & 1.379 & -0.973 & \\
\hline 3907.120 & 63.1 & 0.207 & -1.486 & & 6645.088 & 63.1 & 1.379 & -1.929 & \\
\hline 3907.099 & 63.1 & 0.207 & -0.675 & & 6645.057 & 63.1 & 1.379 & -3.767 & \\
\hline 4129.609 & 63.1 & 0.000 & -1.335 & EuII & 6645.084 & 63.1 & 1.379 & -0.893 & \\
\hline 4129.604 & 63.1 & 0.000 & -1.812 & & 6645.052 & 63.1 & 1.379 & -2.124 & \\
\hline
\end{tabular}


Tabela A.3 - Continuação

\begin{tabular}{|c|c|c|c|c|c|c|c|c|c|}
\hline$\lambda(\AA)$ & Íon & $X_{e x c}(\mathrm{eV})$ & $\log g f$ & Elemento & $\lambda(\AA)$ & Íon & $X_{e x c}(\mathrm{eV})$ & $\log g f$ & Elemento \\
\hline 6645.057 & 63.1 & 1.379 & -0.817 & & 6141.699 & 56.1 & 0.704 & -1.453 & \\
\hline 6645.096 & 63.1 & 1.379 & -1.222 & & 6141.699 & 56.1 & 0.704 & -2.398 & \\
\hline 6645.119 & 63.1 & 1.379 & -2.130 & & 6141.699 & 56.1 & 0.704 & -2.164 & \\
\hline 6645.139 & 63.1 & 1.379 & -3.545 & & 6141.700 & 56.1 & 0.704 & -1.700 & \\
\hline 6645.092 & 63.1 & 1.379 & -1.139 & & 6141.700 & 56.1 & 0.704 & -0.224 & \\
\hline 6645.111 & 63.1 & 1.379 & -1.936 & & 6141.700 & 56.1 & 0.704 & -1.182 & \\
\hline 6645.119 & 63.1 & 1.379 & -3.377 & & 6141.701 & 56.1 & 0.704 & -1.892 & \\
\hline 6645.088 & 63.1 & 1.379 & -1.055 & & 6141.701 & 56.1 & 0.704 & -1.659 & \\
\hline 6645.096 & 63.1 & 1.379 & -1.884 & & 6141.701 & 56.1 & 0.704 & -2.510 & \\
\hline 6645.083 & 63.1 & 1.379 & -3.450 & & 6141.701 & 56.1 & 0.704 & -2.277 & \\
\hline 6645.083 & 63.1 & 1.379 & -0.973 & & 6141.702 & 56.1 & 0.704 & -1.909 & \\
\hline 6645.070 & 63.1 & 1.379 & -1.929 & & 6141.702 & 56.1 & 0.704 & -2.465 & \\
\hline 6645.023 & 63.1 & 1.379 & -3.767 & & 6141.702 & 56.1 & 0.704 & -2.143 & \\
\hline 6645.075 & 63.1 & 1.379 & -0.893 & & 6141.703 & 56.1 & 0.704 & -2.231 & \\
\hline 6645.028 & 63.1 & 1.379 & -2.124 & & 6496.900 & 56.1 & 0.604 & -2.000 & BaII \\
\hline 6645.059 & 63.1 & 1.379 & -0.817 & & 6496.906 & 56.1 & 0.604 & -2.764 & \\
\hline 5853.696 & 56.1 & 0.604 & -2.915 & BaII & 6496.907 & 56.1 & 0.604 & -2.367 & \\
\hline 5853.697 & 56.1 & 0.604 & -2.857 & & 6496.889 & 56.1 & 0.604 & -3.066 & \\
\hline 5853.697 & 56.1 & 0.604 & -3.148 & & 6496.910 & 56.1 & 0.604 & -2.367 & \\
\hline 5853.698 & 56.1 & 0.604 & -3.090 & & 6496.892 & 56.1 & 0.604 & -2.367 & \\
\hline 5853.699 & 56.1 & 0.604 & -3.295 & & 6496.896 & 56.1 & 0.604 & -1.919 & \\
\hline 5853.699 & 56.1 & 0.604 & -3.061 & & 6496.900 & 56.1 & 0.604 & -1.482 & \\
\hline 5853.700 & 56.1 & 0.604 & -2.760 & & 6496.906 & 56.1 & 0.604 & -2.531 & \\
\hline 5853.700 & 56.1 & 0.604 & -3.693 & & 6496.908 & 56.1 & 0.604 & -2.133 & \\
\hline 5853.700 & 56.1 & 0.604 & -2.546 & & 6496.888 & 56.1 & 0.604 & -2.832 & \\
\hline 5853.700 & 56.1 & 0.604 & -2.530 & & 6496.912 & 56.1 & 0.604 & -2.133 & \\
\hline 5853.700 & 56.1 & 0.604 & -3.459 & & 6496.891 & 56.1 & 0.604 & -2.133 & \\
\hline 5853.700 & 56.1 & 0.604 & -2.313 & & 6496.896 & 56.1 & 0.604 & -1.686 & \\
\hline 5853.700 & 56.1 & 0.604 & -1.054 & & 6496.900 & 56.1 & 0.604 & -0.524 & \\
\hline 5853.700 & 56.1 & 0.604 & -2.012 & & 4082.924 & 25.0 & 2.178 & -1.910 & MnI \\
\hline 5853.700 & 56.1 & 0.604 & -2.994 & & 4082.924 & 25.0 & 2.178 & -1.588 & \\
\hline 5853.701 & 56.1 & 0.604 & -3.295 & & 4082.924 & 25.0 & 2.178 & -1.764 & \\
\hline 5853.702 & 56.1 & 0.604 & -3.061 & & 4082.929 & 25.0 & 2.178 & -1.956 & \\
\hline 5853.703 & 56.1 & 0.604 & -2.857 & & 4082.930 & 25.0 & 2.178 & -1.433 & \\
\hline 5853.703 & 56.1 & 0.604 & -3.090 & & 4082.930 & 25.0 & 2.178 & -1.354 & \\
\hline 5853.704 & 56.1 & 0.604 & -3.148 & & 4082.938 & 25.0 & 2.178 & -2.132 & \\
\hline 5853.704 & 56.1 & 0.604 & -2.915 & & 4082.938 & 25.0 & 2.178 & -1.412 & \\
\hline 6141.695 & 56.1 & 0.704 & -3.641 & BaII & 4082.939 & 25.0 & 2.178 & -1.081 & \\
\hline 6141.695 & 56.1 & 0.704 & -3.407 & & 4082.948 & 25.0 & 2.178 & -2.512 & \\
\hline 6141.697 & 56.1 & 0.704 & -2.495 & & 4082.949 & 25.0 & 2.178 & -1.558 & \\
\hline 6141.697 & 56.1 & 0.704 & -2.261 & & 4082.949 & 25.0 & 2.178 & -0.868 & \\
\hline 6141.698 & 56.1 & 0.704 & -3.465 & & 4709.693 & 25.0 & 2.888 & -0.949 & MnI \\
\hline 6141.698 & 56.1 & 0.704 & -3.231 & & 4709.698 & 25.0 & 2.888 & -1.940 & \\
\hline 6141.699 & 56.1 & 0.704 & -1.686 & & 4709.701 & 25.0 & 2.888 & -1.940 & \\
\hline
\end{tabular}

Continua na próxima página... 
Tabela A.3 - Continuação

\begin{tabular}{|c|c|c|c|c|c|c|c|c|c|}
\hline$\lambda(\AA)$ & Íon & $X_{e x c}(\mathrm{eV})$ & $\log g f$ & Elemento & $\lambda(\AA)$ & Íon & $X_{e x c}(\mathrm{eV})$ & $\log g f$ & Elemento \\
\hline 4709.706 & 25.0 & 2.888 & -1.119 & & 5399.497 & 25.0 & 3.850 & -1.204 & \\
\hline 4709.711 & 25.0 & 2.888 & -1.758 & & 5399.521 & 25.0 & 3.850 & -1.030 & \\
\hline 4709.713 & 25.0 & 2.888 & -1.758 & & 5399.522 & 25.0 & 3.850 & -0.655 & \\
\hline 4709.717 & 25.0 & 2.888 & -1.304 & & 5399.555 & 25.0 & 3.850 & -1.132 & \\
\hline 4709.721 & 25.0 & 2.888 & -1.727 & & 6013.520 & 25.0 & 3.073 & -0.765 & MnI \\
\hline 4709.723 & 25.0 & 2.888 & -1.727 & & 6013.545 & 25.0 & 3.073 & -0.977 & \\
\hline 4709.726 & 25.0 & 2.888 & -1.496 & & 6013.567 & 25.0 & 3.073 & -1.250 & \\
\hline 4709.729 & 25.0 & 2.888 & -1.792 & & 6013.573 & 25.0 & 3.073 & -1.454 & \\
\hline 4709.730 & 25.0 & 2.888 & -1.792 & & 6013.584 & 25.0 & 3.073 & -1.660 & \\
\hline 4709.733 & 25.0 & 2.888 & -1.671 & & 6013.587 & 25.0 & 3.073 & -1.308 & \\
\hline 4709.735 & 25.0 & 2.888 & -1.990 & & 6013.598 & 25.0 & 3.073 & -1.329 & \\
\hline 4709.736 & 25.0 & 2.888 & -1.990 & & 6013.605 & 25.0 & 3.073 & -1.484 & \\
\hline 4709.737 & 25.0 & 2.888 & -1.735 & & 6013.615 & 25.0 & 3.073 & -2.408 & \\
\hline 4739.072 & 25.0 & 2.941 & -1.518 & MnI & 6013.615 & 25.0 & 3.073 & -1.806 & \\
\hline 4739.072 & 25.0 & 2.941 & -1.041 & & 6013.619 & 25.0 & 3.073 & -2.028 & \\
\hline 4739.088 & 25.0 & 2.941 & -1.416 & & 6013.619 & 25.0 & 3.073 & -1.852 & \\
\hline 4739.088 & 25.0 & 2.941 & -1.590 & & 6016.613 & 25.0 & 3.073 & -1.444 & MnI \\
\hline 4739.088 & 25.0 & 2.941 & -1.518 & & 6016.640 & 25.0 & 3.073 & -0.666 & \\
\hline 4739.100 & 25.0 & 2.941 & -1.416 & & 6016.640 & 25.0 & 3.073 & -1.281 & \\
\hline 4739.101 & 25.0 & 2.941 & -1.548 & & 6016.661 & 25.0 & 3.073 & -1.276 & \\
\hline 4739.101 & 25.0 & 2.941 & -3.125 & & 6016.662 & 25.0 & 3.073 & -0.929 & \\
\hline 4739.109 & 25.0 & 2.941 & -1.916 & & 6016.678 & 25.0 & 3.073 & -1.378 & \\
\hline 4739.109 & 25.0 & 2.941 & -1.548 & & 6016.679 & 25.0 & 3.073 & -1.260 & \\
\hline 5004.887 & 25.0 & 2.920 & -4.332 & MnI & 6016.689 & 25.0 & 3.073 & -1.444 & \\
\hline 5004.887 & 25.0 & 2.920 & -3.115 & & 6016.690 & 25.0 & 3.073 & -1.707 & \\
\hline 5004.887 & 25.0 & 2.920 & -2.197 & & 6016.691 & 25.0 & 3.073 & -1.640 & \\
\hline 5004.891 & 25.0 & 2.920 & -3.980 & & 6016.697 & 25.0 & 3.073 & -2.406 & \\
\hline 5004.891 & 25.0 & 2.920 & -2.939 & & 6016.701 & 25.0 & 3.073 & -1.281 & \\
\hline 5004.891 & 25.0 & 2.920 & -2.337 & & 6016.707 & 25.0 & 3.073 & -1.640 & \\
\hline 5004.894 & 25.0 & 2.920 & -3.855 & & 6016.708 & 25.0 & 3.073 & -1.276 & \\
\hline 5004.894 & 25.0 & 2.920 & -2.913 & & 6016.709 & 25.0 & 3.073 & -1.378 & \\
\hline 5004.894 & 25.0 & 2.920 & -2.495 & & 6021.746 & 25.0 & 3.075 & -2.668 & MnI \\
\hline 5004.896 & 25.0 & 2.920 & -3.934 & & 6021.772 & 25.0 & 3.075 & -1.451 & \\
\hline 5004.896 & 25.0 & 2.920 & -2.980 & & 6021.774 & 25.0 & 3.075 & -2.316 & \\
\hline 5004.896 & 25.0 & 2.920 & -2.679 & & 6021.795 & 25.0 & 3.075 & -1.275 & \\
\hline 5004.898 & 25.0 & 2.920 & -3.186 & & 6021.798 & 25.0 & 3.075 & -2.191 & \\
\hline 5004.898 & 25.0 & 2.920 & -3.156 & & 6021.804 & 25.0 & 3.075 & -0.533 & \\
\hline 5004.898 & 25.0 & 2.920 & -2.901 & & 6021.813 & 25.0 & 3.075 & -1.249 & \\
\hline 5399.450 & 25.0 & 3.850 & -1.162 & MnI & 6021.817 & 25.0 & 3.075 & -2.271 & \\
\hline 5399.455 & 25.0 & 3.850 & -1.030 & & 6021.821 & 25.0 & 3.075 & -0.673 & \\
\hline 5399.465 & 25.0 & 3.850 & -1.530 & & 6021.827 & 25.0 & 3.075 & -1.316 & \\
\hline 5399.465 & 25.0 & 3.850 & -1.132 & & 6021.834 & 25.0 & 3.075 & -0.831 & \\
\hline 5399.478 & 25.0 & 3.850 & -2.740 & & 6021.837 & 25.0 & 3.075 & -1.492 & \\
\hline 5399.494 & 25.0 & 3.850 & -1.162 & & 6021.843 & 25.0 & 3.075 & -1.015 & \\
\hline
\end{tabular}

Continua na próxima página... 
Tabela A.3 - Continuação

\begin{tabular}{|c|c|c|c|c|c|c|c|c|c|}
\hline$\lambda(\AA)$ & Íon & $X_{e x c}(\mathrm{eV})$ & $\log g f$ & Elemento & $\lambda(\AA)$ & Íon & $X_{e x c}(\mathrm{eV})$ & $\log g f$ & Elemento \\
\hline 6021.846 & 25.0 & 3.075 & -1.522 & & 5303.512 & 57.1 & 0.321 & -2.362 & \\
\hline 6021.847 & 25.0 & 3.075 & -1.237 & & 5303.512 & 57.1 & 0.321 & -1.872 & \\
\hline 4662.506 & 57.1 & 0.000 & -1.763 & LaII & & & & & \\
\hline 4662.490 & 57.1 & 0.000 & -2.252 & & & & & & \\
\hline 4662.477 & 57.1 & 0.000 & -2.951 & & & & & & \\
\hline 4662.504 & 57.1 & 0.000 & -2.056 & & & & & & \\
\hline 4662.491 & 57.1 & 0.000 & -2.136 & & & & & & \\
\hline 4662.481 & 57.1 & 0.000 & -2.511 & & & & & & \\
\hline 4662.502 & 57.1 & 0.000 & -2.511 & & & & & & \\
\hline 4662.492 & 57.1 & 0.000 & -2.256 & & & & & & \\
\hline 4662.485 & 57.1 & 0.000 & -2.240 & & & & & & \\
\hline 4748.715 & 57.1 & 0.926 & -1.229 & LaII & & & & & \\
\hline 4748.720 & 57.1 & 0.926 & -1.323 & & & & & & \\
\hline 4748.724 & 57.1 & 0.926 & -1.424 & & & & & & \\
\hline 4748.728 & 57.1 & 0.926 & -1.535 & & & & & & \\
\hline 4748.729 & 57.1 & 0.926 & -2.310 & & & & & & \\
\hline 4748.732 & 57.1 & 0.926 & -1.656 & & & & & & \\
\hline 4748.732 & 57.1 & 0.926 & -2.095 & & & & & & \\
\hline 4748.734 & 57.1 & 0.926 & -1.790 & & & & & & \\
\hline 4748.734 & 57.1 & 0.926 & -2.017 & & & & & & \\
\hline 4748.736 & 57.1 & 0.926 & -2.005 & & & & & & \\
\hline 4748.737 & 57.1 & 0.926 & -1.938 & & & & & & \\
\hline 4748.738 & 57.1 & 0.926 & -2.045 & & & & & & \\
\hline 4748.739 & 57.1 & 0.926 & -2.096 & & & & & & \\
\hline 4748.740 & 57.1 & 0.926 & -2.143 & & & & & & \\
\hline 4748.741 & 57.1 & 0.926 & -2.348 & & & & & & \\
\hline 4748.741 & 57.1 & 0.926 & -3.691 & & & & & & \\
\hline 4748.742 & 57.1 & 0.926 & -3.297 & & & & & & \\
\hline 4748.743 & 57.1 & 0.926 & -3.213 & & & & & & \\
\hline 4748.743 & 57.1 & 0.926 & -3.029 & & & & & & \\
\hline 4748.743 & 57.1 & 0.926 & -3.013 & & & & & & \\
\hline 4748.743 & 57.1 & 0.926 & -3.100 & & & & & & \\
\hline 5303.546 & 57.1 & 0.321 & -2.350 & LaII & & & & & \\
\hline 5303.546 & 57.1 & 0.321 & -2.365 & & & & & & \\
\hline 5303.532 & 57.1 & 0.321 & -2.621 & & & & & & \\
\hline 5303.545 & 57.1 & 0.321 & -2.621 & & & & & & \\
\hline 5303.531 & 57.1 & 0.321 & -2.246 & & & & & & \\
\hline 5303.513 & 57.1 & 0.321 & -3.061 & & & & & & \\
\hline 5303.530 & 57.1 & 0.321 & -2.165 & & & & & & \\
\hline
\end{tabular}


Apêndice B

\section{Código terra}

B.0.1 Código para estimar a massa convectiva

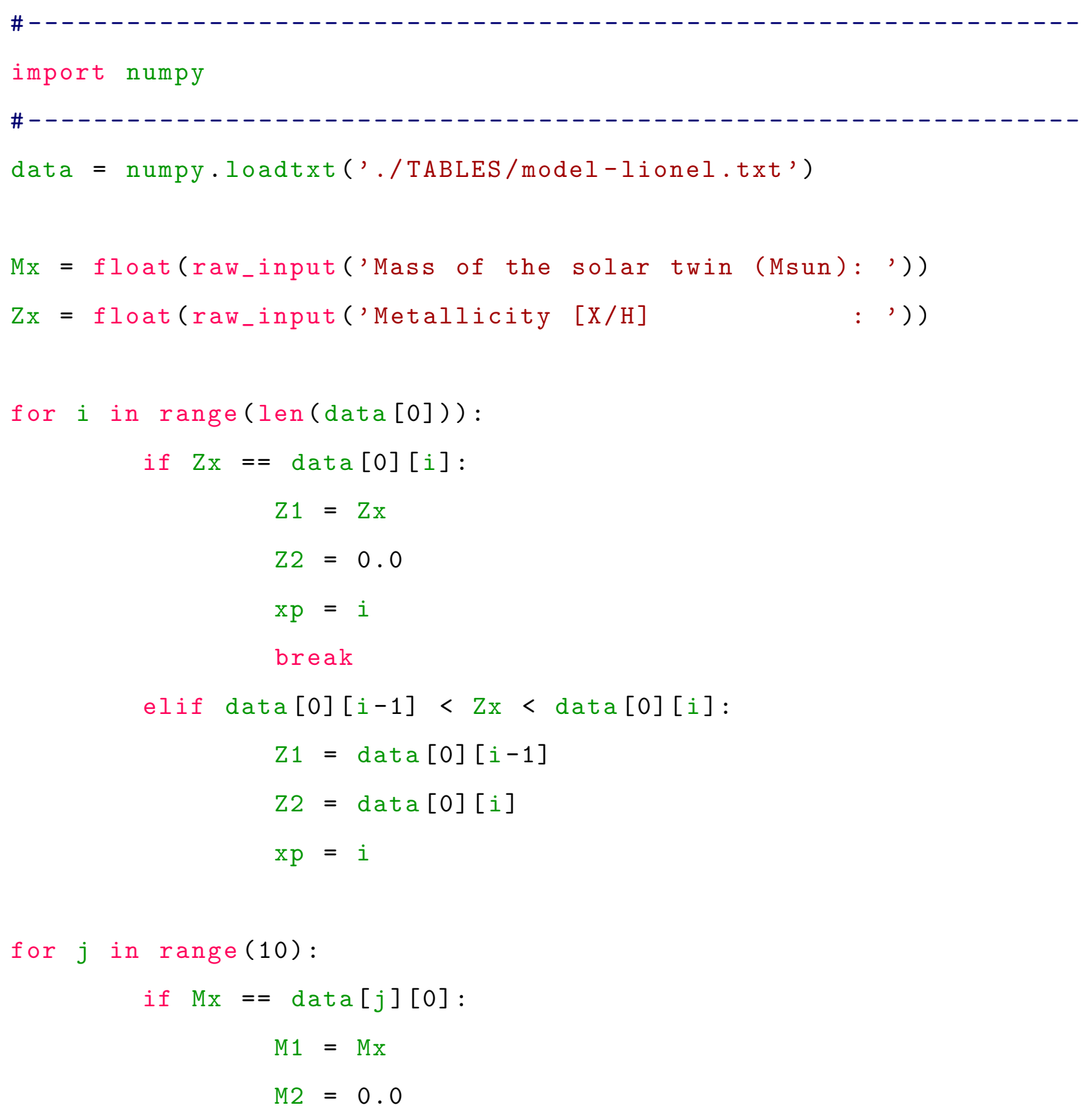




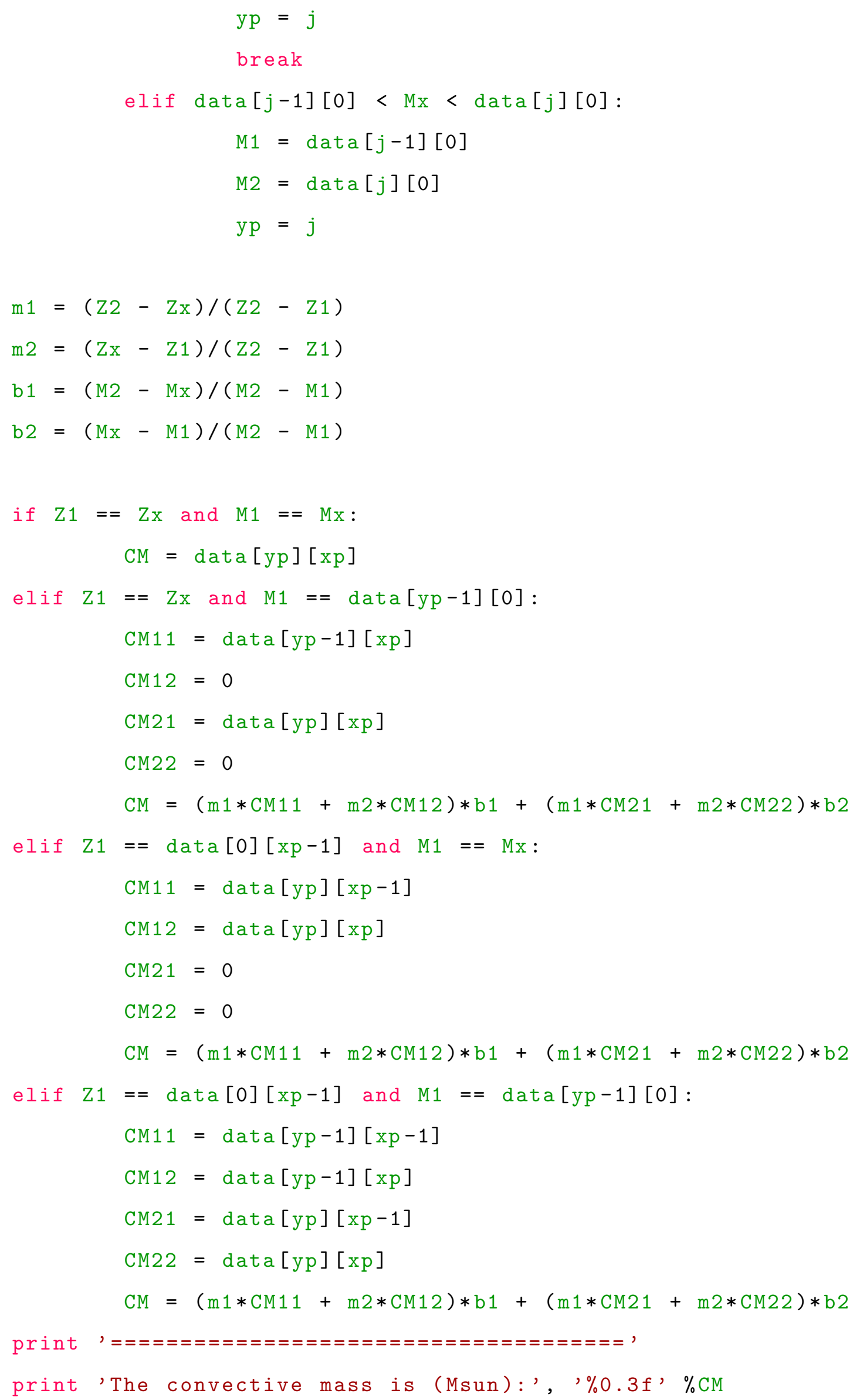




\section{B.0.2 Código para estimar a massa rochosa faltante}

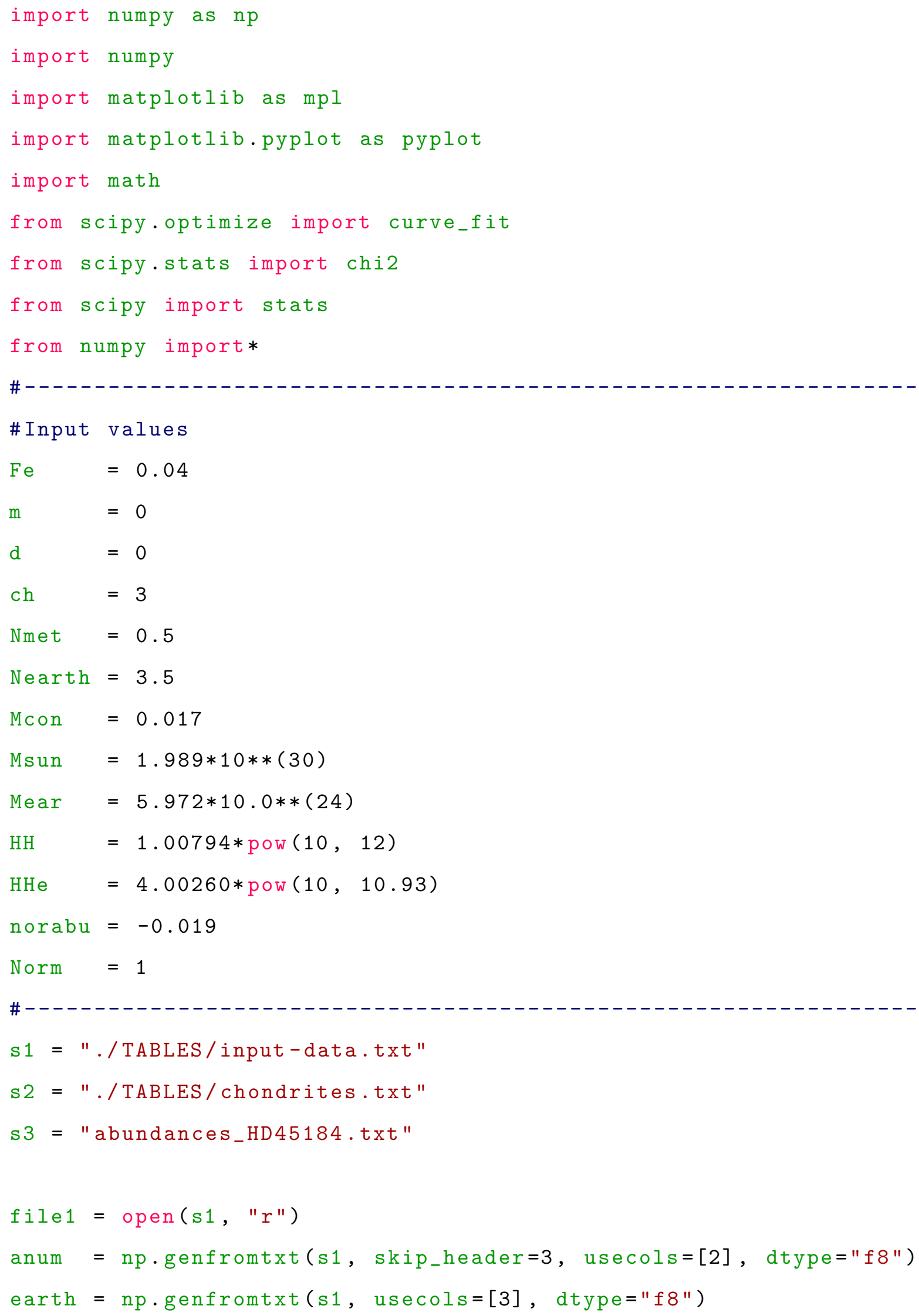




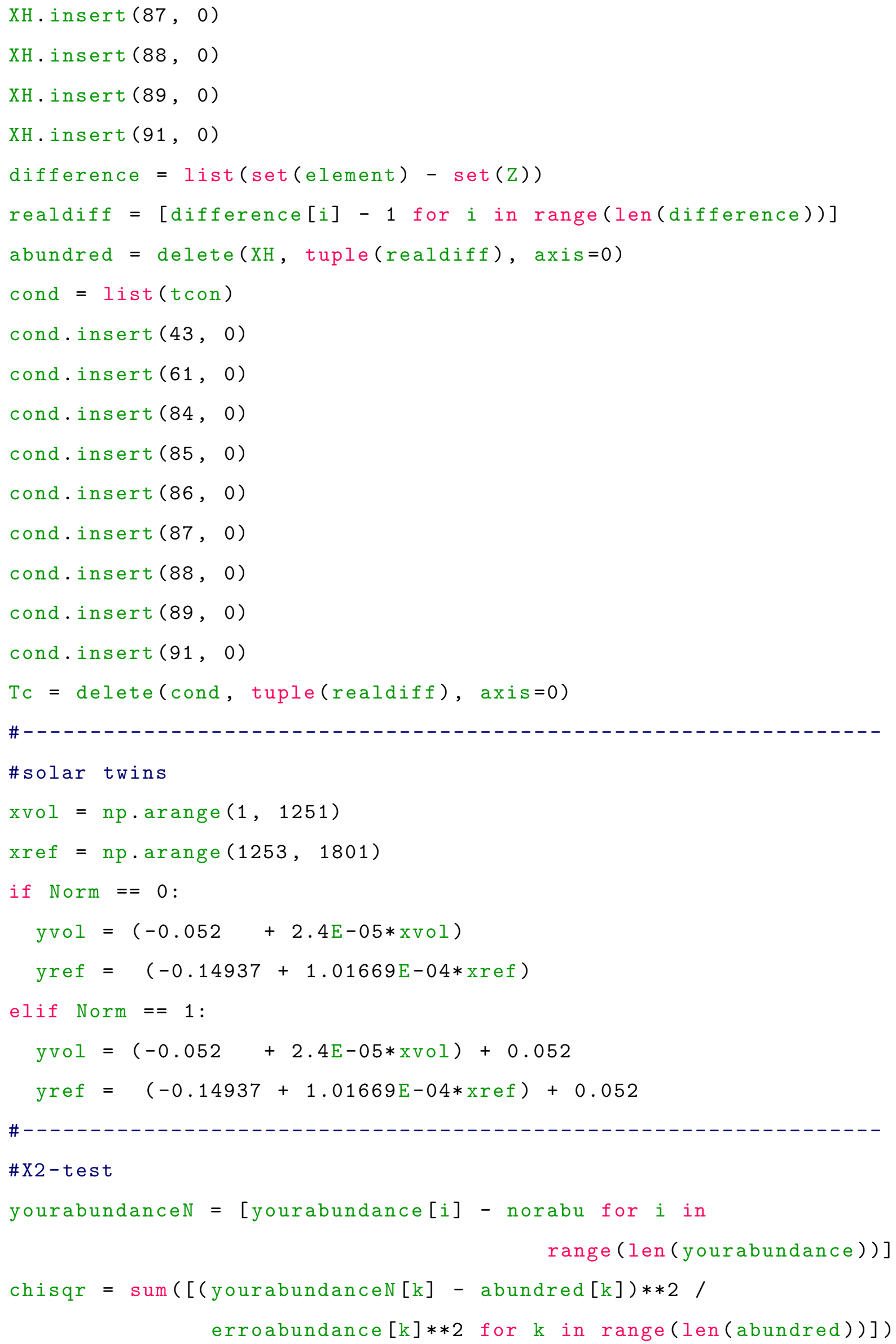




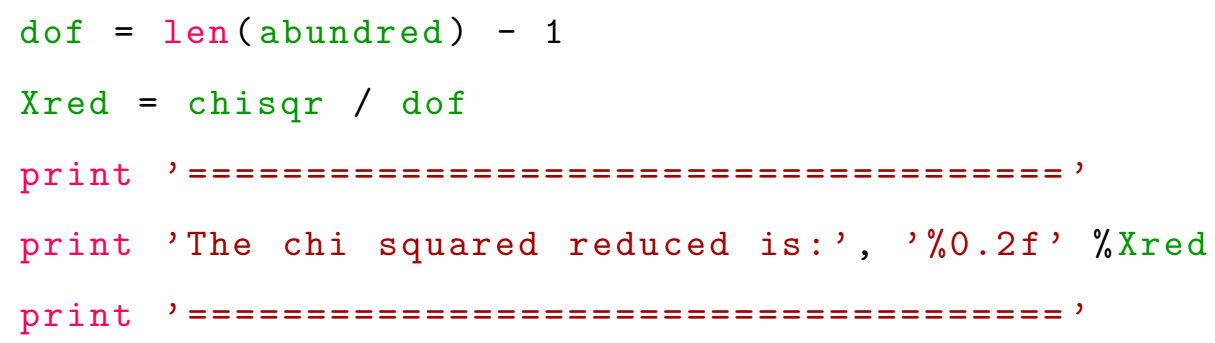

\section{\#set global settings}

def init_plotting ():

pyplot.rcParams ['figure.figsize'] = (15, 9)

pyplot.rcParams ['font.size'] = 10

pyplot.rcParams ['axes.labelsize'] = pyplot.rcParams['font.size']

pyplot.rcParams ['axes.titlesize'] = 1.5*pyplot.rcParams ['font.size']

pyplot.rcParams ['legend.fontsize'] = pyplot.rcParams ['font.size']

pyplot.rcParams ['xtick.labelsize'] = pyplot.rcParams['font.size']

pyplot.rcParams ['ytick.labelsize'] = pyplot.rcParams['font.size']

pyplot.rcParams ['savefig.dpi'] = 40*pyplot.rcParams ['savefig.dpi']

pyplot.rcParams ['xtick.major.size'] = 9

pyplot.rcParams ['xtick.minor.size'] $=5$

pyplot.rcParams ['xtick.major.width'] $=1.2$

pyplot.rcParams ['xtick.minor.width'] = 1.2

pyplot.rcParams ['ytick.major.size'] $=9$

pyplot.rcParams ['ytick.minor.size'] $=5$

pyplot.rcParams ['ytick.major.width'] $=1.2$

pyplot.rcParams ['ytick.minor.width'] $=1.2$

pyplot.rcParams ['legend.frameon'] = True

pyplot.rcParams ['legend.1oc'] = 'best'

pyplot.rcParams ['axes.linewidth'] $=2.0$

init_plotting ()

\#-

\#plotting results

figure = 'Abundance-vs-Tc_HD45184.pdf'

pyplot.plot(Tc, yourabundanceN, linestyle=" ", marker="o", color="\#ec7063",

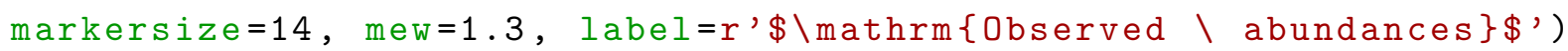
pyplot.errorbar (Tc, yourabundanceN, yerr=erroabundance, linestyle="None", 


$$
\text { marker="None", color="\#ec7063", elinewidth=2.) }
$$

pyplot.plot (Tc, abundred, linestyle=" ", marker="-", color="blue", markersize=12, label $=r^{\prime} \$ \backslash$ mathrm\{ Predicted $\backslash$ abundances $\}$ \$') pyplot.plot(xvol, yvol, linestyle="--", marker=" ", color="black", linewidth $=2.2$, label=r'\$ $\backslash$ mathrm\{Twins $\backslash-\backslash$ Sun $\backslash$ (Melendez\et $\backslash$ al. $\backslash 2009)\} \$^{\prime}$ ) pyplot.plot(xref, yref, linestyle="--", marker=" ", color="black", linewidth $=2.2$ )

pyplot.legend (loc='best', numpoints=1, prop=\{'size':19\}, shadow=True) pyplot.xlabel(r'\$ $\$$ mathrm\{Condensation $\backslash$ Temperature (K) \} $\$$ ', color='black', fontsize=28)

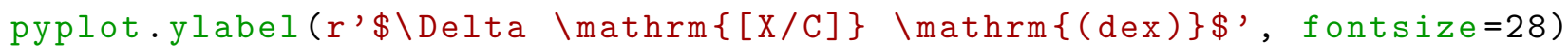
pyplot.minorticks_on ()

pyplot.tick_params (axis='both', labelsize=19)

pyplot.tight_layout()

pyplot.savefig( $f$ igure)

pyplot.clf ( )

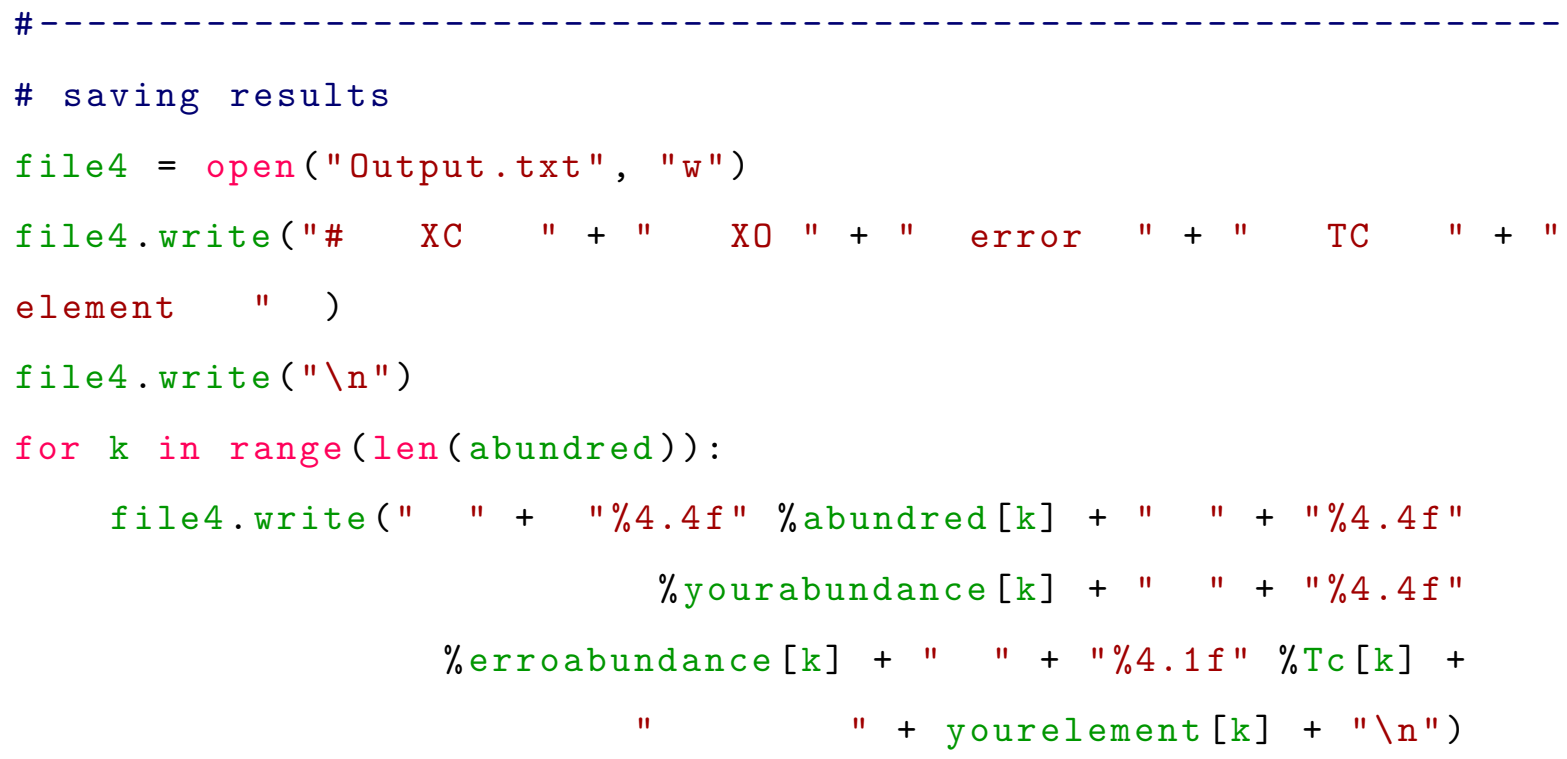

file 4 . close () 


\section{Apêndice C}

\section{Determinação de abundâncias químicas usando MOOG}

\section{C.0.1 Síntese do lítio}

Para estimar a abundância de lítio através da síntese espectral, primeiro são necessários os cálculos das velocidades de macroturbulência $\left(v_{\text {macro }, \star}\right)$ e de rotação $\left(v \sin i_{\star}\right)$. Estes valores são usados como parâmetros de entrada na ferramenta synth do código MOOG, que gera o espectro sintético. Um exemplo de entrada com uma explicação detalhada de seus parâmetros é mostrado na Figura C.1.

A velocidade de macroturbulência é obtida usando a equação 4.13 (ver seção 4.4.3). Na síntese entra também o fator de escurecimento de limbo da estrela, dado por:

$$
\frac{I(\theta)}{I(\theta=0)}=(1-u)+u \cos \theta
$$

sendo $I(\theta=0)$ a intensidade no centro da estrela e $u$ o coeficiente de escurecimento do limbo, cujo valor solar é 0.6. Nesta dissertação adotei este valor devido a que as estrelas em análise são gêmeas solares.

O procedimento para estimar a abundância de lítio consiste em:

- Obter a velocidade de macroturbulência do Sol $\left(v_{\text {macro, } \odot)}\right)$ usando os perfis de 5 linhas de Fe I: $6027.050 \AA, 6093.644 \AA, 6151.618 \AA, 6165.360 \AA, 6705.102 \AA$, e uma linha de Ni I em 6767.772 A. Para tal fim, emprega-se a ferramenta synth do código MOOG(ver Figura C.1), onde fixa-se o valor de $v \sin i \odot$ e o escurecimento do limbo em $1.9 \mathrm{~km} \mathrm{~s}^{-1}$ (Bruning, 1984; Saar e Osten, 1997) e 0.6, respectivamente.

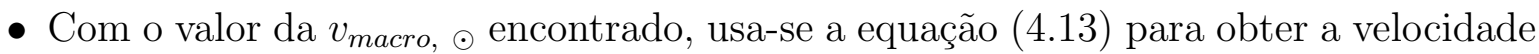
de macroturbulência da estrela $\left(v_{\text {macro }, \star}\right)$. 


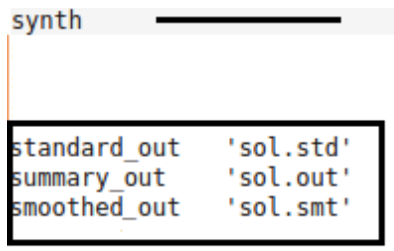

Ferramenta utilizada para o cálculo de espectros sintéticos.

\begin{tabular}{lr}
\hline model_in & 'sol.mod' \\
lines_in & 'sol.dat' \\
obspectrum & 5 \\
observed_in & 'sol.asc' \\
\hline
\end{tabular}

Arquivos de saída: sol.std é o arquivo de saida padrão (verbose), sol.out é um arquivo sumário com as abundâncias calculadas e sol.smt é o arquivo de saída do espectro sintético gerado.

Arquivos de entrada: sol.mod é o modelo de atmoferas utilizado, sol.dat é a lista de linhas utilizada, sol.asc é o espectro observado em formato ascii e obspectrum $\mathbf{5}$ indica que 0 espectro observado deve estar no formato ascii.

\begin{tabular}{ll} 
atmosphere & 1 \\
\hline freeform & 1 \\
lines & 1 \\
terminal & ${ }^{\prime} \times 11 '$ \\
plot & 2 \\
\hline
\end{tabular}

\begin{tabular}{ll}
\hline units & 0 \\
\hline trudamp & 1 \\
molecules & 1 \\
flux/int & 0 \\
damping & 0 \\
opacit & 0 \\
\hline
\end{tabular}

Como o modelo de atmosferas é mostrado no arquivo de saida padrão: 1 igual a informação básica.

Opções de entrada e saida para os plots e resultados. freeform 1 indica 0 formato da lista de linhas utilizada, terminal x11 indica o tipo de interface gráfica utilizada. lines 1 é a informação padrão de saida com relacão à lista de linhas e plot 2 indica que serão plotados os espectros sintético e observado. Indica unidades de comprimento de onda em $\AA$.

Opções de cálculos efetuados pelo código. trudamp 1 mostra o cálculo dealhado do amortecimento para transições moleculares, molecules 1 aplica equilíbrio molecular e não mostra resultado no arquivo de saida, flux/int $\mathbf{0}$ indica a realização do cálculo de fluxo integrado, damping $\mathbf{0}$ indica a utilização da aproximação Unsold para os parâmetros de amortecimento de van der Waals e opacit $\mathbf{0}$ indica que não há aplicação de fator de correção para este caso.

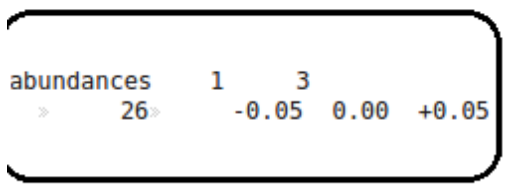

Abundância do espectro sintético para o Fe. Neste são criados três espectros sintéticos de abundâncias distintas, abundância do Fe encontrada no modelo de atmosferas menos 0.05 dex, mais 0.05 dex e ela mesma.

\begin{tabular}{llll}
\hline $\begin{array}{l}\text { Synlimits } \\
5849.000\end{array}$ & 5861.000 & 0.010 & 0.500 \\
\hline & \\
\hline $\begin{array}{l}\text { iraf } \\
\text { iraf_out }\end{array}$ & 'sol.rtext' \\
\hline
\end{tabular}

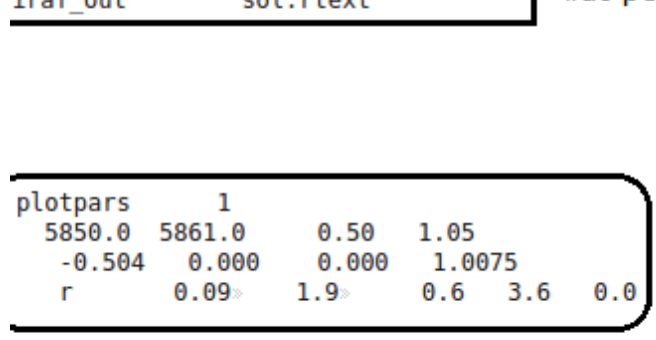

Limites para o cálculo da síntese espectral.

Indica a criação(1) ou não (0) de um arquivo de saida que pode ser lido pelo pacote IRAF.

Indica a criação de um plot com parâmetros especificos. A primeira linha contém valores para o tamanho da caixa a ser plotada.

A segunda linha contém os seguintes parâmetros em ordem: valor de correção de velocidades, valor de correção em comp. de onda, correção aditiva vertical e correção multiplicativa vertical do espectro observado em relação ao sintético.

A terceira linha contém os parâmetros para o tipo de ajuste do espectro sintético para o ajuste em relação ao espectro observado, onde $r$ sianifica levar em consideração, nesta ordem, a largura gaussiana do espectro, vseni, fator de escurecimento de limbo, velocidade de macroturbulência e largura lorentziana.

Figura C.1: Parâmetros de entrada para a ferramenta synth. Fonte: Carlos (2015). 


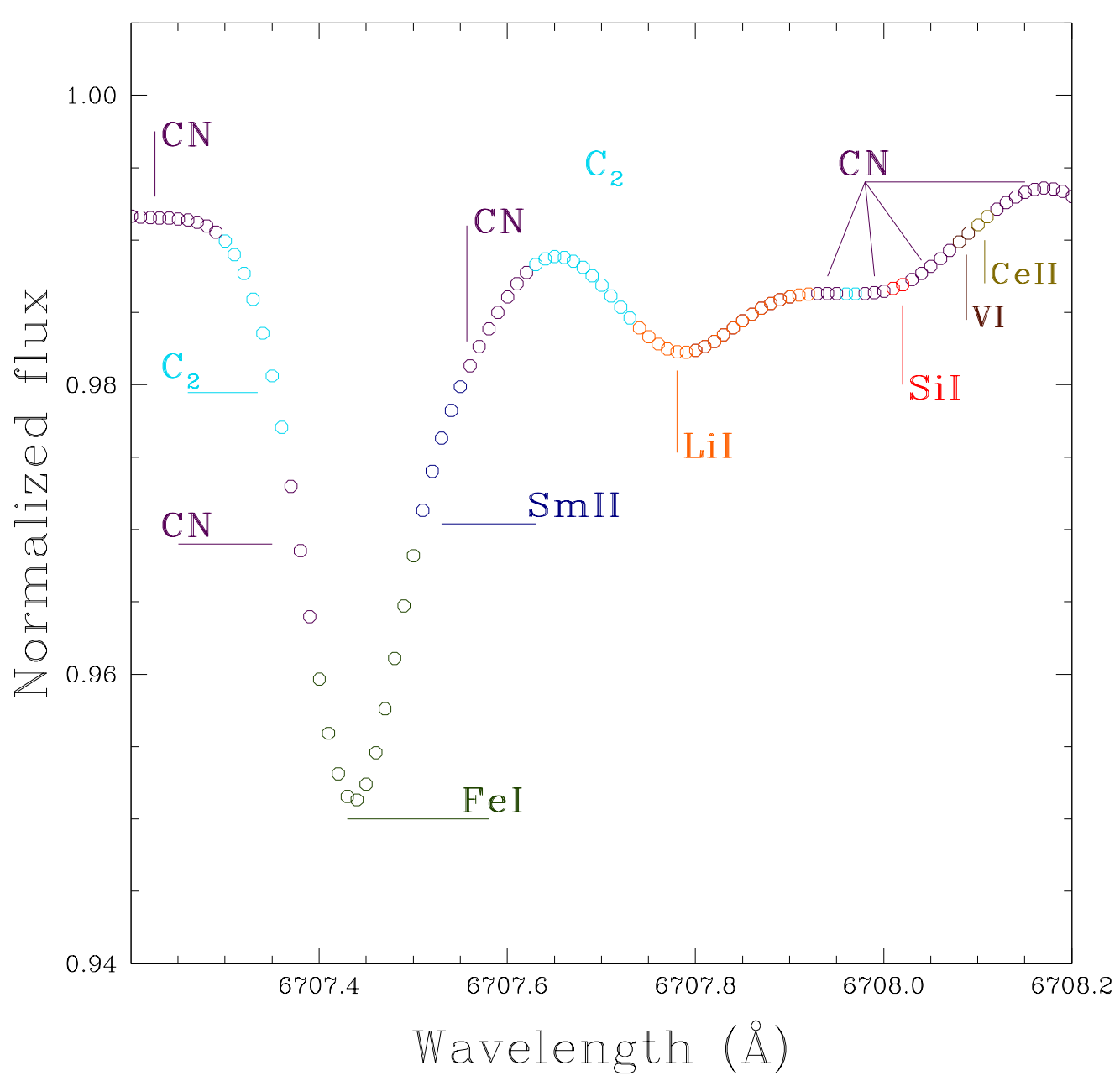

Figura C.2: Espectro do Sol na faixa de 6707.3-6708.2 $\AA$ mostrando os diferentes elementos químicos que influem na determinação da abundância do lítio (6707.75 Å) . Fonte: Carlos et al. (2016).

- A velocidade de rotação da estrela $\left(v \sin i_{\star}\right)$ é obtida através da síntese das linhas de Fe I e Ni I mencionadas acima. Para isso usa-se novamente a ferramenta synth junto com o valor de $v_{\text {macro, } \star}$.

- Finalmente, com o valor de $v_{m a c r o, ~}$ e $v \sin i_{\star}$, pode-se estimar a abundância de lítio. Na ferramenta synth muda-se os valores das abundâncias de CN, Fe I, Sm II, C2, Li I, Si I, V I e Ce II até que o espectro sintético ajuste o perfil observado da linha de Li. Para ajudar no ajuste, na Figura C.2 é mostrada a posição das linhas mencionadas acima e seus efeitos sobre o perfil observado.

O erro do lítio foi estimado da seguinte forma:

- Variando a $\mathrm{A}(\mathrm{Li})$ para reproduzir o espectro observado.

- Assumindo diferentes níveis de contínuo dentro do ruido do espectro. 


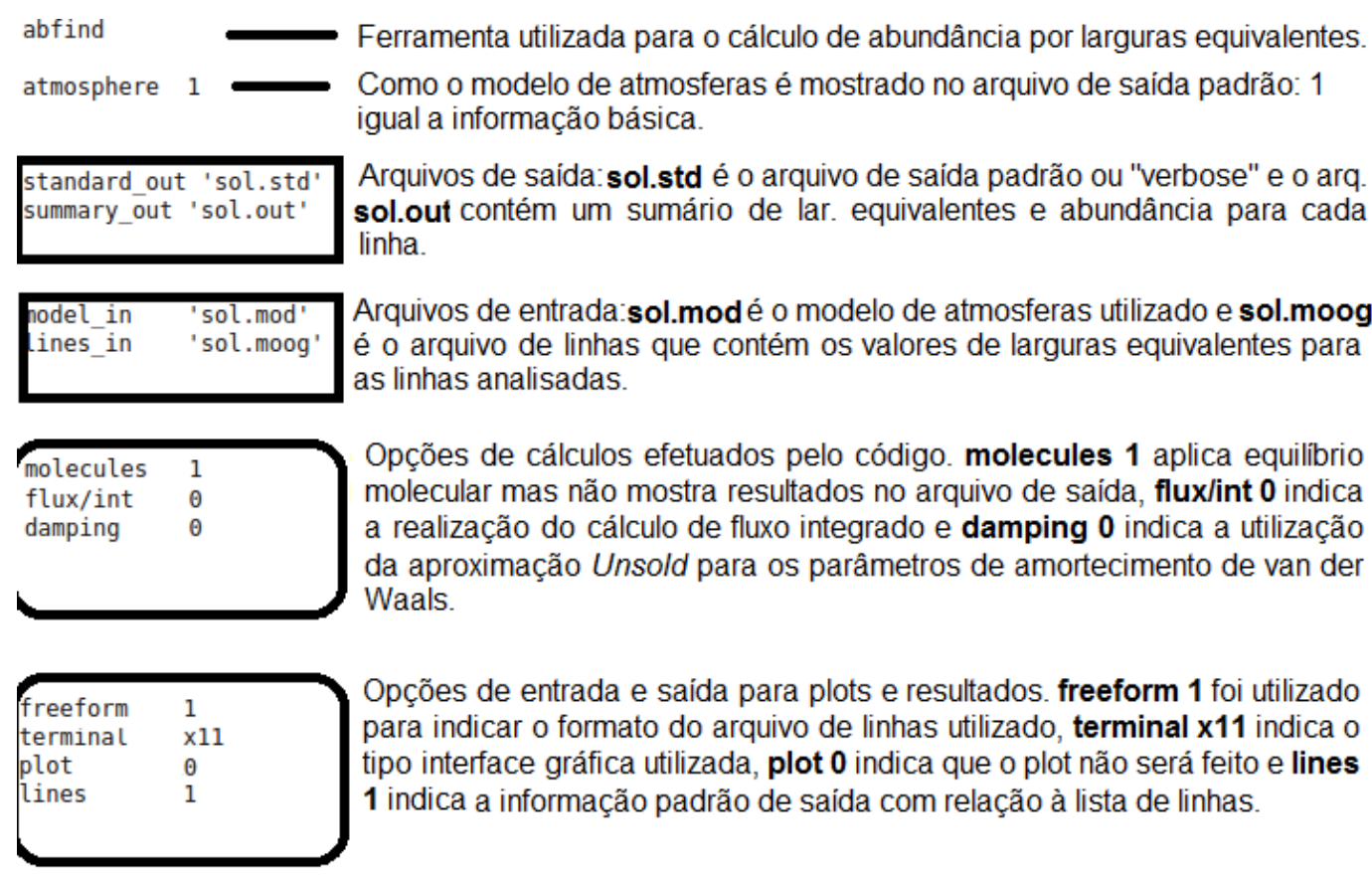

Figura C.3: Parâmetros de entrada para a ferramenta abfind. Imagem tirada de Carlos (2015).

- Levando em conta os erros nos parâmetros atmosféricos

- E finalmente o erro total é obtido da soma quadrática das três fontes explanadas acima.

\section{C.0.2 Abundâncias químicas a partir da curva de crescimento}

As abundâncias químicas são estimadas a través da ferramenta abfind do código MOOG. Esta ferramenta usa como parâmetro de entrada uma lista de linhas para as quais as larguras equivalentes foram medidas junto com os seus respectivos comprimentos de onda, potenciais de excitação das transições, os parâmetros de van der Waals (C6) e os valores gf. É importante notar que na última versão de MOGG 2014 os C6 já vêm por defeito (ver seção 2.7). Na Figura C.3 são explicados em detalhe os parâmetros de entrada da ferramenta abfind. 
Apêndice D

Artigos 


\title{
Serendipitous discovery of the faint solar twin Inti $1^{\star}$
}

\author{
Jhon Yana Galarza ${ }^{1}$, Jorge Meléndez ${ }^{1}$, and Judith G. Cohen ${ }^{2}$ \\ 1 Universidade de São Paulo, IAG, Departamento de Astronomia, São Paulo, Rua do Matão 1226, 05508-090 SP, Brasil \\ e-mail: ramstojh@usp.br \\ 2 California Institute of Technology, 1200 E. California Blvd., MC 249-17, Pasadena, CA 91195, USA
}

Received 29 September 2015 / Accepted 26 February 2016

\begin{abstract}
Context. Solar twins are increasingly the subject of many studies owing to their wide range of applications from testing stellar evolution models to the calibration of fundamental observables; these stars are also of interest because high precision abundances could be achieved that are key to investigating the chemical anomalies imprinted by planet formation. Furthermore, the advent of photometric surveys with large telescopes motivates the identification of faint solar twins in order to set the zero point of fundamental calibrations.

Aims. We intend to perform a detailed line-by-line differential analysis to verify whether 2MASS J23263267-0239363 (designated here as Inti 1) is indeed a solar twin.

Methods. We determine the atmospheric parameters and differential abundances using high-resolution $(R \approx 50000)$, high signal-tonoise $(S / N \approx 110-240$ per pixel) Keck/HIRES spectra for our solar twin candidate, the previously known solar twin HD 45184, and the Sun (using reflected light from the asteroid Vesta).

Results. For the bright solar twin HD 45184, we found $T_{\text {eff }}=5864 \pm 9 \mathrm{~K}, \log g=4.45 \pm 0.03$ dex, $v_{\mathrm{t}}=1.11 \pm 0.02 \mathrm{~km} \mathrm{~s}^{-1}$, and $[\mathrm{Fe} / \mathrm{H}]=0.04 \pm 0.01 \mathrm{dex}$, which are in good agreement with previous works. Our abundances are in excellent agreement with a recent high-precision work, with an element-to-element scatter of only 0.01 dex. The star Inti 1 has atmospheric parameters $T_{\text {eff }}=$ $5837 \pm 11 \mathrm{~K}, \log g=4.42 \pm 0.03 \mathrm{dex}, v_{\mathrm{t}}=1.04 \pm 0.02 \mathrm{~km} \mathrm{~s}^{-1}$, and $[\mathrm{Fe} / \mathrm{H}]=0.07 \pm 0.01 \mathrm{dex}$ that are higher than solar. The age and mass of the solar twin HD 45184 ( $3 \mathrm{Gyr}$ and $1.05 M_{\odot}$ ) and the faint solar twin Inti 1 (4 Gyr and $1.04 M_{\odot}$ ) were estimated using isochrones. The differential analysis shows that HD 45184 presents an abundance pattern that is similar to typical nearby solar twins; this means this star has an enhanced refractory relative to volatile elements, while Inti 1 has an abundance pattern closer to solar, albeit somewhat enhanced in refractories. The abundance pattern of HD 45184 and Inti 1 could be reproduced by adding $\approx 3.5 M_{\oplus}$ and $\approx 1.5 M_{\oplus}$ of Earth-like material to the convective zone of the Sun.

Conclusions. The star Inti 1 is a faint solar twin, therefore, it could be used to calibrate the zero points of different photometric systems. The distant solar twin Inti 1 has an abundance pattern similar to the Sun with only a minor enhancement in the refractory elements. It would be important to analyze other distant solar twins to verify whether they share the Sun's abundance pattern or if they are enhanced in refractories, as is the case in the majority of nearby solar twins.
\end{abstract}

Key words. Sun: abundances - stars: abundances - stars: fundamental parameters - Earth - stars: solar-type - planetary systems

\section{Introduction}

Cayrel de Strobel (1996) defines a solar twin as a star with the same atmospheric parameters (effective temperature, surface gravity, and microturbulent velocity) as the Sun. The first discovery of a solar twin was made by Porto de Mello \& da Silva (1997), showing that 18 Sco has atmospheric parameters similar to the Sun. About a decade later three new solar twins were found (King et al. 2005; Meléndez et al. 2006; Takeda et al. 2007), however, these three solar twins and 18 Sco have an overabundance of lithium by a factor of 3-6 higher than the Sun. Later Meléndez \& Ramírez (2007) discovered HIP 56948, which is the best solar twin that we have until this point, with stellar parameters and abundances that are similar to the Sun and a low lithium abundance (Meléndez et al. 2012).

$\star$ The data presented herein were obtained at the W.M. Keck Observatory, which is operated as a scientific partnership among the California Institute of Technology, the University of California, and the National Aeronautics and Space Administration. The Observatory was made possible by the generous financial support of the W.M. Keck Foundation.
In the last few years, the number of solar twins have increased to about 100 (Pasquini et al. 2008; Meléndez et al. 2009, 2014b; Ramírez et al. 2009, 2014; Takeda \& Tajitsu 2009; Baumann et al. 2010; Önehag et al. 2011; Datson et al. 2012; do Nascimento et al. 2013; Porto de Mello et al. 2014). Solar twins could be a useful source for astronomical tests and applications. For example, they could set the zero point of fundamental calibrations (Holmberg et al. 2006; Casagrande et al. 2010; Datson et al. 2014), and they are used to subtract the Sun's reflected light on asteroids to study their mineralogy (e.g., Lazzaro et al. 2004; Jasmim et al. 2013). Solar twins are also useful for testing stellar interior and evolution models (e.g., Tucci Maia et al. 2015), investigating the chemical evolution of the Galactic disk (Nissen 2015; Spina et al. 2016), studying the rotational evolution of the Sun (do Nascimento et al. 2013, 2014), and measuring distances using spectroscopically identified solar twins (Jofré et al. 2015).

Another application of solar twins is the study of refractories locked by planet formation. Meléndez et al. (2009) found that the difference between abundances of the Sun relative to the solar twins is not zero, showing that the Sun presents abundance 


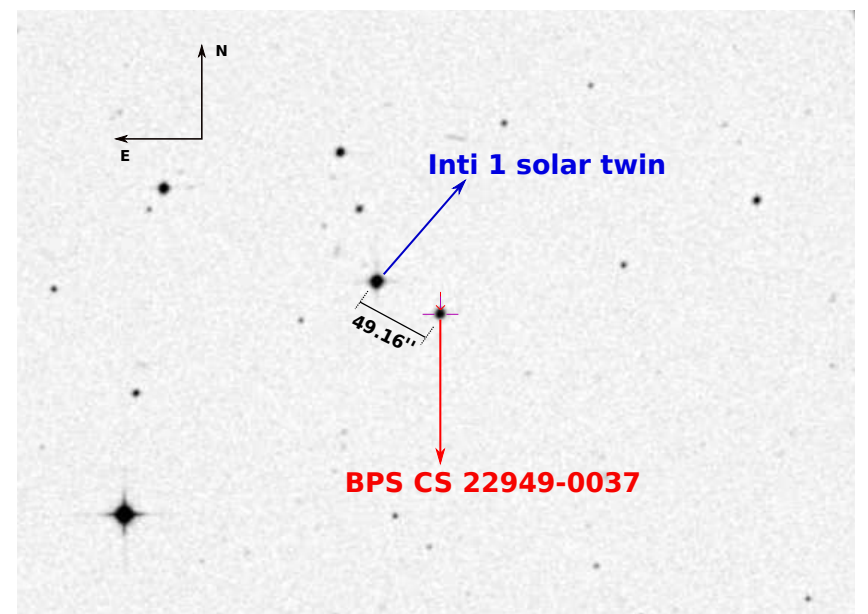

Fig. 1. Separation between Inti 1 and BPS CS 22949-0037 is 49.16". Image from the Aladin Sky Atlas (http://aladin.ustrasbg.fr).

anomalies that are correlated with the condensation temperature, $T_{\mathrm{C}}$, (Lodders 2003). The Sun presents a deficiency in refractory $\left(T_{\mathrm{C}} \leq 900 \mathrm{~K}\right)$ relative to volatile $\left(T_{\mathrm{C}} \geq 900 \mathrm{~K}\right)$ elements, which could be a signature of rocky planet formation (Chambers 2010). Later, Ramírez et al. (2009) supported this idea by studying the abundance of 64 stars with fundamental parameters similar to the Sun; their result showed a strong relation between the abundances and condensation temperature in the majority of their sample. Other authors have been investigating this relation with the existence of planets, although the results are still not conclusive (Gonzalez et al. 2010; Schuler et al. 2011; Adibekyan et al. 2014; Maldonado et al. 2015; Nissen 2015). Are the abundance anomalies a phenomenon restricted to the solar neighborhood or is it also present in other regions of the Galaxy? This could be investigated using distant solar twins.

In this paper, we report the discovery of the faint solar twin 2MASS J23263267-0239363, which we call Inti $1^{1}$ for practical reasons.

\section{Spectroscopy observations and data reduction}

Inti 1 was observed with the HIRES spectrograph (Vogt et al. 1994) at the Keck I telescope at the coordinates $(\alpha=$ 23:26:32.61, $\delta=-2: 39: 35.3)$ because it was mistaken for the carbon star BPS CS 22949-0037, whose coordinates are actually ( $\alpha=23: 26: 29.80, \delta=-2: 39: 57.94)$. This mistake was due to their proximity (Fig. 1). We intended to take two exposures of $1200 \mathrm{~s}$, but after the first exposure it was realized that the star observed was not BPS CS 22949-0037, and the planned exposure sequence was terminated after only one exposure. Fortunately, in the same night we observed the Sun using the same setup. A recent inspection of the spectrum of the wrongly observed target revealed a similarity to the solar spectrum (see Fig. 2), thus making Inti 1 a good candidate to be a solar twin, which we confirmed after high precision analysis. During the same observing run, we also obtained a spectrum for the bright solar twin HD 45184 (e.g., Nissen 2015).

The spectra of HD 45184, Inti 1 and the Sun (using solar reflected light from the Vesta asteroid), were obtained with Keck/HIRES on November 1-3, 2004, covering the wavelength region from $3190-5980 \AA$. The exposure time for HD 45184 , Inti 1 and Vesta were $2 \times 300 \mathrm{~s}, 1200 \mathrm{~s}$, and $100 \mathrm{~s}$. The spectral

\footnotetext{
1 Inti is Quechua for "Sun".
}

resolution, $R=\lambda / \lambda \Delta$ is about 50000 , while the signal-to-noise ratios $(\mathrm{S} / \mathrm{N})$ estimated for HD 45184, Inti 1 and Vesta are 160, 110 and 240 per pixel.

The spectra were extracted using the $\mathrm{MAKEE}^{2}$ pipeline that was specifically designed by T. Barlow to reduce HIRES spectra. The standard procedure is followed with bias subtraction, flat fielding, sky subtraction, order extraction, and wavelength calibration. We note that MAKEE already applies the heliocentric correction, so that the output wavelengths are heliocentric. Further processing was performed with $\mathrm{IRAF}^{3}$.

We estimated the radial velocity of the star using the rvidlines task in IRAF, and then the spectrum was corrected to the rest frame with the dopcor task. The spectra were normalized using IRAF's continuum task with orders of the polynomial spline varying from 1 to 5 for each order. In Fig. 2 we show a part of the reduced spectra of HD 45184, Inti 1, and the Sun in the region 5321-5336 $\AA$, where we can see that both stars have an impressive resemblance to the Sun.

The similarity between Inti 1 and the Sun also extends to colors; using VIZIER ${ }^{4}$, we found the magnitudes ${ }^{5}: V=$ $12.857 \pm 0.028, B=13.516 \pm 0.032, I=12.045 \pm 0.072$, $J=11.559 \pm 0.023, H=11.247 \pm 0.023, K=11.168 \pm 0.024$, $W 1=11.125 \pm 0.023$, and $W 2=11.180 \pm 0.022$. Inti 1 and the Sun present similar color magnitudes (Table 1) reinforcing the idea that it is a solar twin. Extinction coefficients for $(B-V),(V-I),(V-J),(V-H),(V-K)$ photometry were taken from Ramírez \& Meléndez (2005) and for $(V-W 1)$, $(V-W 2)$ from Yuan et al. (2013). For the extinction correction, we used $E(B-V)^{6}=0.044 \pm 0.002$, that is from the reddening maps of Schlegel et al. (1998), with the correction proposed by Schlafly \& Finkbeiner (2011).

\section{Abundance analysis}

We adopted the line list of Meléndez et al. (2014a) to measure the equivalent widths (EWs) of the spectral lines; we used the IRAF splot task and fitted the line profiles using Gaussians. The pseudo-continuum regions were determined as in Bedell et al. (2014) in a window of $8 \AA$.

In order to compute the stellar parameters, we employed the MARCS model atmospheres (Gustafsson et al. 2008) and the 2014 version of the local thermodynamic equilibrium (LTE) code MOOG (Sneden 1973). The LTE is adequate for differential studies of solar twins, as the differential non-LTE effects in solar twins are negligible (Meléndez et al. 2012; Monroe et al. 2013).

Spectroscopic equilibrium is used to determine the effective temperature $\left(T_{\text {eff }}\right)$, surface gravity $(\log g)$, metallicity $([\mathrm{Fe} / \mathrm{H}])$, and microturbulent velocity $\left(v_{\mathrm{t}}\right)$. This is performed by imposing the relative excitation and ionization equilibrium, and evaluating the lack of dependence of differential iron abundance with reduced equivalent width $(\mathrm{EW} / \lambda)$. All the calculations are strictly differential $\left(\Delta A_{i}\right)^{7}$.

\footnotetext{
2 www.astro.caltech.edu/ tb/

3 IRAF is distributed by the National Optical Astronomy Observatory, which is operated by the Association of the Universities for Research in Astronomy, Inc. (AURA) under cooperative agreement with the National Science Foundation.

4 http://vizier.u-strasbg.fr

5 V,I magnitudes adopted from APASS (The AAVSO Photometric All-Sky Survey), J, H, K magnitudes adopted from Cutri et al. (2003), $W 1, W 2$ magnitudes adopted from Cutri \& et al. (2012).

6 http://irsa.ipac. caltech. edu/frontpage

7 The differential abundances is defined as $\Delta A_{\mathrm{i}}=A_{\mathrm{i}}^{*}-A_{\mathrm{i}}^{\odot}$.
} 


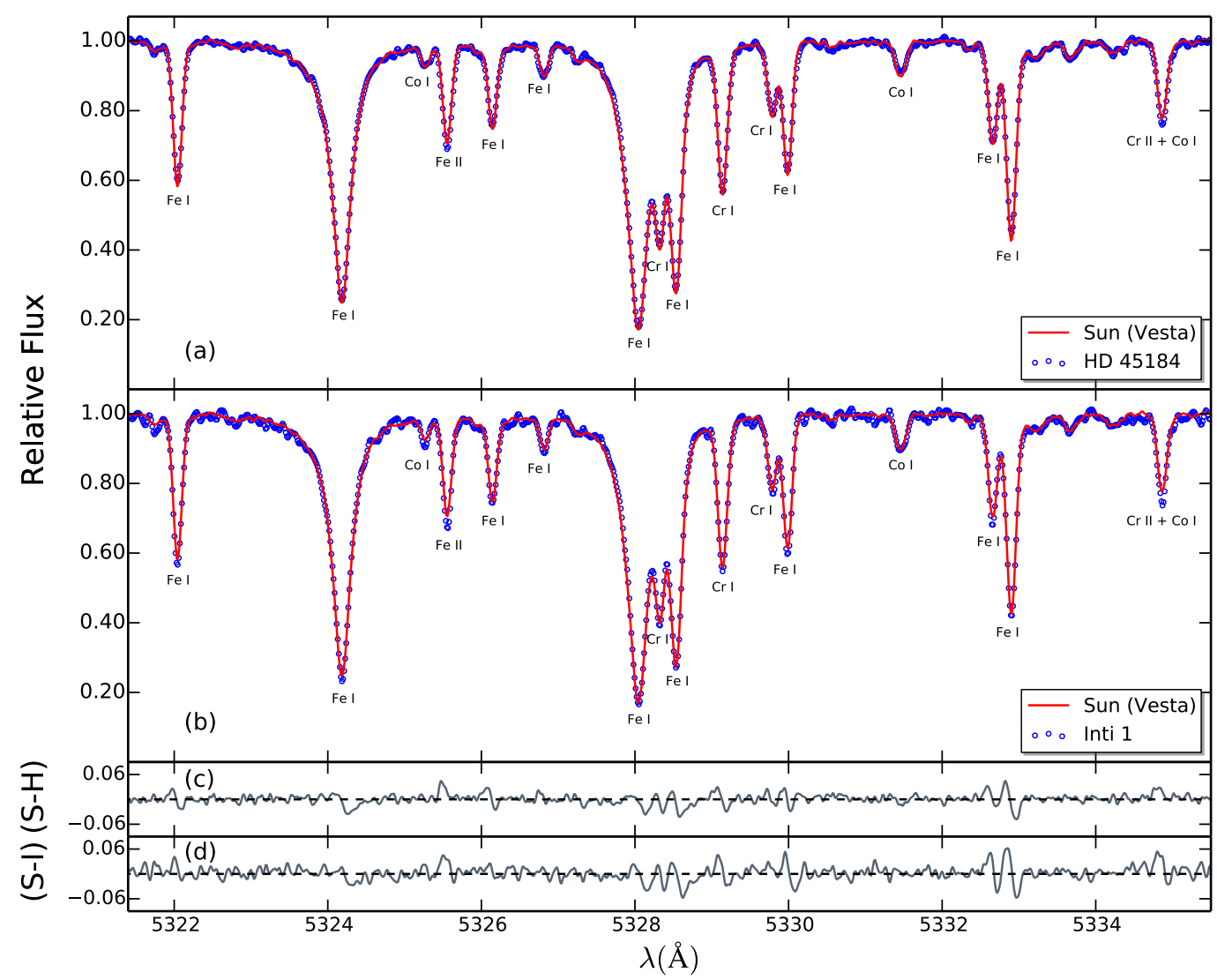

Fig. 2. Comparison between the spectra of HD 45184, Inti 1, and the Sun in the region 5321-5336 ̊. Panel a) shows the spectra of HD 45184 (blue open circles) and the Sun (red solid line). Panel b) shows the spectra of the Sun (red solid line) and candidate solar twin Inti 1 (blue open circles), showing a striking similarity. The different chemical composition is revealed through careful line-by-line measurements. Residuals between the Sun and HD 45184 (S-H), and the Sun and Inti 1 (S-I) are shown in the panel c) and d), respectively.

Table 1. Comparison of colors of the Sun and Inti 1.

\begin{tabular}{cccc}
\hline \hline \multirow{2}{*}{ Color } & \multicolumn{2}{c}{ Inti 1 } & Sun \\
& observed & derredened & \\
\hline$(B-V)^{a}$ & $0.659 \pm 0.042$ & $0.615 \pm 0.042$ & $0.653 \pm 0.005$ \\
$(V-I)^{a}$ & $0.812 \pm 0.077$ & $0.755 \pm 0.077$ & $0.702 \pm 0.010$ \\
$(V-J)^{b}$ & $1.298 \pm 0.036$ & $1.203 \pm 0.036$ & $1.198 \pm 0.005$ \\
$(V-H)^{b}$ & $1.610 \pm 0.036$ & $1.500 \pm 0.036$ & $1.484 \pm 0.009$ \\
$(V-K)^{b}$ & $1.689 \pm 0.036$ & $1.570 \pm 0.036$ & $1.560 \pm 0.008$ \\
$(V-W 1)^{b}$ & $1.731 \pm 0.036$ & $1.603 \pm 0.036$ & $1.608 \pm 0.008$ \\
$(V-W 2)^{b}$ & $1.676 \pm 0.035$ & $1.556 \pm 0.035$ & $1.583 \pm 0.008$ \\
\hline
\end{tabular}

Notes. ${ }^{(a)}$ Predicted solar colors from Ramírez et al. $(2012){ }^{(b)}$ predicted solar colors from Casagrande et al. (2012).

As a first step, we determined the abundances of the $\operatorname{Sun}\left(A_{\mathrm{i}}^{\odot}\right)$ for each line, adopting the standard solar parameters $\left(T_{\text {eff }}=\right.$ $5777 \mathrm{~K}, \log g=4.44$ dex Cox 2000, and $v_{\mathrm{t}}=1.00 \mathrm{~km} \mathrm{~s}^{-1}$ as in Ramírez et al. 2014). The second step is the determination of stellar parameters of Inti 1; initially we set as the atmospheric parameters those of the Sun, then the abundances $\left(A_{i}^{\star}\right)$ were found running the MOOG code. We achieved the spectroscopic solution varying the values for the parameters until achieving differential spectroscopic equilibrium (Fig. 3).

We first study the bright solar twin HD 45184 to validate our method. The stellar parameters that we found are $T_{\mathrm{eff}}=$ $5864 \pm 9 \mathrm{~K}, \log g=4.45 \pm 0.03 \mathrm{dex}, v_{\mathrm{t}}=1.11 \pm 0.02 \mathrm{~km} \mathrm{~s}^{-1}$, and $[\mathrm{Fe} / \mathrm{H}]=0.04 \pm 0.01 \mathrm{dex}$. These values are in a good agreement with all previous works found in the literature, as shown in Table 2, as well as in good accord with the weighted mean value, $T_{\text {eff }}=5863 \pm 5 \mathrm{~K}, \log g=4.44 \pm 0.01 \mathrm{dex}, v_{\mathrm{t}}=1.05 \pm 0.02 \mathrm{~km} \mathrm{~s}^{-1}$, and $[\mathrm{Fe} / \mathrm{H}]=0.040 \pm 0.004 \mathrm{dex}$. The stellar parameters found for Inti 1 are $T_{\text {eff }}=5837 \pm 11 \mathrm{~K}, \log g=4.42 \pm 0.03 \mathrm{dex}$, $v_{\mathrm{t}}=1.04 \pm 0.02 \mathrm{~km} \mathrm{~s}^{-1}$, and $[\mathrm{Fe} / \mathrm{H}]=0.07 \pm 0.01 \mathrm{dex}$. According to the solar twin definition of Ramírez et al. (2009), a solar twin should be within $\Delta T_{\text {eff }}=100 \mathrm{~K}, \Delta \log g=0.1 \mathrm{dex}$, and $\Delta[\mathrm{Fe} / \mathrm{H}]$ $=0.1 \mathrm{dex}$ of the Sun; our results agree with this definition, hence, Inti 1 is a solar twin.

Once the atmospheric parameters were set, we measured the abundances of 18 elements other than iron using atomic lines: $\mathrm{C}$, $\mathrm{Na}, \mathrm{Mg}, \mathrm{Si}, \mathrm{Ca}, \mathrm{Sc}, \mathrm{Ti}, \mathrm{Cr}, \mathrm{Mn}, \mathrm{Co}, \mathrm{Ni}, \mathrm{Cu}, \mathrm{Zn}, \mathrm{Y}, \mathrm{Zr}, \mathrm{Ce}$, and $\mathrm{Nd}$. For carbon we also used $\mathrm{CH}$ molecular lines and for nitrogen we used NH. The hyperfine correction was made for Mn, Co, Y, and $\mathrm{Cu}$, adopting the HFS data from Meléndez et al. (2014a). We compare our abundances for the bright solar twin HD 45184 with the most precise abundances available (Fig. 4), which are from Nissen (2015). We found a difference (this work - Nissen 2015) of $\Delta[\mathrm{X} / \mathrm{H}]=0.007(\sigma=0.009 \mathrm{dex})$ and $\Delta[\mathrm{X} / \mathrm{Fe}]=0.000(\sigma=$ $0.009 \mathrm{dex})$. This shows that our precision is about $0.01 \mathrm{dex}$. We also compared with two other works in the literature, resulting in $\Delta[\mathrm{X} / \mathrm{H}]=0.023(\sigma=0.016 \mathrm{dex})$ and $\Delta[\mathrm{X} / \mathrm{Fe}]=-0.007(\sigma=$ $0.016 \mathrm{dex})$ for Spina et al. (2016), and $\Delta[\mathrm{X} / \mathrm{H}]=0.014(\sigma=$ $0.030 \mathrm{dex})$ and $\Delta[\mathrm{X} / \mathrm{Fe}]=0.004(\sigma=0.030 \mathrm{dex})$ for González Hernández et al. (2010).

The differential abundances for HD 45184 and Inti 1 are presented in Table 4, including the observational errors and systematic errors (due to uncertainties in the stellar parameters), and we 

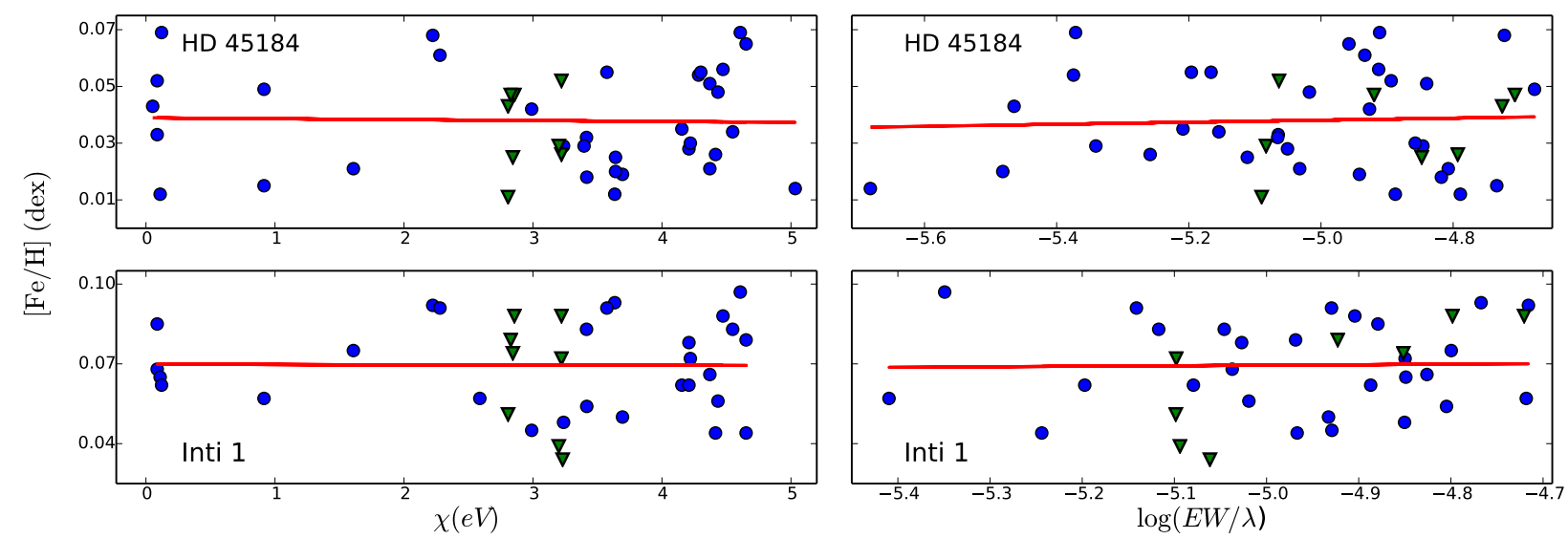

Fig. 3. Differential iron abundances as a function of excitation potential (left panels) and reduced equivalent width (right panels) for the solar twin HD 45184 and Inti 1. Blue filled circles and green filled triangles represent Fe I and Fe II, while red lines are the fits.

Table 2. Comparison of stellar parameters for the solar twin HD 45184.

\begin{tabular}{ccccccccccccc}
\hline \hline $\begin{array}{c}T_{\text {eff }} \\
(\mathrm{K})\end{array}$ & $\begin{array}{c}\text { Error } \\
(\mathrm{K})\end{array}$ & $\begin{array}{c}\log g \\
(\mathrm{dex})\end{array}$ & $\begin{array}{c}\text { Error } \\
(\mathrm{dex})\end{array}$ & $\begin{array}{c}{[\mathrm{Fe} / \mathrm{H}]} \\
(\mathrm{dex})\end{array}$ & $\begin{array}{c}\text { Error } \\
(\mathrm{dex})\end{array}$ & $\begin{array}{c}v_{\mathrm{t}} \\
\left(\mathrm{km} \mathrm{s}^{-1}\right)\end{array}$ & $\begin{array}{c}\text { Error } \\
\left(\mathrm{km} \mathrm{s}^{-1}\right)\end{array}$ & $\begin{array}{c}\text { Age } \\
(\mathrm{Gyr})\end{array}$ & $\begin{array}{c}\text { Error } \\
(\mathrm{Gyr})\end{array}$ & $\begin{array}{c}\text { Mass } \\
M_{\odot}\end{array}$ & $\begin{array}{c}\text { Error } \\
M_{\odot}\end{array}$ & Source \\
\hline 5864 & 9 & 4.45 & 0.03 & 0.040 & 0.010 & 1.11 & 0.02 & 3.0 & 1.2 & 1.05 & 0.01 & This work \\
5873 & 18 & 4.41 & 0.04 & 0.070 & 0.016 & 1.03 & 0.04 & 3.7 & 1.2 & 1.06 & 0.02 & $1^{\dagger}$ \\
5871 & 6 & 4.45 & 0.01 & 0.047 & 0.006 & 1.06 & 0.02 & 2.7 & 0.5 & 1.06 & 0.01 & $2^{\dagger}$ \\
5833 & 10 & 4.37 & 0.02 & 0.010 & 0.010 & 1.04 & 0.06 & $\ldots$ & $\ldots$ & $\ldots$ & $\ldots$ & $3^{\dagger}$ \\
5849 & 86 & 4.45 & 0.11 & 0.040 & 0.090 & 1.11 & 0.09 & 4.4 & 2.3 & 1.03 & 0.05 & $4^{\dagger}$ \\
5869 & 14 & 4.47 & 0.02 & 0.040 & 0.010 & 1.03 & 0.04 & 2.3 & $\ldots$ & 1.05 & $\ldots$ & $5^{*, \dagger}$ \\
5863 & 5 & 4.44 & 0.01 & 0.040 & 0.004 & 1.05 & 0.02 & 2.9 & 0.5 & 1.06 & 0.01 & 6 \\
\hline
\end{tabular}

Notes. 1) Spina et al. (2016); 2) Nissen (2015); 3) ?; 4) Bensby et al. (2014); 5) Sousa et al. (2008), Delgado Mena et al. (2014); 6) weighted mean from the literature. ${ }^{(*)}$ Stellar parameters from Sousa et al. (2008); age and mass from Delgado Mena et al. (2014) and Schneider et al. (2011). (†) The parameters reported here are based on the differential stellar parameters and adopting for the Sun $T_{\text {eff }}=5777 \mathrm{~K}, \log g=4.44$ dex and $v_{\mathrm{t}}=1.00 \mathrm{~km} \mathrm{~s}^{-1}$.

also included the total error obtained from quadratically adding the statistical and systematic errors.

We computed the mass and age of HD 45184 and Inti 1 using our atmospheric parameters and employing the $\mathrm{q}^{2}$ (qoyllurquipu) code ${ }^{8}$. This code is based in python and was developed by Ramírez et al. (2014), to determine the masses and ages of stars using the Yonsei-Yale isochrones (e.g., Yi et al. 2001).

Our results show a mass of $1.05 M_{\odot}$ and $1.04 M_{\odot}$ for HD 45184 and Inti 1 . The age obtained is about 3 Gyr and 4 Gyr for HD 45184 and Inti 1 (Fig. 5). The mass and age of HD 45184 are in excellent agreement with the weighted mean value found in the literature (Table 2). The Yonsei-Yale grids of stellar models do not include nonstandard physics such as those included in studies of lithium depletion (Do Nascimento et al. 2009; Denissenkov 2010; Li et al. 2012). We tested our method for the star 18 Sco, which was analyzed using nonstandard models by Li et al. (2012), and found the same mass and age. Furthermore, Meléndez et al. (2014a) shows that the exact choice of isochrone do not have an important impact on the masses and ages relative to the Sun.

\section{Abundance trends and results}

A comparison between our chemical pattern and that of Nissen (2015) is shown in Fig. 6. It is reassuring that we get the same trend as the precise work by Nissen (2015). In Fig. 7 we show

\footnotetext{
8 https://github.com/astroChasqui/q2
}

the differential abundances normalized to carbon for HD 45184 (upper panel) and Inti 1 (lower panel), as a function of condensation temperature (Lodders 2003). The chemical pattern of HD 46184 follows the abundance pattern of the fit of the mean trend of 11 solar twins studied by Meléndez et al. (2009), as shown by the dashed lines after a vertical shift. Inti 1 has an abundance pattern closer to solar, albeit slightly enhanced in refractories. The offset between the refractory and volatiles elements of HD 45184 and Inti 1 are 0.076 dex and 0.025 dex, respectively.

Nissen (2015) showed that the $[\mathrm{Y} / \mathrm{Mg}]$ ratio is an age indicator. Using his relation, we estimate ages of $3.7 \pm 0.6 \mathrm{Gyr}$ and $4.1 \pm 0.6$ Gyr for HD 45184 and Inti 1 ; these results are in agreement with the isochronal ages computed by using $\mathrm{q}^{2}$.

Following Chambers (2010), we computed the mass of rocky material needed to reproduce the abundance trend of HD 45184 and Inti 1 . Our results show a value of $3.5 \pm 1 M_{\oplus}$ of refractory elements using a mixture of Earth-like and CM-chondrite-like material for HD 45184 and $1.5 \pm 1 M_{\oplus}$ for Inti 1 . These patterns are represented by blue filled triangles in Fig. 7.

We developed a code ${ }^{9}$ in python to make this calculation easier. The code first computes the convective mass of a solar twin, and then estimates the mass of the rocky material missing in the convective zone. The convective mass is calculated making a double interpolation to the mass and metallicity of the

\footnotetext{
9 Our code is freely available online at https://github.com/ ramstojh/terra
} 

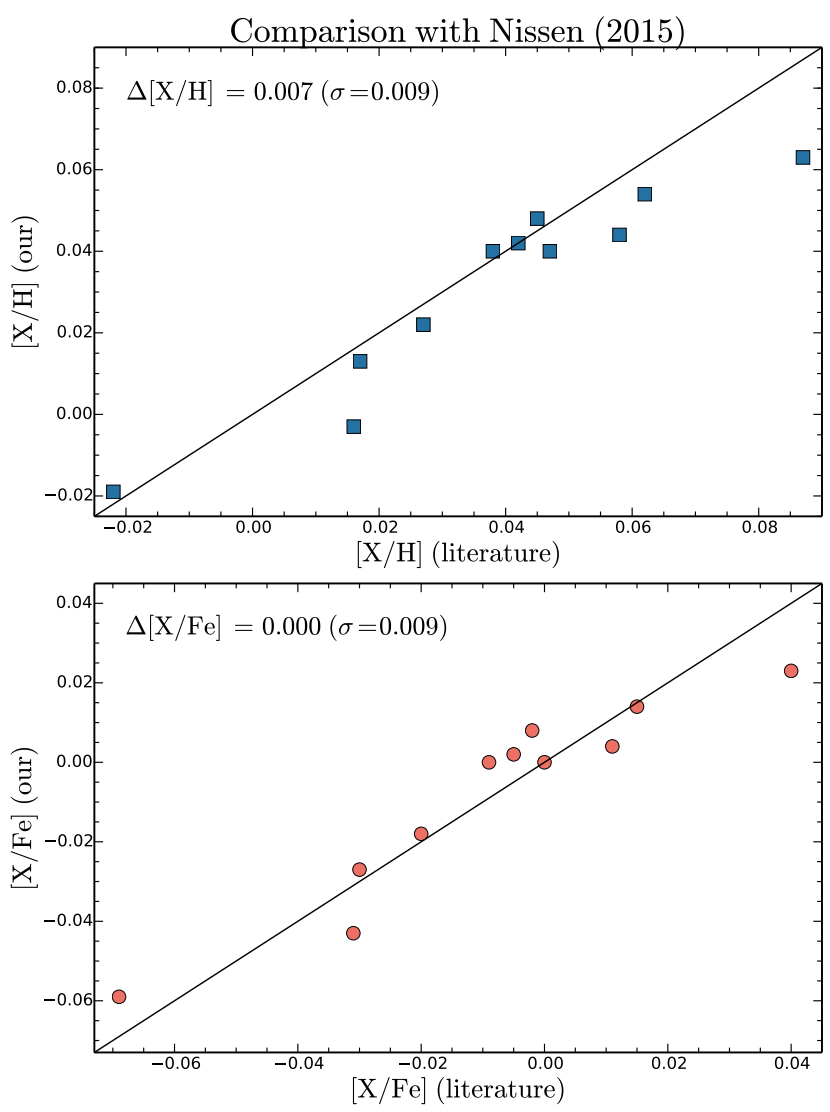

Fig. 4. Upper panel: comparison between our $[\mathrm{X} / \mathrm{H}]$ ratios and those from the high precision work by Nissen (2015). Lower panel: as above for $[\mathrm{X} / \mathrm{Fe}]$.
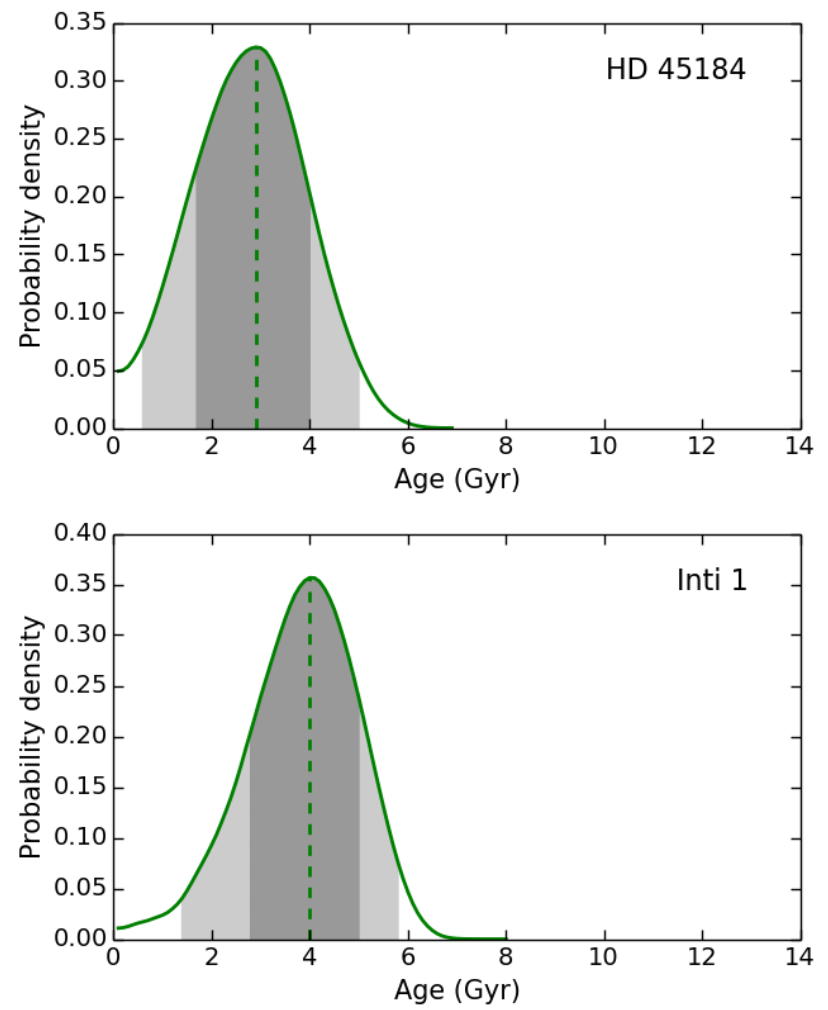

Fig. 5. Age probability distribution of HD 45184 (upper panel) and Inti 1 (lower panel). The dashed lines represent the most probable age. The different regions represent \pm 1 sigma and \pm 2 sigma confidence level.

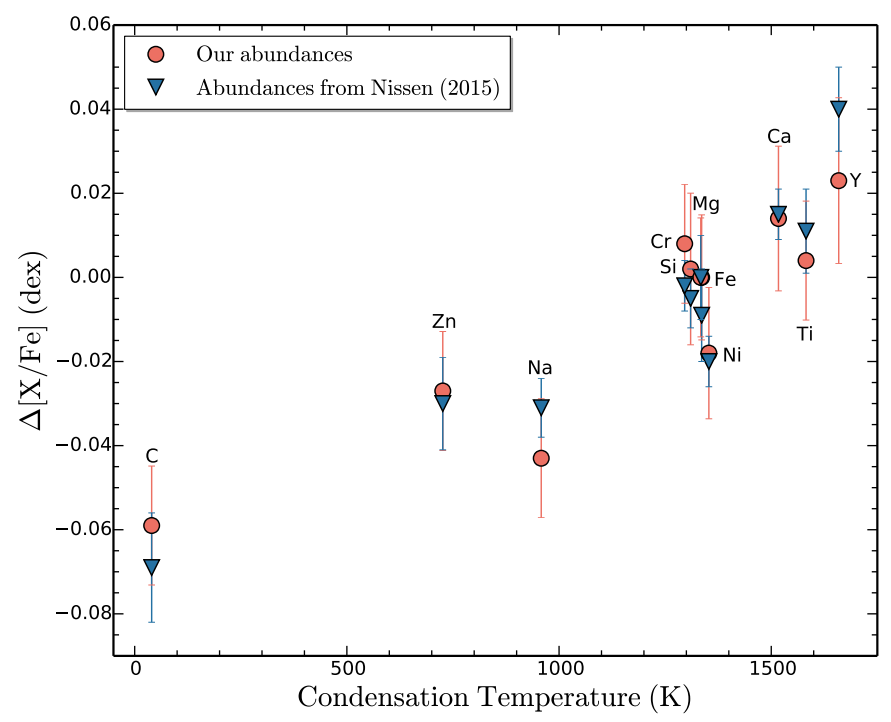

Fig. 6. Comparison between our abundance and Nissen (2015), as a function of condensation temperature (Lodders 2003).

Table 3. Fundamental parameters for Inti 1.

\begin{tabular}{cc}
\hline \hline Inti 1 & Parameters \\
\hline$T_{\text {eff }}$ & $5837 \pm 11 \mathrm{~K}$ \\
$\log g$ & $4.42 \pm 0.03 \mathrm{dex}$ \\
{$[\mathrm{Fe} / \mathrm{H}]$} & $0.07 \pm 0.01 \mathrm{dex}$ \\
$v_{\mathrm{t}}$ & $1.04 \pm 0.02 \mathrm{~km} \mathrm{~s}^{-1}$ \\
Mass & $1.04_{-0.08}^{+0.01} M_{\odot}^{* *}$ \\
Distance & $389.70 \pm 36.00 \mathrm{pc}^{*}$ \\
Convective Mass & $0.019 M_{\odot}^{* * *}$ \\
Age & $4.00_{-1.26}^{+1.00} \mathrm{Gyr}^{* *}$ \\
$\log L$ & $0.06 \pm 0.032 L_{\odot}^{* *}$ \\
$M_{V}$ & $4.68_{-0.07}^{+0.08} \mathrm{mag}^{* *}$ \\
Radius & $1.05 \pm 0.04 R_{\odot}^{* *}$ \\
\hline
\end{tabular}

Notes. Error of the distance modulus was calculated assuming an uncertainty of 0.2 mags. ${ }^{(*)}$ From the q 2 code. ${ }^{(* *)}$ Using Siess et al. (2000) models.

solar twin. The convective masses adopted for this calculation are from Siess et al. $(2000)^{10}$.

Once the convective mass is obtained, the code computes the convective mass of each element present in the Sun, adopting the abundances of Asplund et al. (2009). Adopting the same approach, we use the abundances of Wasson \& Kallemeyn (1988) and Allègre et al. (2001) for the chemical composition of $\mathrm{CM}$ chondrites and the Earth. This is explained in more detail in Appendix A (see also Chambers 2010; Mack et al. 2014). All our calculations for Inti 1 are listed in Table 3.

To verify our results, we reproduced the calculation of Chambers (2010) in Fig. 8, adding a mixture of $2 M_{\oplus}$ of Earthlike material and $2 M_{\oplus}$ of chondrite-like material. Our abundances are represented by blue filled circles, while the abundances of Chambers by filled red stars. Our results agree well with the calculation of Chambers, who used the same meteoritic composition as us, but he adopted another reference for the Earth (Waenke \& Dreibus 1988).

${ }^{10}$ http://www . astro.ulb.ac.be/ siess. 
Table 4. Stellar abundances $[\mathrm{X} / \mathrm{H}]$ and errors for HD 45184 and Inti 1.

\begin{tabular}{|c|c|c|c|c|c|c|c|c|}
\hline \multicolumn{9}{|c|}{ HD 45184} \\
\hline Element & $\begin{array}{r}\Delta[\mathrm{X} / \mathrm{H}] \\
\mathrm{LTE} \\
(\mathrm{dex})\end{array}$ & $\begin{array}{l}\Delta T_{\text {eff }} \\
\pm 9 \mathrm{~K} \\
(\mathrm{dex})\end{array}$ & $\begin{array}{r}\Delta \log g \\
\pm 0.03 \text { dex } \\
(\operatorname{dex})\end{array}$ & $\begin{array}{r}\Delta v_{t} \\
\pm 0.02 \mathrm{~km} \mathrm{~s}^{-1} \\
(\mathrm{dex})\end{array}$ & $\begin{array}{r}\Delta[\mathrm{Fe} / \mathrm{H}] \\
\pm 0.01 \mathrm{dex} \\
(\mathrm{dex})\end{array}$ & Param. $^{a}$ & $\begin{array}{l}\text { Obs. }^{b} \\
(\operatorname{dex})\end{array}$ & Total $^{c}$ \\
\hline $\mathrm{C}$ & -0.019 & 0.005 & 0.007 & 0.000 & 0.000 & 0.009 & 0.006 & 0.010 \\
\hline $\mathrm{Na}$ & -0.003 & 0.004 & 0.002 & 0.000 & 0.000 & 0.004 & 0.008 & 0.009 \\
\hline $\mathrm{Mg}$ & 0.040 & 0.007 & 0.003 & 0.004 & 0.000 & 0.009 & 0.007 & 0.011 \\
\hline $\mathrm{Si}$ & 0.042 & 0.002 & 0.002 & 0.000 & 0.001 & 0.003 & 0.001 & 0.015 \\
\hline $\mathrm{Ca}$ & 0.054 & 0.005 & 0.003 & 0.004 & 0.000 & 0.007 & 0.012 & 0.014 \\
\hline $\mathrm{Sc}$ & 0.041 & 0.007 & 0.003 & 0.000 & 0.000 & 0.008 & 0.006 & 0.010 \\
\hline $\mathrm{Ti}$ & 0.044 & 0.009 & 0.002 & 0.003 & 0.000 & 0.010 & 0.012 & 0.015 \\
\hline $\mathrm{Cr}$ & 0.048 & 0.007 & 0.001 & 0.004 & 0.000 & 0.008 & 0.008 & 0.011 \\
\hline $\mathrm{Mn}$ & 0.014 & 0.006 & 0.001 & 0.003 & 0.000 & 0.007 & 0.012 & 0.014 \\
\hline $\mathrm{Fe}$ & 0.040 & 0.007 & 0.001 & 0.006 & 0.000 & 0.010 & 0.003 & 0.010 \\
\hline Co & 0.006 & 0.006 & 0.003 & 0.001 & 0.000 & 0.007 & 0.014 & 0.016 \\
\hline $\mathrm{Ni}$ & 0.022 & 0.004 & 0.001 & 0.003 & 0.001 & 0.005 & 0.011 & 0.012 \\
\hline $\mathrm{Cu}$ & -0.005 & 0.004 & 0.002 & 0.002 & 0.001 & 0.005 & 0.007 & 0.009 \\
\hline $\mathrm{Zn}$ & 0.013 & 0.002 & 0.001 & 0.007 & 0.002 & 0.008 & 0.006 & 0.010 \\
\hline $\mathrm{Y}$ & 0.063 & 0.001 & 0.010 & 0.009 & 0.002 & 0.014 & 0.010 & 0.017 \\
\hline $\mathrm{Zr}$ & 0.076 & 0.001 & 0.013 & 0.004 & 0.002 & 0.015 & 0.014 & 0.020 \\
\hline $\mathrm{Ce}$ & 0.099 & 0.002 & 0.014 & 0.002 & 0.003 & 0.015 & 0.020 & 0.025 \\
\hline $\mathrm{Nd}$ & 0.124 & 0.002 & 0.014 & 0.001 & 0.003 & 0.014 & 0.032 & 0.035 \\
\hline $\mathrm{C}(\mathrm{CH})$ & -0.021 & 0.007 & 0.001 & 0.001 & 0.006 & 0.009 & 0.013 & 0.016 \\
\hline $\mathrm{N}(\mathrm{NH})$ & 0.003 & 0.009 & 0.001 & 0.000 & 0.006 & 0.011 & 0.011 & 0.015 \\
\hline \multicolumn{9}{|c|}{ Inti 1} \\
\hline Element & $\begin{array}{r}\Delta[\mathrm{X} / \mathrm{H}] \\
\mathrm{LTE} \\
(\mathrm{dex})\end{array}$ & $\begin{array}{r}\Delta T_{\text {eff }} \\
\pm 11 \mathrm{~K} \\
(\mathrm{dex})\end{array}$ & $\begin{array}{r}\Delta \log g \\
\pm 0.03 \text { dex } \\
(\text { dex })\end{array}$ & $\begin{array}{r}\Delta v_{t} \\
\pm 0.02 \mathrm{~km} \mathrm{~s}^{-1} \\
(\mathrm{dex})\end{array}$ & $\begin{array}{r}\Delta[\mathrm{Fe} / \mathrm{H}] \\
\pm 0.01 \mathrm{dex} \\
(\mathrm{dex})\end{array}$ & Param. $^{a}$ & $\begin{array}{l}\text { Obs. }^{b} \\
(\operatorname{dex})\end{array}$ & Total $^{c}$ \\
\hline $\mathrm{C}$ & 0.059 & 0.006 & 0.008 & 0.001 & 0.000 & 0.010 & 0.004 & 0.011 \\
\hline $\mathrm{Na}$ & 0.069 & 0.005 & 0.001 & 0.000 & 0.000 & 0.005 & 0.010 & 0.011 \\
\hline $\mathrm{Mg}$ & 0.076 & 0.009 & 0.005 & 0.004 & 0.001 & 0.011 & 0.003 & 0.011 \\
\hline $\mathrm{Si}$ & 0.075 & 0.003 & 0.002 & 0.001 & 0.001 & 0.004 & 0.007 & 0.008 \\
\hline $\mathrm{Ca}$ & 0.069 & 0.007 & 0.004 & 0.000 & 0.004 & 0.009 & 0.007 & 0.011 \\
\hline Sc & 0.083 & 0.009 & 0.003 & 0.001 & 0.000 & 0.010 & 0.007 & 0.012 \\
\hline $\mathrm{Ti}$ & 0.076 & 0.010 & 0.001 & 0.003 & 0.000 & 0.010 & 0.006 & 0.012 \\
\hline $\mathrm{Cr}$ & 0.066 & 0.010 & 0.003 & 0.006 & 0.000 & 0.012 & 0.006 & 0.013 \\
\hline $\mathrm{Mn}$ & 0.073 & 0.007 & 0.001 & 0.003 & 0.001 & 0.008 & 0.001 & 0.008 \\
\hline $\mathrm{Fe}$ & 0.070 & 0.009 & 0.001 & 0.005 & 0.000 & 0.010 & 0.003 & 0.011 \\
\hline $\mathrm{Co}$ & 0.074 & 0.009 & 0.003 & 0.001 & 0.001 & 0.010 & 0.010 & 0.014 \\
\hline $\mathrm{Ni}$ & 0.085 & 0.006 & 0.000 & 0.003 & 0.001 & 0.007 & 0.003 & 0.007 \\
\hline $\mathrm{Cu}$ & 0.067 & 0.006 & 0.002 & 0.002 & 0.001 & 0.007 & 0.010 & 0.012 \\
\hline $\mathrm{Zn}$ & 0.066 & 0.002 & 0.000 & 0.007 & 0.003 & 0.008 & 0.007 & 0.011 \\
\hline Y & 0.086 & 0.001 & 0.011 & 0.009 & 0.003 & 0.015 & 0.006 & 0.016 \\
\hline $\mathrm{Zr}$ & 0.085 & 0.001 & 0.014 & 0.003 & 0.003 & 0.016 & 0.008 & 0.017 \\
\hline $\mathrm{Ce}$ & 0.084 & 0.003 & 0.015 & 0.002 & 0.003 & 0.016 & 0.007 & 0.017 \\
\hline $\mathrm{Nd}$ & 0.088 & 0.003 & 0.015 & 0.002 & 0.003 & 0.016 & 0.003 & 0.016 \\
\hline $\mathrm{C}(\mathrm{CH})$ & 0.062 & 0.009 & 0.000 & 0.001 & 0.008 & 0.012 & 0.010 & 0.016 \\
\hline $\mathrm{N}(\mathrm{NH})$ & 0.063 & 0.010 & 0.001 & 0.001 & 0.008 & 0.013 & 0.002 & 0.013 \\
\hline
\end{tabular}

Notes. ${ }^{(a)}$ Adding errors in stellar parameters. ${ }^{(b)}$ Observational errors. ${ }^{(c)}$ Total errors (stellar parameters and observational).

\section{Conclusions}

Our atmospheric parameters computed relative to the Sun for HD 45184 are $T_{\text {eff }}=5864 \pm 9 \mathrm{~K}, \log g=4.45 \pm 0.03$ dex, $v_{\mathrm{t}}=$ $1.11 \pm 0.02 \mathrm{~km} \mathrm{~s}^{-1}$, and $[\mathrm{Fe} / \mathrm{H}]=0.04 \pm 0.01 \mathrm{dex}$, and for the faint solar twin Inti 1 are $T_{\text {eff }}=5837 \pm 11 \mathrm{~K}, \log g=4.42 \pm 0.03 \mathrm{dex}$, $v_{\mathrm{t}}=1.04 \pm 0.02 \mathrm{~km} \mathrm{~s}^{-1}$, and $[\mathrm{Fe} / \mathrm{H}]=0.07 \pm 0.01 \mathrm{dex}$, meaning that our star Inti 1 is a solar twin (Ramírez et al. 2009). In Table 1 we showed that the colors of Inti 1 are identical to the Sun within errors. Thus our faint solar solar twin and the distant solar twin found by do Nascimento et al. (2013) could be used to calibrate different photometric surveys.
The abundances of HD 45184 shows an excellent agreement with the highly precise work by Nissen (2015). HD 45184 and Inti 1 present enhancement in the refractory elements compared to volatiles species with an offset of 0.076 dex and 0.025 dex, respectively. This demonstrates that the same chemical anomalies found when the Sun is compared to local solar twins are also present when compared to distant solar twins (albeit the refractory enhancement of Inti 1 is smaller than for the nearby solar twin HD 45184). Using our code and theoretical models from Siess et al. (2000), we estimated the mass of rocky material present in the convective zone for HD $45184\left(\approx 3.5 M_{\oplus}\right)$ and Inti $1\left(\approx 1.5 M_{\oplus}\right)$, relative to the Sun. 
J. Y. Galarza et al.: Serendipitous discovery of Inti 1

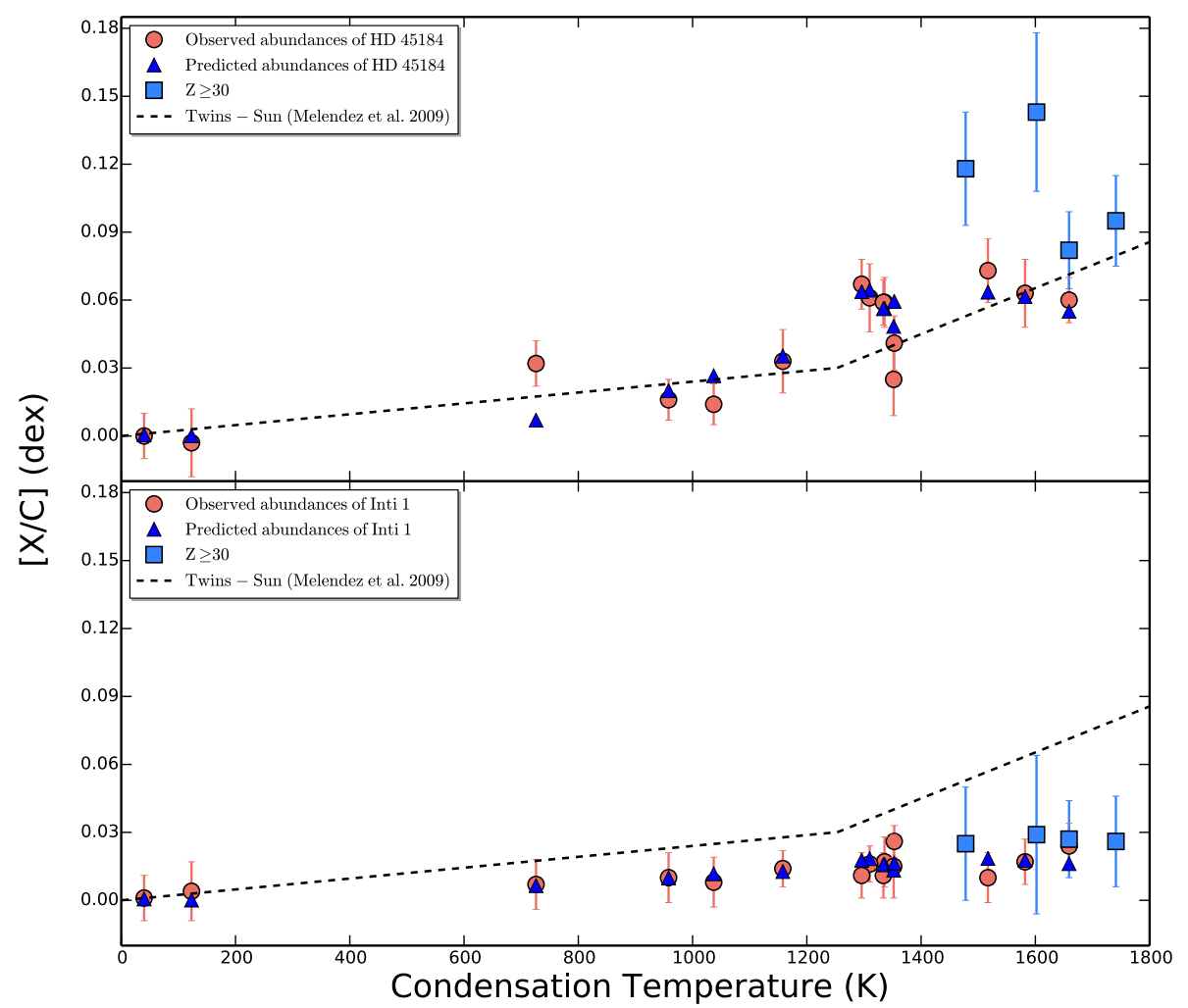

Fig. 7. Upper panel: abundance pattern of HD 45184 (red filled circles) versus condensation temperature. We reproduce the chemical pattern of HD 45184 (blue filled triangles) adding $3.5 M_{\oplus}$ of Earth-like material to the convective zone of the Sun. Lower panel: the differential abundance ratios of Inti 1 (red filled circles) relative to the Sun as a function of condensation temperature. The mean abundance pattern of 11 solar twins studied by Meléndez et al. (2009) is represented by the black dashed line. We could reproduce the trend of Inti 1 (blue filled triangles), adding $1.5 M_{\oplus}$ of Earth-like material to the convective zone of the Sun. Neutron capture elements are represented by squares in both panels.

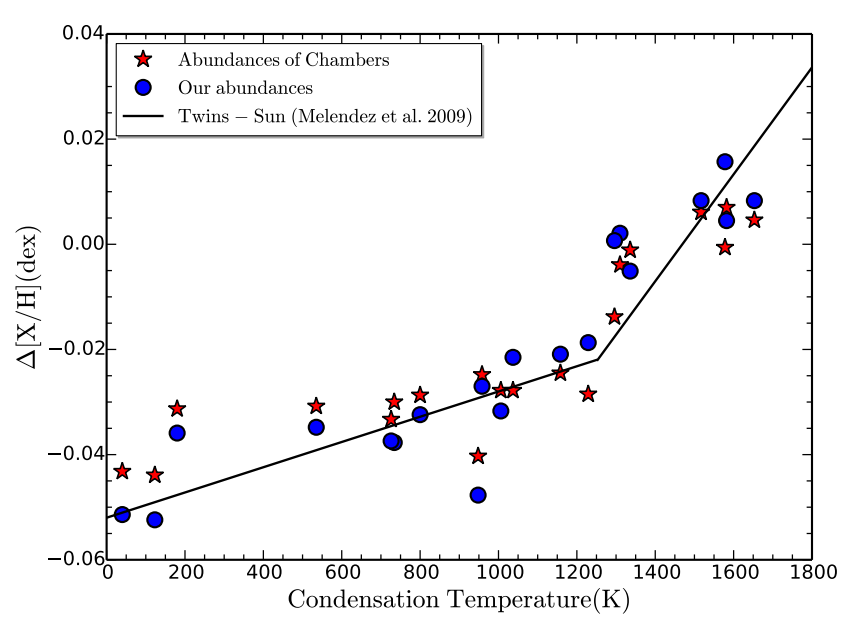

Fig. 8. Composition of the solar photosphere adding $4 M_{\oplus}$ in mixture of rocky material (Earth plus meteoritic) to the convective zone of the Sun.

The lithium abundances are usually determined from the $6708 \AA$ resonance line (or sometimes from the $6104 \AA$ subordinate line). Hence, they were not measured because of our limited spectral coverage (3190-5980 A). However, future observations will allow us to determine the $\mathrm{Li}$ abundance of Inti 1 , and verify if the star follows the lithium-age correlation (e.g., Monroe et al. 2013).

Acknowledgements. J.Y.G. acknowledges support by CNPq. J.M. thanks support from FAPESP (2012/24392-2). We are grateful to the many people who have worked to make the Keck Telescope and its instruments a reality and to operate and maintain the Keck Observatory. The authors wish to extend special thanks to those of Hawaian ancestry on whose sacred mountain we are privileged to be guests. Without their generous hospitality, none of the observations presented herein would have been possible.

\section{References}

Adibekyan, V. Z., González Hernández, J. I., Delgado Mena, E., et al. 2014, A\&A, 564, L15

Allègre, C., Manhès, G., \& Lewin, É. 2001, Earth Planet. Sci. Lett., 185, 49

Asplund, M., Grevesse, N., Sauval, A. J., \& Scott, P. 2009, ARA\&A, 47, 481

Baumann, P., Ramírez, I., Meléndez, J., Asplund, M., \& Lind, K. 2010, A\&A, 519, A87

Bedell, M., Meléndez, J., Bean, J. L., et al. 2014, ApJ, 795, 23

Bensby, T., Feltzing, S., \& Oey, M. S. 2014, A\&A, 562, A71

Casagrande, L., Ramírez, I., Meléndez, J., Bessell, M., \& Asplund, M. 2010, A\&A, 512, A54

Casagrande, L., Ramírez, I., Meléndez, J., \& Asplund, M. 2012, ApJ, 761, 16

Cayrel de Strobel, G. 1996, A\&ARv, 7, 243

Chambers, J. E. 2010, ApJ, 724, 92

Cox, A. N. 2000, Allen's astrophysical quantities (Springer)

Cutri, R. M., Skrutskie, M. F., van Dyk, S., et al. 2003, VizieR Online Data Catalog: II/246

Cutri, R. M., \& et al. 2012, VizieR Online Data Catalog: II/311

Datson, J., Flynn, C., \& Portinari, L. 2012, MNRAS, 426, 484

Datson, J., Flynn, C., \& Portinari, L. 2014, MNRAS, 439, 1028

Delgado Mena, E., Israelian, G., González Hernández, J. I., et al. 2014, A\&A, 562, A92

Denissenkov, P. A. 2010, ApJ, 719, 28

Do Nascimento, Jr., J. D., Castro, M., Meléndez, J., et al. 2009, A\&A, 501, 687 do Nascimento, Jr., J.-D., Takeda, Y., Meléndez, J., et al. 2013, ApJ, 771, L31

do Nascimento, Jr., J.-D., García, R. A., Mathur, S., et al. 2014, ApJ, 790, L23

Gonzalez, G., Carlson, M. K., \& Tobin, R. W. 2010, MNRAS, 407, 314

González Hernández, J. I., Israelian, G., Santos, N. C., et al. 2010, ApJ, 720, 1592

Gustafsson, B., Edvardsson, B., Eriksson, K., et al. 2008, A\&A, 486, 951

Holmberg, J., Flynn, C., \& Portinari, L. 2006, MNRAS, 367, 449

Jasmim, F. L., Lazzaro, D., Carvano, J. M. F., Mothé-Diniz, T., \& Hasselmann, P. H. 2013, A\&A, 552, A85

Jofré, P., Mädler, T., Gilmore, G., et al. 2015, MNRAS, 453, 1428

King, J. R., Boesgaard, A. M., \& Schuler, S. C. 2005, AJ, 130, 2318 
Lazzaro, D., Angeli, C. A., Carvano, J. M., et al. 2004, Icarus, 172, 179 Li, T. D., Bi, S. L., Liu, K., Tian, Z. J., \& Shuai, G. Z. 2012, A\&A, 546, A83 Lodders, K. 2003, ApJ, 591, 1220

Mack, III, C. E., Schuler, S. C., Stassun, K. G., \& Norris, J. 2014, ApJ, 787, 98

Maldonado, J., Eiroa, C., Villaver, E., Montesinos, B., \& Mora, A. 2015, A\&A, 579, A20

Meléndez, J., \& Ramírez, I. 2007, ApJ, 669, L89

Meléndez, J., Dodds-Eden, K., \& Robles, J. A. 2006, ApJ, 641, L133

Meléndez, J., Asplund, M., Gustafsson, B., \& Yong, D. 2009, ApJ, 704, L66

Meléndez, J., Bergemann, M., Cohen, J. G., et al. 2012, A\&A, 543, A29

Meléndez, J., Ramírez, I., Karakas, A. I., et al. 2014a, ApJ, 791, 14

Meléndez, J., Schirbel, L., Monroe, T. R., et al. 2014b, A\&A, 567, L3

Monroe, T. R., Meléndez, J., Ramírez, I., et al. 2013, ApJ, 774, L32

Nissen, P. E. 2015, A\&A, 579, A52

Önehag, A., Korn, A., Gustafsson, B., Stempels, E., \& Vandenberg, D. A. 2011, A\&A, 528, A85

Pasquini, L., Biazzo, K., Bonifacio, P., Randich, S., \& Bedin, L. R. 2008, A\&A, 489, 677

Porto de Mello, G. F., \& da Silva, L. 1997, ApJ, 482, L89

Porto de Mello, G. F., da Silva, R., da Silva, L., \& de Nader, R. V. 2014, A\&A, 563, A52

Ramírez, I., \& Meléndez, J. 2005, ApJ, 626, 465

Ramírez, I., Meléndez, J., \& Asplund, M. 2009, A\&A, 508, L17

Ramírez, I., Michel, R., Sefako, R., et al. 2012, ApJ, 752, 5

Ramírez, I., Meléndez, J., \& Asplund, M. 2014, A\&A, 561, A7

Schlafly, E. F., \& Finkbeiner, D. P. 2011, ApJ, 737, 103

Schlegel, D. J., Finkbeiner, D. P., \& Davis, M. 1998, ApJ, 500, 525

Schneider, J., Dedieu, C., Le Sidaner, P., Savalle, R., \& Zolotukhin, I. 2011, A\&A, 532, A79

Schuler, S. C., Flateau, D., Cunha, K., et al. 2011, ApJ, 732, 55

Siess, L., Dufour, E., \& Forestini, M. 2000, A\&A, 358, 593

Sneden, C. A. 1973, Ph.D. Thesis, The University of Texas at Austin

Sousa, S. G., Santos, N. C., Mayor, M., et al. 2008, A\&A, 487, 373

Spina, L., Meléndez, J., \& Ramírez, I. 2016, A\&A, 585, A152

Takeda, Y., \& Tajitsu, A. 2009, PASJ, 61, 471

Takeda, Y., Kawanomoto, S., Honda, S., Ando, H., \& Sakurai, T. 2007, A\&A, 468, 663

Tucci Maia, M., Meléndez, J., Castro, M., et al. 2015, A\&A, 576, L10

Vogt, S. S., Allen, S. L., Bigelow, B. C., et al. 1994, in Instrumentation in Astronomy VIII, eds. D. L. Crawford, \& E. R. Craine, SPIE Conf. Ser., 2198, 362

Waenke, H., \& Dreibus, G. 1988, Roy. Soc. London Philos. Trans. Ser. A, 325, 545

Wasson, J. T., \& Kallemeyn, G. W. 1988, Roy. Soc. London Philos. Trans. Ser. A, 325,535

Yi, S., Demarque, P., Kim, Y.-C., et al. 2001, ApJS, 136, 417

Yuan, H. B., Liu, X. W., \& Xiang, M. S. 2013, MNRAS, 430, 2188

\section{Appendix A: Estimating the missing mass of rocky material}

Adopting the abundance of Asplund et al. (2009) for the chemical composition of the Sun $\left(A_{\text {Sun }}\right)$, and using $[\mathrm{Fe} / \mathrm{H}]$ of a given star, we could estimate the mass of rocky material missing from its convective zone. First we have to compute the mass of each element, which is given by

$$
X_{\text {conv_mass }}=A \times 10^{\left(A_{\text {Sun }}+[\mathrm{Fe} / \mathrm{H}]\right)} \text {, }
$$

where $A$ is the atomic weight. Then the convective mass of each element is given by

Convective $_{\text {mass }}=M_{\text {conv }} \times M_{\odot} \times \frac{X_{\text {conv_mass }}}{\sum X_{\text {conv_mass }}}$,

where $M_{\text {conv }}$ is the Sun's convective mass $\left(\sim 0.02 M_{\odot}\right)$. For computing the meteoritic mass, we adopted the abundance of Wasson \& Kallemeyn (1988) as composition of chondrites, and for the terrestrial mass we adopted the abundance of Allègre et al. (2001), following the equations:

$$
\begin{aligned}
\text { Meteoritic }_{\text {mass }} & =M_{\oplus} \times \frac{X_{\text {met_mass }}}{\sum X_{\text {met_mass }}} \\
\text { Terrestrial } & =M_{\text {mass }} \times \frac{X_{\text {terr_mass }}}{\sum X_{\text {terr_mass }}},
\end{aligned}
$$

where $X_{\text {met_mass }}$ and $X_{\text {terr_mass }}$ are the masses of each element in Earth masses.

Then the mass of a given element in the convective envelope, necessary to explain the observed abundance difference, is given by

$\Delta M=\log \left(1+\frac{M_{\text {rock }}}{\text { Convective }_{\text {mass }}}\right)$,

where $M_{\text {rock }}$ is the mass of the missing rock, and is given by $M_{\text {rock }}=\alpha \times$ Meteoritical $_{\text {mass }}+\beta \times$ Terrestrial $_{\text {mass }}$, where $\alpha$ and $\beta$ are given in units of Earth masses. 


\title{
High-precision analysis of the solar twin HIP 100963
}

\author{
Jhon Yana Galarza ${ }^{1}$, Jorge Meléndez ${ }^{1}$, Ivan Ramírez², David Yong ${ }^{3}$, Amanda I. Karakas ${ }^{3}$, \\ Martin Asplund ${ }^{3}$, and Fan $\mathrm{Liu}^{3}$
}

\footnotetext{
1 Universidade de São Paulo, IAG, Departamento de Astronomia, Rua do Matão 1226, São Paulo, 05509-900 SP, Brasil e-mail: ramstojh@usp.br

2 University of Texas at Austin, McDonald Observatory and Department of Astronomy, 2515 Speedway, Austin, TX 78712-1205, USA

3 Australian National University, Research School of Astronomy and Astrophysics, Mt. Stromlo Observatory, via Cotter Rd., Weston, ACT 2611, Australia
}

Received 7 December 2015 / Accepted 24 February 2016

\begin{abstract}
Context. HIP 100963 was one of the first solar twins identified. Although some high-precision analyses are available, a comprehensive high-precision study of chemical elements from different nucleosynthetic sources is still lacking from which to obtain potential new insights on planets, stellar evolution, and Galactic chemical evolution (GCE).

Aims. We analyze and investigate the origin of the abundance pattern of HIP 100963 in detail, in particular the pattern of the light element $\mathrm{Li}$, the volatile and refractory elements, and heavy elements from the $s$ - and $r$-processes.

Methods. We used the HIRES spectrograph on the Keck I telescope to acquire high-resolution $(R \approx 70000)$ spectra with a high signal-to-noise ratio $(S / N \approx 400-650$ per pixel) of HIP 100963 and the Sun for a differential abundance analysis. We measured the equivalent widths (EWs) of iron lines to determine the stellar parameters by employing the differential spectroscopic equilibrium. We determined the composition of volatile, refractory, and neutron-capture elements through a differential abundance analysis with respect to the Sun.

Results. The stellar parameters we found are $T_{\text {eff }}=5818 \pm 4 \mathrm{~K}, \log g=4.49 \pm 0.01 \mathrm{dex}, v_{t}=1.03 \pm 0.01 \mathrm{~km} \mathrm{~s}^{-1}$, and $[\mathrm{Fe} / \mathrm{H}]=-0.003 \pm 0.004 \mathrm{dex}$. These low errors allow us to compute a precise mass $\left(1.03_{-0.01}^{+0.02} M_{\odot}\right)$ and age $(2.0 \pm 0.4 \mathrm{Gyr})$, obtained using Yonsei-Yale isochrones. Using our $[\mathrm{Y} / \mathrm{Mg}]$ ratio, we have determined an age of $2.1 \pm 0.4 \mathrm{Gyr}$, in agreement with the age computed using isochrones. Our isochronal age also agrees with the age determined from stellar activity $(2.4 \pm 0.3 \mathrm{Gyr})$. We study the abundance pattern with condensation temperature $\left(T_{\text {cond }}\right)$ taking corrections by the GCE into account. We show that the enhancements of neutron-capture elements are explained by contributions from both the $s$ - and $r$-process. The lithium abundance follows the tight Li-age correlation seen in other solar twins.

Conclusions. We confirm that HIP 100963 is a solar twin and demonstrate that its abundance pattern is about solar after corrections for GCE. The star also shows enrichment in $s$ - and $r$-process elements, as well as depletion in lithium that is caused by stellar evolution.
\end{abstract}

Key words. Sun: abundances - stars: abundances - stars: AGB and post-AGB - stars: fundamental parameters - stars: solar-type planetary systems

\section{Introduction}

Cayrel de Strobel (1996) defined a solar twin as a star very similar to the Sun within the observational errors, in different properties such as mass, chemical composition, age, effective temperature, luminosity, surface gravity, chromospheric activity, equatorial rotation, etc. The first four stars reported as solar twins were 18 Sco (Porto de Mello \& da Silva 1997), HIP 78399 (King et al. 2005), HD 98618 (Meléndez et al. 2006), and HIP 100963 (Takeda et al. 2007). Ramírez et al. (2009) suggested a new definition: a star is a solar twin if its stellar parameters fall into the range of $\Delta T_{\text {eff }}=100 \mathrm{~K}$, $\Delta \log g=0.1 \mathrm{dex}$, and $\Delta[\mathrm{Fe} / \mathrm{H}]=0.1 \mathrm{dex}$, relative to the Sun. With this new constraint as definition, there are about 100 solar twins known up to now (Meléndez \& Ramírez 2007; Meléndez et al. 2009, 2012, 2014b; Pasquini et al. 2008; Petit et al. 2008; Ramírez et al. 2009, 2014; Takeda \& Tajitsu 2009; Baumann et al. 2010; Önehag et al. 2011; Datson et al. 2012; do Nascimento et al. 2013; Porto de Mello et al. 2014; Mahdi et al. 2016).
HIP 100963 was one of the 118 solar analogs ${ }^{1}$ observed by Takeda et al. (2007). The authors determined its stellar parameters, rotational velocity, Li abundance, luminosity, mass, and age. These last two parameters were computed by comparing the position of the luminosity $(L)$ and effective temperature $\left(T_{\text {eff }}\right)$ on the theoretical Hertzsprung-Russell diagram. Their first results suggested that HIP 100963 has an age of $\sim 5$ Gyr with similar stellar parameters as the Sun. Later, Takeda \& Tajitsu (2009) obtained the stellar parameters for HIP 100963 with greater precision. Their results show somewhat higher effective temperature $(+40 \mathrm{~K})$ and higher $\mathrm{Li}$ abundance $(+0.7 \mathrm{dex})$ than the Sun. The authors also analyzed the Be II lines (3130.42 $\AA$ and $3131.07 \AA$ ) and concluded that the Be abundance of HIP 100963 is presumably solar within $0.1 \mathrm{dex}^{2}$. Do Nascimento et al. (2009) determined the age and mass of HIP 100963 employing the Toulouse-Geneva stellar evolution

\footnotetext{
1 Solar analogs are stars with temperatures and metallicities within $\sim 500 \mathrm{~K}$ and 0.3 dex of the Sun.

2 No Be abundances were given, only a comparison of observed and
} synthetic spectra was made. 
Table 1. Comparison of stellar parameters of HIP 100963.

\begin{tabular}{lrrrrrrrl}
\hline \hline $\begin{array}{l}T_{\text {eff }} \\
(\mathrm{K})\end{array}$ & $\begin{array}{r}\text { Error } \\
(\mathrm{K})\end{array}$ & $\begin{array}{r}\log g \\
(\mathrm{dex})\end{array}$ & $\begin{array}{r}\text { Error } \\
(\mathrm{dex})\end{array}$ & $\begin{array}{r}{[\mathrm{Fe} / \mathrm{H}]} \\
(\mathrm{dex})\end{array}$ & $\begin{array}{r}\text { Error } \\
(\mathrm{dex})\end{array}$ & $\begin{array}{r}v_{t} \\
\left(\mathrm{~km} \mathrm{~s}^{-1}\right)\end{array}$ & $\begin{array}{r}\text { Error } \\
\left(\mathrm{km} \mathrm{s}^{-1}\right)\end{array}$ & Source \\
\hline 5818 & 4 & 4.49 & 0.01 & -0.003 & 0.004 & 1.03 & 0.01 & This work \\
5775 & $17-51$ & 4.41 & $0.04-0.12$ & -0.012 & $0.02-0.06$ & 0.98 & $0.09-0.27$ & ${\text { Takeda et al. }(2007)^{*}}^{\dagger}$ \\
5815 & 10 & 4.46 & 0.01 & -0.010 & 0.005 & 1.01 & 0.04 & Takeda \& Tajitsu (2009) \\
5815 & 50 & 4.49 & 0.07 & 0.018 & 0.019 & $\ldots$ & $\ldots$ & Ramírez et al. (2009) \\
5834 & 25 & 4.56 & 0.06 & 0.010 & 0.020 & 1.07 & 0.09 & Notsu et al. (2015a) \\
\hline
\end{tabular}

Notes. ${ }^{(*)}$ Individual errors were not reported by Takeda et al. (2007); the errors vary in the range shown. ${ }^{(\dagger)}$ The parameters reported here are based on the differential stellar parameters and adopting for the Sun $T_{\text {eff }}=5777 \mathrm{~K}, \log g=4.44$ dex, and $v_{t}=1.00 \mathrm{~km} \mathrm{~s}^{-1}$.

code (Hui-Bon-Hoa 2008). They used the stellar parameters found by Takeda et al. (2007) and Takeda \& Tajitsu (2009). Their results agree with the mass derived by Takeda et al. (2007), but the age is $3 \mathrm{Gyr}$, which is younger than the value found by Takeda et al. (2007) using less precise stellar parameters. Using chromospheric activity, an even younger age $(1.7 \mathrm{Gyr})$ has been suggested (Isaacson \& Fischer 2010).

In recent works based on spectroscopy of solar-type superflare stars, Notsu et al. (2015a) carried out high-dispersion spectroscopic observations for a sample of 50 solar-type stars and 8 solar twins (among them HIP 100963). They determined the stellar parameters of HIP 100963 (see Table 1) following the method by Takeda et al. (2005). The rotational velocity, chromospheric activity (Notsu et al. 2015b), and Li abundance (Honda et al. 2015) were also studied.

Ramírez et al. (2009) analyzed the spectra of 64 solar-type stars (HIP 100963 among the sample), finding a correlation between the differential abundances relative to the Sun and the condensation temperature. Meléndez et al. (2009) suggested that this deficiency in refractory elements could be explained by rocky planet formation. Chambers (2010) has reproduced such abundance behavior by adding a mixture of $4 M_{\oplus}$ of Earth-like material and carbonaceous-chondrite-like material into the convection zone of the Sun. In addition to the planet signatures, the Galactic chemical evolution (GCE) can have a strong impact on the abundance pattern (e.g., Adibekyan et al. 2014; Nissen 2015; Spina et al. 2016), as most elements show [X/Fe] ratios that depend on age. Therefore, it is important to continue to identify more solar twins and to conduct high-precision chemical abundance analyses to better understand the relative contributions of the GCE and planetary signatures to be able to distinguish these effects.

In the present work, we determine the stellar parameters of HIP 100963 with high precision to obtain its mass and age, and clarify its evolutionary status in this way. We also derive precise chemical abundances of 27 elements and investigate how the possible presence of planets, stellar evolution, and the GCE can explain the abundance pattern of this solar twin.

\section{Observations and data reduction}

Spectra of HIP 100963 and the Sun (reflected light from the Iris asteroid) were obtained using the HIRES spectrograph (Vogt et al. 1994) at the Keck I telescope, covering the wavelength region from $3940-8350 \AA$, in a mosaic of three CCDs optimized for the blue, green, and red regions. Observations were performed on August 13, 2013, with exposure times of $180 \mathrm{~s}$ for HIP 100963 and $720 \mathrm{~s}$ for Iris. The slit width was set to 0.57 arcsec, giving a spectral resolving power of $R=\lambda / \Delta \lambda=70000$ (3.2 pixels per resolution element); the signal-to-noise ratio $(\mathrm{S} / \mathrm{N})$ at $\sim 6000 \AA$ measured for HIP 100963 is about 400 pixel $^{-1}$, while for the Sun it is about 650 pixel $^{-1}$.

The spectra were reduced using the $\mathrm{MAKEE}^{3}$ pipeline following the standard procedure: bias subtraction, flat fielding, sky subtraction, order extraction, and wavelength calibration. MAKEE performs the heliocentric correction for wavelength. Radial velocity and the rest frame correction were performed using the rvidlines and dopcor tasks in IRAF. The continuumnormalization was performed using the continuum task in IRAF $^{4}$. Part of the reduced spectra of HIP 100963 and the Iris asteroid is shown in Fig. 1.

\section{Abundance analysis}

\subsection{Stellar parameters}

The analysis is based on the line-by-line differential method (e.g., Meléndez et al. 2012, 2014a; Monroe et al. 2013; Liu et al. 2014; Ramírez et al. 2014; Biazzo et al. 2015; Nissen 2015; Spina et al. 2016; Saffe et al. 2015). We measured the EWs using the splot task in IRAF, fitting the line profiles using Gaussians. Pseudo-continuum regions were obtained following Bedell et al. (2014) in a window of $6 \AA$.

To calculate the stellar parameters and chemical abundances, we used the Kurucz ODFNEW model atmospheres (Castelli \& Kurucz 2004) and the 2014 version of the local thermodynamic equilibrium (LTE) code MOOG (Sneden 1973). We determined the elemental abundances of the Sun assuming the standard solar parameters: $T_{\text {eff }}=5777 \mathrm{~K}, \log g=4.44 \mathrm{dex}$ (Cox 2000) and $v_{t}=1.00 \mathrm{~km} \mathrm{~s}^{-1}$, as in Ramírez et al. (2014). We employed the differential spectroscopic equilibrium ${ }^{5}$ for HIP 100963 relative to the Sun (see Fig. 2), giving as a result the following stellar parameters: $T_{\text {eff }}=5818 \mathrm{~K}, \log g=4.49 \mathrm{dex}$, $v_{t}=1.03 \mathrm{~km} \mathrm{~s}^{-1}$, and $[\mathrm{Fe} / \mathrm{H}]=-0.003 \mathrm{dex}$. The stellar parameter errors were determined as in Epstein et al. (2010) and Bensby et al. (2014); these errors consist of observational uncertainties and the degeneracies in the stellar parameters. We have achieved the highest precision ever obtained in stellar parameters for this object: $\sigma\left(T_{\text {eff }}\right)=4 \mathrm{~K}, \sigma(\log g)=0.012$ dex, $\sigma\left(v_{t}\right)=0.01 \mathrm{~km} \mathrm{~s}^{-1}$, and $\sigma([\mathrm{Fe} / \mathrm{H}])=0.004$ dex.

3 MAKEE was developed by T. Barlow to reduce Keck HIRES spectra. It is accessible at www . astro. caltech. edu/ tb/

4 IRAF is distributed by the National Optical Astronomy Observatory, which is operated by the Association of the Universities for Research in Astronomy, Inc. (AURA) under cooperative agreement with the National Science Foundation.

5 Spectroscopic equilibrium is achieved when the differential excitation, ionization balance, and no dependence of differential iron abundance with reduced equivalent width $(\mathrm{EW} / \lambda)$ are reached. 


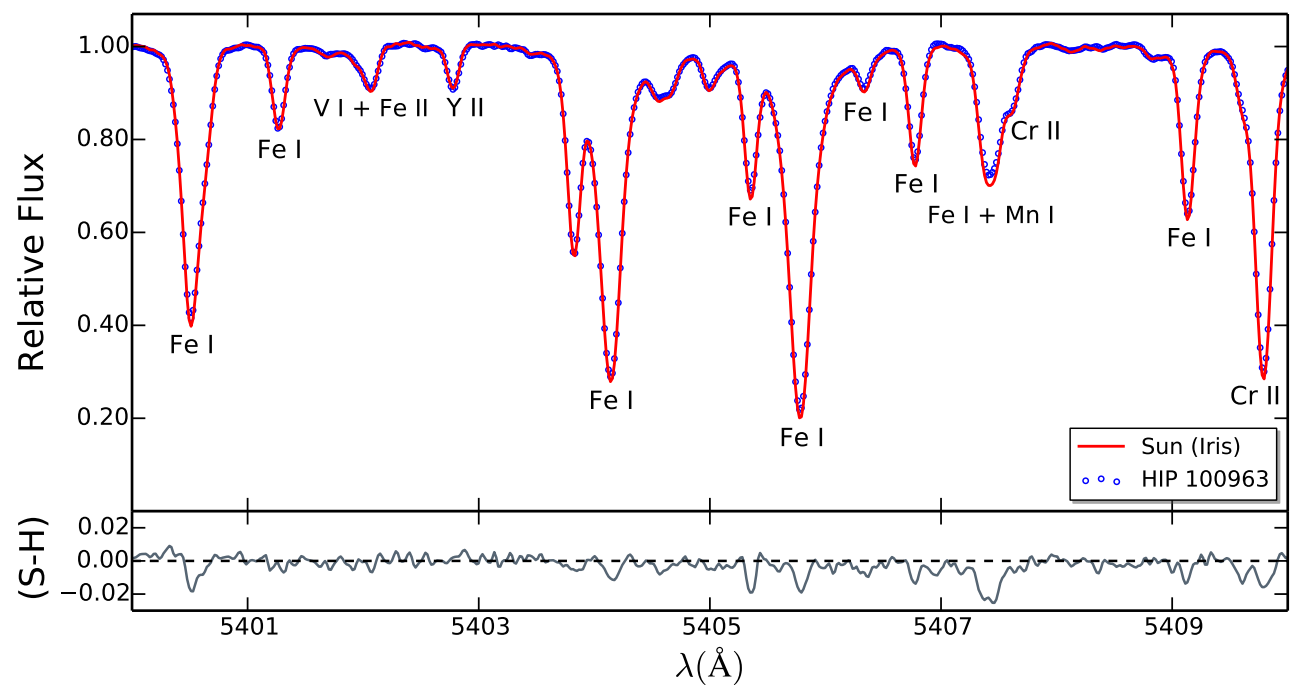

Fig. 1. HIRES spectra of HIP 100963 (blue circles) and the Sun (red line) in the 5400-5410 ̊ region. Residuals between the Sun and HIP 100963 (Sun - HIP) are shown in the lower panel.
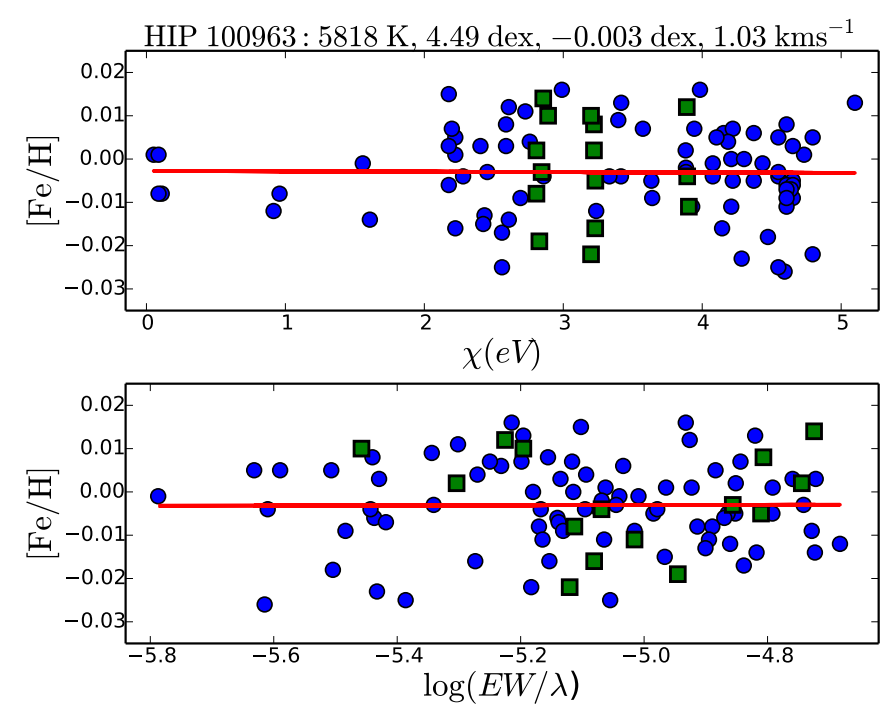

Fig. 2. Differential abundance of HIP 100963 relative to the Sun as a function of excitation potential (top panel) and reduced equivalent width (bottom panel). The blue filled circles represent Fe I, the green filled squares Fe II. The red solid lines in both panels are linear fits to $\mathrm{Fe} \mathrm{I}$.

In Table 1 we compare our stellar parameters with previous studies. They all agree within the errors.

\subsection{Age and mass}

Meléndez et al. (2012) and Nissen (2015) have shown that it is possible to estimate reliable ages of solar-like stars using the isochrone technique (e.g., Lachaume et al. 1999). This was made possible by the extremely precise measurements of the stellar parameters and in particular using an accurate $\log g$ instead of an uncertain absolute magnitude $\left(M_{v}\right)$ as input parameters. Taking into account the considerations above, Ramírez et al. (2014) developed a python code named $q^{2}$ (qoyllur-quipu) ${ }^{6}$, which computes the mass, age, luminosity, and radius. To calculate the

\footnotetext{
${ }^{6}$ Qoyllur-quipu is a free code based on python, and it is available at https://github.com/astroChasqui/q2
}

Table 2. Fundamental parameters.

\begin{tabular}{cc}
\hline \hline HIP 100963 & Parameters \\
\hline Mass & $1.03_{-0.01}^{+0.02} M_{\odot}$ \\
Distance & $28.2 \pm 0.5 \mathrm{pc}$ \\
Convective Mass & $0.018 M_{\odot}$ \\
Age & $2.0 \pm 0.4 \mathrm{Gyr}$ \\
$\log L$ & $-0.02_{-0.01}^{+0.01} L_{\odot}$ \\
$M_{V}$ & $4.83_{-0.03}^{+0.04} \mathrm{mag}$ \\
Radius & $0.97_{-0.02}^{+0.01} R_{\odot}$ \\
\hline
\end{tabular}

Notes. Mass, age, luminosity, and radius were estimated using the $q^{2}$ code, whereas the convective mass was determined by using our code (Yana Galarza et al. 2016) and applying the grid by Siess et al. (2000). The $M_{V}$ and distance were computed using the HIPPARcos parallax given by van Leeuwen (2007).

age, the $q^{2}$ code uses the isochrone method, adopting a fine grid of Yonsei-Yale isochrones (e.g., Yi et al. 2001). Our results are listed in Table 2. The age we determine $(2.0 \pm$ $0.4 \mathrm{Gyr})^{7}$ is also consistent with the high-level activity of this star, which has an average activity indicator of $\log R_{H K}^{\prime}=$ $-4.74(\sigma=0.11)$, according to Wright et al. (2004), White et al. (2007), and Isaacson \& Fischer (2010). We used seven individual $\log R_{H K}^{\prime}$ measurements available in the references above and the color $(B-V)=0.651$ (Ramírez et al. 2012) to determine chromospheric ages from the chromospheric activity indicator $\log R_{H K}^{\prime}$. Following the relations given in Wright et al. (2004) and Mamajek \& Hillenbrand (2008), we find mean ages of $2.3 \pm$ $0.4 \mathrm{Gyr}$ and $2.6 \pm 0.6 \mathrm{Gyr}$, respectively, and a weighted average of $2.4 \pm 0.3$ Gyr. This value agrees well with our isochronal age.

\subsection{Abundance trends}

We measured high-precision chemical abundances of 26 elements other than Li using EWs: C, O, Na, Mg, Al, Si, Ca, Sc, Ti, $\mathrm{V}, \mathrm{Cr}, \mathrm{Mn}, \mathrm{Fe}, \mathrm{Co}, \mathrm{Ni}, \mathrm{Cu}, \mathrm{Zn}, \mathrm{Sr}, \mathrm{Y}, \mathrm{Zr}, \mathrm{Ba}, \mathrm{La}, \mathrm{Ce}, \mathrm{Nd}, \mathrm{Sm}$, and Eu relative to the Sun. We adopted the hyperfine structure data

\footnotetext{
7 The probability distribution functions indicate another solution with age younger than $1 \mathrm{Gyr}$, but this solution was discarded because all other age indicators favor the solution around $2 \mathrm{Gyr}$.
} 
Table 3. Stellar abundances $[\mathrm{X} / \mathrm{H}]$ of HIP 100963 relative to the Sun and corresponding errors.

\begin{tabular}{|c|c|c|c|c|c|c|c|c|c|}
\hline Element & $\begin{array}{r}{[\mathrm{X} / \mathrm{H}]} \\
\mathrm{LTE} \\
(\mathrm{dex})\end{array}$ & $\begin{array}{l}\Delta T_{\text {eff }} \\
\pm 4 \mathrm{~K} \\
(\text { dex })\end{array}$ & $\begin{array}{r}\Delta \log g \\
\pm 0.01 \mathrm{dex} \\
(\operatorname{dex})\end{array}$ & $\begin{array}{r}\Delta v_{t} \\
\pm 0.01 \mathrm{~km} \mathrm{~s}^{-1} \\
(\mathrm{dex})\end{array}$ & $\begin{array}{r}\Delta[\mathrm{Fe} / \mathrm{H}] \\
\pm 0.004 \mathrm{dex} \\
(\mathrm{dex})\end{array}$ & $\operatorname{Param}^{a}$ & $\begin{array}{l}\text { obs. }^{b} \\
\text { (dex) }\end{array}$ & $\begin{array}{l}\operatorname{Total}^{c} \\
(\mathrm{dex})\end{array}$ & $\begin{array}{r}{[\mathrm{X} / \mathrm{H}]^{d}} \\
\mathrm{GCE} \\
(\mathrm{dex})\end{array}$ \\
\hline $\mathrm{C}$ & -0.066 & 0.002 & 0.003 & 0.000 & 0.000 & 0.004 & 0.018 & 0.018 & 0.015 \\
\hline $\mathrm{O}$ & -0.036 & 0.004 & 0.002 & 0.001 & 0.000 & 0.005 & 0.006 & 0.008 & 0.038 \\
\hline $\mathrm{Na}$ & -0.067 & 0.002 & 0.001 & 0.000 & 0.000 & 0.002 & 0.006 & 0.006 & 0.008 \\
\hline $\mathrm{Mg}$ & -0.024 & 0.004 & 0.001 & 0.002 & 0.001 & 0.005 & 0.007 & 0.008 & 0.022 \\
\hline $\mathrm{Al}$ & -0.037 & 0.002 & 0.000 & 0.000 & 0.000 & 0.002 & 0.006 & 0.006 & -0.006 \\
\hline $\mathrm{Si}$ & -0.021 & 0.001 & 0.001 & 0.000 & 0.001 & 0.002 & 0.005 & 0.005 & 0.004 \\
\hline $\mathrm{Ca}$ & 0.010 & 0.003 & 0.001 & 0.002 & 0.001 & 0.004 & 0.006 & 0.007 & -0.009 \\
\hline $\mathrm{Sc}^{*}$ & -0.020 & 0.000 & 0.004 & 0.002 & 0.001 & 0.005 & 0.004 & 0.006 & 0.048 \\
\hline $\mathrm{Ti}^{*}$ & 0.003 & 0.000 & 0.005 & 0.002 & 0.001 & 0.005 & 0.006 & 0.008 & 0.028 \\
\hline $\mathrm{V}$ & -0.018 & 0.004 & 0.001 & 0.000 & 0.000 & 0.004 & 0.006 & 0.007 & 0.002 \\
\hline $\mathrm{Cr}^{*}$ & 0.012 & 0.001 & 0.004 & 0.002 & 0.001 & 0.005 & 0.006 & 0.008 & 0.002 \\
\hline $\mathrm{Mn}$ & -0.027 & 0.003 & 0.000 & 0.001 & 0.001 & 0.003 & 0.006 & 0.007 & 0.021 \\
\hline $\mathrm{Fe}^{*}$ & -0.003 & 0.003 & 0.000 & 0.002 & 0.001 & 0.004 & 0.001 & 0.004 & -0.003 \\
\hline Co & -0.046 & 0.003 & 0.002 & 0.000 & 0.000 & 0.004 & 0.011 & 0.012 & 0.017 \\
\hline $\mathrm{Ni}$ & -0.025 & 0.002 & 0.000 & 0.002 & 0.001 & 0.003 & 0.006 & 0.007 & 0.024 \\
\hline $\mathrm{Cu}$ & -0.056 & 0.002 & 0.001 & 0.002 & 0.001 & 0.003 & 0.009 & 0.010 & 0.027 \\
\hline $\mathrm{Zn}$ & -0.033 & 0.000 & 0.001 & 0.002 & 0.001 & 0.002 & 0.007 & 0.007 & 0.033 \\
\hline $\mathrm{Sr}$ & 0.055 & 0.004 & 0.001 & 0.001 & 0.001 & 0.004 & 0.007 & 0.008 & $\ldots$ \\
\hline $\mathrm{Y}$ & 0.065 & 0.001 & 0.005 & 0.004 & 0.002 & 0.007 & 0.008 & 0.010 & $\ldots$ \\
\hline $\mathrm{Zr}$ & 0.074 & 0.001 & 0.005 & 0.002 & 0.001 & 0.006 & 0.006 & 0.008 & $\ldots$ \\
\hline $\mathrm{Ba}$ & 0.051 & 0.001 & 0.001 & 0.004 & 0.002 & 0.005 & 0.008 & 0.009 & $\ldots$ \\
\hline $\mathrm{La}$ & 0.072 & 0.001 & 0.006 & 0.000 & 0.001 & 0.006 & 0.011 & 0.013 & $\ldots$ \\
\hline $\mathrm{Ce}$ & 0.054 & 0.001 & 0.005 & 0.001 & 0.002 & 0.006 & 0.007 & 0.009 & $\ldots$ \\
\hline $\mathrm{Nd}$ & 0.066 & 0.001 & 0.006 & 0.000 & 0.002 & 0.006 & 0.006 & 0.009 & $\cdots$ \\
\hline $\mathrm{Sm}$ & 0.086 & 0.001 & 0.005 & 0.001 & 0.001 & 0.005 & 0.007 & 0.009 & $\ldots$ \\
\hline $\mathrm{Eu}$ & 0.069 & 0.001 & 0.006 & 0.001 & 0.001 & 0.006 & 0.007 & 0.009 & $\ldots$ \\
\hline
\end{tabular}

Notes. ${ }^{(a)}$ Adding errors in stellar parameters. ${ }^{(b)}$ Observational errors. ${ }^{(c)}$ Total errors (stellar and observational parameters). ${ }^{(d)}$ Abundances corrected by subtracting the chemical evolution of the Galactic thin disk. ${ }^{(*)}$ The errors due to uncertainties in the stellar parameters come from ScII, TiII, CrII, and FeI.

used by Meléndez et al. (2014a) for V, Mn, Co, Cu, Y, Ba, La, and $\mathrm{Eu}$, with isotopic fractions as given in Asplund et al. (2009), McWilliam (1998), and Cohen et al. (2003) for $\mathrm{Cu}, \mathrm{Ba}$, and $\mathrm{Eu}$, respectively.

Non-local thermal equilibrium (NLTE) effects in solar twins are negligible (Meléndez et al. 2012; Monroe et al. 2013), but might be important for the O I triplet. Therefore we applied differential NLTE corrections for O using the NLTE grid of Ramírez et al. (2007). Recent oxygen NLTE calculations (Amarsi et al. 2016) predict quite different absolute NLTE corrections than those from Ramírez et al. (2007), but for our work the effect is negligible because all the calculations are strictly differential. Adopting the grid of Amarsi et al. (2016) would result in a differential abundance lower by only 0.004 dex.

In Table 3 we show our differential abundances relative to the Sun, including observational, systematic, and the total error (obtained from quadratically adding the statistical and systematic errors). Our results agree with the abundances calculated by Ramírez et al. (2009), as shown in Fig. 3, but our results are more precise because of the better quality of the data. The mean difference is $\Delta[\mathrm{X} / \mathrm{H}]$ (Ramírez et al. 2009; this work) $=0.011$ $(\sigma=0.016 \mathrm{dex})$.

Nissen (2015) conducted a similar high-precision chemical abundance analysis of 21 solar twins to investigate abundance trends with age and dust condensation temperature. He found that the $[\mathrm{Y} / \mathrm{Mg}]$ ratio was correlated with age, so that this abundance ratio offers an independent age indicator. Using his relation, we estimate the age of HIP 100963 as $2.1 \pm 0.4 \mathrm{Gyr}$, in agreement with the isochronal age computed by using $q^{2}$ and with the age estimated from a chromospheric diagnostics.

\section{Discussion}

\subsection{Light elements $(Z \leq 30)$}

The abundance pattern of HIP 100963 relative to the Sun is shown in Fig. 4 (blue filled circles in the upper panel). The fit of their light elements $(Z \leq 30)$ gives a positive slope with an average dispersion of 0.019 dex, which is higher than the average error bar $(0.008 \mathrm{dex})$. This might be due to the scatter introduced by the GCE.

A correlation between $T_{\text {cond }}$ trend and age was first observed by Ramírez et al. (2014). Adibekyan et al. (2014) also showed a correlation between the abundance trends versus condensation temperature and stellar ages. They analyzed a sample of 148 solar-like stars and observed that young stars are richer in refractories than old stars. They suggested that this behavior is due to the chemical evolution of the Galactic thin disk. Later, Nissen (2015) and Spina et al. (2016) confirmed this correlation and concluded that the $T_{\text {cond }}$-slope decreases with increasing stellar age.

We employed the $[\mathrm{X} / \mathrm{Fe}]-$ age relation of Spina et al. (2016) to correct for the GCE for elements with $Z \leq 30$. As HIP 100963 is younger than the Sun, we added the effect of the GCE to its 


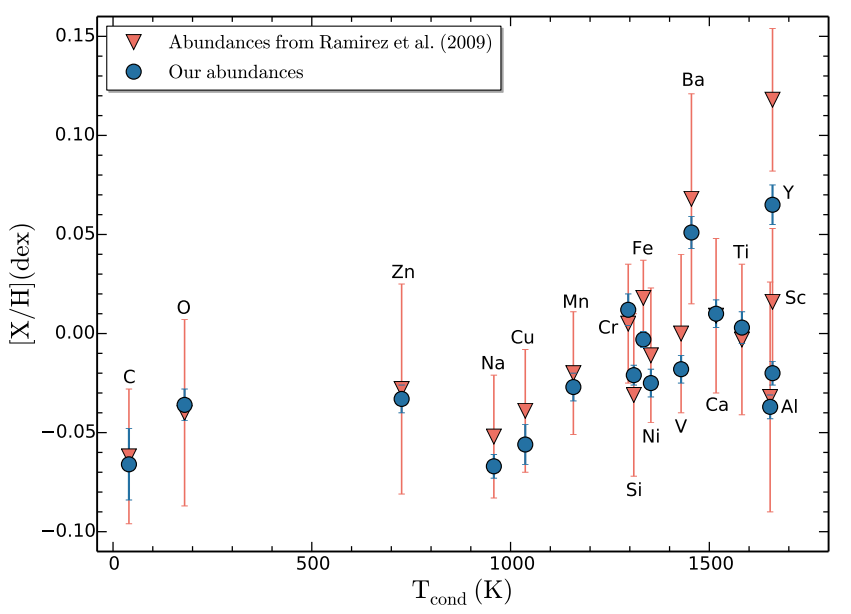

Fig. 3. Comparison between our abundance pattern and that by Ramírez et al. (2009) as a function of condensation temperature, $T_{\text {cond }}$ (Lodders 2003).

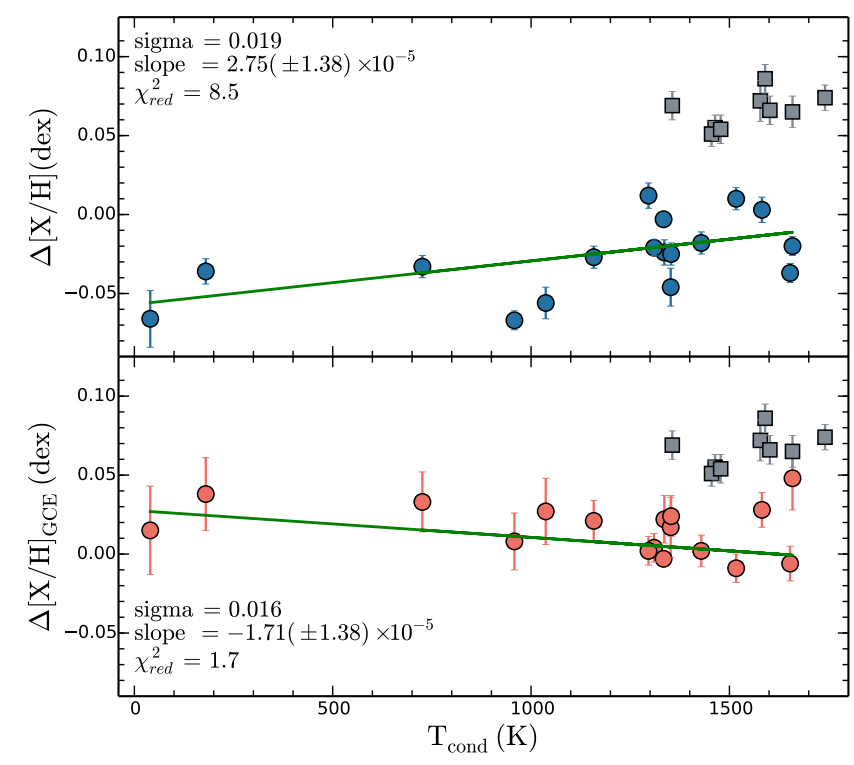

Fig. 4. Upper panel: observed differential abundances relative to the Sun versus condensation temperature. Lower panel: abundance trend after correcting for the GCE to the solar age. Linear fits to the data (excluding the neutron-capture elements) are overplotted in each panel as a green solid line. Neutron-capture elements are represented by gray filled squares. Sigma represents the dispersion about the linear fit.

elemental abundances because our differential abundances are relative to the present-day Sun. This yields

$[\mathrm{X} / \mathrm{H}]_{\mathrm{GCE}}=[\mathrm{X} / \mathrm{H}]+b \times\left(\mathrm{Age}_{\mathrm{Sun}}-\mathrm{Age}_{\mathrm{twin}}\right)$,

where $b$ is the slope found by Spina et al. (2016) ${ }^{8}$. In Fig. 4 (lower panel) we show the elemental abundance differences $\left([\mathrm{X} / \mathrm{H}]_{\mathrm{GCE}}\right)$ adding the GCE effect between HIP 100963 and the Sun (red filled circles) as a function of condensation temperature (Lodders 2003). We did not correct for the $n$-capture elements (gray squares) because Spina et al. (2016) did not include most of these elements. The average dispersion from the fit

\footnotetext{
8 Spina et al. (2016) performed a linear fit $([\mathrm{X} / \mathrm{Fe}]=$ age $\times b+a)$ with their parameters listed in Table 3 of their work. The fits are used to correct for the GCE as a function of age, but do not take possible inhomogeneous GCE effects into account.
}

is $0.016 \mathrm{dex}$, in agreement with the average error bar ( $0.015 \mathrm{dex})$, which now includes the uncertainty in the GCE correction (also including the error in age). Besides that, the $\chi_{\text {red }}^{2}$ decrease to 1.7 from the initial value of 8.5. Within the errors the abundance pattern of HIP 100963 corrected by GCE (to the solar age) is similar to the Sun, or perhaps slightly more depleted in refractories than the Sun. Notice that the slope changed from 2.8 to -1.7 , and that the difference is significant at the $\sim 2$ sigma level, i.e., the contribution of GCE is important.

Meléndez et al. (2009) were the first to find that the Sun is deficient in refractories when compared to the average abundance of 11 solar twins. They argued that the peculiar solar abundance pattern is a mirror image of the abundance pattern of meteorites and inner rocky planets in our solar system. This suggests that the refractory-poor solar pattern may be linked to the formation of terrestrial planets in the solar system. If the Meléndez et al. (2009) scenario is correct, the solar pattern of HIP 100963 means that it may have formed rocky planets.

HIP 100963 is included in the California Planet Search (Isaacson \& Fischer 2010), but no planet has been detected yet. Only a few data points have been reported so far, however.

\subsection{Neutron capture elements $(Z>30)$}

As can be seen in Fig. 4, HIP 100963 presents significant enhancements in neutron-capture elements (gray squares) from the $s$ - and $r$-process. For the solar twin $18 \mathrm{Sco}$, Meléndez et al. (2014a) argued that these enhancements might be due to pollution from asymptotic giant branch (AGB) stars and $r$-process sources, which enrich the interstellar medium over time. Although massive stars dominate the production of the lighter $s$-process elements ( $\mathrm{Sr}, \mathrm{Y}$, and $\mathrm{Zr}$ ) at low metallicites, at solar metallicity the production of these elements is dominated by AGB stars (Bisterzo et al. 2014). We here followed the procedure adopted by Meléndez et al. (2014a) for the solar twin 18 Sco. Assuming that the observed enhancements are due to the pollution from AGB stars, we fit the lighter elements $[\mathrm{X} / \mathrm{H}]_{Z \leq 30}$ to subtract the trend with condensation temperature from heavy elements $[\mathrm{X} / \mathrm{H}]_{\mathrm{Z}>30}$,

$$
[\mathrm{X} / \mathrm{H}]_{T \text { cond }}=[\mathrm{X} / \mathrm{H}]_{Z>30}-\left(-0.056+2.753 \times 10^{-5} T_{\text {cond }}\right),
$$

where $[\mathrm{X} / \mathrm{H}]_{T \text { cond }}$ represents the abundance of neutron-capture elements corrected for the condensation temperature effect, whereas the last two terms come from the fit of the lighter abundances trend versus condensation temperature without GCE (see Fig. 4). To compute the amount of pollution of the protocloud by an AGB star $\left([\mathrm{X} / \mathrm{H}]_{\mathrm{AGB}}\right)$, we used the same model as adopted by Meléndez et al. $(2014 \mathrm{a})^{9}$, with diluted yields of a small fraction of AGB ejecta into a protocloud of solar composition of $1 M_{\odot}$ (Asplund et al. 2009). We estimate a dilution of $0.34 \%$ mass of AGB material to match the average observed enhancements in the $s$-process elements $(\mathrm{Sr}, \mathrm{Y}, \mathrm{Zr}, \mathrm{Ba}, \mathrm{La}$, and $\mathrm{Ce})$. The two abundances $[\mathrm{X} / \mathrm{H}]_{\text {Tcond }}$ and $[\mathrm{X} / \mathrm{H}]_{\mathrm{AGB}}$ are given in Table 4. Figure 5 shows that the $s$-process elements $\mathrm{Y}, \mathrm{Ba}, \mathrm{La}$, and $\mathrm{Ce}$ are well reproduced, but the $r$-process elements $(\mathrm{Sm}$ and $\mathrm{Eu})$ are not. Therefore, the AGB contribution alone cannot explain the heavy abundance enhancement. Another source of enhancement is the contribution from the $r$-process. To determine this enrichment, we first subtracted the AGB contribution from the heavy elements,

$[\mathrm{X} / \mathrm{H}]_{r-\text { process }}=[\mathrm{X} / \mathrm{H}]_{T \text { cond }}-[\mathrm{X} / \mathrm{H}]_{\mathrm{AGB}}$.

9 This is an AGB stellar model with $3 M_{\odot}$ as initial mass, and $Z=0.01$ of metallicity (Karakas et al. 2010; Meléndez et al. 2014a). 
Table 4. Enhancement of neutron-capture elemental abundances and their decomposition in HIP 100963.

\begin{tabular}{rrrrr}
\hline \hline$Z$ & Element & $\begin{array}{r}{[\mathrm{X} / \mathrm{H}]_{T_{\text {cond }}}} \\
(\mathrm{dex})\end{array}$ & $\begin{array}{r}{[\mathrm{X} / \mathrm{H}]_{\mathrm{AGB}}} \\
(\mathrm{dex})\end{array}$ & $\begin{array}{r}{[\mathrm{X} / \mathrm{H}]_{r \text {-process }}} \\
(\mathrm{dex})\end{array}$ \\
\hline 38 & $\mathrm{Sr}$ & 0.071 & 0.061 & 0.010 \\
39 & $\mathrm{Y}$ & 0.076 & 0.066 & 0.010 \\
40 & $\mathrm{Zr}$ & 0.083 & 0.080 & 0.003 \\
56 & $\mathrm{Ba}$ & 0.067 & 0.089 & -0.020 \\
57 & $\mathrm{La}$ & 0.085 & 0.077 & 0.008 \\
58 & $\mathrm{Ce}$ & 0.070 & 0.077 & -0.007 \\
60 & $\mathrm{Nd}$ & 0.078 & 0.053 & 0.025 \\
62 & $\mathrm{Sm}$ & 0.099 & 0.026 & 0.073 \\
63 & $\mathrm{Eu}$ & 0.088 & 0.005 & 0.083 \\
\hline
\end{tabular}

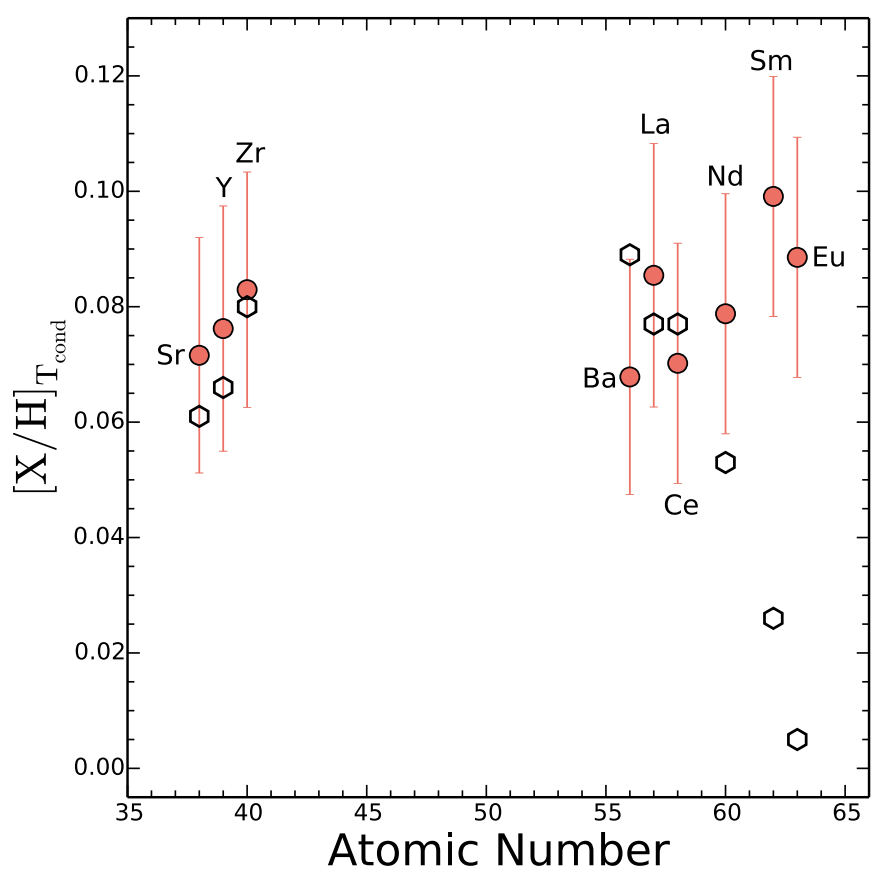

Fig. 5. Comparison of the $[\mathrm{X} / \mathrm{H}]_{T_{\text {cond }}}$ (red filled circles) ratios with predicted abundances from the AGB pollution (open hexagons).

Then we compared these ratios with the predicted enhancements based on the $r$-process in the solar system (Simmerer et al. 2004; Bisterzo et al. 2014). Meléndez et al. (2014a) determined the $r$-process contribution, which is given by

$[\mathrm{X} / \mathrm{H}]_{\mathrm{SS}-r}=\Delta \tau \log _{10} \mathrm{r}_{\mathrm{SS}}+[\mathrm{X} / \mathrm{H}]_{\mathrm{Tcond}}$

where $\Delta \tau$ is the average of the two most enhanced $s$-process and $r$-process elements $(\Delta \tau=0.091 \mathrm{dex})$, and $r_{\mathrm{SS}}$ is the $r$-process fraction in the solar system. In Fig. 6 we show our results, which agree reasonably well with the predicted $r$-process in the solar system (Simmerer et al. 2004; Bisterzo et al. 2014). Even for elements that are partially produced through the contribution of $r$-process (e.g., $\mathrm{Nd}$ ), we obtain agreement within the error. Our results, together with that obtained for 18 Sco (Meléndez et al. 2014a), suggest an enhanced contribution of $r$ - and $s$-process elements in young stars. Our results are also supported by D'Orazi et al. (2009), Maiorca et al. (2011), and D'Orazi et al. (2012), who showed that younger objects exhibit $s$-process enhancements in open clusters.

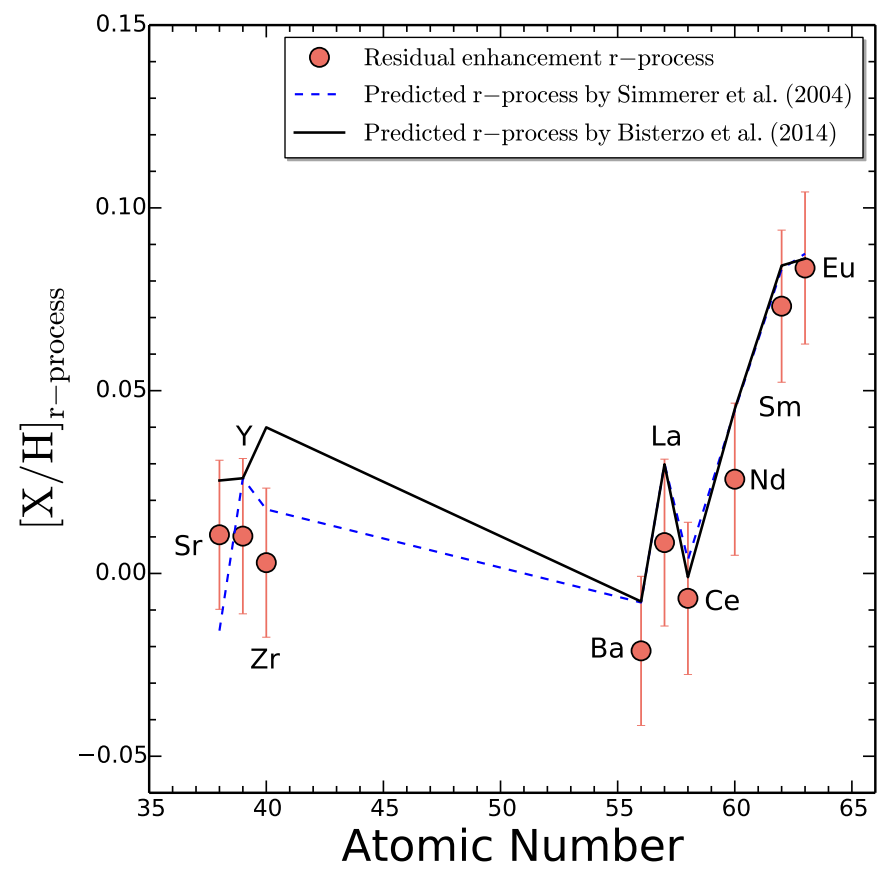

Fig. 6. Residual enhancement $[\mathrm{X} / \mathrm{H}]_{r \text {-process }}$ due to the contribution of the $r$-process. Predicted enhancement by Bisterzo et al. (2014) and Simmerer et al. (2004) are also plotted as solid and dashed lines, respectively.

\subsection{Lithium abundance}

Previous works suggest a strong connection between lithium abundance and stellar age (Soderblom 1983; Charbonnel \& Talon 2005; Denissenkov 2010; Baumann et al. 2010; Monroe et al. 2013; Meléndez et al. 2014b) based on findings that showed younger stars to have large $\mathrm{Li}$ abundances. To determine whether HIP 10093 follows this relation, we estimated the lithium abundance following the procedure explained in Meléndez et al. (2012), which consists of first estimating the line broadening and then performing spectral synthesis of the $\mathrm{Li}$ feature. We computed the stellar macroturbulence velocity (Tucci Maia et al. 2015) through the relation

$v_{\text {macro }}=v_{\text {macro, } \odot}+\left(T_{\text {eff }}-5777\right) / 486$.

We fixed $v \sin i_{\odot}=1.9 \mathrm{~km} \mathrm{~s}^{-1}$ (Bruning 1984; Saar \& Osten 1997) and obtained by spectral synthesis of six lines (see below) $v_{\text {macro, } \odot}=3.34 \mathrm{~km} \mathrm{~s}^{-1}$, which was employed in Eq. (5) to estimate the $v_{\text {macro }}$ of HIP 100963 , which in turn yielded $=3.43 \mathrm{~km} \mathrm{~s}^{-1}$. Then the projected rotational velocity $(v \sin i)$ was measured by fitting the line profiles of five iron lines: $6027.050 \AA, 6093.644 \AA, 6151.618 \AA$ A $6165.360 \AA, 6705.102 \AA$, and one $\mathrm{Ni}$ I line at $6767.772 \AA$. We found $v \sin i=1.93 \pm$ $0.21 \mathrm{~km} \mathrm{~s}^{-1}$, similar to what was determined by Takeda \& Tajitsu (2009; $v \sin i=2.04 \mathrm{~km} \mathrm{~s}^{-1}$; no error bar was given), and in good agreement with the value $1.9 \pm 0.3 \mathrm{~km} \mathrm{~s}^{-1}$ of Honda et al. $(2015)^{10}$.

HIP 100963 (blue open circles) presents a deeper Li feature in Fig. 7 than that in the Sun (black filled circles). Based on the $v_{\text {macro }}$ and $v \sin i$ we determined above, we performed the spectral

${ }^{10}$ The value found by Honda et al. (2015) for HIP 100963 is $2.4 \pm$ $0.3 \mathrm{~km} \mathrm{~s}^{-1}$, with $v \sin i_{\odot}=2.4 \mathrm{~km} \mathrm{~s}^{-1}$. Thus, the result relative to the Sun is $\Delta v \sin i=0.0 \mathrm{~km} \mathrm{~s}^{-1}$. The same is true for Takeda \& Tajitsu (2009), where $v \sin i_{\odot}=2.13 \mathrm{~km} \mathrm{~s}^{-1}$ and $v \sin i=2.27 \mathrm{~km} \mathrm{~s}^{-1}$ for HIP 100963 . 


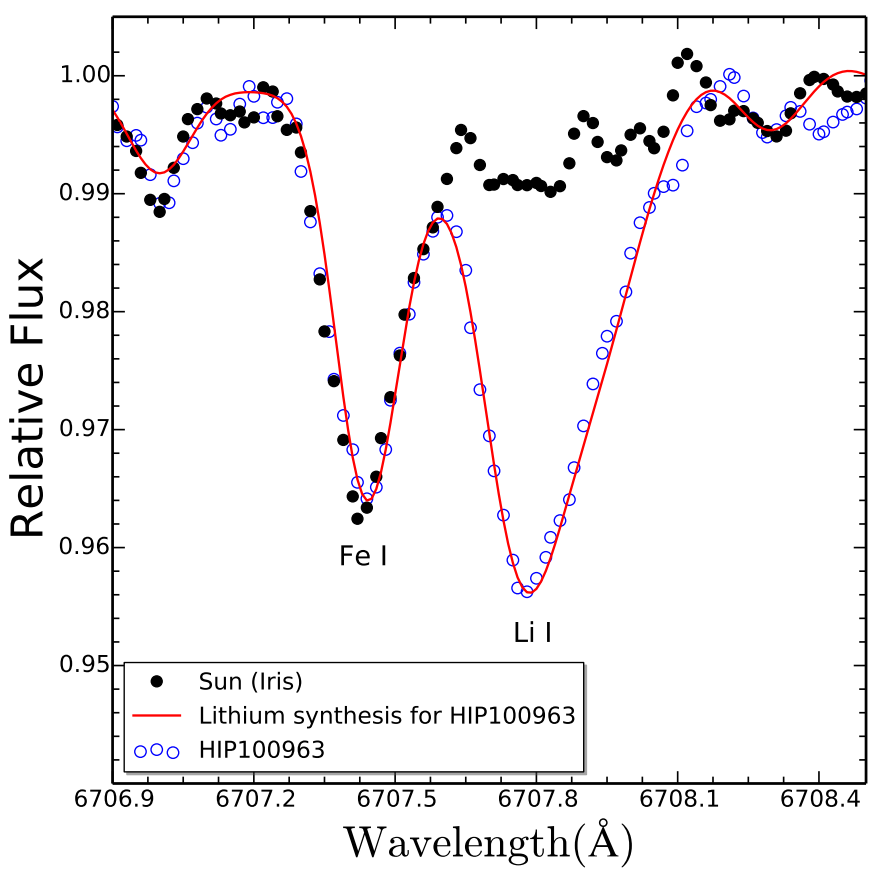

Fig. 7. Spectral synthesis of the Li doublet at 6708 A. Open and filled circles represent the spectra of HIP 100963 and the Sun, respectively, while the synthetic spectrum is overplotted as a red solid line.

synthesis of the Li line adopting the line list of Meléndez et al. (2012) and using the synth driver in MOOG. This yielded an LTE abundance of 1.67 dex. The lithium abundance in NLTE is $1.70 \pm 0.03$; it was obtained by using the NLTE corrections of Lind et al. (2009) ${ }^{11}$. The A(Li) uncertainties were obtained taking into consideration errors due to $\mathrm{S} / \mathrm{N}$, continuum setting, and stellar parameters. The quadratic sum of the three uncertainty sources gives an error of 0.03 dex. Our result closely agrees with the $\mathrm{Li}$ abundance ${ }^{12}$ of $1.72 \mathrm{dex}$ and 1.7 dex determined by Takeda et al. (2007) and Honda et al. (2015), respectively.

Meléndez et al. (2012) analyzed the Li-age correlation using the Sun and two solar twins (18 Sco and HIP 56948). They concluded that lithium decays with age. Additional works (Ramírez et al. 2011; Monroe et al. 2013; Meléndez et al. 2014b) confirmed their results (see also Baumann et al. 2010). Figure 8 shows that HIP 100963 follows the Li-age correlation of previous works, extending the result to stellar ages younger than the Sun. We also compared our findings with non-standard $\mathrm{Li}$ depletion models developed for the Sun (Charbonnel \& Talon 2005; Do Nascimento et al. 2009; Xiong \& Deng 2009; Denissenkov 2010; Andrássy \& Spruit 2015). As can be seen, the agreement is very good. These previous models include transport mechanisms that are not considered in the standard solar model.

\section{Conclusions}

We have performed a high-precision differential study of the solar twin candidate HIP 100963 based on Keck+HIRES spectra. The atmospheric parameters that we found are $T_{\text {eff }}=5818 \pm$ $4 \mathrm{~K}, \log g=4.49 \pm 0.01 \mathrm{dex}, v_{t}=1.03 \pm 0.01 \mathrm{~km} \mathrm{~s}^{-1}$, and $[\mathrm{Fe} / \mathrm{H}]=-0.003 \pm 0.004$ dex. While these values agree with

\footnotetext{
11 INSPECT database available at wWWw . inspect-stars . com

12 No error bars were given by Takeda et al. (2007) and Honda et al. (2015).
}

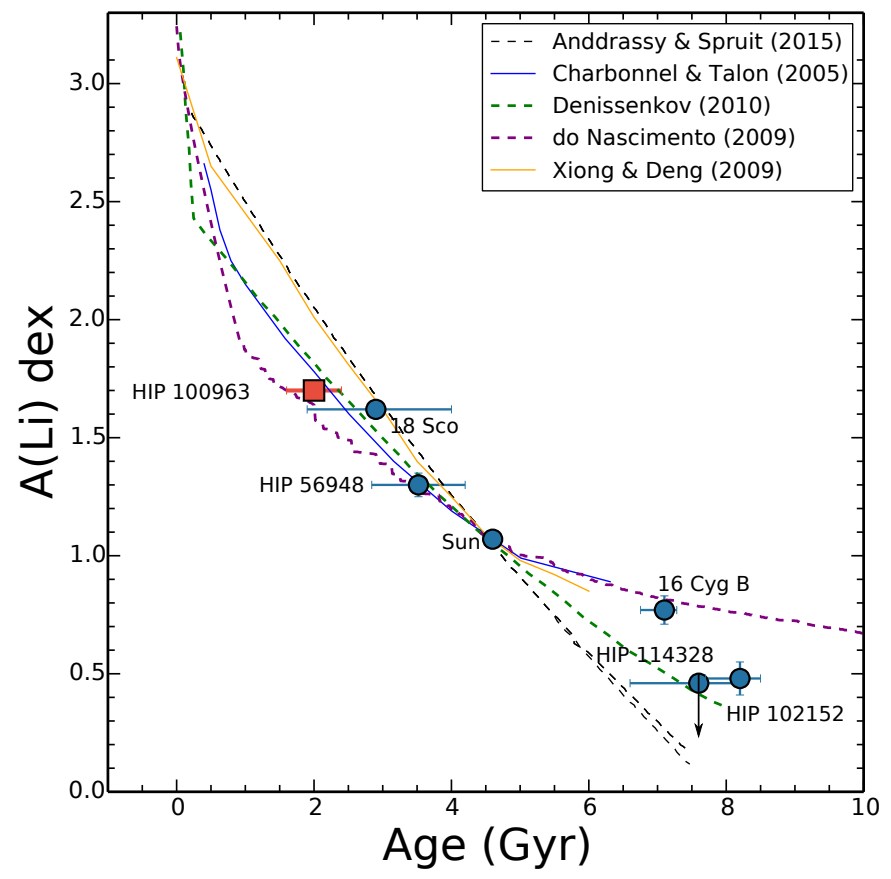

Fig. 8. Li vs. age for HIP 100963 (red filled square) based on NLTE analysis and isochronal age. The Li abundance for other stars analyzed by our group in previous works (Ramírez et al. 2011; Meléndez et al. 2012, 2014a; Monroe et al. 2013) is shown with blue filled circles. The lithium abundance errors are smaller than the size of the circles. Li depletion models are also shown with different lines.

previous studies, we have achieved considerably higher accuracy and confirm that HIP 100963 is a solar twin.

We obtained a precise mass and age $\left(1.03_{-0.01}^{+0.02} M_{\odot}, 2.0 \pm\right.$ $0.4 \mathrm{Gyr}$ ) that both agree with the values reported in the literature. The abundance trend with $T_{\text {cond }}$ before the GCE correction is comparable with the enhancement of refractories seen in other solar twins, but considering corrections for the GCE to the same age as the Sun, the abundance pattern is about solar. This means that this star may have formed rocky planets. The abundances of the $s$ - and $r$-process elements are enhanced relative to the Sun. This is most likely because HIP 100963 is younger than the Sun.

Finally, the lithium abundance of HIP 100963 falls within the correlation between $\mathrm{Li}$ and age suggested in the literature, extending the age coverage that can be used to test models of Li depletion to relatively young ages.

Acknowledgements. J.Y.G. acknowledges support by CNPq. J.M thanks for support from FAPESP (2012/24392-2). We are grateful to the many people who have worked to make the Keck telescope and its instruments a reality and to operate and maintain the Keck Observatory. The authors wish to extend special thanks to those of Hawaian ancestry on whose sacred mountain we are privileged to be guests. Without their generous hospitality, none of the observations presented herein would have been possible. D.Y., F.L., M.A. and A.K. gratefully acknowledge support from the Australian Research Council (grants DP120100991, FL110100012, FT140100554, DP150100250 and FT110100475).

\section{References}

Adibekyan, V. Z., González Hernández, J. I., Delgado Mena, E., et al. 2014, A\&A, 564, L15

Amarsi, A. M., Asplund, M., Collet, R., \& Leenaarts, J. 2016, MNRAS, 455, 3735

Andrássy, R., \& Spruit, H. C. 2015, A\&A, 579, A122

Asplund, M., Grevesse, N., Sauval, A. J., \& Scott, P. 2009, ARA\&A, 47, 481 
Baumann, P., Ramírez, I., Meléndez, J., Asplund, M., \& Lind, K. 2010, A\&A, 519, A87

Bedell, M., Meléndez, J., Bean, J. L., et al. 2014, ApJ, 795, 23

Bensby, T., Feltzing, S., \& Oey, M. S. 2014, A\&A, 562, A71

Biazzo, K., Gratton, R., Desidera, S., et al. 2015, A\&A, 583, A135

Bisterzo, S., Travaglio, C., Gallino, R., Wiescher, M., \& Käppeler, F. 2014, ApJ, 787, 10

Bruning, D. H. 1984, ApJ, 281, 830

Castelli, F., \& Kurucz, R. L. 2004, ArXiv e-prints [arXiv: astro-ph/0405087]

Cayrel de Strobel, G. 1996, A\&ARv, 7, 243

Chambers, J. E. 2010, ApJ, 724, 92

Charbonnel, C., \& Talon, S. 2005, Science, 309, 2189

Cohen, J. G., Christlieb, N., Qian, Y.-Z., \& Wasserburg, G. J. 2003, ApJ, 588, 1082

Cox, A. N. 2000, Allen's astrophysical quantities, Sky and Telescopes, 100, 1

Datson, J., Flynn, C., \& Portinari, L. 2012, MNRAS, 426, 484

Denissenkov, P. A. 2010, ApJ, 719, 28

Do Nascimento, Jr., J. D., Castro, M., Meléndez, J., et al. 2009, A\&A, 501, 687

do Nascimento, Jr., J.-D., Takeda, Y., Meléndez, J., et al. 2013, ApJ, 771, L31

D’Orazi, V., Magrini, L., Randich, S., et al. 2009, ApJ, 693, L31

D’Orazi, V., Biazzo, K., Desidera, S., et al. 2012, MNRAS, 423, 2789

Epstein, C. R., Johnson, J. A., Dong, S., et al. 2010, ApJ, 709, 447

Honda, S., Notsu, Y., Maehara, H., et al. 2015, PASJ, 67, 85

Hui-Bon-Hoa, A. 2008, Ap\&SS, 316, 55

Isaacson, H., \& Fischer, D. 2010, ApJ, 725, 875

Karakas, A. I., Campbell, S. W., \& Stancliffe, R. J. 2010, ApJ, 713, 374

King, J. R., Boesgaard, A. M., \& Schuler, S. C. 2005, AJ, 130, 2318

Lachaume, R., Dominik, C., Lanz, T., \& Habing, H. J. 1999, A\&A, 348, 897

Lind, K., Asplund, M., \& Barklem, P. S. 2009, A\&A, 503, 541

Liu, F., Asplund, M., Ramírez, I., Yong, D., \& Meléndez, J. 2014, MNRAS, 442, L51

Lodders, K. 2003, ApJ, 591, 1220

Mahdi, D., Soubiran, C., Blanco-Cuaresma, S., \& Chemin, L. 2016, A\&A, 587, A131

Maiorca, E., Randich, S., Busso, M., Magrini, L., \& Palmerini, S. 2011, ApJ, 736,120

Mamajek, E. E., \& Hillenbrand, L. A. 2008, ApJ, 687, 1264

McWilliam, A. 1998, AJ, 115, 1640

Meléndez, J., \& Ramírez, I. 2007, ApJ, 669, L89

Meléndez, J., Dodds-Eden, K., \& Robles, J. A. 2006, ApJ, 641, L133

Meléndez, J., Asplund, M., Gustafsson, B., \& Yong, D. 2009, ApJ, 704, L66
Meléndez, J., Bergemann, M., Cohen, J. G., et al. 2012, A\&A, 543, A29

Meléndez, J., Ramírez, I., Karakas, A. I., et al. 2014a, ApJ, 791, 14

Meléndez, J., Schirbel, L., Monroe, T. R., et al. 2014b, A\&A, 567, L3

Monroe, T. R., Meléndez, J., Ramírez, I., et al. 2013, ApJ, 774, L32

Nissen, P. E. 2015, A\&A, 579, A52

Notsu, Y., Honda, S., Maehara, H., et al. 2015a, PASJ, 67, 32

Notsu, Y., Honda, S., Maehara, H., et al. 2015b, PASJ, 67, 33

Önehag, A., Korn, A., Gustafsson, B., Stempels, E., \& Vandenberg, D. A. 2011, A\&A, 528, A85

Pasquini, L., Biazzo, K., Bonifacio, P., Randich, S., \& Bedin, L. R. 2008, A\&A, 489, 677

Petit, P., Dintrans, B., Solanki, S. K., et al. 2008, MNRAS, 388, 80

Porto de Mello, G. F., \& da Silva, L. 1997, ApJ, 482, L89

Porto de Mello, G. F., da Silva, R., da Silva, L., \& de Nader, R. V. 2014, A\&A, 563, A52

Ramírez, I., Allende Prieto, C., \& Lambert, D. L. 2007, A\&A, 465, 271

Ramírez, I., Meléndez, J., \& Asplund, M. 2009, A\&A, 508, L17

Ramírez, I., Meléndez, J., Cornejo, D., Roederer, I. U., \& Fish, J. R. 2011, ApJ, 740, 76

Ramírez, I., Michel, R., Sefako, R., et al. 2012, ApJ, 752, 5

Ramírez, I., Meléndez, J., \& Asplund, M. 2014, A\&A, 561, A7

Saar, S. H., \& Osten, R. A. 1997, MNRAS, 284, 803

Saffe, C., Flores, M., \& Buccino, A. 2015, A\&A, 582, A17

Siess, L., Dufour, E., \& Forestini, M. 2000, A\&A, 358, 593

Simmerer, J., Sneden, C., Cowan, J. J., et al. 2004, ApJ, 617, 1091

Sneden, C. A. 1973, Ph.D. Thesis, The University of Texas at Austin

Soderblom, D. R. 1983, ApJS, 53, 1

Spina, L., Meléndez, J., \& Ramírez, I. 2016, A\&A, 585, A152

Takeda, Y., \& Tajitsu, A. 2009, PASJ, 61, 471

Takeda, Y., Hashimoto, O., Taguchi, H., et al. 2005, PASJ, 57, 751

Takeda, Y., Kawanomoto, S., Honda, S., Ando, H., \& Sakurai, T. 2007, A\&A, 468, 663

Tucci Maia, M., Meléndez, J., Castro, M., et al. 2015, A\&A, 576, L10

van Leeuwen, F. 2007, A\&A, 474, 653

Vogt, S. S., Allen, S. L., Bigelow, B. C., et al. 1994, in Instrumentation in Astronomy VIII, eds. D. L. Crawford, \& E. R. Craine, SPIE Conf. Ser., 2198, 362

White, R. J., Gabor, J. M., \& Hillenbrand, L. A. 2007, AJ, 133, 2524

Wright, J. T., Marcy, G. W., Butler, R. P., \& Vogt, S. S. 2004, ApJS, 152, 261

Xiong, D. R., \& Deng, L. 2009, MNRAS, 395, 2013

Yana Galarza, J., Meléndez, J., \& Cohen, J. G. 2016, A\&A, in press, DOI: $10.1051 / 0004-6361 / 201527477$

Yi, S., Demarque, P., Kim, Y.-C., et al. 2001, ApJS, 136, 417 